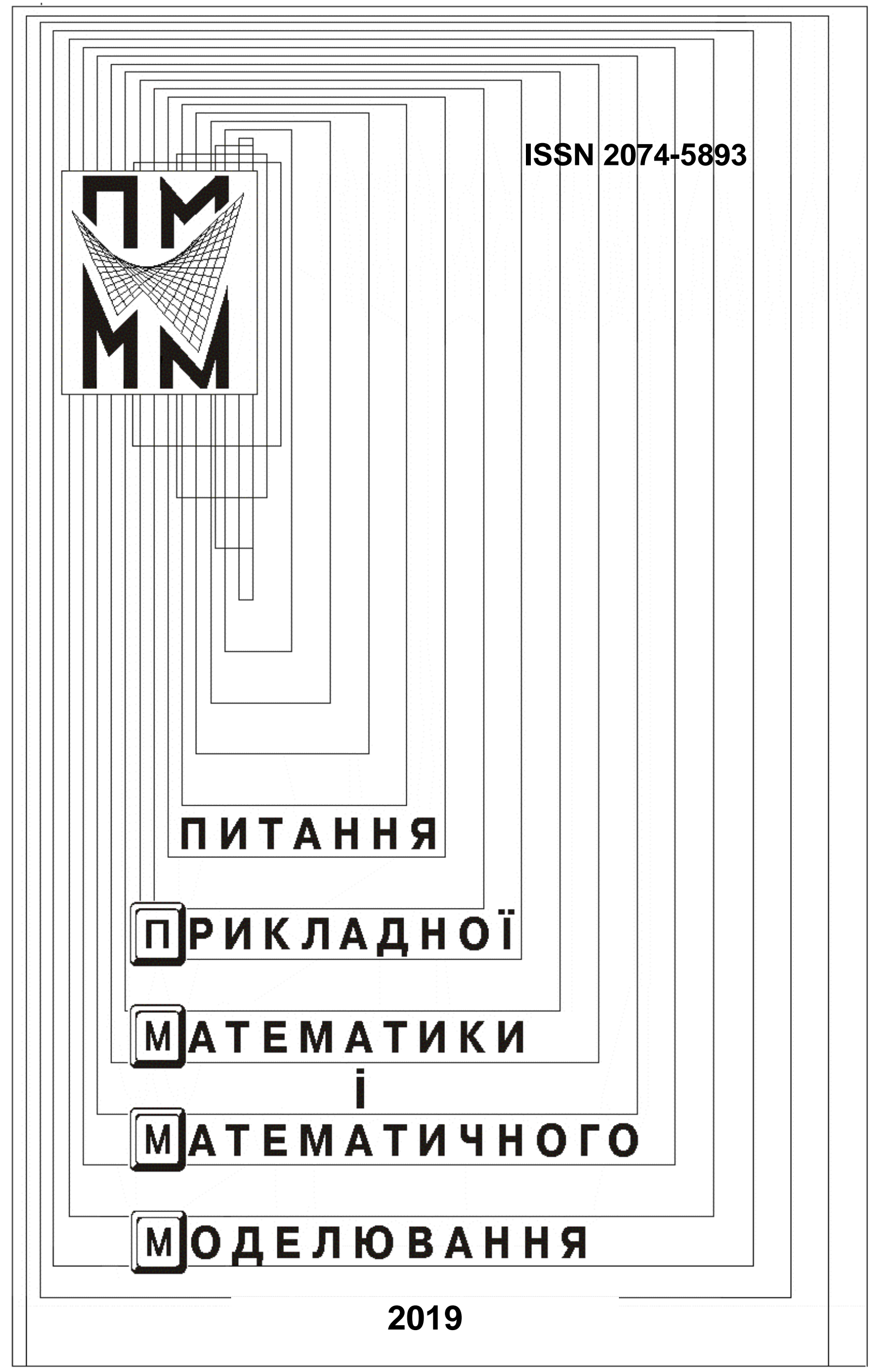


Міністерство освіти і науки України

Дніпровський національний університет імені Олеся Гончара

\author{
ПИТАННЯ ПРИКЛАДНОЇ МАТЕМАТИКИ \\ І МАТЕМАТИЧНОГО МОДЕЛЮВАННЯ \\ PROBLEMS OF APPLIED MATHEMATICS \\ AND MATHEMATIC MODELING \\ ВОПРОСЫ ПРИКЛАДНОЙ МАТЕМАТИКИ \\ И МАТЕМАТИЧЕСКОГО МОДЕЛИРОВАНИЯ
}

Збірник наукових праць

Випуск 19

До 60-річчя кафедри

обчислювальної математики

та математичної кібернетики

Дніпровського начіонального

університету імені Олеся

Гончара (1959-2019)

Дніпро

ЛІРА

2019 
УДК 004, 517, 519, 539, 51-76

ББК 22.12я431+22.311я431+22.176я431+22.18я431

$\Pi 32$

Надруковано за рішенням Вченої ради

Дніпровського національного університету імені Олеся Гончара

П 32 Питання прикладної математики і математичного моделювання [Текст]: зб. наук. пр. / редкол.: О.М. Кісельова (відп. ред.) [та ін.]. - Дніпро: Ліра, 2019. - Вип. 19. $196 \mathrm{c.}$

\section{Рецензенти:}

д-р фіз.-мат. наук, проф. В. В. Лобода

д-р фіз.-мат. наук, проф. С. Б. Вакарчук

У збірнику вміщено результати фундаментальних та прикладних досліджень із проблем математичного моделювання складних систем, розробки і програмної реалізації ефективних обчислювальних методів та алгоритмів розв'язання актуальних задач оптимізації, математичної фізики та системного аналізу. Призначений для науковців в галузі прикладної математики, викладачів ЗВО, аспірантів та студентів.

В сборнике помещены результаты фундаментальных и прикладных исследований по проблемам математического моделирования сложных систем, разработки и программной реализации эффективных вычислительных методов и алгоритмов решения актуальных задач оптимизации, математической физики и системного анализа. Предназначен для ученых в области прикладной математики, преподавателей, аспирантов и студентов.

The collection of scientific papers contains the results of fundamental and applied research on the problems of mathematical modeling of complex systems, the development and software implementation of effective computational methods and algorithms for solving actual problems of optimization, mathematical physics and system analysis. It is intended for scientists in the field of applied mathematics, teachers of higher education establishments, postgraduate students and students.

УДК 004, 517, 519, 539, 51-76

ББК 2.12я431+22.311я431+22.176я431+22.18я431

\section{Редакційна колегія:}

чл.-кор. НАН України, д-р фіз.-мат. наук, проф. О.М. Кісельова (відп. ред.); д-р фіз.-мат. наук, доц. Л.Л. Гарт (заст. відп. ред.); чл.-кор. НАН України, д-р техн. наук, проф. Н.Д. Панкратова, чл.-кор. НАН України, д-р техн. наук, проф. Ю.Г. Стоян; д-р техн. наук, проф. Т.Є. Романова; д-р фіз.-мат. наук, проф. Н.А. Гук, д-р фіз.-мат. наук, проф. П.I. Когут; д-р техн. наук, проф. О.І. Михальов; д-р фіз.-мат. наук В. Дейнеко (Велика Британія); д-р фіз.-мат. наук, проф. Ю. Мельников (США); $\mathrm{PhD}$ О. Блюсс (Велика Британія); канд. екон. наук, доц. О.М. Притоманова (відп. секр.).

ISSN 2074-5893

doi: $10.15421 / 32191901$

(C) Дніпровський національний університет імені Олеся Гончара, 2019 


\author{
Ya.S. Bondarenko, S.V. Kravchenko \\ Department of Statistics and Probability Theory \\ Oles Honchar Dnipro National University
}

\title{
BAYESIAN APPROACH TO LANDING PAGE TESTING
}

В роботі байссівський метод статистичного оцінювання застосовусться до оптимізації коефіціснта конверсії. Запропоновано методологію байссівського $\mathrm{A} / \mathrm{B} / \mathrm{C}$ тестування цільової сторінки сайту, при цьому математичне сподівання функції втрат знайдено аналітично. Результати байссівського $\mathrm{A} / \mathrm{B} / \mathrm{C}$ тестування представлено графічно та описово.

Ключові слова: A/B/C тестування, байєсівський метод статистичного оцінювання, оптимізація коефіцієнта конверсії, математичне сподівання функції втрат, оптимізація цільової сторінки, функція втрат, щільність розподілу.

В работе байесовский метод статистического оценивания применяется для оптимизации коэффициента конверсии. Предложена методология байесовского $\mathrm{A} / \mathbf{B} / \mathrm{C}$ тестирования целевой страницы сайта, при этом математическое ожидание функции потерь найдено аналитически. Результаты байесовского $\mathrm{A} / \mathrm{B} / \mathrm{C}$ тестирования представлены графически и описательно.

Ключевые слова: A/B/C тестирование, байесовский метод статистического оценивания, оптимизация коэффициента конверсии, математическое ожидание функции потерь, оптимизация целевой страницы, функция потерь, плотность распределения.

In this paper a Bayesian inference to conversion rate optimization is considered. Bayesian $\mathbf{A} / \mathbf{B} / \mathrm{C}$ testing methodology with the expected value of the loss function computed analytically is proposed. Bayesian $\mathrm{A} / \mathrm{B} / \mathrm{C}$ testing results are presented graphically and descriptively.

Keywords: $\mathrm{A} / \mathrm{B} / \mathrm{C}$ testing, Bayesian inference, conversion rate optimization, expected loss, landing page optimization, loss function, probability density function.

\section{Introduction}

Each company directs its activity to generate profit. It is important for the company to have an effective website at the time when a significant part of the target audience receives information about the products and services via the Internet. Company website must be constantly optimized to increase profit. The object of optimization is conversion rate (percent of website visitors who engage in desired target action for the website owner). $\mathrm{A} / \mathrm{B}, \mathrm{A} / \mathrm{B} / \mathrm{C}$, and multivariate landing page testing are the ways to conversion rate optimization. $\mathrm{A} / \mathrm{B}$ testing is an experiment of showing two variants of the landing page to website visitors at the same time and comparing which variants give more conversion actions. $\mathrm{A} / \mathrm{B} / \mathrm{C}$ testing is an experiment of showing three variants of the landing page to website visitors, and statistical analysis is used to determine which

(C) Bondarenko Ya.S., Kravchenko S.V., 2019 
one performs better for a given conversion aim. In multivariate landing page testing, several elements are selected on the landing page and their modifications are created. All kinds of combinations for these modified elements are further created, therefore landing page variations are generated. Website visitors are equally divided between landing page variations. A variation is suggested viewing for each visitor and visitor's behavior is monitored. All possible combinations of page elements simultaneously are tested. It makes possible to assess the effect of each element and their interaction to conversion rate. Landing page variation (the optimal combination of elements) is selected depending on the outcome of the testing. For more details, see [1], [2], [3] and [4].

Moving away from classical hypothesis testing, like the t-test, to sequential testing developed by A. Wald [5] and by M. Girshick [6] was presented in papers [7], [8], [9], [10], [11]. The number of visitors required for landing page testing isn't fixed in advanced, conversions are evaluated as they are collected, and testing is stopped in accordance with a predefined stopping rule as soon as the significant result is observed. But experimental design without prior information about the statistical properties of the observed random variable occurs rarely. Classical methods of unbiased estimation and maximum likelihood method don't give insight adjusted for prior knowledge. Theory of Bayesian estimation allows combining prior information with observed random variables. The main difference between Bayesian and Frequentist approaches is that parameters of the distribution are considered as random variables in the first case and are defined as constant variables in the second one. Mathematical models of Bayesian testing were developed in [12]. The expected value of the loss function was proposed to calculate numerically and arising problems were described in this case.

In this paper Bayesian $\mathrm{A} / \mathrm{B} / \mathrm{C}$ testing implementation with the expected value of the loss function computed analytically is proposed. The paper consists of 5 sections. Section 2 is devoted to the main definitions. Posterior distributions for probabilities of success are considered. Section 3 deals with the analytical solution for expected value of the loss function. Bayesian testing implementation is described in section 4 and Bayesian testing results are discussed in section 5.

\section{The posterior distribution for the probability of success}

Bernoulli trials with probabilities $\theta_{A}, \theta_{B}, \theta_{C}$ of success are conducted in three groups of visitors $(\mathrm{A}, \mathrm{B}, \mathrm{C})$. Probabilities $\theta_{A}, \theta_{B}, \theta_{C}$ of success are unknown random variables. Let $p\left(\theta_{A}\right), p\left(\theta_{B}\right), p\left(\theta_{C}\right)$ be the prior probability density functions for $\theta_{A}, \theta_{B}, \theta_{C}$, respectively. Let $p\left(\theta_{A} \mid x_{1}, x_{2}, \ldots, x_{n}\right), p\left(\theta_{B} \mid y_{1}, y_{2}, \ldots, y_{n}\right)$, $p\left(\theta_{C} \mid z_{1}, z_{2}, \ldots, z_{n}\right)$ be the posterior probability density functions for $\theta_{A}, \theta_{B}, \theta_{C}$ given the sample vectors $x=\left(x_{1}, x_{2}, \ldots, x_{n}\right), y=\left(y_{1}, y_{2}, \ldots, y_{n}\right), z=\left(z_{1}, z_{2}, \ldots, z_{n}\right)$ are observed. Our goal is to find Bayesian estimators for probabilities $\theta_{A}, \theta_{B}, \theta_{C}$ of success concerning the loss function $L\left(\theta_{A}, \theta_{B}, \theta_{C}, \cdot\right)$. 
Bernoulli trials with two possible outcomes (success $\{x=1\}$ and failure $\{x=0\}$ ) are conducted in group A of visitors. The number of successes in one trial has Bernoulli distribution with parameter $\theta_{A}$ :

$$
P\left(x, \theta_{A}\right)=\theta_{A}^{x}\left(1-\theta_{A}\right)^{1-x}, 0<\theta_{A}<1 .
$$

The function $\theta_{A}$ defined by:

$$
p\left(x_{1}, x_{2}, \ldots, x_{n} \mid \theta_{A}\right)=\theta_{A}^{\sum_{i=1}^{n} x_{i}}\left(1-\theta_{A}\right)^{n-\sum_{i=1}^{n} x_{i}}, i=1, \ldots, n,
$$

is the likelihood function. The prior information about probability $\theta_{A}$ of success determined by:

$$
p\left(\theta_{A}\right)=\frac{\theta_{A}^{a-1}\left(1-\theta_{A}\right)^{b-1}}{B(a, b)}, 0 \leq \theta_{A} \leq 1,
$$

is Beta distribution with parameters $(a, b)$.

According to Bayes' theorem, the posterior distribution for probability $\theta_{A}$ of success is given by

$$
\begin{gathered}
p\left(\theta_{A} \mid x_{1}, x_{2}, \ldots, x_{n}\right)=\frac{p\left(\theta_{A}\right) p\left(x_{1}, x_{2}, \ldots, x_{n} \mid \theta_{A}\right)}{\int_{0}^{1} p\left(\theta_{A}\right) p\left(x_{1}, x_{2}, \ldots, x_{n} \mid \theta_{A}\right) d \theta_{A}}, \\
p\left(\theta_{A} \mid x_{1}, x_{2}, \ldots, x_{n}\right)=\frac{\theta_{A}^{a+\sum_{i=1}^{n} x_{i}-1}\left(1-\theta_{A}\right)^{b+n-\sum_{i=1}^{n} x_{i}-1}}{B\left(a+\sum_{i=1}^{n} x_{i}, b+n-\sum_{i=1}^{n} x_{i}\right)},
\end{gathered}
$$

consequently, the posterior distribution for probability $\theta_{A}$ of success in group $\mathrm{A}$ is Beta distribution with parameters $(\tilde{a}, \tilde{b})$ :

$$
p\left(\theta_{A} \mid x_{1}, x_{2}, \ldots, x_{n}\right)=\frac{\theta_{A}^{\tilde{a}-1}\left(1-\theta_{A}\right)^{\tilde{b}-1}}{B(\tilde{a}, \tilde{b})},
$$

where

$$
\tilde{a}=a+\sum_{i=1}^{n} x_{i}, \tilde{b}=b+n-\sum_{i=1}^{n} x_{i} .
$$

The posterior distribution for probability $\theta_{B}$ of success in group B is Beta distribution with parameters $(\tilde{c}, \tilde{d})$ :

$$
p\left(\theta_{B} \mid y_{1}, y_{2}, \ldots, y_{n}\right)=\frac{\theta_{B}^{\tilde{c}-1}\left(1-\theta_{B}\right)^{\tilde{d}-1}}{B(\tilde{c}, \tilde{d})},
$$

where

$$
\tilde{c}=c+\sum_{i=1}^{n} y_{i}, \tilde{d}=d+n-\sum_{i=1}^{n} y_{i}
$$


The posterior distribution for probability $\theta_{C}$ of success in group $\mathrm{C}$ is Beta distribution with parameters $(\tilde{e}, \tilde{f})$ :

$$
p\left(\theta_{C} \mid z_{1}, z_{2}, \ldots, z_{n}\right)=\frac{\theta_{C}^{\tilde{e}-1}\left(1-\theta_{C}\right)^{\tilde{f}-1}}{B(\tilde{e}, \tilde{f})},
$$

where

$$
\tilde{e}=e+\sum_{i=1}^{n} z_{i}, \tilde{f}=f+n-\sum_{i=1}^{n} z_{i}
$$

\section{Expected loss $E L\left(\theta_{A}, \theta_{B}, \theta_{C}, \cdot\right)$}

The loss function $L\left(\theta_{A}, \theta_{B}, \theta_{C}, \cdot\right)$ describes the loss under decision making about choosing landing page variant which can be published on website. The loss functions are

$$
\begin{aligned}
& L\left(\theta_{A}, \theta_{B}, \theta_{C}, A\right)=\max \left\{\theta_{B}-\theta_{A}, \theta_{C}-\theta_{A}, 0\right\}, \\
& L\left(\theta_{A}, \theta_{B}, \theta_{C}, B\right)=\max \left\{\theta_{A}-\theta_{B}, \theta_{C}-\theta_{B}, 0\right\}, \\
& L\left(\theta_{A}, \theta_{B}, \theta_{C}, C\right)=\max \left\{\theta_{A}-\theta_{C}, \theta_{B}-\theta_{C}, 0\right\}
\end{aligned}
$$

for group $\mathrm{A}, \mathrm{B}$ and $\mathrm{C}$, respectively [12].

The expected value of the loss function is computed analytically in this section. The expected loss for group A is determined by:

$$
\operatorname{EL}\left(\theta_{A}, \theta_{B}, \theta_{C}, A\right)=\int_{0}^{1} \int_{0}^{1} \int_{0}^{1} L(x, y, z, A) p(x, y, z) d x d y d z,
$$

where $p(x, y, z)$ is the joint density of $\theta_{A}, \theta_{B}, \theta_{C}$.

By definition of the loss function for group $\mathrm{A}$, we have

$$
\begin{gathered}
E L\left(\theta_{A}, \theta_{B}, \theta_{C}, A\right)= \\
=\int_{0}^{1} d x \int_{x}^{1} d y \int_{0}^{y}(y-x) \frac{x^{a-1}(1-x)^{b-1}}{B(a, b)} \frac{y^{c-1}(1-y)^{d-1}}{B(c, d)} \frac{z^{e-1}(1-z)^{f-1}}{B(e, f)} d z+ \\
+\int_{0}^{1} d x \int_{0}^{x} d y \int_{x}^{1}(z-x) \frac{x^{a-1}(1-x)^{b-1}}{B(a, b)} \frac{y^{c-1}(1-y)^{d-1}}{B(c, d)} \frac{z^{e-1}(1-z)^{f-1}}{B(e, f)} d z+ \\
+\int_{0}^{1} d x \int_{x}^{1} d y \int_{y}^{1}(z-x) \frac{x^{a-1}(1-x)^{b-1}}{B(a, b)} \frac{y^{c-1}(1-y)^{d-1}}{B(c, d)} \frac{z^{e-1}(1-z)^{f-1}}{B(e, f)} d z .
\end{gathered}
$$

The expected value of the loss function for group A has the following form:

$$
\begin{gathered}
E L\left(\theta_{A}, \theta_{B}, \theta_{C}, A\right)= \\
=\frac{B(c+1, d)}{B(c, d)}(1-h(a, b, c+1, d))-\frac{B(a+1, b)}{B(a, b)}(1-h(a+1, b, c, d))-
\end{gathered}
$$




$$
\begin{aligned}
- & \frac{B(c+1, d)}{B(c, d)} \sum_{i=0}^{e-1} \frac{B(c+1+i, d+f)}{(f+i) B(1+i, f) B(c+1, d)}(1-h(a, b, c+i+1, d+f)+ \\
+ & \frac{B(a+1, b)}{B(a, b)} \sum_{i=0}^{e-1} \frac{B(c+i, d+f)}{(f+i) B(1+i, f) B(c, d)}(1-h(a+1, b, c+i, d+f)+ \\
& +\frac{B(e+1, f)}{B(e, f)}(1-h(a, b, e+1, f))-\frac{B(a+1, b)}{B(a, b)}(1-h(a+1, b, e, f)- \\
& -\frac{B(e+1, f)}{B(e, f)} \sum_{i=0}^{e} \frac{B(a+i, b+f)}{(i+f) B(1+i, f) B(a, b)}(1-h(a+i, b+f, c, d))+ \\
+ & \frac{B(a+1, b)}{B(a, b)} \sum_{i=0}^{e-1} \frac{B(a+1+i, b+f)}{(i+f) B(1+i, f) B(a+1, b)}(1-h(a+1+i, b+f, c, d))+ \\
& +\frac{B(e+1, f)}{B(e, f)} \sum_{i=0}^{e} \frac{B(c+i, d+f)}{(i+f) B(1+i, f) B(c, d)}(1-h(a, b, c+i, d+f))- \\
- & \frac{B(a+1, b)}{B(a, b)} \sum_{i=0}^{e-1} \frac{B(c+i, d+f)}{(i+f) B(1+i, f) B(c, d)}(1-h(a+1, b, c+i, d+f)) .
\end{aligned}
$$

where the function $h$ is equal to:

$$
h(a, b, c, d)=1-\sum_{i=0}^{c-1} \frac{B(a+i, b+d)}{(d+i) B(1+i, d) B(a, b)} .
$$

Expected loss for group B is determined by:

$$
E L\left(\theta_{A}, \theta_{B}, \theta_{C}, B\right)=\int_{0}^{1} \int_{0}^{1} \int_{0}^{1} L\left(\theta_{A}, \theta_{B}, \theta_{C}, B\right) p(x, y, z) d x d y d z,
$$

where $p(x, y, z)$ is the joint density of $\theta_{A}, \theta_{B}, \theta_{C}$.

By definition of the loss function for group $\mathrm{B}$, we have

$$
\operatorname{EL}\left(\theta_{A}, \theta_{B}, \theta_{C}, B\right)=
$$

$$
\begin{aligned}
& =\int_{0}^{1} d x \int_{0}^{x} d y \int_{0}^{x}(x-y) \frac{x^{a-1}(1-x)^{b-1}}{B(a, b)} \frac{y^{c-1}(1-y)^{d-1}}{B(c, d)} \frac{z^{e-1}(1-z)^{f-1}}{B(e, f)} d z+ \\
& +\int_{0}^{1} d x \int_{0}^{x} d y \int_{x}^{1}(z-y) \frac{x^{a-1}(1-x)^{b-1}}{B(a, b)} \frac{y^{c-1}(1-y)^{d-1}}{B(c, d)} \frac{z^{e-1}(1-z)^{f-1}}{B(e, f)} d z+ \\
& +\int_{0}^{1} d x \int_{x}^{1} d y \int_{y}^{1}(z-y) \frac{x^{a-1}(1-x)^{b-1}}{B(a, b)} \frac{y^{c-1}(1-y)^{d-1}}{B(c, d)} \frac{z^{e-1}(1-z)^{f-1}}{B(e, f)} d z .
\end{aligned}
$$

Expected value of the loss function for group B has the following form: 


$$
\begin{gathered}
E L\left(\theta_{A}, \theta_{B}, \theta_{C}, B\right)= \\
=\frac{B(a+1, b)}{B(a, b)} h(a+1, b, c, d)-\frac{B(a+1, b)}{B(a, b)}(1-h(a+1, b, e, f))+ \\
+\frac{B(a+1, b)}{B(a, b)} \sum_{i=0}^{e-1} \frac{B(a+i+1, b+f)}{(i+f) B(i+1, f) B(a+1, b)}(1-h(a+i+1, b+f, c, d))- \\
\quad-\frac{B(c+1, d)}{B(c, d)} h(a, b, c+1, d)+\frac{B(c+1, d)}{B(c, d)}(1-h(a, b, e, f)- \\
-\frac{B(c+1, d)}{B(c, d)} \sum_{i=0}^{e-1} \frac{B(a+i, b+f)}{(i+f) B(i+1, f) B(a, b)}(1-h(a+i, b+f, c+1, d))+ \\
+\frac{B(e+1, f)}{B(e, f)}\left(1-h(a, b, e+1, f)-\frac{B(c+1, d)}{B(c, d)}(1-h(a, b, e, f))-\right. \\
-\frac{B(e+1, f)}{B(e, f)} \sum_{i=0}^{e} \frac{B(a+i, b+f)}{(i+f) B(i+1, f) B(a, b)}(1-h(a+i, b+f, c, d))+ \\
+\frac{B(c+1, d)}{B(c, d)} \sum_{i=0}^{e-1} \frac{B(a+i, b+f)}{(i+f) B(i+1, f) B(a, b)}(1-h(a+i, b+f, c+1, d))+ \\
+\frac{B(e+1, f)}{B(e, f)} \sum_{i=0}^{e} \frac{B(c+i, d+f)}{B(c, d)(i+f) B(i+1, f)}(1-h(a, b, c+i, d+f))- \\
-\frac{B(c+1, d)}{B(c, d)} \sum_{i=0}^{e-1} \frac{B(c+i+1, d+f)}{B(c+1, d)(i+f) B(i+1, f)}(1-h(a, b, c+i+1, d+f)),
\end{gathered}
$$

where the function $h$ is equal to:

$$
h(a, b, c, d)=1-\sum_{i=0}^{c-1} \frac{B(a+i, b+d)}{(d+i) B(1+i, d) B(a, b)} .
$$

The expected loss for group $\mathrm{C}$ is determined by:

$$
E L\left(\theta_{A}, \theta_{B}, \theta_{C}, C\right)=\int_{0}^{1} \int_{0}^{1} \int_{0}^{1} L\left(\theta_{A}, \theta_{B}, \theta_{C}, C\right) p(x, y, z) d x d y d z
$$

where $p(x, y, z)$ is the joint density of $\theta_{A}, \theta_{B}, \theta_{C}$.

By definition of the loss function for group $\mathrm{C}$, we have

$$
\begin{gathered}
E L\left(\theta_{A}, \theta_{B}, \theta_{C}, C\right)= \\
=\int_{0}^{1} d x \int_{0}^{x} d y \int_{0}^{x}(x-z) \frac{x^{a-1}(1-x)^{b-1}}{B(a, b)} \frac{y^{c-1}(1-y)^{d-1}}{B(c, d)} \frac{z^{e-1}(1-z)^{f-1}}{B(e, f)} d z+
\end{gathered}
$$




$$
+\int_{0}^{1} d x \int_{x}^{1} d y \int_{0}^{y}(y-z) \frac{x^{a-1}(1-x)^{b-1}}{B(a, b)} \frac{y^{c-1}(1-y)^{d-1}}{B(c, d)} \frac{z^{e-1}(1-z)^{f-1}}{B(e, f)} d z .
$$

Expected value of the loss function for group $C$ has the following form:

$$
\begin{gathered}
E L\left(\theta_{A}, \theta_{B}, \theta_{C}, C\right)= \\
=\frac{B(a+1, b)}{B(a, b)} h(a+1, b, c, d)-\frac{B(a+1, b)}{B(a, b)}(1-h(a+1, b, e, f))+ \\
+\frac{B(a+1, b)}{B(a, b)} \sum_{i=0}^{e-1} \frac{B(a+i+1, b+f)}{(i+f) B(i+1, f) B(a+1, b)}(1-h(a+i+1, b+f, c, d))- \\
-\frac{B(e+1, f)}{B(e, f)}+\frac{B(c+1, d)}{B(c, d)}(1-h(a, b, c+1, d))+\frac{B(e+1, f)}{B(e, f)}(1-h(a, b, e+1, f))- \\
-\frac{B(e+1, f)}{B(e, f)} \sum_{i=0}^{e} \frac{B(a+i, b+f)}{(i+f) B(i+1, f) B(a, b)}(1-h(a+i, b+f, c, d))- \\
-\frac{B(c+1, d)}{B(c, d)} \sum_{i=0}^{e-1} \frac{B(c+i+1, d+f)}{(f+i) B(1+i, f) B(c, d)}(1-h(a, b, c+i+1, d+f))- \\
+\frac{B(e+1, f)}{B(e, f)} \sum_{i=0}^{e} \sum_{j=0}^{c+i-1} \frac{B(c+i, d+f) B(a+j, d+f+b)}{B(a, b)(i+f) B(i+1, f) B(c, d)(j+d+f) B(j+1, d+f)},
\end{gathered}
$$

where the function $h$ is equal to:

$$
h(a, b, c, d)=1-\sum_{i=0}^{c-1} \frac{B(a+i, b+d)}{(d+i) B(1+i, d) B(a, b)} .
$$

The foregoing results for three group of visitors $\mathrm{A}, \mathrm{B}, \mathrm{C}$ can be easily converted into results for two groups. Expected value of the loss function for group A has the following form:

$$
E L\left(\theta_{A}, \theta_{B}, A\right)=\frac{B(c+1, d)}{B(c, d)}(1-h(a, b, c+1, d))-\frac{B(a+1, b)}{B(a, b)}(1-h(a+1, b, c, d))
$$

and expected value of the loss function for group B has the following form:

$$
E L\left(\theta_{A}, \theta_{B}, B\right)=\frac{B(a+1, b)}{B(a, b)} h(a+1, b, c, d)-\frac{B(c+1, d)}{B(c, d)} h(a, b, c+1, d) .
$$

\section{Bayesian testing implementation}

Landing page variants A, B, C are suggested viewing for the first, second and third group of visitors. We need to identify users during testing for clear experiment and suggest them the same landing page variant that they have viewed earlier in case of repeated visits. The flow of visitors has been simulated. Each visitor can belong to the first, second and third group with probability $1 / 3$. Visitor behavior is simulated after identification of visitor belonging to group. Visitor 
behavior is determined with two outcomes: success - conversion action is done, failure - conversion action isn't done. If visitor belongs to the first group, success will happen with probability $\theta_{A}$, and if visitor belongs to the second group, success will happen with probability $\theta_{B}$, and if visitor belongs to the third group, success will happen with probability $\theta_{C}$. Prior information about unknown distribution for probabilities $\theta_{A}, \theta_{B}$ and $\theta_{C}$ of success is defined with Beta distribution with parameters $a=1, b=1$ and $c=1, d=1$, and $e=1, f=1$, respectively.

According to Bayes' theorem, posterior distribution for probability $\theta_{A}$ of success is Beta-distribution with $(\tilde{a}, \tilde{b})$ parameters:

$$
\tilde{a}=a+x_{i}, \tilde{b}=b+\left(1-x_{i}\right),
$$

where $x_{i}$ is number of successes in one trial $\left(x_{i}=0,1\right)$, the posterior distribution for probability $\theta_{B}$ of success is Beta-distribution with $(\tilde{c}, \tilde{d})$ parameters:

$$
\tilde{c}=c+y_{i}, \tilde{d}=d+\left(1-y_{i}\right),
$$

where $y_{i}$ is number of successes in one trial $\left(y_{i}=0,1\right)$,

the posterior distribution for probability $\theta_{C}$ of success is Beta-distribution with $(\tilde{e}, \tilde{f})$ parameters:

$$
\tilde{e}=e+z_{i}, \tilde{f}=f+\left(1-z_{i}\right),
$$

where $z_{i}$ is number of successes in one trial $\left(z_{i}=0,1\right)$.

Expected loss $L\left(\theta_{A}, \theta_{B}, \theta_{C}, \cdot\right)$ compares with threshold of loss $\varepsilon$ after each visit of landing page variant $\mathrm{A}, \mathrm{B}, \mathrm{C}$. If

$$
E L\left(\hat{\theta}_{A}, \hat{\theta}_{B}, \hat{\theta}_{C}, A\right) \leq \varepsilon, E L\left(\hat{\theta}_{A}, \hat{\theta}_{B}, \hat{\theta}_{C}, B\right)>\varepsilon, E L\left(\hat{\theta}_{A}, \hat{\theta}_{B}, \hat{\theta}_{C}, C\right)>\varepsilon,
$$

then testing will be stopped, landing page variant $\mathrm{A}$ will be chosen for publishing on website, if

$$
E L\left(\hat{\theta}_{A}, \hat{\theta}_{B}, \hat{\theta}_{C}, A\right)>\varepsilon, E L\left(\hat{\theta}_{A}, \hat{\theta}_{B}, \hat{\theta}_{C}, B\right) \leq \varepsilon, E L\left(\hat{\theta}_{A}, \hat{\theta}_{B}, \hat{\theta}_{C}, C\right)>\varepsilon,
$$

then testing will be stopped, landing page variant $\mathrm{B}$ will be chosen for publishing on website, if

$$
E L\left(\hat{\theta}_{A}, \hat{\theta}_{B}, \hat{\theta}_{C}, A\right)>\varepsilon, E L\left(\hat{\theta}_{A}, \hat{\theta}_{B}, \hat{\theta}_{C}, B\right)>\varepsilon, E L\left(\hat{\theta}_{A}, \hat{\theta}_{B}, \hat{\theta}_{C}, C\right) \leq \varepsilon,
$$

then testing will be stopped, landing page variant $\mathrm{C}$ will be chosen for publishing on website [12].

Likelihood that probability of success in one group is greater than the probability of success in another two groups is defined by (see [13])

$$
\begin{gathered}
P\left\{\theta_{A}>\max \left\{\theta_{B}, \theta_{C}\right\}\right\}=1-P\left\{\theta_{B}>\theta_{A}\right\}-P\left\{\theta_{C}>\theta_{A}\right\}+ \\
+\sum_{i=0}^{c-1} \sum_{j=0}^{e-1} \frac{B(i+j+a, b+d+f)}{(d+i)(f+j) B(1+i, d) B(1+j, f) B(a, b)},
\end{gathered}
$$




$$
\begin{gathered}
P\left\{\theta_{B}>\max \left\{\theta_{A}, \theta_{C}\right\}\right\}=1-P\left\{\theta_{A}>\theta_{B}\right\}-P\left\{\theta_{C}>\theta_{B}\right\}+ \\
+\sum_{i=0}^{a-1} \sum_{j=0}^{e-1} \frac{B(i+j+c, b+d+f)}{(b+i)(f+j) B(1+i, b) B(1+j, f) B(c, d)}, \\
P\left\{\theta_{C}>\max \left\{\theta_{A}, \theta_{B}\right\}\right\}=1-P\left\{\theta_{A}>\theta_{C}\right\}-P\left\{\theta_{B}>\theta_{C}\right\}+ \\
+\sum_{i=0}^{a-1} \sum_{j=0}^{c-1} \frac{B(i+j+e, b+d+f)}{(b+i)(d+j) B(1+i, b) B(1+j, d) B(e, f)} .
\end{gathered}
$$

\section{Bayesian testing results}

Minimally-informative prior densities are shown in Figure 1. Prior densities for probability $\theta_{A}, \theta_{B}, \theta_{C}$ of success are represented with blue, red and green color, respectively. Likelihoods that probability of success in one group is greater than the probabilities of success in two other groups are equal to

$$
P\left\{\hat{\theta}_{A}>\max \left\{\hat{\theta}_{B}, \hat{\theta}_{C}\right\}\right\}=P\left\{\hat{\theta}_{B}>\max \left\{\hat{\theta}_{A}, \hat{\theta}_{C}\right\}\right\}=P\left\{\hat{\theta}_{C}>\max \left\{\hat{\theta}_{A}, \hat{\theta}_{B}\right\}\right\}=0,33
$$

Bayesian testing results on several iterations are considered. On 21st iteration posterior density for probability $\theta_{A}$ of success (Beta-distribution with $\tilde{a}=7, \tilde{b}=3$ parameters) is represented with blue color, posterior density for probability $\theta_{B}$ of success (Beta-distribution with $\tilde{c}=6, \tilde{d}=2$ parameters) is represented with red color, posterior density for probability $\theta_{C}$ of success (Beta-distribution with $\tilde{e}=3, \tilde{f}=5$ parameters) is represented with green color (see Fig. 2). Bayesian estimators for probabilities $\theta_{A}, \theta_{B}, \theta_{C}$ of success are equal to

$$
\hat{\theta}_{A}=0,75 ; \hat{\theta}_{B}=0,83 ; \hat{\theta}_{C}=0,33 \text {. }
$$

Likelihoods that probability of success in one group is greater than the probabilities of success in two other groups are equal to

$$
\begin{aligned}
& P\left\{\hat{\theta}_{A}>\max \left\{\hat{\theta}_{B}, \hat{\theta}_{C}\right\}\right\}=0,39, \\
& P\left\{\hat{\theta}_{B}>\max \left\{\hat{\theta}_{A}, \hat{\theta}_{C}\right\}\right\}=0,60, \\
& P\left\{\hat{\theta}_{C}>\max \left\{\hat{\theta}_{A}, \hat{\theta}_{B}\right\}\right\}=0,01 .
\end{aligned}
$$

On 39th iteration posterior density for probability $\theta_{A}$ of success (Betadistribution with $\tilde{a}=13, \tilde{b}=6$ parameters) is represented with blue color, posterior density for probability $\theta_{B}$ of success (Beta-distribution with $\tilde{c}=10, \tilde{d}=2$ parameters) is represented with red color, posterior density for probability $\theta_{C}$ of success (Beta-distribution with $\tilde{e}=3, \tilde{f}=10$ parameters) is represented with 
green color (see Fig. 4). Bayesian estimators for probabilities $\theta_{A}, \theta_{B}, \theta_{C}$ of success are equal to

$$
\hat{\theta}_{A}=0,70 ; \hat{\theta}_{B}=0,90 ; \hat{\theta}_{C}=0,18 \text {. }
$$

Likelihoods that probability of success in one group is greater than the probabilities of success in two other groups are equal to

$$
\begin{aligned}
P\left\{\hat{\theta}_{A}>\max \left\{\hat{\theta}_{B}, \hat{\theta}_{C}\right\}\right\} & =0,151, \\
P\left\{\hat{\theta}_{B}>\max \left\{\hat{\theta}_{A}, \hat{\theta}_{C}\right\}\right\} & =0,848, \\
P\left\{\hat{\theta}_{C}>\max \left\{\hat{\theta}_{A}, \hat{\theta}_{B}\right\}\right\} & =0,001 . \\
\mathrm{P}\left\{\theta_{A}>\max \left\{\theta_{B}, \theta_{C}\right\}\right\} & =0.33
\end{aligned}
$$

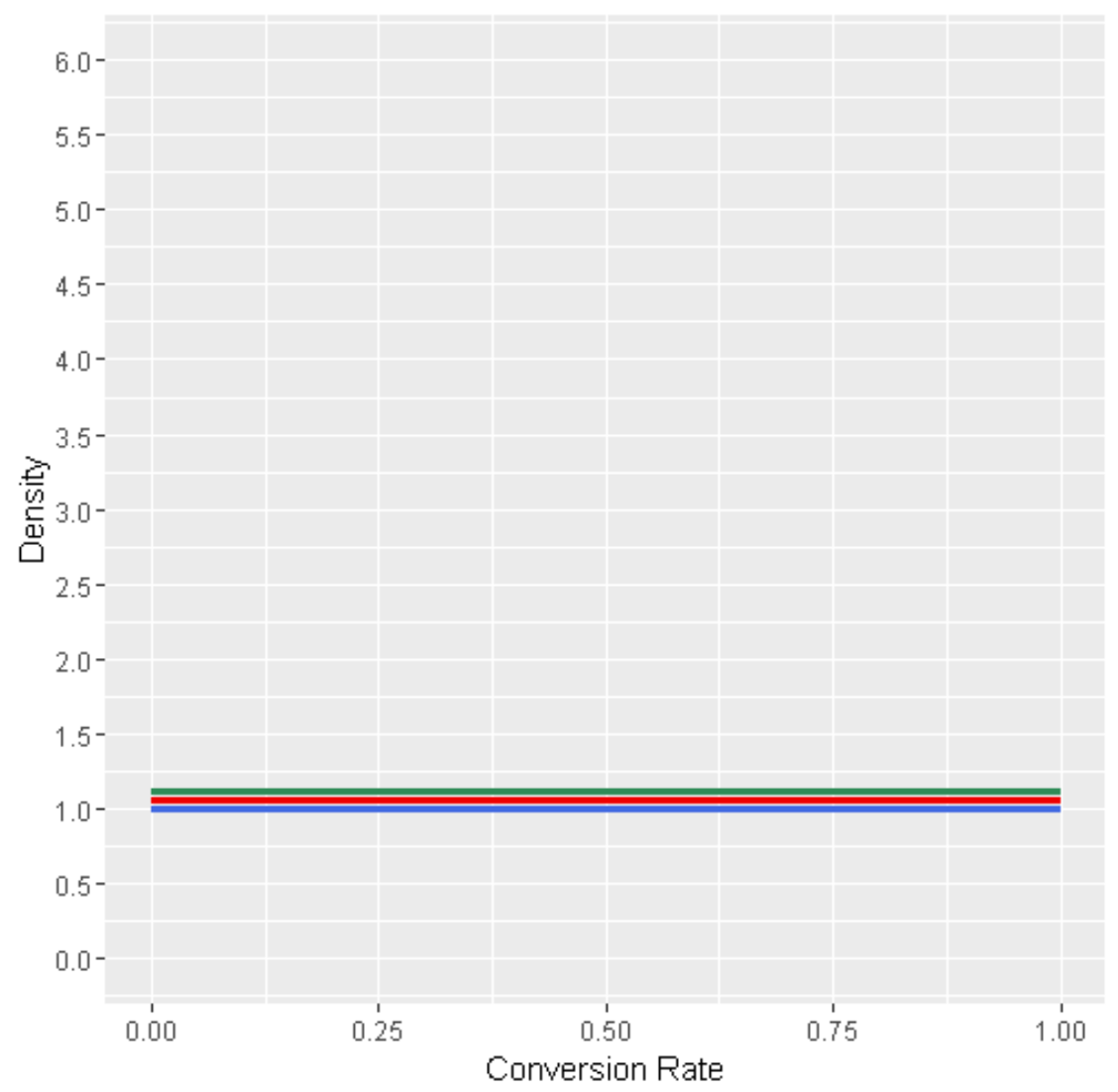

Fig. 1. Prior densities for probabilities $\theta_{A}, \theta_{B}, \theta_{C}$ of success

On 60th iteration posterior density for probability $\theta_{A}$ of success (Betadistribution with $\tilde{a}=16, \tilde{b}=9$ parameters) is represented with blue color, posterior density for probability $\theta_{B}$ of success (Beta-distribution with $\tilde{c}=14, \tilde{d}=2$ parameters) is represented with red color, posterior density for probability $\theta_{C}$ of success (Beta-distribution with $\tilde{e}=7, \tilde{f}=17$ parameters) is represented with green 
color (see Fig. 5). Bayesian estimators for probabilities $\theta_{A}, \theta_{B}, \theta_{C}$ of success are equal to $\hat{\theta}_{A}=0,65 ; \hat{\theta}_{B}=0,93 ; \hat{\theta}_{C}=0,27$.

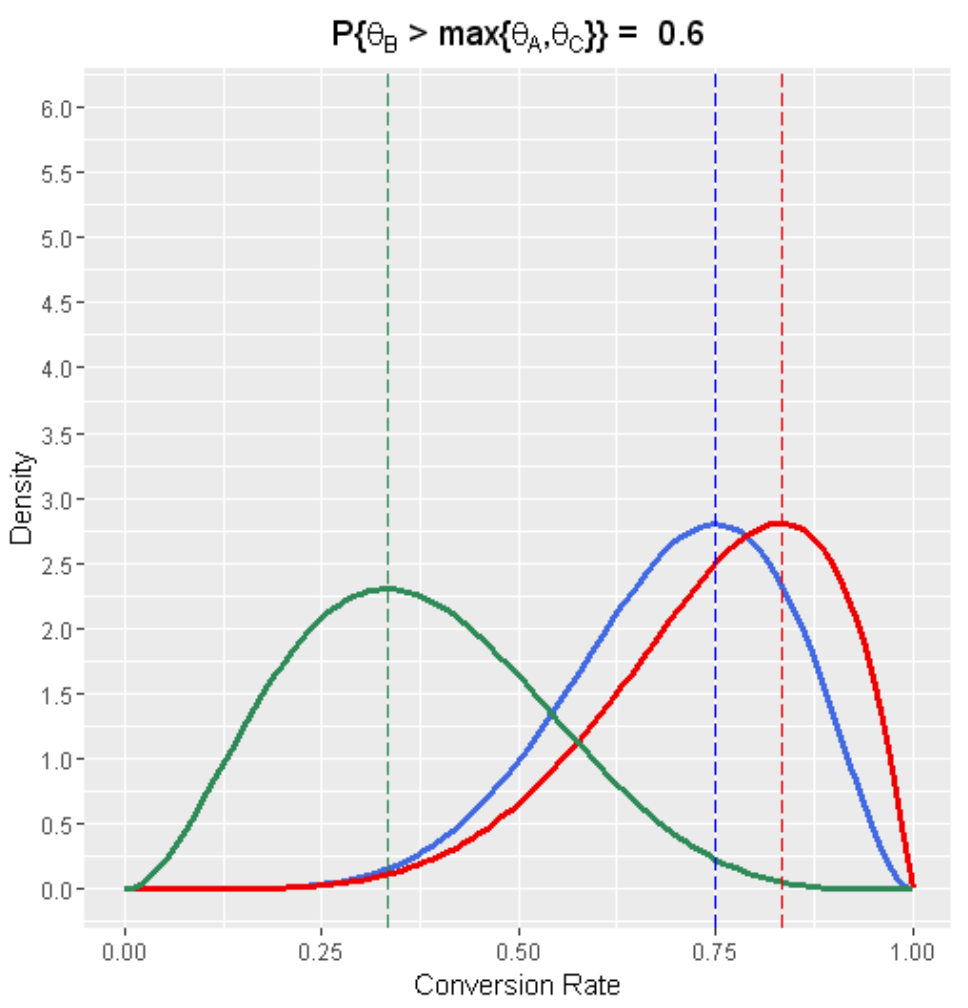

Fig. 2. Posterior densities for probabilities $\theta_{A}, \theta_{B}, \theta_{C}$ of success on 21st iteration

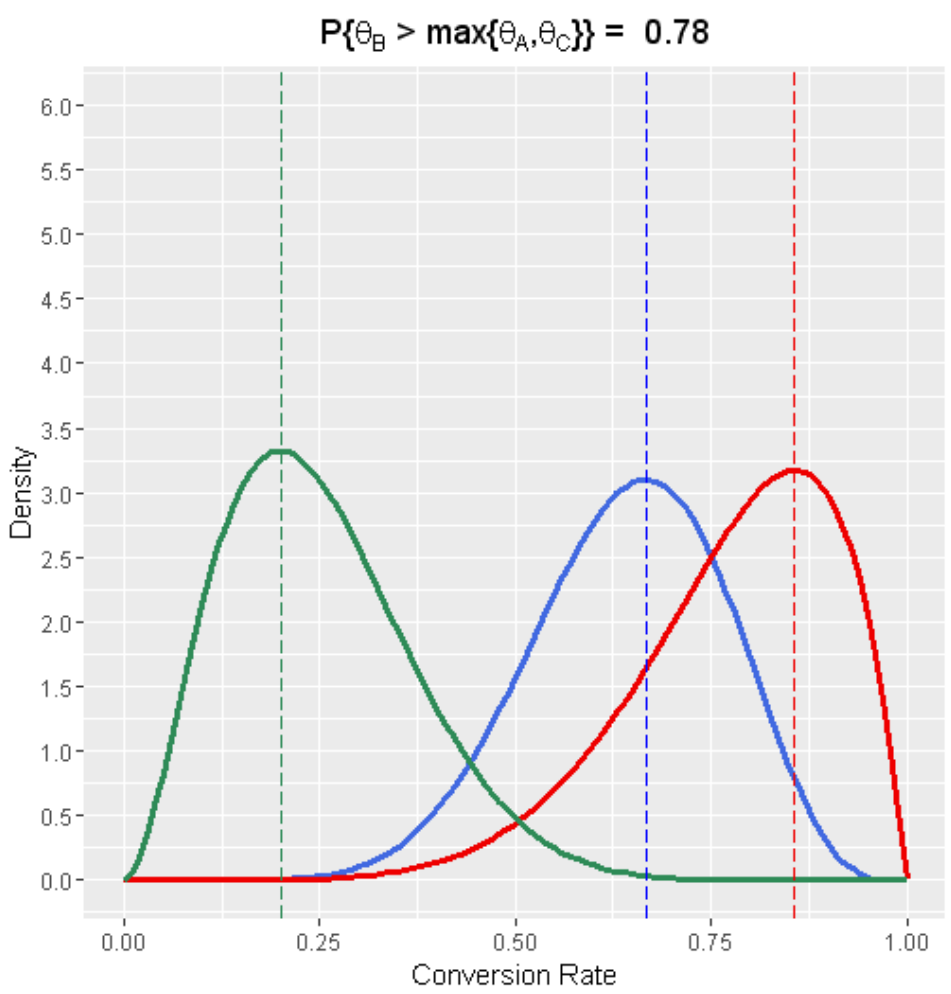

Fig. 3. Posterior densities for probabilities $\theta_{A}, \theta_{B}, \theta_{C}$ of success on 30th iteration 


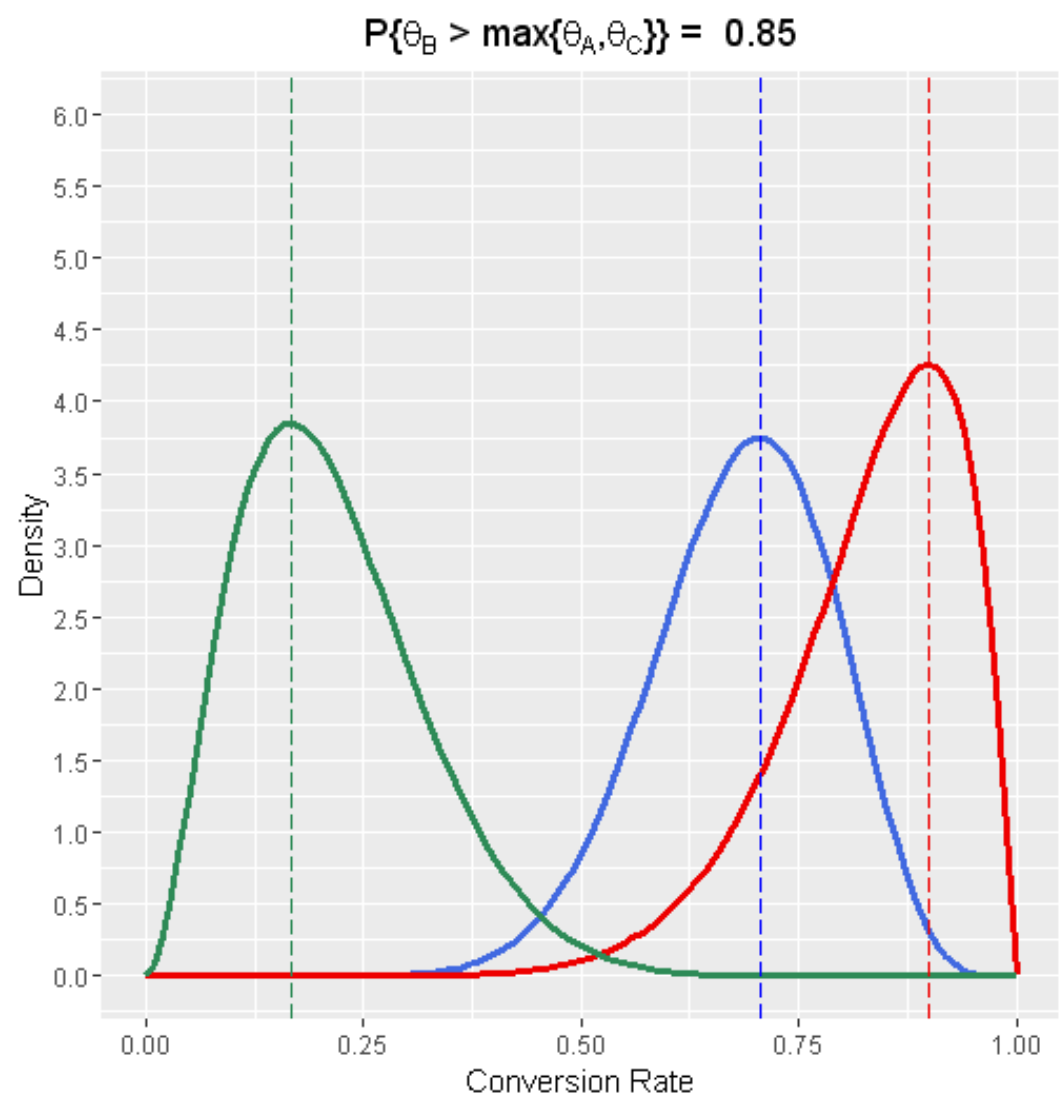

Fig. 4. Posterior densities for probabilities $\theta_{A}, \theta_{B}, \theta_{C}$ of success on 39th iteration

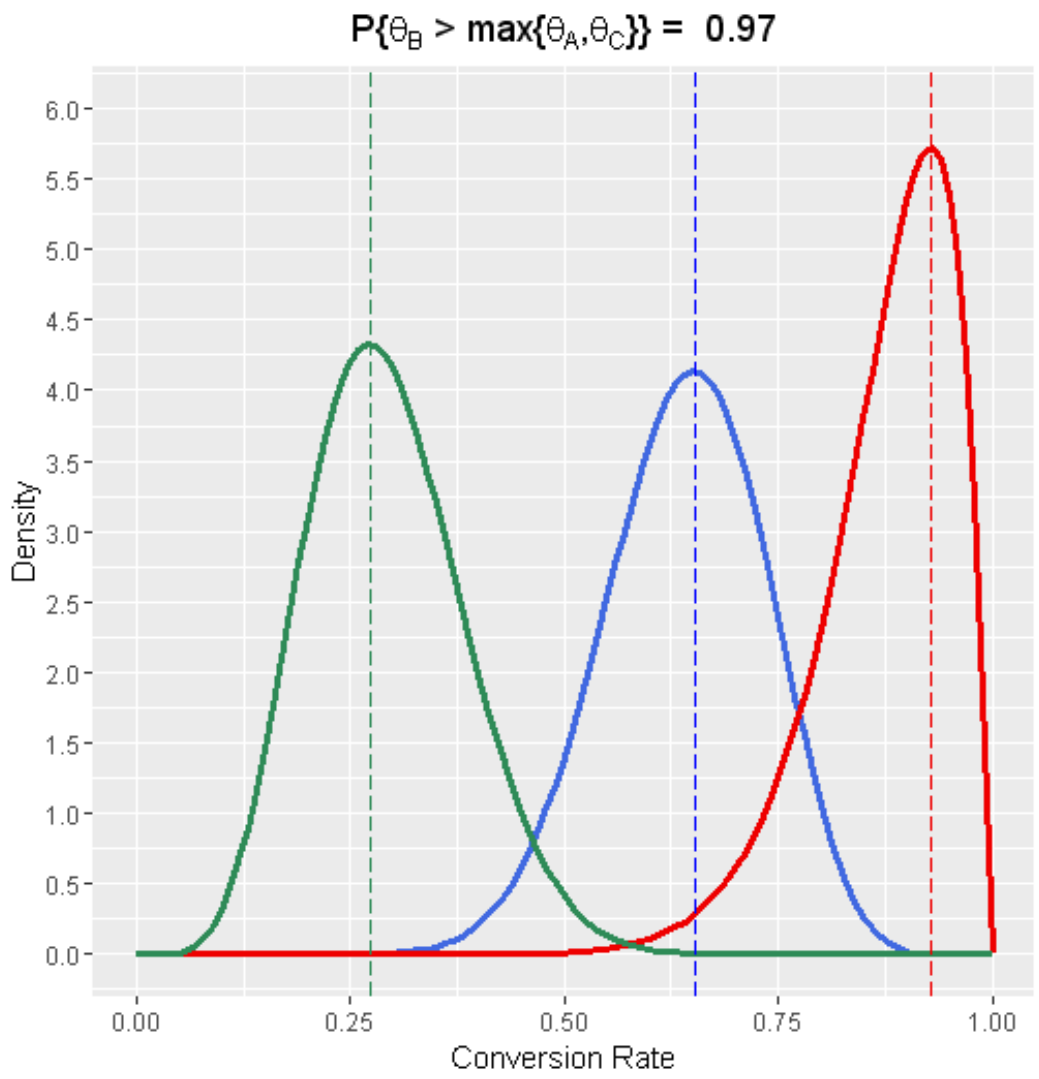

Fig. 5. Posterior densities for probabilities $\theta_{A}, \theta_{B}, \theta_{C}$ of success on $60^{\text {th }}$ iteration 


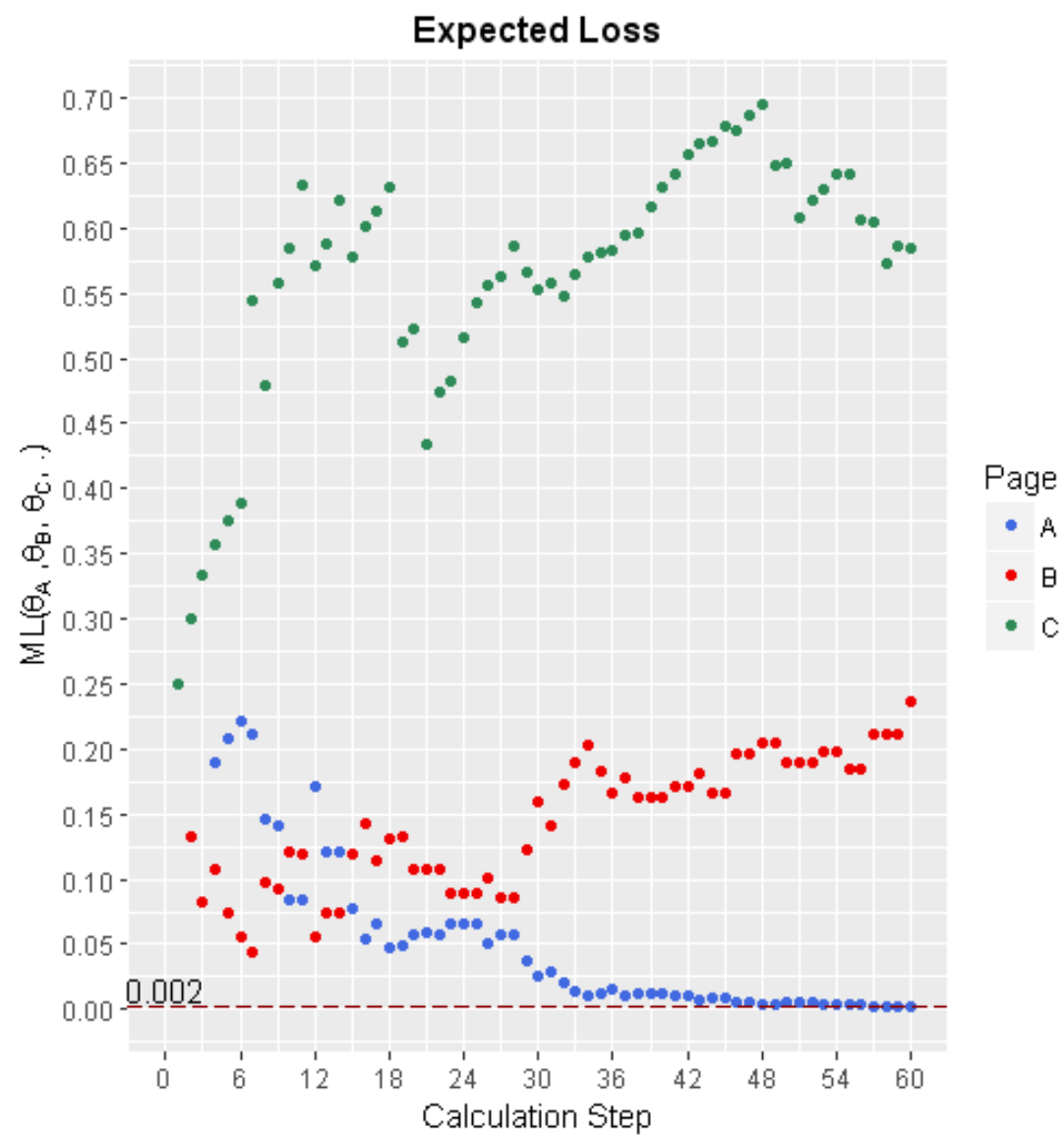

Fig. 6. Expected loss $L\left(\theta_{A}, \theta_{B}, \theta_{C}, \cdot\right)$ on each iteration

Likelihoods that probability of success in one group is greater than the probabilities of success in two other groups are equal to

$$
\begin{gathered}
P\left\{\hat{\theta}_{A}>\max \left\{\hat{\theta}_{B}, \hat{\theta}_{C}\right\}\right\}=0,03, \\
P\left\{\hat{\theta}_{B}>\max \left\{\hat{\theta}_{A}, \hat{\theta}_{C}\right\}\right\}=0,97, \\
P\left\{\hat{\theta}_{C}>\max \left\{\hat{\theta}_{A}, \hat{\theta}_{B}\right\}\right\}=9,65 \cdot 10^{-6} .
\end{gathered}
$$

Testing has been finished with expected loss:

$$
E L\left(\hat{\theta}_{A}, \hat{\theta}_{B}, \hat{\theta}_{C}, A\right)=0,251, E L\left(\hat{\theta}_{A}, \hat{\theta}_{B}, \hat{\theta}_{C}, B\right)=0,002, E L\left(\hat{\theta}_{A}, \hat{\theta}_{B}, \hat{\theta}_{C}, C\right)=0,585 \text {. }
$$

\section{Conclusion}

We proposed a Bayesian $\mathrm{A} / \mathrm{B} / \mathrm{C}$ testing implementation with the expected value of the loss function computed analytically. $\mathrm{A} / \mathrm{B} / \mathrm{C}$ testing procedure has several advantages over the multivariate testing. $\mathrm{A} / \mathrm{B} / \mathrm{C}$ testing can be used when we have enough traffic for $\mathrm{A} / \mathrm{B} / \mathrm{C}$ test, but not for a multivariate test. $\mathrm{A} / \mathrm{B} / \mathrm{C}$ testing should be used when we wanted to improve element on a website that may have multiple versions: $\mathrm{A}, \mathrm{B}, \mathrm{C} . \mathrm{A} / \mathrm{B} / \mathrm{C}$ must be used to answer the question "what is probability that landing page variant $\mathrm{A}$ is better than landing page variants $\mathrm{B}$ and $\mathrm{C}$ ?" 
Bayesian $\mathrm{A} / \mathrm{B} / \mathrm{C}$ testing can easily be converted into Bayesian $\mathrm{A} / \mathrm{B}$ testing with a closed-form solution.

\section{References}

1. R. Kohavi, R. M. Henne, and D. Sommerfield. Practical guide to controlled experiments on the web: listen to your customers not to the hippo [Text] // Proceedings of the 13th ACM SIGKDD international conference on Knowledge discovery and data mining, pp. 959-967, ACM, 2007.

2. R. Kohavi, R. Longbotham, D. Sommerfield, and R. M. Henne. Controlled experiments on the web: survey and practical guide [Text] // Data mining and knowledge discovery, vol. 18, no. 1, pp. 140-181, 2009.

3. R. Kohavi, A. Deng, B. Frasca, T. Walker, Y. Xu, and N. Pohlmann. Online controlled experiments at large scale [Text] // Proceedings of the 19th ACM SIGKDD international conference on Knowledge discovery and data mining, pp. 1168-1176. ACM, 2013.

4. R. Kohavi, A. Deng, R. Longbotham, and Y. Xu. Seven rules of thumb for web site experimenters [Text] // Proceedings of the 14th ACM SIGKDD international conference on Knowledge discovery and data mining, 2014.

5. A. Wald. Sequential tests of statistical hypotheses [Text] // Ann. Math. Statist., vol. 16, no. 2, pp. 117-186, 1945.

6. M. Girshick. Contributions to the theory of sequential analysis [Text] // I, Ann. Math. Statist., vol. 17, no. 2, pp. 123-143, 1946.

7. L. Pekelis, D. Walsh, R. Johari. The new stats engine [Text] // Technical report, Optimizely, 2015.

8. R. Johari, P. Koomen, L. Pekelis, and D. Walsh. Peeking at a/b tests: Why it matters, and what to do about it [Text] // Proceedings of the 23rd ACM SIGKDD International Conference on Knowledge Discovery and Data Mining, pp. 1517-1525, 2017.

9. R. Johari, L. Pekelis, and D. Walsh. Always valid inference: Bringing sequential analysis to A/B testing, arXiv preprint arXiv:1512.04922v3, Optimizely, 2019.

10. E. Miller. Simple sequential a/b testing, URL http://www.evanmiller.org/sequential-abtesting.html, blog post, 2015.

11. Ya. Bondarenko, and O. Yashchuk. Sequential analysis in the A/B testing [Text] // Problems of Applied Mathematics and Mathematical modelling, pp. 192-203, 2016.

12. C. Stucchio. Bayesian A/B Testing at VWO [Text] // Technical report, Visual Website Optimizer, 2015.

13. E. Miller. Formulas for Bayesian A/B testing, URL http://www.evanmiller.org/bayesian-abtesting.html, blog post, 2015.

14. Ya. Bondarenko, and S. Kravchenko. On the Frequentist Approach to Multivariate Landing Page Testing [Text] // Visnyk DNU. Series: Modelling, vol. 9, no. 8, pp. 142-151, 2017.

15. Ya. Bondarenko, and S. Kravchenko. Bayesian A/B/C testing [Text] // The Fifth BalticNordic Conference on Survey Statistics, 16-20 June 2019 in Örebro, Sweden.

Received 17.09.2019. 


\author{
В.Є. Білозьоров, А.С. Івлев \\ Дніпровський наиіональний університет імені Олеся Гончара
}

\title{
НЕЙРОМЕРЕЖЕВИЙ ПІДХІД ДЛЯ МОДЕЛЮВАННЯ ЦІН НА РИНКУ ДОРОГОЦІННИХ МЕТАЛІВ
}

У даній статті представлено новий метод використання штучної нейронної мережі в задачах прогнозування цін. Проведено експериментальні дослідження методу на основі курсу ціноутворення дорогоцінних металів на українській міжбанківській біржі. Зроблено відповідні висновки щодо ефективності методу та можливостей його подальшого удосконалення на основі результатів цих досліджень.

Ключові слова: нейронна мережа, прогнозування, курс цін, часовий ряд.

В данной статье представлен новый метод использования искусственной нейронной сети в задачах прогнозирования. Проведены экспериментальные исследования данного метода на основе курса ценообразования драгоценных металлов на украинской межбанковской бирже. Сделаны соответствующие выводы касательно эффективности метода и возможностей его дальнейшего усовершенствования на основе результатов этих исследований.

Ключевые слова: нейронная сеть, прогнозирование, курс цен, временной ряд.

The modern development of the science of artificial neural networks (ANN) has allowed to use their nature and properties in various applied fields of science. One of the most important applications of ANN is the modeling of prices in the precious metals market. Just like in any other market, based on the prediction of current prices, because the ability of ANN to learn like a true biological neural network, relying on the input with subsequent testing of the output, provides a significant advantage in the prediction tasks compared to the classical mathematical algorithms. Predicting the price of precious metals with relatively high precision and low error is in great demand among all individuals and legal entities that carry out transactions which are directly related to the purchase and sale of these precious metals, since accurate knowledge of the future price of a particular metal will bring maximum benefits of these operations. Numerous methods have been developed [2-4] for the use of neural networks in the modeling of price forecasts, which make the prediction of the rate of exchange for a particular currency (rather objective). The applied methods make the prediction using the classical perceptron along with astrological cyclic indices [2], recursive neural networks [3], and/or using elements of mathematical statistics (for example, use of $U$-statistic and the coefficient of determination $R^{2}$ ) [4]. The goal of this paper is the attempt to usethe ANN in the forecasting problem that allows predicting the price of precious metals in the near future, based on an algorithm that makes predictions by learning based on an array of input data and does not depend on the said elements of mathematical statistics. The paper presents a new method for using an artificial neural network in forecasting problems. Experimental studies of this method were carried out on the basis of the precious metals pricing rate on the Ukrainian Interbank Exchange. The corresponding conclusions are made regarding the effectiveness of the method and the possibilities for its further improvement based on the results of these studies. It is expected that such an algorithm will give a prediction as close as possible to the real value.

Key words: neural network, forecasting, price rate, time series.

() Білозьоров В.С., Івлев А.С., 2019 
Вступ. Сучасний розвиток науки штучних нейронних мереж (ШНС) дозволив використовувати їх природу та властивості в різноманітних прикладних галузях науки. Одним з таких найважливіших прикладних застосувань ШНС є моделювання цін на ринку дорогоцінних металів. Так само як і на будь-якому іншому ринку, на основі передбачення поточних цін, оскільки здатність ШНС до навчання подібно справжній біологічній нейронної мережі, опираючись на вхідні дані із наступним тестуванням вихідних даних, надає значну перевагу в задачах прогнозування у порівнянні із класичними математичними алгоритмами.

Передбачення курсу цін дорогоцінних металів з відносно високою точністю і малою похибкою користується великим попитом серед усіх фізичних та юридичних осіб, які здійснюють операції, пов'язані безпосередньо з купівлею-продажем цих дорогоцінних металів, оскільки точне знання майбутньої ціни на той чи інший метал дозволить приносити максимальну вигоду від цих операцій.

Були розроблені численні методи [2-4] використання нейронних мереж у моделюванні прогнозу цін, що роблять прогноз курсу цін на ту чи іншу валюту (доволі об'єктивним). Застосовані методи здійснюють прогноз з використанням класичного перцептрона та астрологічних циклічних індексів [2], рекурсивних нейронних мереж [3], та/або із застосуванням елементів математичної статистики (наприклад, використання U-статистики і коефіцієнту детермінації $R^{2}$ ) [4].

Метою цієї статті є спроба використати у задачі прогнозування таку модель ШНС, яка дозволяє передбачувати ціну на дорогоцінні метали на найближчий час. Ця спроба грунтується на алгоритмі навчання, який здійснює прогноз на основі масиву вхідних даних та не залежить від вище зазначених елементів математичної статистики. Очікується, що такий алгоритм даватиме прогноз, максимально близький до реального значення.

Основні результати. У якості ШНС, використовуватимемо нелінійну авторегресійну модель нейронної мережі (англ. Nonlinear autoregressive model, NAR) (рис. 1), вбудовану в математичному пакеті MATLAB:

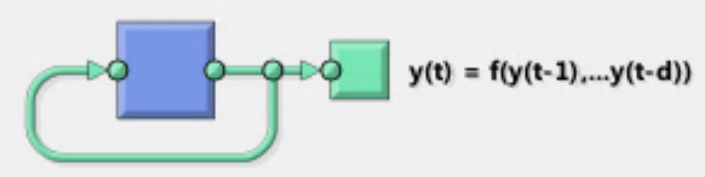

Рис. 1: Загальна схема моделі NAR.

Ця модель здійснює передбачення на основі вхідного часового ряду $y(t)$ :

$$
y(t)=f(y(t-1), y(t-2), \ldots, y(t-d)),
$$

де $d$ - параметр запізнення (скільки перших елементів вхідного ряду не увійде до прогнозованого ряду), $f$ - функція нейронної мережі, що здійснює прогнозування ряду. 
В якості вхідного часового ряду для нейронної мережі візьмемо ціни на золото з сайту Міністерства фінансів України [1] за курсом Національного банку України в період з 22.04.2019 по 16.09.2019 без урахування вихідних і святкових днів, а також днів, в які Національний банк України не надавав нових цін. Розмір такого часового ряду становить 100 значень (рис. 2):

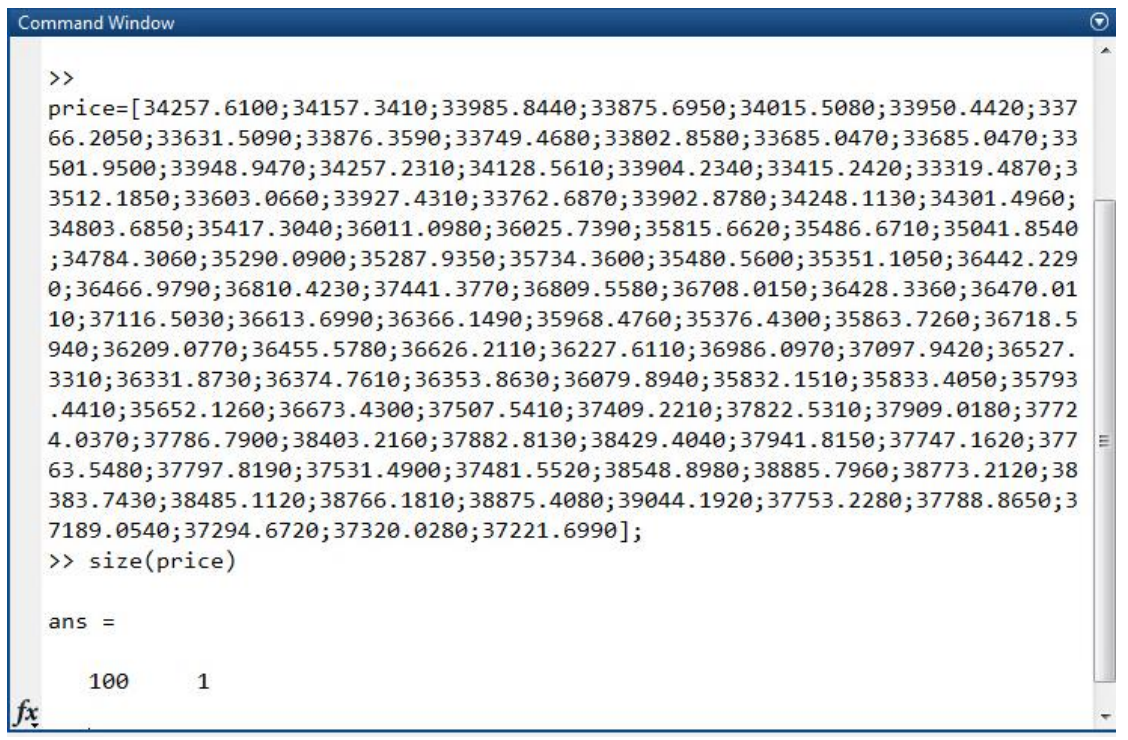

Рис. 2: Вхіднийчасовий ряд цін на золото із 100 значень в період с 22.04.2019 по 16.09.2019.

Тепер використовуємо алгоритм нейронної мережі NAR для прогнозування часового ряду цін на золото на декілька днів вперед, і потім порівняємо отримане значення 3 істинним значенням ціни на золото в період від 17.09.2019 до 30.09.2019.

На рис. 3 представлена розширена схема моделі нейронної мережі NAR:

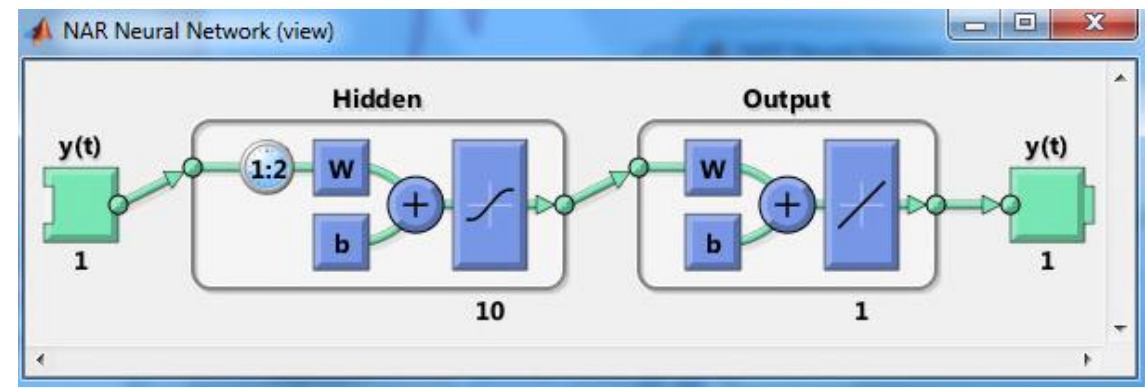

Рис. 3: Розширена схема нейронної мережі.

Тут $W$ - вектор вагових коефіціснтів, $b=2$ - коефіціснт зсуву ряду на значення параметра запізнення.

Перед початком навчання нейронної мережі, задаємо параметр запізнення i розмір прихованого шару нейронної мережі.

Також встановлюються наступні параметри навчання мережі (рис. 4): 


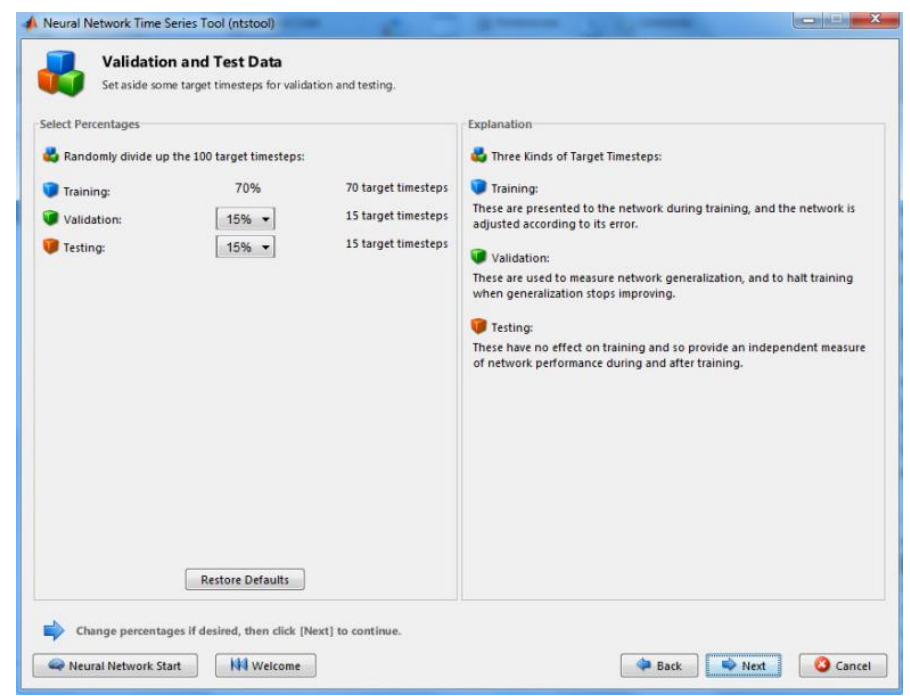

Рис. 4: Параметри навчання нейронної мережі:

Навчання (Training - 75\%), Перевірка (Validation - 15\%), та Тестування (Testing - 15\%).

1) Навчання - скільки відсотків вхідного часового ряду буде задіяно при навчанні (На рис. $4-75 \%)$.

2) Перевірка - скільки відсотків часового ряду буде використано для узагальнення мережі. Якщо узагальнення не покращується, то навчання припиняється (На рис. 4 - 15\%).

3) Тестування - скільки відсотків часового ряду буде використовуватися для перевірки узагальнення мережі (На рис. 4 - 15\%).

Задавши всі необхідні параметри, запускаємо навчання нейронної мережі. Навчання відбувається на основі методу зворотного поширення регуляризації Баєса. Після навчання, відбувається так зване «замикання» (close-looping) нейронної мережі (див. рис. 5):

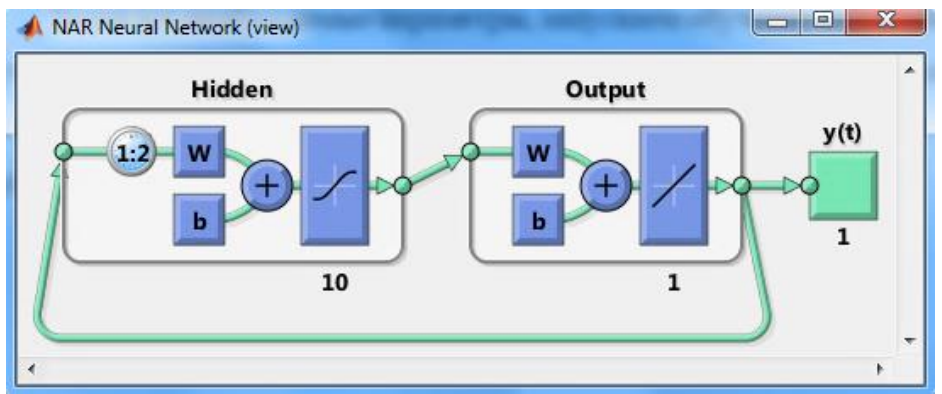

Рис. 5: Замикання нейронної мережі.

Потім, нейронна мережа здійснює прогноз часового ряду (рис. 6):

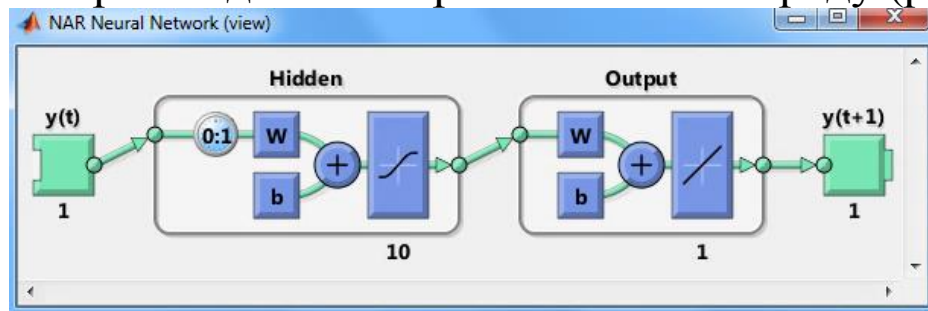

Рис. 6: Виведення прогнозу нейронної мережі у час $y(t+1)$. 
На рис. 7 представлені оригінальний часовий ряд курсу ціни на золото і навчений за допомогою ШНС цей же часовий ряд.

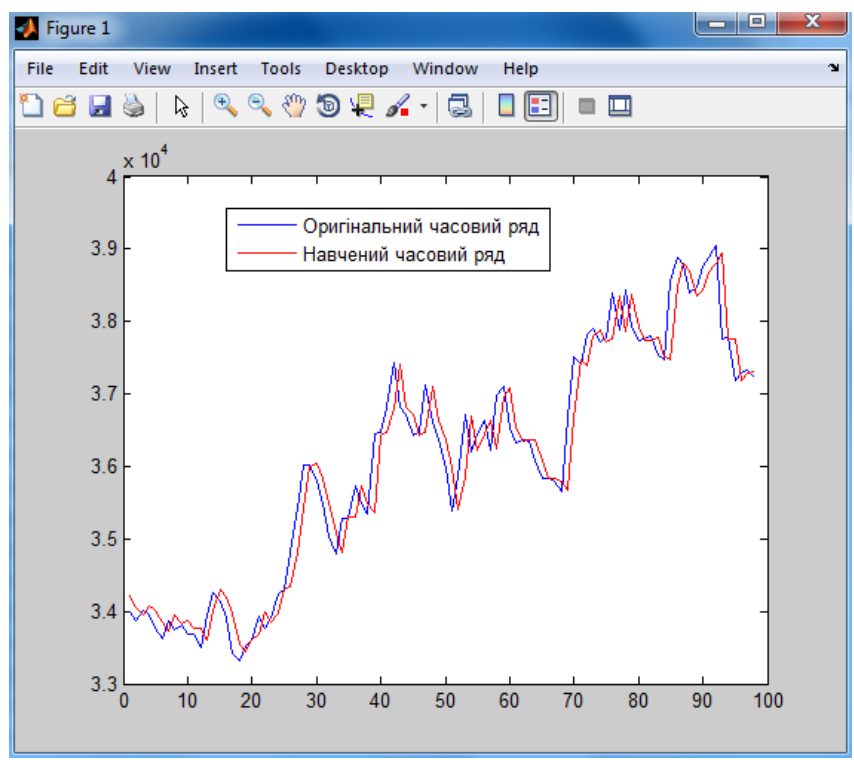

Рис. 7: Графіки навченого часового ряду курсу ціни золота.

На рис. 8 представлені прогнози цін на золото у період з 17.09.2019 до 30.09.2019.

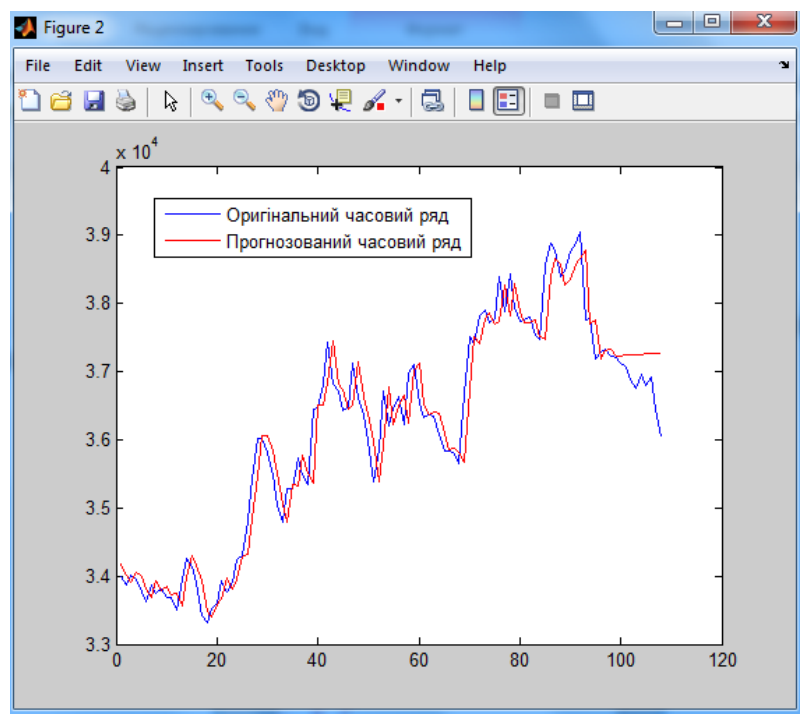

Рис. 8: Графіки часового ряду курсу ціни золота. Дальність прогнозування: 10 кроків.

На рис. 7-8 видно, що прогнозування здійснюється із достатньо великою похибкою, особливо це виявляється на етапі передбачення ціни на 10 кроків у майбутній час. Така розбіжність із реальними даними може бути обумовлена тим фактом, що часовий ряд цін на золото не має певної математичної асоціації, і цей факт створює ускладнення для ШНС у передбачені цін.

Метод може бути модифіковано шляхом здійснювання прогнозування через циклічне передбачення на 1 крок вперед із відповідним зсувом часового ряду. Результат навчання вхідного часового ряду можна побачити на рис. 9: 


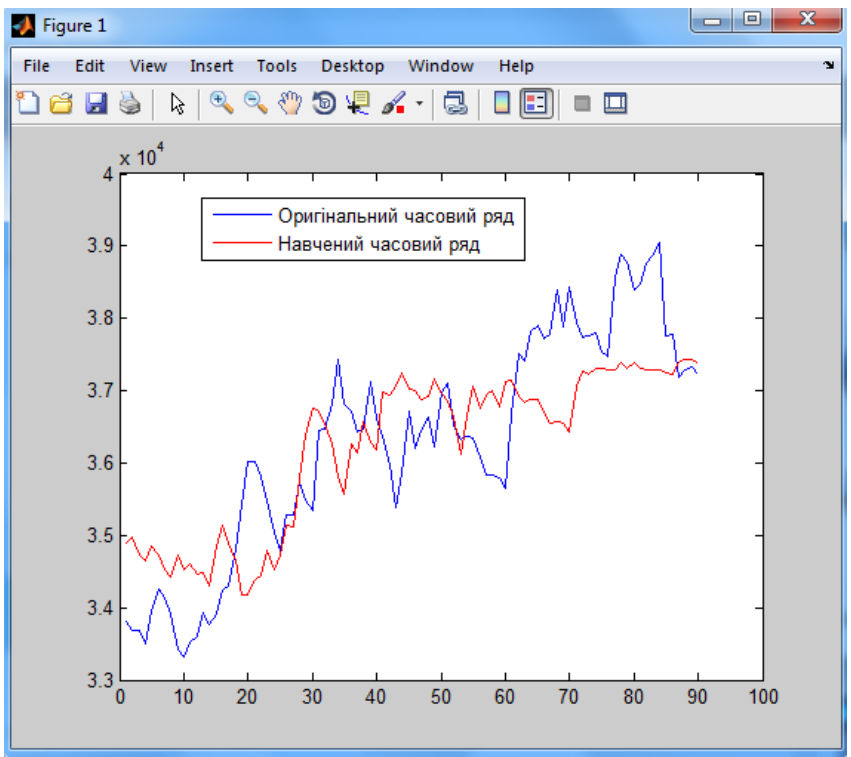

Рис. 9: Графіки навченого часового ряду за перетвореним методом.

Відхилення навченого часового ряду від реальних даних у такому разі $\epsilon$ дуже значним через те, що вхідний ряд декілька разів проходить через навчання у ШНС та зсувається на 1 крок вперед. Проте, на відміну від попереднього результату передбачення, у прогнозованому часовому ряду спостерігається тенденція, подібна той, що має реальний курс цін на період прогнозування, хоча похибка передбачення залишається значною (рис. 10):

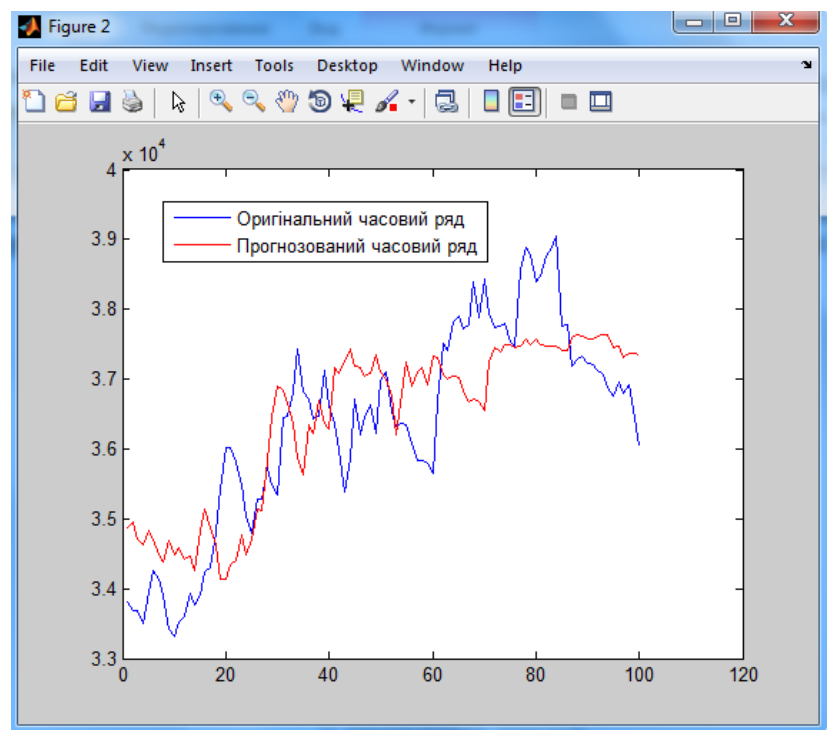

Рис. 10: Графіки часового ряду курсу ціни золота за перетвореним методом.

Висновки. Було представлено новий метод прогнозування курсу цін на дорогоцінні метали за допомогою ШНС, що використовує нелінійну авторегресійну модель нейронної мережі.

Результати тестування даного методу мають відчутну похибку, на яку впливає фактор відсутності математичної моделі часового ряду курсу ціноутворення. Хаотичність та невпорядкованість такого ряду надає елемент непе- 
редбаченості, і внаслідок цього, ускладнюється та погіршується процес прогнозування.

Однак при зміні алгоритму передбачення можна побачити, що поведінка прогнозованого часового ряду починає нагадувати поведінку, присутню справжньому ряду цін, із котрим йдеться порівняння.

Даний метод може бути удосконалений у майбутньому, шляхом подальших змін процедури прогнозування татестувань навчання нейронної мережі, збільшення навчальної вибірки, збільшення кількості навчань, зміни розміру запізнення та кількості нейронів прихованого шару, а також зміни розподілу часток вхідного часового ряду на навчання, перевірку і тестування.

\section{Бібліографічні посилання}

1. Архив валютных курсов [Электронный ресурс]: [Веб-сайт]. - Электронные данные. Киев : ООО «МинфинМедиа», 2008-2019. - Режим доступа: https://index.minfin.com.ua/exchange/archive/ (дата обращения 19.09.2019) - Название с экрана.

2. Ломакин, Н.И. Нейронные сети для прогнозирования курса доллара с использованием астрологических циклических индексов Гюшон и Ганю [Текст] / Н.И. Ломакин, О.Н. Максимова, В.А. Экова, О.А. Гаврилова, В.Е. Вагина // Международный журнал прикладных и фундаментальных исследований. - 2016. - № 6 (1). - С. 133-136.

3. Париси, А. Прогнозирование изменений цены на золото: свернутые и регрессионные модели нейронных сетей [Текст] / А. Париси, Ф. Париси, Д. Диаз // журнал международного финансового менеджмента. - 2008. - № 18. - С. 477-487.

4. Фёдорова, Е.А. Прогнозирование курса валюты с помощью нейронных сетей [Текст] / Е.А. Фёдорова, М.А. Линкова // Денежно-кредитная политика. - 2013. - № 11 (149). C. 27-31.

Надійшла до редколегії 11.09.2019. 


\author{
Л.Т. Бойко, А.А. Конончук \\ Дніпровський національний університет імені Олеся Гончара
}

\title{
АЛГОРИТМ ПОБУДОВИ ПРЯМОГО ТА ОБЕРНЕНОГО ОПЕРАТОРА РЕАЛЬНОГО ПРОЦЕСУ
}

Розглянуто алгоритм побудови оберненого оператора реального процесу, що переводить вхідні дані у вихідний результат. Обернений оператор реального процесу дозволяє знайти значення вхідних даних для заданого результату на виході. Задача зводиться до розв'язування нелінійного рівняння в некоректній постановці. Програмна реалізація алгоритму перевірялася на трьох тестових прикладах.

Ключові слова: реальний процес, прямий та обернений оператори, вхідні та вихідні дані, некоректна задача, метод Тихонова.

Рассмотрен алгоритм построения обратного оператора реального процесса, переводящего входные данные у выходной результат. Обратный оператор реального процесса позволяет найти значения входных данных для заданного результата на выходе. Задача сводится к решению нелинейного уравнения в некорректной постановке. Программная реализация алгоритма проверялась на трёх тестовых примерах.

Ключевые слова: реальный процесс, прямой и обратный операторы, входные и выходные данные, некорректная задача, метод Тихонова.

Consider the task of building a mathematical model of the real process, which translates the data at the entrance to a certain result at the output. Considered the case when several data is submitted to the entrance, and the output result is only one.

The direct operator of the real process makes it possible to determine (provide) the result at the exit based on the known data at the entrance. The reverse operator on a known result on the way out of the real process allows you to find the necessary input.

Operators of the real process are modeled with algebraic polynom to some extent. The degree of algebraic polynomic and its coefficients depend on a specific real process.

Since input and output are known with some error in real-world processes, we take into account input and output errors when building operators. The task of building such operators is incorrect on Adamar, so we use the method of regularization of Tikhonov. This method allows you to build sustainable approach (taking into account the error of the input and output data) the right operators.

The article examines in detail the algorithm for building a reverse operator. The direct operator algorithm is reviewed in the authors' previous article (link [2] in this article). Building a reverse operator comes down to solving a non-linear equation in an incorrect setting. The non-linear equation is solved by Newton's iterative method.

The software implementation of the algorithm has been carried out. Three test examples are considered, which confirm the correctness of the algorithm and program.

The algorithm can be summarized in case there are several data (at least two) at both the entrance and exit.

Key words: real process, direct and inverse operators, input data, output data, incorrect task, Tikhonov method.

(С) Бойко Л.Т., Конончук А.А., 2019 
Вступ. Існують багато реальних процесів, які переводять деякі вхідні дані у інші - вихідні дані. При цьому, внутрішній процес «переробки» вхідних даних у вихідні залишається або зовсім невідомим, або мало дослідженим. В реальних ситуаціях виникає необхідність передбачати результат по відомих вхідних даних, тобто розв'язувати пряму задачу, або навпаки, по заданому результату передбачати набір вхідних даних, тобто розв'язувати обернену задачу.

Математично це означає, що потрібно побудувати наближену модель оператора, який відображує свою область визначення (множину вхідних даних реального процесу), у свою область значень (множину вихідних даних реального процесу). Знання такого оператора дозволить розв'язувати пряму задачу. До побудованого оператора треба вміти будувати обернений оператор. Задача побудови прямого і оберненого операторів для багатьох реальних процесів залишається актуальною.

В реальних процесах вхідні та вихідні дані відомі, як правило, з деякими похибками, тобто наближено. Отже, оператори (прямий і обернений) потрібно будувати теж наближено (у відповідності до похибок даних). Задача побудови таких операторів $\epsilon$ некоректною за Адамаром [1].

Дана стаття $є$ продовженням роботи [2], в якій детально (з ілюстраціями на відповідних тестових прикладах) описано алгоритм побудови прямого оператора реального процесу. В даній роботі детально розглядається алгоритм побудови оберненого оператора до відомого прямого.

Постановка задачі. Від конкретного реального процесу залежить кількість вхідних та вихідних даних. Для простоти розглянемо випадок, коли на вхід подається декілька даних $a_{j}, j=\overline{2, n}, n \geq 2$, а вихідний результат $b$ лише один. Відомі проміжки, до яких належать дані $a_{j} \in\left[\alpha_{j}, \beta_{j}\right], j=\overline{2, n}$, при цьому результат $b$ попадає в деякий свій проміжок $[\gamma, \delta]$.

Реальний процес встановлює залежність $b=f\left(a_{2}, a_{3}, \ldots, a_{n}\right)$, де функція $f\left(a_{2}, a_{3}, \ldots, a_{n}\right) \in$ невідомою. Побудувати прямий оператор означає побудувати математичну модель, за допомогою якої можна встановити наближено аналітичну залежність результату $b$ від вхідних даних $a_{j}, j=\overline{2, n}$. Таку математичну модель будемо називати «прогнозною». Знаючи прогнозну модель, можна для реального процесу по відомих на вході даних $a_{j}, j=\overline{2, n}$ передбачити (прогнозувати) результат $b$. Позначимо прогнозну модель $F\left(a_{2}, a_{3}, \ldots, a_{n}\right)$.

Алгоритм побудови прогнозної моделі у вигляді алгебраїчного многочлена різного степеня розглянуто в роботі [2]. Отже, маємо залежність

$$
b=f\left(a_{2}, a_{3}, \ldots, a_{n}\right) \approx F\left(a_{2}, a_{3}, \ldots, a_{n}\right) \equiv x_{1}+\sum_{j=2}^{s} x_{j} c_{j} .
$$


Тут $s$ - загальна кількість доданків у многочлена (1). Коефіцієнти $c_{j}$ обчислюємо через вхідні дані $a_{j}, j=\overline{2, n}$ за такими формулами:

$$
\begin{aligned}
& c_{j}=a_{j}, j=\overline{2, n} ; c_{n+j-1}=a_{2} a_{j}, j=\overline{2, n} ; c_{2 n+j-3}=a_{3} a_{j}, j=\overline{3, n} ; \\
& c_{3 n+j-6}=a_{4} a_{j}, j=\overline{4, n} ; \ldots .
\end{aligned}
$$

Після побудови прогнозної моделі коефіцієнти $x_{i}, i=\overline{1, s}$ в залежності (1) стають відомими. Отже, використовуючи (1), можна наближено прогнозувати результат $b$ для кожного варіанту вхідних даних $a_{j} \in\left[\alpha_{j}, \beta_{j}\right], j=\overline{2, n}$.

Алгоритм побудови оберненого оператора. Для побудови оберненого оператора використаємо прогнозну модель (1), вважаючи відомими коефіцієнти $x_{i}, i=\overline{1, s}$ та результат $b \in[\gamma, \delta]$. Шуканим стає вектор $z^{*}$, де

$$
z^{*}=\left[\begin{array}{l}
a_{2} \\
\cdots \\
a_{n}
\end{array}\right], a_{j} \in\left[\alpha_{j}, \beta_{j}\right], j=\overline{2, n}, n \geq 2 .
$$

Для розв'язування цієї задачі створимо із прогнозної моделі (1) нелінійне алгебраїчне рівняння

$$
\Phi\left(a_{2}, a_{3}, \ldots, a_{n}\right) \equiv\left(x_{1}-b\right)+\sum_{j=2}^{s} x_{j} c_{j}\left(a_{2}, a_{3}, \ldots, a_{n}\right)=0 .
$$

Рівняння (4) може мати не один розв'язок. Із множини можливих розв'язків шукатимемо такий вектор $z^{*}$, який буде найближчим до деякого бажаного фіксованого вектора $\psi$, який виберемо таким чином:

$$
\psi=\left[\begin{array}{c}
\psi_{2} \\
\ldots \\
\psi_{n}
\end{array}\right], \quad \psi_{i}=\frac{\alpha_{i}+\beta_{i}}{2}, i=\overline{2, n} .
$$

Нелінійне рівняння (4) розв'язуємо ітераційним методом Ньютона. Нехай $z^{(p)}-p$-та ітерація, що наближує шуканий вектор $z^{*}$. Ітераційна формула матиме вигляд

$$
z^{(p+1)}=z^{(p)}+\varepsilon^{(p)}, p=0,1, \ldots,
$$

де вектор поправок $\varepsilon^{(p)}$ знаходимо як розв'язок системи лінійних алгебраїчних рівнянь

Тут позначено

$$
\Phi\left(z^{(p)}\right)+W\left(z^{(p)}\right) \cdot \varepsilon^{(p)}=0 .
$$

$$
W\left(z^{(p)}\right) \equiv\left[\frac{\partial \Phi}{\partial a_{2}}, \frac{\partial \Phi}{\partial a_{3}}, \cdots, \frac{\partial \Phi}{\partial a_{n}}\right]_{z=z^{(p)}} .
$$


Розв'язавши систему (7) методом Тихонова, добудемо вектор $\varepsilon^{(p)}$ i, підставивши його в ітераційну формулу (6), добудемо наступну ітерацію $z^{(p+1)}$. В якості вектора $z^{(0)}$ беремо вектор $\psi$ за формулами (5).

Для формування рядка (8) обчислимо необхідні похідні від лівої частини рівняння (4)

$$
\frac{\partial \Phi}{\partial a_{k}}=\sum_{j=2}^{s} x_{j} \frac{\partial c_{j}}{\partial a_{k}}, \quad k=\overline{2, n} .
$$

Для зупинки ітераційного методу використана умова $\left\|\varepsilon^{(p)}\right\| \leq \varepsilon$, де $\varepsilon-$ задане достатньо мале додатне число.

Програмна реалізація та тестування алгоритму. 3 використанням мови програмування С\# у середовищі візуальної розробки програм MS Visual Studio 2017 була виконана програмна реалізація алгоритму побудови прямого та оберненого оператора. Правильність роботи програмного продукту в задачі побудови прямого оператора була перевірена на трьох тестових прикладах, розглянутих в роботі [2]. На цих же тестових прикладах розглянемо роботу алгоритму побудови оберненого (до прогнозної моделі) оператора реального процесу. В усіх тестових прикладах припускалося, що $a_{j} \in[0 ; 1], j=\overline{2, n}$.

Приклад 1. Розглянемо реальний процес, який визначимо такою лінійною функцією $(n=4)$ :

$$
f\left(a_{2}, a_{3}, a_{4}\right)=5+a_{2}+2 a_{3}-a_{4} .
$$

Функція (10) буде використана в задачі побудови прогнозної моделі лише для обчислення результату $b$ при фіксованих варіантах коефіцієнтів $a_{j} \in[0 ; 1], j=\overline{2,4}$ та для визначення проміжку $[\gamma, \delta]$, якому належить результат $b$.

Прогнозну модель, тобто функцію $F\left(a_{2}, a_{3}, a_{4}\right)$, будуємо у двох варіантах: у вигляді лінійної прогнозної моделі

$$
F_{1}\left(a_{2}, a_{3}, a_{4}\right)=x_{1}+a_{2} x_{2}+a_{3} x_{3}+a_{4} x_{4}
$$

та квадратичної прогнозної моделі

$$
\begin{gathered}
F_{2}\left(a_{2}, a_{3}, a_{4}\right)=x_{1}+ \\
a_{2} x_{2}+a_{3} x_{3}+a_{4} x_{4}+a_{2}^{2} x_{5}+a_{2} a_{3} x_{6}+a_{2} a_{4} x_{7}+ \\
+ \\
+a_{3}^{2} x_{8}+a_{3} a_{4} x_{9}+a_{4}^{2} x_{10} .
\end{gathered}
$$

Для прогнозних моделей (11), (12) шукаємо коефіцієнти $\left\{x_{j}\right\}_{j=1}^{s}$. Результати роботи програми виявилися такими [2]:

$$
\begin{gathered}
F_{1}\left(a_{2}, a_{3}, a_{4}\right)=4,999092+0,999362 \cdot a_{2}+1,999400 \cdot a_{3}-0,999798 \cdot a_{4} ; \\
F_{2}\left(a_{2}, a_{3}, a_{4}\right)=4,999064+0,999345 \cdot a_{2}+1,999393 \cdot a_{3}-0,999709 \cdot a_{4}+ \\
+0,000000 \cdot a_{2}^{2}+0,000000 \cdot a_{2} a_{3}+0,000000 \cdot a_{2} a_{4}+0,000000 \cdot a_{3}^{2}+ \\
+0,000000 \cdot a_{3} a_{4}+0,000000 \cdot a_{4}^{2} .
\end{gathered}
$$


Як видно з (13), (14), квадратична прогнозна модель підтвердила лінійність реального процесу (10), оскільки у (14) виявилися нульовими всі коефіцієнти при квадратичних доданках. Крім того, з точністю до четвертого розряду після коми коефіцієнти прогнозних моделей (13), (14) є близькими до відповідних коефіцієнтів реального процесу (10).

Далі використаємо лінійну прогнозну модель (13) для розв'язування оберненої задачі. Для цього випадку з (4) маємо

$$
\Phi\left(a_{2}, a_{3}, a_{4}\right)=\left(x_{1}-b\right)+a_{2} x_{2}+a_{3} x_{3}+a_{4} x_{4} .
$$

За формулами (9) знаходимо з (15): $\frac{\partial \Phi}{\partial a_{2}}=x_{2}, \frac{\partial \Phi}{\partial a_{3}}=x_{3}, \frac{\partial \Phi}{\partial a_{4}}=x_{4}$. Рядок (8) набуває вигляду $W\left(z^{(p)}\right)=\left[x_{2}, x_{3}, x_{4}\right]$. Як видно, $W\left(z^{(p)}\right)$ не залежить від номера ітерації.

Передаємо у програму: $b=5 ; \quad \varepsilon=0,001 ; \quad z^{(0)}=\psi=\left[\begin{array}{l}0,5 \\ 0,5 \\ 0,5\end{array}\right]$.

За одну ітерацію (оскільки прогнозна модель була лінійною) програма видала результат, показаний на рис.1.

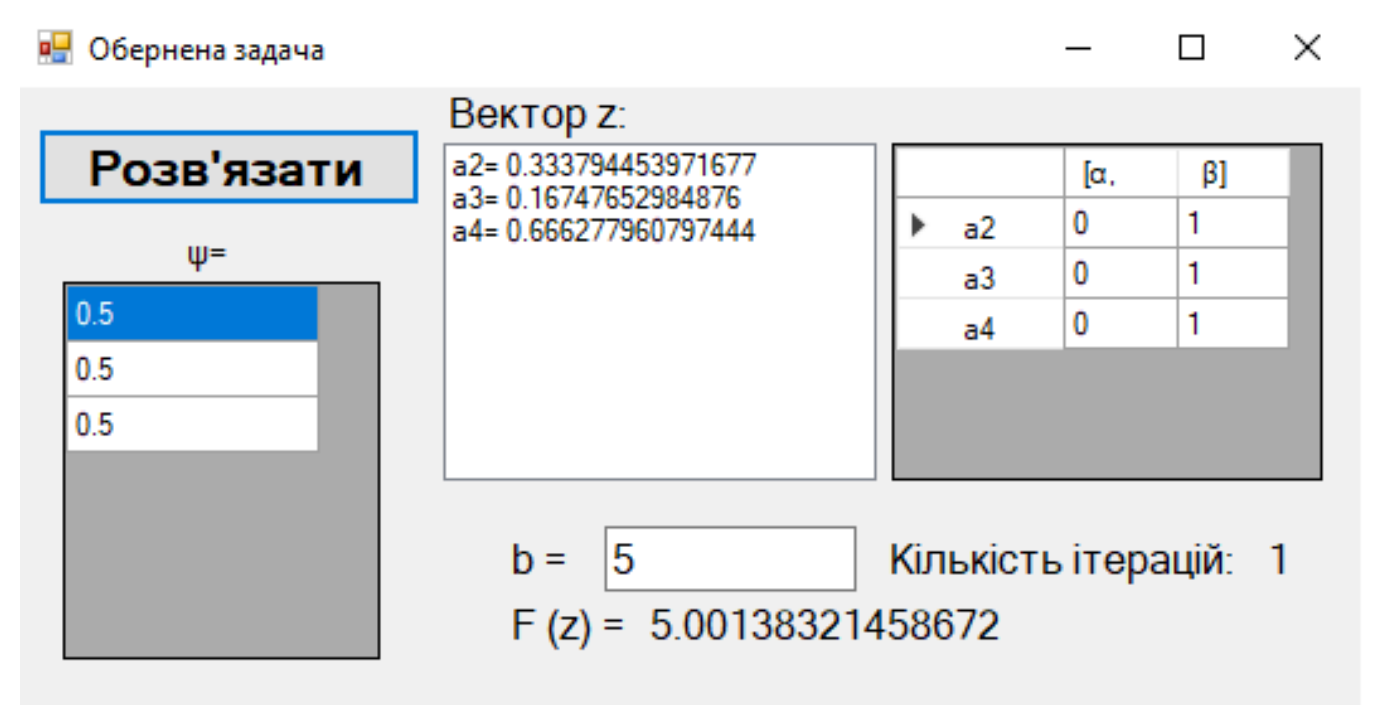

Рис. 1. Результат розв'язування оберненої задачі для прикладу 1

Як видно, знайдені коефіцієнти $a_{j}, j=\overline{2,4}$ попадають у проміжок [0;1]. Якщо підставити ці коефіцієнти у прогнозну модель (13), то отримаємо приблизне значення числа $b$, а саме $b \approx 5,001$.

Приклад 2. Для простоти візьмемо $n=3$. Реальний процес виберемо у вигляді такої квадратичної функції:

$$
f\left(a_{2}, a_{3}\right)=-3+a_{2}-5 a_{3}+a_{2} a_{3}+a_{3}^{2} .
$$


Для прогнозної моделі розглянемо три варіанти:

лінійна прогнозна модель

$$
F_{1}\left(a_{2}, a_{3}\right)=x_{1}+a_{2} x_{2}+a_{3} x_{3}
$$

квадратична прогнозна модель

$$
F_{2}\left(a_{2}, a_{3}\right)=x_{1}+a_{2} x_{2}+a_{3} x_{3}+a_{2}^{2} x_{4}+a_{2} a_{3} x_{5}+a_{3}^{2} x_{6} ;
$$

кубічна прогнозна модель

$$
\begin{aligned}
F_{3}\left(a_{2}, a_{3}\right)= & x_{1}+a_{2} x_{2}+a_{3} x_{3}+a_{2}^{2} x_{4}+a_{2} a_{3} x_{5}+a_{3}^{2} x_{6}+a_{2}^{3} x_{7}+ \\
& +a_{2}^{2} a_{3} x_{8}+a_{2} a_{3}^{2} x_{9}+a_{3}^{3} x_{10} .
\end{aligned}
$$

Для прогнозних моделей (17), (18) (19) шукаємо коефіцієнти $\left\{x_{j}\right\}_{j=1}^{s}$, тобто розв'язуємо пряму задачу, використовуючи метод Тихонова. Результати роботи програми виявилися такими [2]:

$$
\begin{gathered}
F_{1}\left(a_{2}, a_{3}\right)=-3,634766+1,731650 \cdot a_{2}-3,304419 \cdot a_{3} ; \\
F_{2}\left(a_{2}, a_{3}\right)=-3,001522+1,001327 \cdot a_{2}-4,992501 \cdot a_{3}+0,000380 \cdot a_{2}^{2}+ \\
+0,999031 \cdot a_{2} a_{3}+0,995694 \cdot a_{3}^{2} ; \\
F_{3}\left(a_{2}, a_{3}\right)=-3,01833+1,043906 \cdot a_{2}-4,878557 \cdot a_{3}-0,001719 \cdot a_{2}^{2}+ \\
+0,980397 \cdot a_{2} a_{3}+0,978338 \cdot a_{3}^{2}-0,000164 \cdot a_{2}^{3}+0,000790 \cdot a_{2}^{2} a_{3}- \\
-0,001086 \cdot a_{2} a_{3}^{2}+0,002822 \cdot a_{3}^{3} .
\end{gathered}
$$

Як видно з (20), (21), (22), квадратична та кубічна прогнозні моделі $є$ ближчими між собою і дають кращі наближення до реального процесу (16), ніж лінійна прогнозна модель (20). Зауважимо, що цей результат є очікуваним.

Застосуємо алгоритм побудови оберненого оператора до квадратичної прогнозної моделі (18) у вигляді (21) при $n=3.3$ формули (4) маємо

$$
\Phi\left(a_{2}, a_{3}\right)=x_{1}-b+a_{2} x_{2}+a_{3} x_{3}+a_{2}^{2} x_{4}+a_{2} a_{3} x_{5}+a_{3}^{2} x_{6} .
$$

Звідси знаходимо потрібні похідні:

$$
\frac{\partial \Phi}{\partial a_{2}}=x_{2}+2 x_{4} a_{2}+x_{5} a_{3} ; \quad \frac{\partial \Phi}{\partial a_{3}}=x_{3}+x_{5} a_{2}+2 x_{6} a_{3} .
$$

Знаходимо значення похідних (23) у точці $z^{(p)}$ :

$$
\left.\frac{\partial \Phi}{\partial a_{2}}\right|_{z=z^{(p)}}=x_{2}+2 x_{4} a_{2}^{(p)}+x_{5} a_{3}^{(p)} ;\left.\quad \frac{\partial \Phi}{\partial a_{3}}\right|_{z=z^{(p)}}=x_{3}+x_{5} a_{2}^{(p)}+2 x_{6} a_{3}^{(p)} .
$$

Підставимо (24) у (8) і те, що вийде, - у (7). Як видно, координати рядка $W\left(z^{(p)}\right)$ будуть мінятися від ітерації до ітерації. 
Передаємо у комп'ютерну програму: $b=-3 ; \quad \varepsilon=0,001 ; \quad z^{(0)}=\psi=\left[\begin{array}{l}0,5 \\ 0,5\end{array}\right]$.

За чотири ітерації програма видала результат, показаний на рис.2.

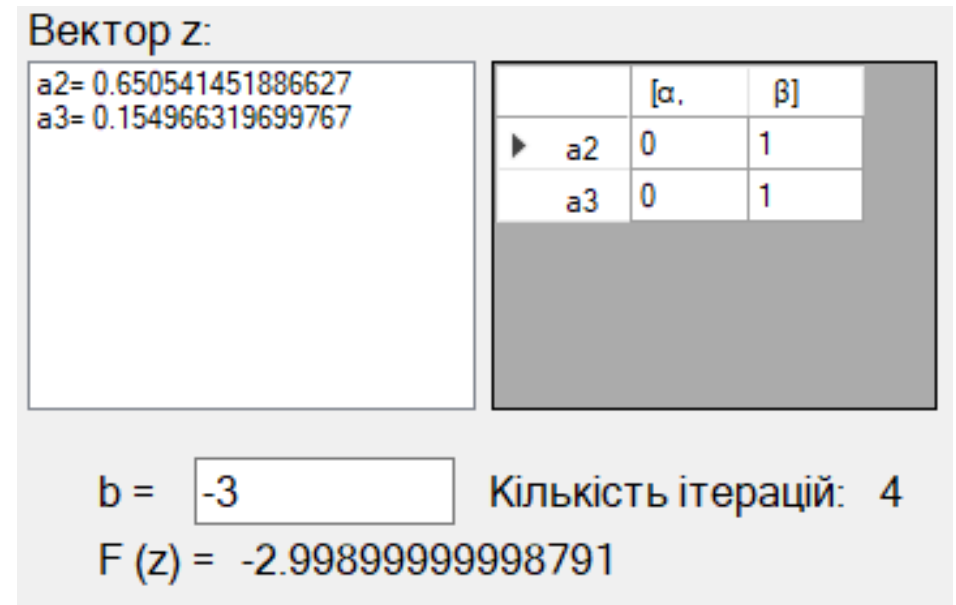

Рис. 2. Результат розв'язування оберненої задачі для прикладу 2

Як видно, знайдені коефіцієнти $a_{2}, a_{3}$ попадають у проміжок [0;1]. Якщо підставити значення цих коефіцієнтів у прогнозну модель (21), то отримаємо приблизне значення числа $b$, а саме $b \approx-2,999$.

Приклад 3. Візьмемо $n=3$ і зафіксуємо кубічний реальний процес такою функцією:

$$
f\left(a_{2}, a_{3}\right)=4-a_{2}^{2}+a_{2} a_{3}+a_{3}^{3} .
$$

Прогнозні моделі побудуємо так же, як у прикладі 2, тобто за формулами (17), (18), (19). Результати програмної побудови прогнозних моделей такі [2]:

$$
\begin{gathered}
F_{1}\left(a_{2}, a_{3}\right)=3,480499-0,259965 \cdot a_{2}+1,567229 \cdot a_{3} ; \\
\begin{array}{c}
F_{2}\left(a_{2}, a_{3}\right)=4,050609-0,100724 \cdot a_{2}-0,615177 \cdot a_{3}-0,886646 \cdot a_{2}^{2}+ \\
+1,030751 \cdot a_{2} a_{3}+1,516834 \cdot a_{3}^{2} ;
\end{array} \\
F_{3}\left(a_{2}, a_{3}\right)=3,970925+0,161384 \cdot a_{2}+0,021750 \cdot a_{3}-1,274541 \cdot a_{2}^{2}+ \\
+0,933896 \cdot a_{2} a_{3}+0,003209 \cdot a_{3}^{2}+0,141933 \cdot a_{2}^{3}+0,072789 \cdot a_{2}^{2} a_{3}- \\
-0,030191 \cdot a_{2} a_{3}^{2}+1,000000 \cdot a_{3}^{3} .
\end{gathered}
$$

Як видно, з трьох прогнозних моделей (26), (27), (28) кубічна прогнозна модель $є$ найближчою до кубічного реального процесу (25).

Будувати обернений оператор методом Ньютона будемо до кубічної прогнозної моделі (19) у вигляді (28) при $n=3.3$ формули (4) маємо нелінійне рівняння 
ISSN 2074-5893 Питання прикладної математики і математичного моделювання. Випуск 19

$\Phi\left(a_{2}, a_{3}\right)=x_{1}-b+a_{2} x_{2}+a_{3} x_{3}+a_{2}^{2} x_{4}+a_{2} a_{3} x_{5}+a_{3}^{2} x_{6}+a_{2}^{3} x_{7}+a_{2}^{2} a_{3} x_{8}+a_{2} a_{3}^{2} x_{9}+a_{3}^{3} x_{10}$. Знаходимо потрібні похідні

$$
\begin{aligned}
& \frac{\partial \Phi}{\partial a_{2}}=x_{2}+2 x_{4} a_{2}+x_{5} a_{3}+3 a_{2}^{2} x_{7}+2 a_{2} a_{3} x_{8}+a_{3}^{2} x_{9} \\
& \frac{\partial \Phi}{\partial a_{3}}=x_{3}+x_{5} a_{2}+2 x_{6} a_{3}+a_{2}^{2} x_{8}+2 a_{2} a_{3} x_{9}+3 a_{3}^{2} x_{10} .
\end{aligned}
$$

Обчислюємо значення похідних (29) у точці $z^{(p)}$ :

$$
\begin{aligned}
& \left.\frac{\partial \Phi}{\partial a_{2}}\right|_{z=z^{(p)}}=x_{2}+2 x_{4} a_{2}^{(p)}+x_{5} a_{3}^{(p)}+3\left(a_{2}^{(p)}\right)^{2} x_{7}+2 a_{2}^{(p)} a_{3}^{(p)} x_{8}+\left(a_{3}^{(p)}\right)^{2} x_{9} \\
& \left.\frac{\partial \Phi}{\partial a_{3}}\right|_{z=z^{(p)}}=x_{3}+x_{5} a_{2}^{(p)}+2 x_{6} a_{3}^{(p)}+\left(a_{2}^{(p)}\right)^{2} x_{8}+2 a_{2}^{(p)} a_{3}^{(p)} x_{9}+3\left(a_{3}^{(p)}\right)^{2} x_{10} .
\end{aligned}
$$

Значення (30) підставимо до (8) а те, що вийде, - до (7) і застосуємо метод Тихонова до розв'язування СЛАР (7).

Передаємо у комп'ютерну програму: $b=5,5 ; \quad \varepsilon=0,001 ; \quad z^{(0)}=\psi=\left[\begin{array}{l}0,5 \\ 0,5\end{array}\right]$. Програма видає результат, показаний на скріншоті (рис. 3) і обчислений за три ітерації.

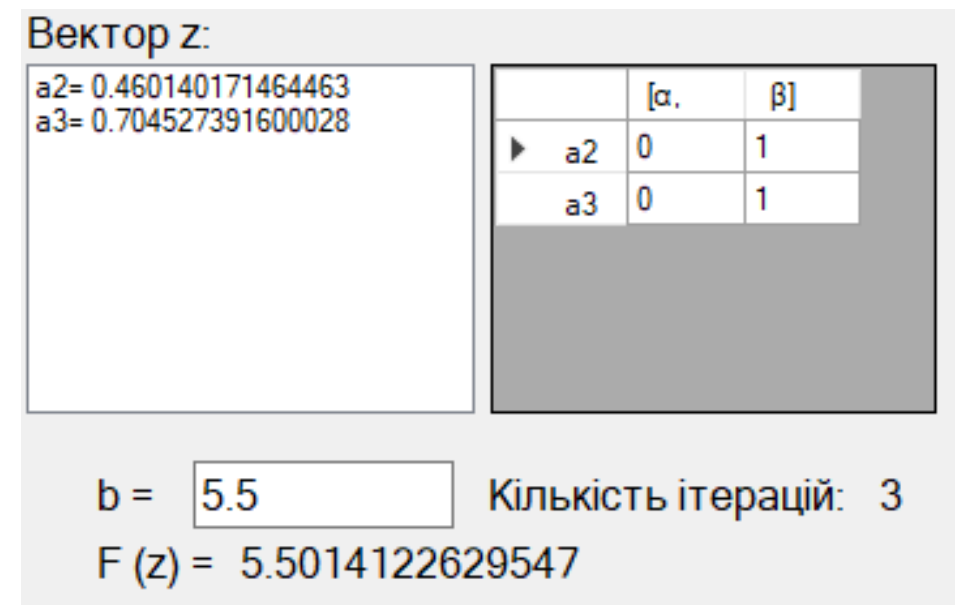

Рис. 3. Результат розв'язування оберненої задачі для прикладу 3 при $\varepsilon=0,001$

Як видно, знайдені коефіцієнти $a_{2}, a_{3}$ попадають у проміжок [0;1]. Якщо підставити значення цих коефіцієнтів у прогнозну модель (28), то отримаємо приблизне значення числа $b$, а саме $b \approx 5,501$.

Якщо в методі Ньютона взяти $\varepsilon=0,000001$, то результати покращяться при невеликому збільшені кількості ітерацій (рис. 4). 


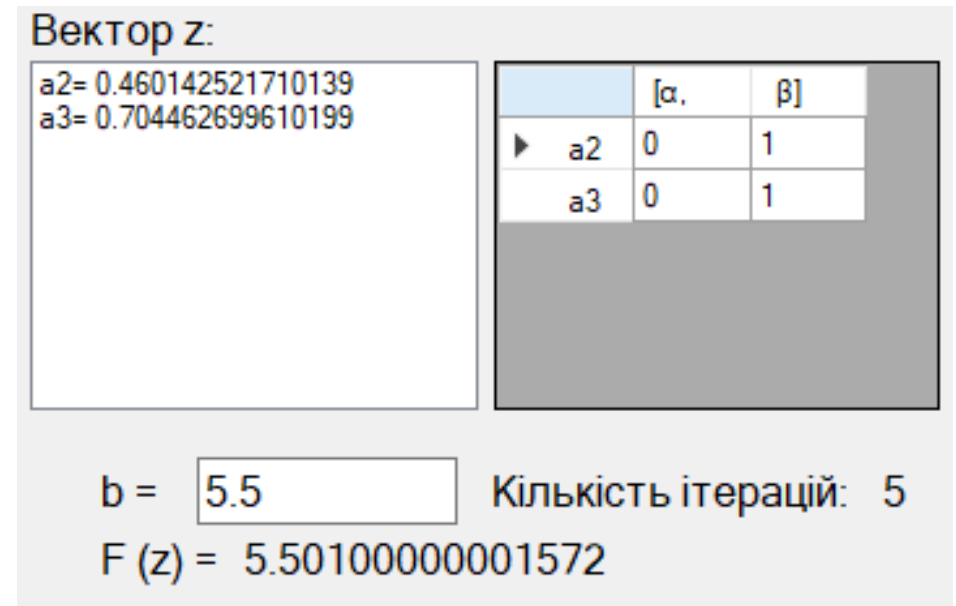

Рис. 4. Результат розв'язування оберненої задачі для прикладу 3 при $\varepsilon=0,000001$

Також, якщо підставимо знайдений вектор $z$ у прогнозну модель (28), то отримаємо число, яке $\epsilon$ ближчим до заданого числа $b$, ніж при $\varepsilon=0,001$ (рис. 3, 4).

Висновки. Тестування програмно реалізованого алгоритму підтверджує його дієздатність. Планується застосувати алгоритм до дійсно реальної практичної задачі.

Алгоритм може бути узагальненим на випадок декількох даних на вході та декількох $(\geq 2)$ даних на виході із реального процесу.

\section{Бібліографічні посилання}

1. Тихонов, А.Н. Методы решения некорректных задач [Текст] / А.Н. Тихонов, В.Я. Арсенин. - М., 1979. -288 с.

2. Бойко, Л.Т. Алгоритм відтворення аналітичної залежності між даними на вході і на виході моделі «чорна скриня» [Електронний збірник] / Л.Т. Бойко, А.А. Конончук // Тhe 10th International conference "Science and society" 15th March 2019. - Hamilton, Canada, 2019. - P. 406-415.

Надійшла до редколегії 22.10.2019. 
Н.В. Варех, Н.Л. Козакова, А.О. Лаврентьєва

Дніпровський національний університет імені Олеся Гончара

\section{ДОСЛІДЖЕННЯ АСИМПТОТИЧНОЇ ПОВЕДІНКИ РОЗВ'ЯЗКІВ ОДНОГО КЛАСУ СИСТЕМ ДИФЕРЕНЦІАЛЬНИХ РІВНЯНЬ З ВІДХИЛЕННЯМ АРГУМЕНТУ}

Проведено дослідження асимптотичної поведінки розв'язків на нескінченному інтервалі часу одного класу систем диференціальних рівнянь 3 відхиленням аргументу, що узагальнюють рівняння Емдена-Фаулера в сублінійному випадку. Знайдено умови, за яких кожний розв'язок або сильно осцилюс, або всі його компоненти монотонно прямують до нуля на нескінченності. Доведено дві теореми за різних обмежень на відхилення аргументу.

Ключові слова: система диференціальних рівнянь, відхилення аргументу, нескінченний інтервал часу, асимптотична поведінка розв'язків.

Проведено исследование асимптотического поведения решений на бесконечном интервале времени одного класса систем дифференциальных уравнений с отклонением аргумента, которые являются обобщением уравнения Эмдена-Фаулера в сублинейном случае. Найдены условия, при которых каждое решение или сильно осциллирует, или все его компоненты монотонно стремятся к нулю на бесконечности. Доказано две теоремы при различных ограничениях на отклонения аргумента.

Ключевые слова: система дифференциальных уравнений, отклонение аргумента, бесконечный интервал времени, асимптотическое поведение решений.

In this paper, we study the asymptotic behavior of solutions at an infinite time interval of one class of systems of differential equations with the deviation of an argument, which are a generalization of the Emden-Fowler equation in the sublinear case. Conditions were found under which each solution either oscillates strongly or all its components monotonically tend to zero at infinity. Two theorems under different constraints on the deviation of an argument are proved.

Equation $d^{(n)} y(t) / d t^{n}+\delta p(t) f(y(t))=0, f(u)=u^{\alpha}, \delta=-1$ or 1 , has been the object of much research. Some cases of this equation are models of processes in theoretical physics (Emden, Fowler, Fermi equations). After that, this physical problem becomes a mathematical problem at an infinite interval. It is found that the asymptotic properties of the solutions depend on the sign $\delta$, type of nonlinearity $f(u)\left(f(u)=u^{\alpha}\right),(0<\alpha<1-$ sublinear case, $\alpha=1-$ linear case, $\alpha>1$ - superlinear), $n$ - even or odd. For this equation, conditions have already been found under which, when $\delta=1$ and $n$ are even, all solutions oscillates; if $n$ is odd, then each solution either oscillates or monotonically goes to zero indefinitely. If $\delta=-1, n$ is even, then each solution oscillates either monotonically to zero or to infinity when $t \rightarrow \infty$ together with the derivatives of order $(n-1)$. If $\delta=-1, n$ is odd, then each solution oscillates or is monotonically infinite for $t \rightarrow \infty$ together with the derivatives of order (n -1). Then, the following results were obtained for differential systems and equations with the general nature of the argument rejection (differential-functional equations). The next stage of the study is to summarize the results for such systems. This article investigates the system of differential equations with the deviation of the argument for the case $\delta=1, n=3$. The obtained

(C) Варех Н.В., Козакова Н.Л., Лаврентьєва А.О., 2019 
results are refined and the results obtained earlier are generalized. Two theorems with different assumptions about rejection of the argument by analytical methods are proved. These theorems have different applications. The results of the study are a generalization of the sublinear case for odd $n$.

Keywords: system of differential equations, argument deviation, infinite time interval, asymptotic behavior of solutions.

Вступ. Емден і Фаулер в своїх астрофізичних дослідженнях при описі стану зірок, Фермі при досліджені розподілу електронів в атомі отримали окремі випадки одного класу диференціального рівняння другого порядку. Зацікавившись цими рівняннями, математики дослідили і узагальнили їх. Вони назвали рівняння вигляду

$$
\begin{gathered}
d^{(n)} y(t) / d t^{n}+\delta p(t) f(y(t))=0 \\
f(u)=u^{\alpha}, \delta= \pm 1, p(t)>0
\end{gathered}
$$

рівняннями типу Емдена - Фаулера.

Для таких рівнянь було встановлено [1], що властивості розв'язків суттєво залежать від знаку $\delta$, типу нелінійності $(0<\alpha<1-$ сублінійний випадок, $\alpha=1-$ лінійний, $\alpha>1-$ суперлінійний).

Було знайдено умови, за яких при $\delta=1$ i парному $n$ кожний розв'язок осцилює, а при непарному $n$ або осцилює, або монотонно прямує до нуля разом зі своїми похідними до порядку $(n-1)$.

За тих самих умов при $\delta=-1$ при парному $n$ кожний розв'язок або осцилює, або монотонно прямує до нуля, або до нескінченості при $t \rightarrow \infty$ разом зі своїми похідними до порядку $(n-1)$. При непарному $n$ кожний розв’язок або осцилює, або монотонно прямує до нескінченності при $t \rightarrow \infty$ разом з похідними до порядку $(n-1)$.

Відомо, що рівняння з запізнюванням аргументу є моделями процесів, які залежать не тільки від теперішнього стану, але від минулого. Результати асимптотичної поведінки розв'язків для одного рівняння $n$-го порядку підсумовані в [2]. Далі питання було перенесено на системи диференціальних рівнянь без відхилення і з відхиленням аргументу. В роботах [3], [4] досліджено систему при $\delta=-1$ для більш загальних умов на нелінійність і відхилення аргументу ніж в попередніх роботах.

Нижче розглянуто дослідження системи диференціальних рівнянь з відхиленням аргументу для $\delta=1, n=3$.

Постановка задачі. На нескінченному проміжку розглянемо систему

$$
\begin{aligned}
& d y_{1} / d t=a_{i}(t) f_{i}\left(y_{i+1}\left(\tau_{i+1}(t)\right)\right), i=\overline{1, n-1}, \\
& d y_{n}(t) / d t=-\delta a_{n}(t) f_{n}\left(y_{1}\left(\tau_{1}(t)\right)\right)
\end{aligned}
$$

при таких припущеннях:

$$
0 \leq a_{i}(t) \in C\left[t_{0}, \infty\right), 0 \leq \tau_{i}(t) \in C\left[t_{0}, \infty\right), \lim _{t \rightarrow \infty} \tau_{i}(t)=\infty,
$$

де $u f_{i}(u)>0, i=\overline{1, n-1}, f_{i}(u)-$ неспадні функції. 
Теорема 1. Нехай виконуються умови:

1. $n=3$,

2. $\tau_{3}\left(\tau_{2}\left(\tau_{1}(t)\right)\right) \leq t$,

3. $|f(u v)| \geq K|f(u)||f(v)|$,

$\int_{+0}^{c} \frac{d u}{f_{3}\left(f_{1}\left(f_{2}(u)\right)\right)}<\infty, \int_{-0}^{-c} \frac{d u}{f_{3}\left(f_{1}\left(f_{2}(u)\right)\right)}<\infty$,

$4 \cdot \int_{t_{0}}^{\infty} a_{1}(t) d t=\infty, \int_{t_{0}}^{\infty} a_{2}(t) d t=\infty$,

$5 . \int_{t_{1}}^{\infty} a_{3}(t) f_{3}\left(\int_{t_{1}}^{\tau_{1}(t)} a_{1}(s) f_{1}\left(\int_{t_{1}}^{\tau_{2}(s)} a_{2}(p) d p\right) d s\right) d t=\infty$,

6. $\int_{t_{1}}^{\infty} a_{1}(t) f_{1}\left(\int_{\tau_{2}(t)}^{c \tau_{2}(t)} a_{2}(s) f_{2}\left(\int_{\tau_{3}(s)}^{c \tau_{3}(s)} a_{3}(p) d p\right) d s\right) d t=\infty, c>1$.

Тоді кожний розв'язок системи (1) або сильно осцилює, або кожна компонента розв'язку монотонно прямує до нуля при $t \rightarrow \infty$.

Доведення. Розглянемо довільний розв'язок $y(t)=\left(y_{1}(t), y_{2}(t), y_{3}(t)\right)$. Якщо розв'язок $y(t)$ - сильно осцилює, то теорему доведено.

Нехай $y(t)$ має неосцилюючу компоненту $y_{i}(t)$, тоді з структури системи випливає, що всі інші компоненти також не осцилюють, тобто зберігають знак для достатньо великих $t$.

Припустимо, для визначеності, що $y_{1}(t)>0$ для $t \geq t_{0}$, отже, $y_{1}\left(\tau_{1}(t)\right)>0$ при $t \geq t_{1} \geq t_{0}$. Тоді з останнього рівняння випливає, що $y_{3}(t)$ монотонно спадна функція, тому або $1 . y_{3}(t)<0$ для $t \geq t_{1}$, або 2 . $y_{3}(t)>0$ для $t \geq t_{1}$.

1 . Нехай $y_{3}(t)<0$. Доведемо, що це неможливо. Використаємо монотонне спадання $y_{3}(t)<-c .3$ другого рівняння системи (1) маємо

$$
y_{2}(t)-y_{2}\left(t_{1}\right)<f_{2}(-c) \int_{t_{1}}^{t} a_{2}(s) d s, f_{2}(-c)<0 .
$$

3 умови (4) випливає $\lim _{t \rightarrow \infty} y_{2}(t)=-\infty$, тобто

$$
y_{2}(t)<-K<0 .
$$

Тоді $з$ першого рівняння системи (1) маємо

$$
y_{1}(t)-y_{1}\left(t_{1}\right)<f_{1}(-K) \int_{t_{1}}^{t} a_{1}(s) d s .
$$

3 умови (3) можна зробити висновок, що $\lim _{t \rightarrow \infty} y_{1}(t)=-\infty$, а це суперечить припущенню $y_{1}(t)>0$. 
2. Нехай $y_{3}(t)>0$. Тоді з другого рівняння системи випливає, що $y_{2}(t)$ монотонно зростає і тому або $a . y_{2}(t)>0$, або $b . y_{2}(t)<0$.

2a. Нехай $y_{2}(t)>0\left(y_{3}(t)>0\right)$. Тоді $y_{2}(t)$ монотонно зростаюча додатна функція, а $y_{3}(t)$ - монотонно спадна додатна функція. Використовуючи такі властивості, з другого рівняння отримаємо

$$
y_{2}(t) \geq f_{2}\left(y_{3}\left(\tau_{1}(t)\right)\right) \int_{t_{1}}^{t} a_{2}(s) d s .
$$

3 (7) при $t=\tau_{2}(t)$ та монотонного зростання функції $f_{1}(u)$ з першого рівняння отримаємо

$$
y_{1}(t) \geq f_{1}\left(f_{2}\left(y_{3}\left(\tau_{3}\left(\tau_{2}(t)\right)\right)\right)\right) \int_{t_{1}}^{t} a_{1}(s) f_{1}\left(\int_{t_{1}}^{\tau_{2}(s)} a_{2}(p) d p\right) d s .
$$

Оскільки $y_{3}(t)$ - спадна, то $y_{3}\left(\tau_{3}\left(\tau_{2}\left(\tau_{1}(t)\right)\right)\right) \geq y_{3}(t)$.

Звідси випливає

$$
\begin{aligned}
y_{1}\left(\tau_{1}(t)\right) & \geq f_{1}\left(f_{2}\left(y_{3}\left(\tau_{3}\left(\tau_{2}\left(\tau_{1}(t)\right)\right)\right)\right)\right) \int_{t_{1}}^{\tau_{1}(t)} a_{1}(s) f_{1}\left(\int_{t_{1}}^{\tau_{2}(s)} a_{2}(p) d p\right) d s \geq \\
& \geq f_{1}\left(f_{2}\left(y_{3}((t))\right)\right) \int_{t_{1}}^{\tau_{1}(t)} a_{1}(s) f_{1}\left(\int_{t_{1}}^{\tau_{2}(s)} a_{2}(p) d p\right) d s .
\end{aligned}
$$

Використовуючи ці нерівності, з останнього рівняння системи (1), після інтегрування маємо

$$
\int_{0}^{c} \frac{d y_{3}(t) / d t}{f_{3}\left(f_{1}\left(f_{2}(u)\right)\right)} d t \leq-\int_{t_{1}}^{\infty} a_{3}(t) f_{3}\left(\int_{t_{1}}^{\tau_{1}(t)} a_{1}(s) f_{1}\left(\int_{t_{1}}^{\tau_{2}(s)} a_{2}(p) d p\right)\right) d t .
$$

Отримали суперечність. Ліворуч маємо обмежену величину внаслідок умови (3), а праворуч - в наслідок умови (5) необмежену від'ємну.

2b. Нехай $y_{2}(t)<0\left(y_{3}(t)>0, \frac{d y_{3}(t)}{d t}<0\right)$. Тоді з системи (1) маємо $y_{1}(t)-$ монотонно спадна додатна функція, $y_{2}(t)$ - монотонно зростаюча від'ємна функція, а $y_{3}(t)$ - монотонно спадна додатна функція. Тоді існують

$$
\lim _{t \rightarrow \infty} y_{1}(t)=k \geq 0, \lim _{t \rightarrow \infty} y_{2}(t)=-l \leq 0, \lim _{t \rightarrow \infty} y_{3}(t)=m \geq 0 .
$$

Доведемо, що $k=0, l=0, m=0$. Припустимо супротивне $l \neq 0$.Тоді

$$
\begin{aligned}
& -3 l / 2 \leq y_{2}(t) \leq-l / 2, t \geq t_{1}, \\
& -3 l / 2 \leq y_{2}\left(\tau_{2}(t)\right) \leq-l / 2, t \geq t_{2} \geq t_{1} .
\end{aligned}
$$

Тоді $з$ першого рівняння маємо

$$
y_{1}(t)-y_{1}\left(t_{2}\right) \leq f_{1}(-3 l / 2) \int_{t_{2}}^{t} a_{1}(s) d s .
$$

Внаслідок умови (4) отримаємо $y_{1}(t)<0$, що суперечить припущенню. 
Аналогічно методом від супротивного можна довести, що $\lim _{t \rightarrow \infty} y_{3}(t)=0$.

Доведемо, що $\lim _{t \rightarrow \infty} y_{1}(t)=k=0$.

Припустимо супротивне $k \neq 0$. Тоді $k / 2 \leq y_{1}\left(\tau_{1}(t)\right) \leq 3 l / 2$.

3 третього рівняння в результаті інтегрування з урахуванням додатності $y_{3}(t)$ і неспадання $f(u)$ отримаємо

$$
-y_{3}\left(t_{1}\right) \leq-f_{3}(k / 2) \int_{t_{1}}^{\infty} a_{3}(s) d s .
$$

Замінюючи $t_{1}$ на будь-яке $t$ маємо

$$
y_{3}(t) \geq f_{3}(k / 2) \int_{t}^{c t} a_{3}(s) d s, c>1 .
$$

Застосовуючи отриману оцінку при $t=\tau_{3}(t)$, $з$ другого рівняння, враховуючи від’ємність $y_{2}(t)$, отримаємо

$$
-y_{2}\left(t_{1}\right) \geq M \int_{t_{1}}^{\infty} a_{2}(s) f_{2}\left(\int_{\tau_{3}(s)}^{c \tau_{3}(s)} a_{3}(p) d p\right) d s, M>0 .
$$

Поступаючи як перед цим, отримаємо оцінку

$$
y_{2}\left(\tau_{2}(t)\right) \leq-M \int_{\tau_{2}(t)}^{c \tau_{2}(t)} a_{2}(s) f_{2}\left(\int_{\tau_{3}(s)}^{c \tau_{3}(s)} a_{3}(p) d p\right) d s .
$$

Застосовуючи цю нерівність, з першого рівняння системи (1) отримаємо

$$
y_{1}(t)-y_{1}\left(t_{1}\right) \leq-M_{1} \int_{t_{1}}^{t} a_{1}(s) f_{1}\left(\int_{\tau_{2}(s)}^{c \tau_{2}(s)} a_{2}(s) f_{2}\left(\int_{\tau_{3}(s)}^{c \tau_{3}(s)} a_{3}(p) d p\right) d s\right) d s, M_{1}>0 .
$$

Переходячи до границі при $t \rightarrow \infty$, враховуючи умову (6), отримуємо суперечність. Отже, $\lim _{t \rightarrow \infty} y_{1}(t)=0$. Теорему доведено.

При інших обмеженнях на функції $\tau_{i}(t), i=\overline{1,3}$ має місце

Теорема 2. Нехай виконуються умови (3), (4) та умови:

1. $\tau_{2}(t) \leq t, \tau_{3}(t) \leq t, g(t)=\min \left(\tau_{1}(t), t\right)$,

2. $\int_{t_{1}}^{\infty} a_{3}(t)\left(f_{3}\left(\int_{t_{1}}^{g(t)} a_{1}(s) f_{1}\left(\int_{t_{1}}^{\tau_{2}(s)} a_{2}(p) d p\right)\right) d s\right) d t=\infty$,

3. $\int_{t_{1}}^{\infty} a_{1}(t)\left(f_{1}\left(\int_{t}^{c t} a_{2}(s) f_{2}\left(\int_{s}^{c s} a_{3}(p) d p\right)\right) d s\right) d t=\infty, c>1$.

Тоді кожний розв'язок системи (1) або сильно осцилює, або кожна компонента розв'язку монотонно прямує до нуля при $t \rightarrow \infty$.

Доведення. Проводиться за схемою доведення теореми 1. Припустивши, що система (1) має неосцилюючу компоненту, приходимо до висновку, що всі компоненти не осцилюють. 
Припустимо для визначеності, що $y_{1}(t)>0$ (для $y_{1}(t)<0$ доведення проводиться так само). Розглянемо дві можливості для функції $y_{3}(t)$ : 1. $y_{3}(t)<0,2 . y_{3}(t)>0$.

1. Нехай $y_{3}(t)<0$. Застосовуючи ті самі міркування, що і в теоремі 1 приходимо до суперечності $y_{1}(t)<0$. Тобто цей випадок неможливий.

2. Нехай $y_{3}(t)>0$. Тоді $y_{2}(t)-$ монотонно зростає. Виникають дві можливості для $y_{2}(t): a . y_{2}(t)>0, b . y_{2}(t)<0$.

$2 a$. Нехай $y_{2}(t)>0\left(y_{3}(t)>0\right)$. Через спадання $y_{3}(t)$ і зростання $f_{i}(u)$, $\tau_{3}(t) \leq t, \tau_{2}(t) \leq t$ з нерівності (7) отримаємо

$$
\begin{aligned}
& y_{2}(t) \geq f_{2}\left(y_{3}(t)\right) f_{2}\left(\int_{t_{1}}^{t} a_{2}(s) d s\right), \\
& y_{2}\left(\tau_{2}(t)\right) \geq f_{2}\left(y_{3}(t)\right) f_{2}\left(\int_{t_{1}}^{\tau_{2}(t)} a_{2}(s) d s\right) .
\end{aligned}
$$

Використовуючи цю нерівність, з першого рівняння маємо через спадання функції $f_{3}(u)$ i (8)

$$
y_{1}(t)-y_{1}\left(t_{1}\right) \geq f_{1}\left(f_{2}\left(y_{3}(t)\right)\right) \int_{t_{1}}^{t} a_{1}(s) f_{1}\left(\int_{t_{1}}^{\tau_{2}(s)} a_{2}(p) d p\right) d s .
$$

Оскільки $g(t) \leq \tau_{1}(t)$ i $g(t) \leq t, y_{3}(t)$ спадає і $y_{1}(t)$ зростає, то 3 попередньої нерівності випливає

$$
\begin{aligned}
y_{1}\left(\tau_{1}(t)\right) \geq & y_{1}(g(t)) \geq f_{1}\left(f_{2}\left(y_{3}(g(t))\right)\right) \int_{t_{1}}^{g(t)} a_{1}(s) f_{1}\left(\int_{t_{1}}^{\tau_{2}(s)} a_{2}(p) d p\right) d s \geq \\
& \geq f_{1}\left(f_{2}\left(y_{3}(t)\right)\right) \int_{t_{1}}^{g(t)} a_{1}(s) f_{1}\left(\int_{t_{1}}^{\tau_{2}(s)} a_{2}(p) d p\right) d s .
\end{aligned}
$$

3 останнього рівняння системи, використовуючи цю нерівність, отримаємо

$$
\int_{t_{1}}^{\infty} \frac{d y_{3}(t) / d t}{f_{3}\left(f_{1}\left(f_{2}\left(y_{3}(t)\right)\right)\right)} d t \leq-\int_{t_{1}}^{\infty} a_{3}(t) f_{3}\left(\int_{t_{1}}^{g(t)} a_{1}(s) f_{1}\left(\int_{t_{1}}^{\tau_{2}(s)} a_{2}(p) d p\right)\right) d t .
$$

Поклавши $y_{3}(t)=u$, і врахувавши умови (3) і (10) отримаємо суперечність. Отже цей випадок також неможливий.

$2 b$. Нехай $y_{2}(t)<0$. Тоді $y_{1}(t)-$ спадна функція, $y_{2}(t)$ - від'ємна та зростаюча, а $y_{3}(t)$ - додатна спадна. Як і при доведенні теореми 1 приходимо до висновку $\lim _{t \rightarrow \infty} y_{2}(t)=0, \lim _{t \rightarrow \infty} y_{3}(t)=0$.

Залишилось довести, що $\lim _{t \rightarrow \infty} y_{1}(t)=0$. Припустимо супротивне $\lim _{t \rightarrow \infty} y_{1}(t)=k \neq 0$. Так само як в теоремі 1 отримаємо нерівність (8). 
Оскільки $y_{3}(t)$ - спадна функція і $\tau_{3}(t) \leq t, 3$ (8) випливає

$$
y_{3}\left(\tau_{3}(t)\right) \geq y_{3}(t) \geq f_{3}(k / 2) \int_{t}^{c t} a_{3}(s) d s .
$$

Тоді $з$ другого рівняння, з урахуванням умови $y_{2}(t)<0$, можна отримати

$$
-y_{2}\left(t_{1}\right) \geq M \int_{t_{1}}^{\infty} a_{2}(s) f_{2}\left(\int_{s}^{c s} a_{3}(p) d p\right) d s \geq M \int_{t_{1}}^{c t_{1}} a_{2}(s) f_{2}\left(\int_{s}^{c s} a_{3}(p) d p\right) d s, c>1 .
$$

Змінивши для зручності $t_{1}$ на $t, 3$ урахуванням монотонного зростання $y_{2}(t)$ і $\tau_{2}(t) \leq t$, отримаємо

$$
y_{2}\left(\tau_{2}(t)\right) \leq y_{2}(t) \leq-M \int_{t}^{c t} a_{2}(s) f_{2}\left(\int_{s}^{c s} a_{3}(p) d p\right) d s .
$$

Тоді $з$ першого рівняння маємо

$$
y_{1}(t)-y_{1}\left(t_{1}\right) \leq-M_{1} \int_{t_{1}}^{t} a_{1}(s) f_{1}\left(\int_{s}^{c s} a_{2}(p) f_{2}\left(\int_{p}^{c p} a_{3}(q) d q\right) d p\right) d s .
$$

Застосовуючи умову (11), при $t \rightarrow \infty, 3$ цієї нерівності отримуємо суперечність.

Отже $\lim _{t \rightarrow \infty} y_{1}(t)=0$. Теорему доведено.

Зауважимо, якщо $\tau_{i}(t), i=\overline{1,3}$ мають характер запізнення, то умови (10) $\mathrm{i}$ (5) збігаються, а умова (11) слабша за умову (6). В інших випадках кожна 3 теорем має свою область застосування.

Висновки. Досліджено систему диференціальних рівнянь 3 відхиленням аргументу для випадку $\delta=1, n=3$. Отримані результати покращують і узагальнюють результати, що отримані в роботі [5]. Доведено дві теореми з різними припущеннями відносно відхилення аргументу аналітичними методами. Ці теореми мають різні області застосування. Вони містять різні обмеження на відхилення аргументу. Результати дослідження є узагальненням сублінійного випадку при непарному $n$.

\section{Бібліографічні посилання}

1. Кигурадзе, И.Т. К вопросу колеблемости решений нелинейных дифференциальных уравнений [Текст] / И.Т. Кигурадзе // Дифференциальные уравнения, 1965, Т. 1 - № 8 C. $995-1006$.

2. Шевело, В.Н. Осцилляция решений дифференциальных уравнений с отклоняющимся аргументом [Текст] / В.Н. Шевело. - Київ: Наукова думка, 1978. - 156 с.

3. Варех, Н.В. Дослідження асимптотичної поведінки розв'язків диференціальнофункціональних систем [Текст] / Н.В. Варех, О.Я. Вольфсон, Г.Ф. Мусаєва, О.А. Падалка // Математичне та програмне забезпечення інтелектуальних систем (MPZIS-2017): Матеріали XV Міжнародної наукової конференції, м. Дніпро. - 2017. - С. 34-35.

4. Варех, Н.В. Дослідження поведінки розв'язків диференціальних систем з відхиленням аргументу [Текст] / Н.В. Варех, О.Я. Вольфсон, О.А. Падалка // Питання прикладної математики і математичного моделювання. - Д: ДНУ, 2018. - С. 14-23. 
ISSN 2074-5893 Питання прикладної математики і математичного моделювання. Випуск 19

5. Шевело, В.Н. Осцилляторные свойства решений систем дифференциальных уравнений с отклоняющимся аргументом [Текст] / В.Н. Шевело, Н.В. Варех, А.Г. Грицай. - Препринт 85.10. - Київ, 1985. - 48 с.

Надійшла до редколегії 10.10.2019. 


\section{ЩОДО РОЗВ'ЯЗУВАННЯ КРАЙОВОЇ ЗАДАЧІ ТЕОРІЇ ПЛАСТИН ДЛЯ ОБЛАСТЕЙ СКЛАДНОЇ ФОРМИ}

Розглянута гранична задача теорії пластин, яка зводиться до системи інтегральних рівнянь Фредгольма першого роду та алгоритм саморегуляризації цієї системи. При розв'язуванні лінійної задачі для бігармонічного рівняння застосовується метод потенціалів. Наведені приклади чисельної реалізації, які демонструють високу обчислювальну ефективність у випадку областей складної форми.

Ключові слова: бігармонічне рівняння, метод потенціалів, саморегуляризація, система інтегральних рівнянь, формула Симпсона, фундаментальний розв'язок

Рассмотрена граничная задача теории пластин, которая сводится к системе интегральных уравнений Фредгольма первого рода и алгоритм саморегуляризации этой системы. При решении линейной задачи для бигармонического уравнения применяется метод потенциалов. Приведены примеры численной реализации, которые демонстрируют высокую вычислительную эффективность в случае областей сложной формы.

Ключевые слова: бигармоническое уравнение, метод потенциалов, саморегуляризация, система интегральных уравнений, формула Симпсона, фундаментальное решение.

Mathematical model construction of complicate physical phenomenon often leads to the setting and solving problems of parameters optimal control in differential equations in partial derivatives. Chosen equation with boundary and initial conditions is usually mathematical model basis of the object, which is under analysis. Optimal control of righthand side function in non-linear problem for inhomogeneous biharmonic has been investigated. With the help of various gradient methods the problems of parameters control in such equations are solved successfully. Herewith linear problem is solved with the potential method on every step. The boundary value problem of plate theory, which is reduced to a system of Fredholm integral equations of the first kind and an algorithm of self-regularization of this system, is considered. The potential method is used to solve the linear problem for the harmonic equation. Examples of numerical implementation are shown that demonstrate high computational efficiency in the case of complex form regions.

Algorithm for linear boundary value problem solution with boundary integral equations overcomes this problem successfully. Physical examples of numerical implementation have been presented, analysis of obtained solutions have been conducted. Their accuracy, algorithm simplicity and time spent evidence about this approach promising for practical results obtaining in plate theory and mathematical physics problems successful numerical solving.

Keywords: biharmonic equation, potential method, self-regulation, system of integral equations, Simpson formula, fundamental solution.

(C) Волошко В.Л., Петулько М.П., 2019 
Вступ. Для постановки i розв'язування складних задач оптимізації, механіки, теорії керування [3] необхідні ефективні обчислювальні алгоритми розв'язку крайових задач рівнянь математичної фізики.

На відміну від точних (аналітичних) розв'язків для канонічних областей отримати такий розв'язок у випадку складної форми області становить істотні труднощі. Далі розглядається наближений метод розв'язування крайової задачі, який базується на інтегральному представленні певного типу i, головне, при цьому ефективно враховується складність області.

Обчислювальна ефективність цього методу, який має назву методу потенціалу, грунтується на двох відомих обставинах. Перша з них полягає в тому, що крайова задача зводиться до системи інтегральних рівнянь. Це означає, що апроксимації при чисельній реалізації методів потенціалу підлягають інтегральні оператори, а не диференціальні. А така апроксимація може бути здійснена 3 високою точністю при малих затратах часу на обчислення. Другий момент, - зведення вихідної крайової задачі до контурних інтегральних рівнянь - приводить до скорочення на одиницю розмірності множини, на якій відшукуються невідомі. Метод полягає в тому, що ядрами відповідних потенціалів $\epsilon$ фундаментальні розв'язки відповідних диференціальних рівнянь, саме такий варіант методу потенціалу був використаний. В процесі розробки, засвоєння і поглиблення уявлень про обчислювальні можливості цього підходу виявлені його істотні переваги і помітна конкурентна спроможність порівняно 3 іншими наближеними методами - скінчених елементів і кінцевих різниць $[1,3]$.

\section{1. Крайова задача для бігармонічного рівняння.}

$$
\begin{gathered}
\Delta \Delta w(x, y)=0 \quad(x, y) \in \Omega, \\
\left.w\right|_{\Gamma}=\varphi,\left.\quad \frac{d w}{d n}\right|_{\Gamma}=\psi,
\end{gathered}
$$

де $w=w(x, y)$ - невідома функція; $\Gamma$ - контур складної форми, який обмежує область $\Omega ; \varphi, \psi$ - неперервні в $\Omega$ функції. На відміну від точних розв'язків для канонічних областей, використовується наближений метод розв'язування граничної задачі для такого рівняння. Останній базується на інтегральному представленні розв'язку у вигляді суми бігармонічних потенціалів, ядра яких є фундаментальними розв'язками рівняння (1). Отже, розв'язок задачі (1)-(2) будемо шукати у вигляді:

$$
w(x, y)=\int_{\Gamma}\left[\mu_{1}(s) \cdot r^{2} \ln r+\mu_{2}(s) \cdot \frac{\partial}{\partial v}\left(r^{2} \ln r\right)\right] d \Gamma(s),
$$

де $\mu_{1}, \mu_{2}-$ невідомі функції щільності, $r=\sqrt{(x-\xi)^{2}+(y-\eta)^{2}}$

Далі крайова задача (1) - (2) зводиться до системи інтегральних рівнянь Фредгольма першого роду 


$$
\left\{\begin{array}{l}
\int_{\Gamma} r^{2} \ln r \mu_{1}(s) d \Gamma(s)+\int_{\Gamma} \frac{\partial}{\partial v}\left(r^{2} \ln r\right) \mu_{2}(s) d \Gamma(s)=\varphi(x, y) \\
\int_{\Gamma} \frac{\partial}{\partial n}\left(r^{2} \ln r\right) \mu_{1}(s) d \Gamma(s)+\int_{\Gamma} \frac{\partial^{2}}{\partial n \partial v}\left(r^{2} \ln r\right) \mu_{2}(s) d \Gamma(s)=\psi(x, y),
\end{array}\right.
$$

які є некоректними за третьою умовою Адамара [4]. Систему (4) подамо у вигляді, зручному для наближеного обчислення інтегралів. Для цього треба знайти похідні по нормалі, подати їх у вигляді, зручному для застосування відомих формули аналітичної геометрії для знаходження тригонометричних функцій кутів:

$$
\left\{\begin{array}{l}
\int_{\Gamma} r^{2} \ln r \mu_{1}(s) d \Gamma(s)+\int_{\Gamma}-r(2 \ln r+1) \cos \left(r^{\wedge} v\right) \mu_{2}(s) d \Gamma(s)=\varphi(x, y) \\
\int_{\Gamma} r(2 \ln r+1) \cos \left(r^{\wedge} n\right) \mu_{1}(s) d \Gamma(s)+ \\
+\int_{\Gamma}\left[(2 \ln r+3) \cos \left(r^{\wedge} v\right) \cos \left(r^{\wedge} n\right)+k_{1} k_{2}(2 \ln r+1) \sin \left(r^{\wedge} n\right) \sin \left(r^{\wedge} v\right)\right] \mu_{2}(s) d \Gamma(s)=\psi(x, y)
\end{array}\right.
$$

де $k_{1}=\operatorname{sign}\left(\Pi p_{o z}[n \times r]\right), k_{2}=\operatorname{sign}\left(\Pi p_{o z}[v \times r]\right)$.

Наявність в ядрах системи рівнянь (5) логарифмічних особливостей дозволяє домогтися регуляризуючого ефекту їх розв'язку прямими обчислювальними методами, що підтверджено досвідом розв'язування інтегральних рівнянь подібного типу [3]. Їх суть полягає в тому, що систему інтегральних рівнянь (5) зводимо до системи алгебраїчних. Для цього контур $\Gamma$ розбиваємо на $n$ елементарних дуг, на кожній з яких обираємо проміжну точку. Далі наближено, заміною інтегралів по елементарним дугам, (5) подаємо у вигляді системи лінійних алгебраїчних рівнянь

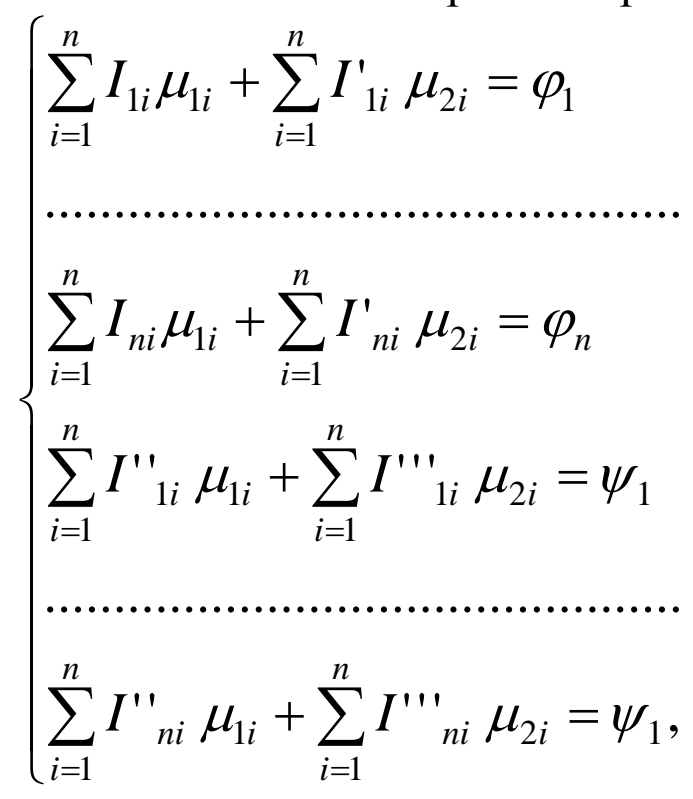

де $\mu_{1 i}, \mu_{1 i}$ - невідомі значення функції щільності, $\phi_{i}$ і $\psi_{i}-$ відомі значення функцій $\phi$ і $\psi$ на $i$-тій частині контуру, $I_{j i}, I^{\prime}{ }_{j i}, I^{\prime \prime}{ }_{j i}, I^{\prime \prime \prime}{ }_{j i}-$ коефіцієнти 
системи лінійних алгебраїчних рівнянь, обчислені за формулою Симпсона [2].

В результаті розв'язку системи (6) визначаємо $\mu_{1}$ i $\mu_{2}$ на ділянках контуру. Після цього можна підрахувати значення функції $w(x, y)$ в будьякій внутрішній точці області.

Далі досліджуємо обчислювальну ефективність методу потенціалу, для чого використовуємо модельні функції та аналітичні формули, за якими можна отримати точні розв'язки для канонічних областей.

Для перевірки чисельних результатів розглядаємо різні бігармонічні в області $\Omega$ функції $f(x, y)$, тобто $\Delta \Delta f(x, y)=0$. Такі функції далі називаються модельними. Вони наведені в другій колонці табл.1. Потім формулюємо граничну задачу

$$
\left.w\right|_{\Gamma}=\left.f\right|_{\Gamma},\left.\quad \frac{\partial w}{\partial n}\right|_{\Gamma}=\left.\frac{\partial f}{\partial n}\right|_{\Gamma}
$$

де Г - контур, який має форму еліпса, $\frac{x^{2}}{a^{2}}+\frac{y^{2}}{b^{2}}=1$ (рис.1). В силу єдиності розв'язку останньої, знайдена функція $w(x, y)$ у внутрішніх точках області повинна тотожно співпадати з модельною функцією.

В табл.1 наведені результати цього обчислювального експерименту.

\begin{tabular}{|l|c|c|c|c|}
\hline \multicolumn{1}{|c|}{$\begin{array}{c}\text { Форма } \\
\text { контура }\end{array}$} & $f(x, y)$ & $(x, y) \in \Omega$ & $\begin{array}{c}\text { Точний } \\
\text { розв'язок }\end{array}$ & $\begin{array}{c}\text { Наближений } \\
\text { розв'язок }\end{array}$ \\
\hline $\begin{array}{l}\text { коло радіуса } \\
R=6\end{array}$ & $\frac{1}{2} x^{2}+\frac{1}{2} y^{2}$ & $(1,0)$ & 0.500000 & 0.497914 \\
\hline $\begin{array}{l}\text { коло радіуса } \\
R=8\end{array}$ & 3 & $(3,0)$ & 3.00000 & 3.00007 \\
\hline $\begin{array}{l}\text { еліпс } \\
a=10, b=8\end{array}$ & $\frac{1}{2} x^{2}+\frac{1}{2} y^{2}$ & $(0,5)$ & 12.5000 & 12.5009 \\
\hline $\begin{array}{l}\text { еліпс } \\
a=3, b=15\end{array}$ & 5 & $(0,4)$ & 5.00000 & 4.99949 \\
\hline $\begin{array}{l}\text { еліпс } \\
a=7, b=5\end{array}$ & $x+y$ & $(3,4)$ & 7.00000 & 7.00142 \\
\hline
\end{tabular}

Дані цієї таблиці свідчать про явище саморегуляризації системи інтегральних рівнянь (4), а також про високу точність отриманих результатів для областей канонічної форми, які мають форму еліпса. Варто зауважити, що в цьому випадку точність знайдених чисельних результатів також підтверджується шляхом застосування точних аналітичних формул, викладених в [1]. Розглянемо тепер випадки областей більш складної форми (рис. 2 -4), для яких точних аналітичних розв'язків не існує (крім квадрата), а достовірність можна перевірити тільки за допомогою модельних функцій. В табл. 2 наведені чисельні результати в деяких внутрішніх точках складних 44 
областей у випадку, коли розглядається гранична задача для бігармонічного рівняння.

Пластина має форму гіпоциклоїди (рис.3)

$$
\begin{aligned}
& x=(R-r) \cos \phi+d \cos \left(\frac{R-r}{r} \phi\right), \\
& y=(R-r) \sin \phi+d \sin \left(\frac{R-r}{r} \phi\right)
\end{aligned}
$$

з параметрами $R=7$ м $, r=1,2 \mathrm{M}, d=0,6$ м.

\begin{tabular}{|c|c|c|c|c|}
\hline Контур & $n$ & $(x, y) \in \Omega$ & Точний розв'язок & Наближений розв'язок \\
\hline Еліпс $a=6, b=8$ & 40 & $(0,5 ; 0,2)$ & 0,00409999 & 0,06564821 \\
\hline Еліпс $a=6, b=8$ & 100 & $(3 ; 0)$ & 81 & 80,9855333 \\
\hline Еліпс $a=6, b=8$ & 200 & $(1,5 ; 0)$ & 5,0625 & 5,06285312 \\
\hline Квадрат $a=4$ & 40 & $(0,5 ; 0,4)$ & $-0,1519$ & $-0,14965914$ \\
\hline Квадрат $a=4$ & 104 & $(1,5 ; 0,4)$ & 2,9281 & 2,93074988 \\
\hline Квадрат $a=4$ & 200 & $(1,5 ; 0,4)$ & 2,9281 & 2,93063146 \\
\hline $\begin{array}{l}\text { Гіпоциклоїда } \\
R=7 . \mu \\
r=1,2 \mathrm{M}, \\
d=0,6 м\end{array}$ & 40 & $(0 ; 0)$ & 0 & 1,87983955 \\
\hline $\begin{array}{l}\text { Гіпоциклоїда } \\
R=7 . \mu \\
r=1,2 \mathrm{M}, \\
d=0,6 \mu\end{array}$ & 100 & $(0 ; 0)$ & 0 & 0,11555555 \\
\hline $\begin{array}{l}\text { Гіпоциклоїда } \\
R=7 . \mu \\
r=1,2 \mathrm{M}, \\
d=0,6 м\end{array}$ & 200 & $(3 ; 0,2)$ & 78,8416 & 78,8457022 \\
\hline $\begin{array}{l}\text { Овал Касіні } \\
a=6, c=5,5 м\end{array}$ & 40 & $(0 ; 0)$ & 0 & $-0,00636387$ \\
\hline $\begin{array}{l}\text { Овал Касіні } \\
a=6, c=5,5 \mu\end{array}$ & 100 & $(1,5 ; 0,4)$ & 2,9281 & 2,92795265 \\
\hline $\begin{array}{l}\text { Овал Касіні } \\
a=6, c=5,5 м\end{array}$ & 200 & $(2 ; 0)$ & 16 & 16,0012047 \\
\hline
\end{tabular}

Таблиия 2 


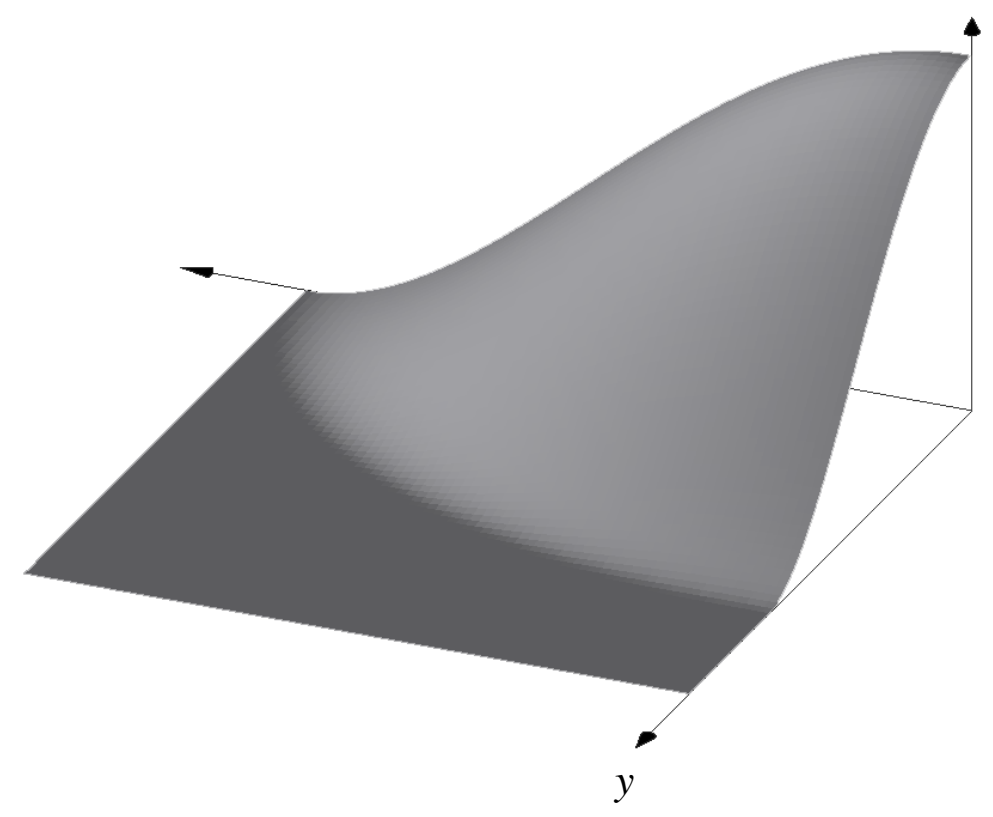

Рис. 1 Пластина форми еліпса

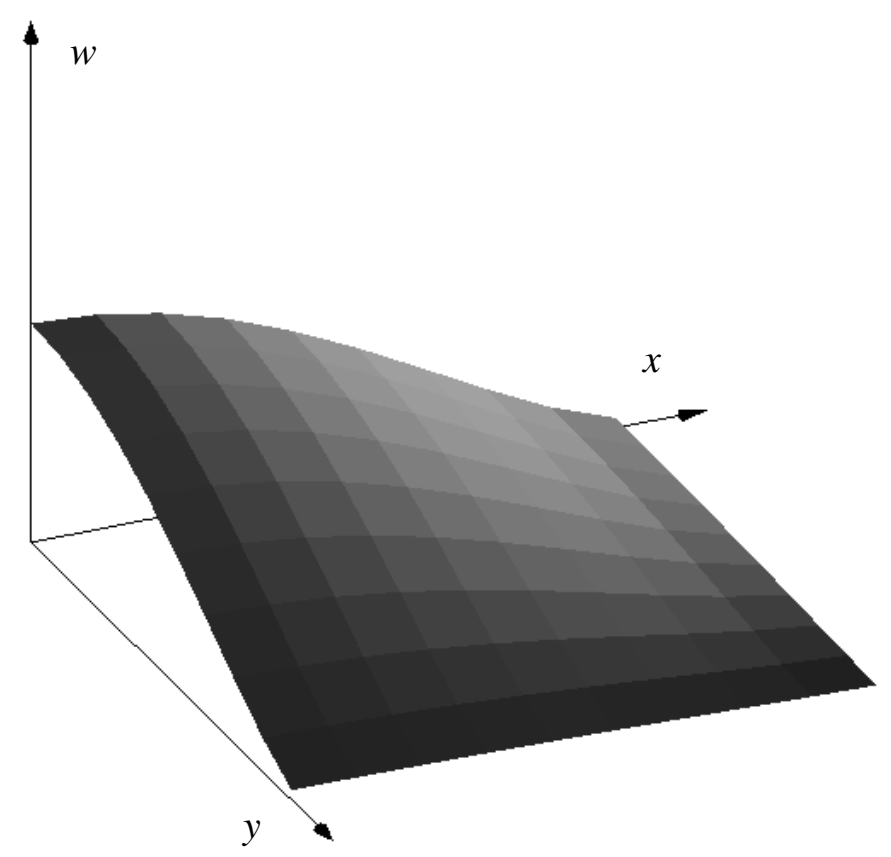

Рис. 2 Квадрат зі стороною $\mathbf{a}=4$ 


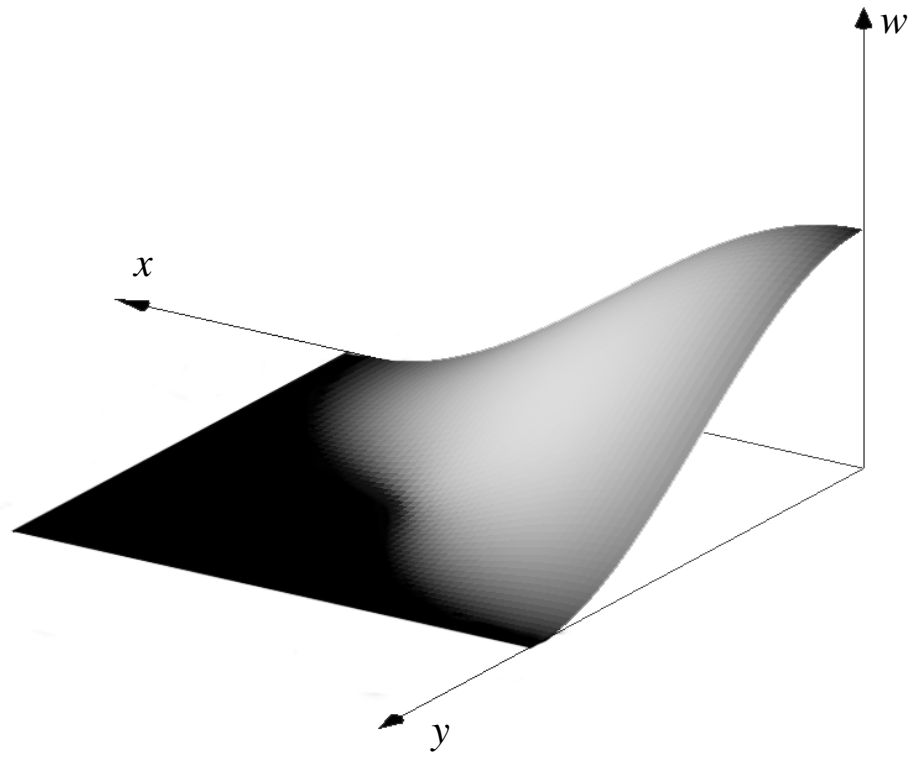

Рис. 3

Пластина має форму овалу Кассіні (рис.4) $\rho^{2}=c^{2} \cos 2 \varphi+\sqrt{a^{4}-c^{4} \sin ^{2} 2 \varphi}$, де $a=6 м, c=5,5 м$.

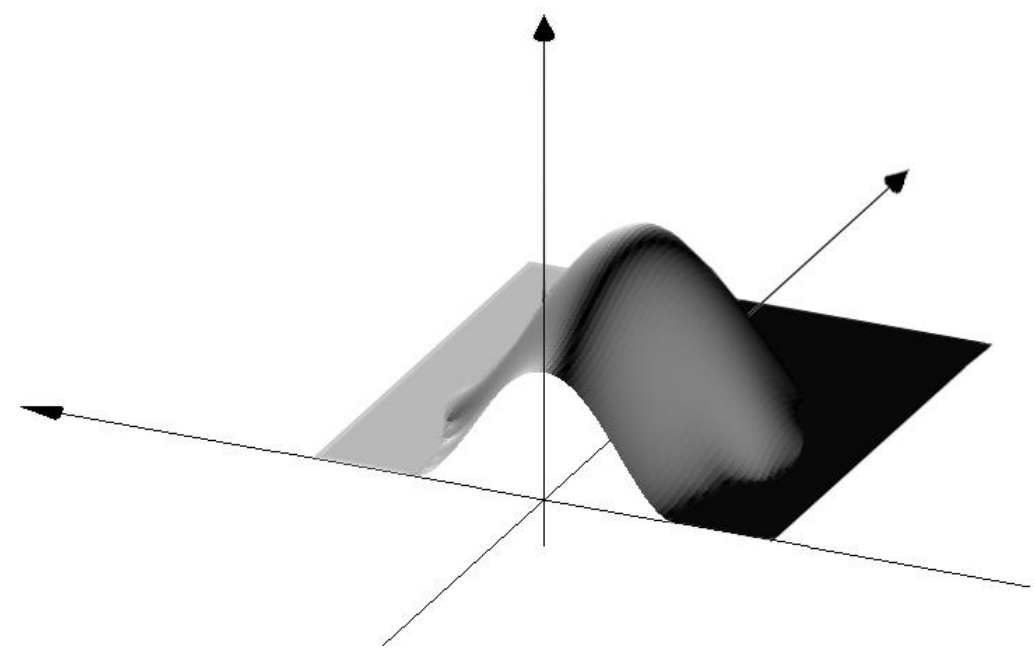

Pис. 4

2. Крайова задача для неоднорідного бігармонічного рівняння. Фізичний приклад. Розглянемо рівняння Софі Жермен, тобто рівняння згину серединних точок тонкої пружної пластини

$$
\Delta \Delta w(x, y)=\frac{q}{D}
$$




$$
\left.w(x, y)\right|_{\tilde{A}}=0,\left.\quad \frac{\partial w(x, y)}{\partial n}\right|_{\tilde{A}}=0,
$$

де $w=w(x, y)$ - невідома функція згину серединної точки $(x, y)$ пластини (призматичне тіло, товщина якого мала порівняно з іншими геометричними параметрами), $\Gamma$ - контур пластини, який обмежує її область $\Omega ; q=$ const інтенсивність поперекового навантаження; $D=\frac{E h^{2}}{12\left(1-\sigma^{2}\right)}-$ циліндрична жорсткість пластини, $h$ - товщина пластини, $E$ - модуль пружності першого роду, $\sigma$ - коефіцієнт Пуассона іi матеріалу. Крайові умови (8) фізично відповідають випадку, коли пластина в граничних точках жорстко закріплена. Легко перевірити безпосередньою підстановкою, що розв'язком рівняння (7) буде

$$
w_{1}(x, y)=\frac{q\left(x^{2}+y^{2}\right)^{2}}{D} .
$$

Тоді

$$
\Delta \Delta w_{1}(x, y)=\frac{q}{D} \quad \text { в } \quad \Omega,
$$

Далі розв'яжемо однорідну задачу з неоднорідними крайовими умовами

$$
\begin{gathered}
\Delta \Delta w_{2}(x, y)=0 \quad \text { в } \quad \Omega, \\
\left.w_{2}(x, y)\right|_{\tilde{A}}=-w_{1}(x, y) \\
\left.\frac{\partial w_{2}(x, y)}{\partial n}\right|_{\tilde{A}}=-\frac{\partial w_{1}(x, y)}{\partial n},
\end{gathered}
$$

Тобто при формуванні крайових умов (12) ми фактично обчислюємо на контурі $\Gamma$ відому функцію $w_{1}(x, y)$ та iї нормальну похідну. Алгоритм розв'язку задачі (11) - (12) є таким самим, як і для задачі (1)-(2). Знайшовши функції щільності $\mu_{1}, \mu_{2}$ маємо розв'язок задачі (7)-(8)

$$
\begin{gathered}
w(x, y)=w_{1}(x, y)+w_{2}(x, y) \quad \text { або } \\
w(x, y)=\frac{q\left(x^{2}+y^{2}\right)^{2}}{64 D}+\int_{\Gamma}\left(r^{2} \ln r\right) \cdot \mu_{1}(\xi, \eta) d \Gamma(\xi, \eta)+ \\
+\int_{\Gamma}[-r(2 \ln r+1)] \cdot \mu_{2}(\xi, \eta) d \Gamma(\xi, \eta),
\end{gathered}
$$

де $r=\sqrt{(x-\xi)^{2}+(y-\eta)^{2}}$, а $(x, y)-$ тепер внутрішня точка області $\Omega$.

Наведемо конкретний приклад розрахунку напружено-деформованого стану пластини $з$ такими параметрами: $h=0,07 \mathrm{M} ., q=3 \kappa \mathrm{H} / \mathrm{M}^{2}, \sigma=0,3$, 
$E=21,6 \cdot 10^{10} \mathrm{H} / \mathrm{M}^{2}$. Для еліпса(зокрема, круга) отримані результати можна порівняти з відомими, обчисленими аналітично. В табл.3 наведено такі порівняння для пластини, яка має форму круга радіуса 5. Дані таблиці свідчать про високу точність методу.

Таблиия 3

\begin{tabular}{|c|c|c|c|}
\hline $\begin{array}{c}\text { Координати } \\
\text { точок } \\
\text { пластини }\end{array}$ & $\begin{array}{c}\text { Отриманий } \\
\text { розв'язок }\end{array}$ & $\begin{array}{c}\text { Точний } \\
\text { розв'язок }\end{array}$ & Похибка \\
\hline$(5,0)$ & 0.00000 & 0.00000 & $-.131861 \mathrm{E}-08$ \\
\hline$(4,0)$ & $0.331926 \mathrm{E}-06$ & $0.332885 \mathrm{E}-06$ & $0.958352 \mathrm{E}-09$ \\
\hline$(2,0)$ & $0.181387 \mathrm{E}-05$ & $0.181237 \mathrm{E}-05$ & $-.150112 \mathrm{E}-08$ \\
\hline$(0,0)$ & $0.257184 \mathrm{E}-05$ & $0.256856 \mathrm{E}-05$ & $-.328873 \mathrm{E}-08$ \\
\hline$(-1,0)$ & $0.236998 \mathrm{E}-05$ & $0.236718 \mathrm{E}-05$ & $-.279783 \mathrm{E}-08$ \\
\hline$(-3,0)$ & $0.105203 \mathrm{E}-05$ & $0.105208 \mathrm{E}-05$ & $0.518412 \mathrm{E}-10$ \\
\hline$(-4,0)$ & $0.331929 \mathrm{E}-06$ & $0.332885 \mathrm{E}-06$ & $0.956305 \mathrm{E}-09$ \\
\hline$(-5,0)$ & 0.00000 & 0.00000 & $-.748359 \mathrm{E}-09$ \\
\hline
\end{tabular}

3. Крайова задача для неоднорідного бігармонічного рівняння 3 неоднорідними крайовими умовами.

$$
\begin{gathered}
\Delta \Delta w(x, y)=f \text { в } \Omega, \\
\left.w\right|_{\Gamma}=\phi,\left.\quad \frac{d w}{d n}\right|_{\Gamma}=\psi,
\end{gathered}
$$

де $w=w(x, y)$ - невідома функція, $f, \phi, \psi-$ задані неперервні функції, $\Gamma-$ контур, який обмежує область $\Omega$.

За теоремою Гілберта [1] розв'язок рівняння (13) має вид:

$$
w_{1}(x, y)=\frac{1}{8 \pi D} \iint_{\Omega} r^{2} \ln r \cdot f(\xi, \eta) d \Omega(\xi, \eta),
$$

тобто $w_{1}(x, y)$ знайдена через подвійний інтеграл задовольняє рівняння (13). Отже,

$$
\Delta \Delta w_{1}(x, y)=f,
$$

а для того, щоб задовольнити граничним умовам формулюємо таку задачу:

$$
\begin{gathered}
\Delta \Delta w_{2}(x, y)=0 \text { в } \Omega \\
\left.w_{2}\right|_{\Gamma}=\left.\left(\phi-w_{1}\right)\right|_{\Gamma},\left.\quad \frac{d w_{2}}{d n}\right|_{\Gamma}=\left.\left(\psi-\frac{\partial w_{1}}{\partial n}\right)\right|_{\Gamma},
\end{gathered}
$$

де при формуванні крайових умов (18) треба знайти різницю значень функцій $\phi, \psi$ та $w_{1}(x, y)$ і іiі нормальної похідної на границі $\Gamma$ відповідно. Для знаходження функції $w_{1}(x, y)$ та іiі нормальної похідної треба обчислити 
відповідні подвійні інтеграли по області прямокутної форми,що охоплює контур $\Gamma$. Цю область, покриваємо прямокутною сіткою. Далі задача (17) (18) аналогічна задачі (1)-(2), детально викладеній в частині 1. Як і в частині 2, розв'язком задачі (13)-(14) буде

$$
\begin{gathered}
w(x, y)=w_{1}(x, y)+w_{2}(x, y) \\
w(x, y)=\frac{1}{8 \pi D} \iint_{\Omega} r^{2} \ln r \cdot f(\xi, \eta) d \Omega(\xi, \eta)+\int_{\Gamma}\left(r^{2} \ln r\right) \cdot \mu_{1}(\xi, \eta) d \Gamma(\xi, \eta)+ \\
+\int_{\Gamma}[-r(2 \ln r+1)] \cdot \mu_{2}(\xi, \eta) d \Gamma(\xi, \eta) .
\end{gathered}
$$

Висновок. Приклади чисельної реалізації методу потенціалу свідчать про його високу обчислювальну ефективність. При розгляді різних модельних функцій і складних форм областей точність становить понад 99\%, яка зростала при збільшенні числа елементарних дуг від $n=40$ до $n=200$. Характерним і важливим висновком чисельного експерименту є збереження точності шуканої функції при ускладненні форми контура.

Результати можуть бути базою для постановки і розв'язування складних задач оптимізації, крайових задач рівнянь математичної фізики в нелінійній постановці з побудовою різних схем ітераційних процесів.

\section{Бібліографічні посилання}

1. Арсенін, В.Я. Методи математичної фізики і спеціальні функції [Текст] / В.Я. Арсенін. - М.: Наука, 1984. -385с.

2. Бойко, Л.Т. Основи чисельних методів [Текст] / Л.Т. Бойко. - Д.: Видавництво ДНУ, 2009. - 244c.

3. Киселева, Е.М. Решение задачи оптимального граничного управления для неоднородного бигармонического уравнения [Текст] / Е.M. Киселева, Л.В. Волошко // Проблемы управления и информатики. - 2014. - №4. - С. 58-68.

4. Кузьменко, В.І. Конспект лекцій 3 курсу «Некоректні задачі» [Текст] / В.І. Кузьменко. -Д.: Видавництво ДНУ, 2009. - 76с.

5. Самуль, В.I. Основи теорії пружності і пластичності [Текст] / В.І.Самуль.- М.: Вища школа, 1970. - 287c.

Надійшла до редколегії 11.09.2019. 


\author{
Л.Л. Гарт, М.О. Васенін, Н.В. Балейко \\ Дніпровський національний університет імені Олеся Гончара
}

\title{
ПОРІВНЯЛЬНИЙ АНАЛІЗ АЛГОРИТМІВ РОЗВ'ЯЗАННЯ ІНТЕГРАЛЬНОГО РІВНЯННЯ ФРЕДГОЛЬМА ДРУГОГО РОДУ У СЕРЕДОВИЩІ МАТLАВ
}

Досліджено найбільш поширені наближені методи розв'язання лінійного інтегрального рівняння Фредгольма другого роду, розроблено відповідні обчислювальні схеми та оцінено порядок їх точності. Для проведення експериментів виконано програмну реалізацію обраних методів на мові програмування Маtlab. Проведено якісний порівняльний аналіз результатів роботи реалізованих алгоритмів на прикладі розв'язання конкретних задач.

Ключові слова: інтегральне рівняння Фредгольма другого роду, обчислювальні схеми, порівняльний аналіз, наближений розв'язок, похибка, якісна оцінка.

Исследованы наиболее распространенные приближенные методы решения линейного интегрального уравнения Фредгольма второго рода, разработаны соответствующие вычислительные схемы и оценен порядок их точности. Для проведения экспериментов выполнена программная реализация выбранных методов на языке программирования Matlab. Проведен качественный сравнительный анализ результатов работы реализованных алгоритмов на примере решения конкретных задач.

Ключевые слова: интегральное уравнение Фредгольма второго рода, вычислительные схемы, сравнительный анализ, приближенное решение, погрешность, качественная оценка.

The most common approximate methods for solving the linear Fredholm integral equation of the second kind are investigated, corresponding computational schemes are developed, and the order of their accuracy is estimated. For experiments, a software implementation of the selected methods was executed in the Matlab programming language. A qualitative comparative analysis of the results of the implemented algorithms was carried out on the example of solving specific problems.

The problems of modeling complex physical processes are one of the most advanced and important ones throughout human history and today. One of the tools that helps to create a model of a process or phenomenon is integral equations. It is a very large class of problems and equations, consisting of many varieties.

One of the types of equations of this class is the Fredholm integral equations of the second kind, because these equations help to solve problems such as the analysis of dynamic machines and mechanisms in mechanics, the problem of self-oscillations of aircraft wings in aerodynamics, the problem of forced vibrations of a string, the problem of determining the critical criticality shaft rotation and a huge range of tasks in the fields of electrical engineering, physics, auto-regulation, astronomy, acoustics and more. However often these processes are quite complex, and it is very difficult to solve the integral equation explicitly. Therefore, it is advisable to make a comparative analysis of approximate methods for solving Fredholm second kind equations and to conclude in which case one or the other method produces the best results.

(C) Гарт Л.Л., Васенін М.О., Балейко Н.В., 2019 
The results of the studies can be applied to the modeling of physical oscillation or regulation processes that require the solution of a linear Fredholm equation of the second kind with a complex kernel and a free term, which makes it impossible to find the exact solution of the equation.

Key words: Fredholm integral equation of the second kind, computational schemes, comparative analysis, approximate solution, error, qualitative estimation.

Вступ. Проблеми моделювання складних фізичних процесів є одними 3 найпередовіших да найважливіших протягом історії людства та сьогодення. Одним з інструментів, що допомагають створити модель процесу або явища, $\epsilon$ інтегральні рівняння. Це дуже великий клас задач і рівнянь, що складається з багатьох різновидів.

Одним $з$ типів рівнянь цього класу є інтегральні рівняння Фредгольма другого роду, адже ці рівняння допомагають вирішити такі задачі, як аналіз динамічних машин та механізмів у механіці, задача про власні коливання крил літака у аеродинаміці, задача о вимушених коливаннях струни, задача про визначення критичної швидкості обертання валу та ще величезний спектр задач у областях електротехніки, фізики, авторегулювання, астрономії, акустики та інших. Але часто ці процеси бувають досить складними і розв’язати інтегральне рівняння у явному вигляді дуже важко. Тому було доцільно виконати порівняльний аналіз найбільш поширених наближених методів розв’язання інтегральних рівнянь Фредгольма другого роду та зробити висновки щодо ефективності того чи іншого методу на класі таких рівнянь 3 певними властивостями.

Власне, сам Ерік Фредгольм створив теорію (яка отримала назву теорія Фредгольма), що призначена для дослідження можливості розв'язання виключно таких рівнянь. Свій внесок у розвиток існуючих та пошук нових наближених методів розв'язання інтегральних рівнянь Фредгольма другого роду зробили багато вчених-математиків, серед яких Борис Гальоркін та Микола Петров [1].

Постановка задачі. Інтегральним рівнянням називають рівняння, в якому невідома функція входить під знак інтеграла. Інтегральне рівняння Фредгольма другого роду, як відомо, має вигляд

$$
y(x)-\lambda \int_{a}^{b} K(x, s) y(x) d s=f(x), \quad a \leq x \leq b,
$$

де $[a, b]$ - заданий проміжок числової осі; $K(x, s)$ - відома функція в області $S=\{(x, s): a \leq x \leq b ; a \leq s \leq b\}$, яку називають ядром інтегрального рівняння; $f(x)$ - відома функція на відрізку $[a, b]$ (вільний член або права частина рівняння); $y(x)$ - шукана функція на $[a, b] ; \lambda$ - числовий параметр, який може бути як заданий, так і ні. В останньому випадку рівняння (1) являє собою не одне рівняння, а сім’ю рівнянь, що залежить від числового параметра $\lambda$.

Нагадаємо деякі важливі поняття і терміни, пов’язані з розглядуваним рівнянням. Значення параметра $\lambda$, при яких відповідне однорідне інтегральне рівняння 


$$
y(x)-\lambda \int_{a}^{b} K(x, s) y(s) d s=0, \quad a \leq x \leq b
$$

має нетривіальні розв'язки, називають характеристичними значеннями інтегрального рівняння (1), а ненульові розв'язки, що їм відповідають, - власними функціями інтегрального рівняння. При цьому числа $\frac{1}{\lambda}$ називають власними числами (значеннями) інтегрального рівняння (1). Характеристичні значення і власні функції інтегрального рівняння Фредгольма часто називають характеристичними значеннями і власними функціями ядра $K(x, s)$. 3 теорії інтегральних рівнянь відомо [1], що якщо $\lambda$ не $\epsilon$ характеристичним значенням ядpa, то рівняння (1) має єдиний розв'язок $y(x) \in L_{2}[a, b]$ для будь-якої правої частини $f(x) \in L_{2}[a, b]$.

Ядро $K(x, s)$ інтегрального рівняння (1) називають фредгольмовим, якщо воно належить простору $L_{2}(S)$; якщо $K(x, s) \in L_{2}(S)$ є ядром зі слабкою особливістю, то відповідне інтегральне рівняння називають рівнянням зі слабкою особливістю. Ядро $K(x, s)$ називають виродженим, якщо воно має вигляд

$$
K(x, s)=\alpha_{1}(x) \beta_{1}(s)+\ldots+\alpha_{m}(x) \beta_{m}(s), \quad(x, s) \in S,
$$

де $\left\{\alpha_{i}(x)\right\}_{i=1}^{m},\left\{\beta_{i}(s)\right\}_{i=1}^{m}$ - дві системи лінійно-незалежних на $[a, b]$ функцій. Ядро $K(x, s)$ називають різницевим, якщо воно залежить від різниці аргументів:

$$
K(x, s)=K(x-s), \quad(x, s) \in S .
$$

Ядро $K(x, s)$ називається симетричним, якщо

$$
K(x, s)=K(s, x), \quad(x, s) \in S .
$$

При цьому інтегральне рівняння, отримане з (1) заміною ядра $K(x, s)$ на $K(s, x)$, називають спряженим (союзним, транспонованим) рівнянням по відношенню до рівняння (1).

Змінні $s$ та $x$ можуть змінюватись у різних інтервалах (наприклад, $a \leq s \leq b$ та $c \leq x \leq d)$. Для визначеності будемо вважати, що $c=a$ та $b=d$ (цього завжди можливо досягти лінійною підстановкою $x=\alpha \bar{x}+\beta$ за допомогою правильного вибору сталих $\alpha$ та $\beta$ ).

Випадок, коли границі інтегрування $a$ i/aбо $b$ можуть бути нескінченними, не виключається, але тоді слід уважно перевіряти виконання умови квадратичного інтегрування ядра $K(x, s)$ у квадраті $S=\{a \leq x \leq b ; a \leq s \leq b\}$.

Метою даної роботи $є$ порівняльний аналіз найбільш поширених методів наближеного розв'язання інтегрального рівняння (1), що передбачає побудову відповідних обчислювальних схем, їх програмну реалізацію та оцінку ефективності на прикладі розв'язання конкретних задач. 
За досліджувальні методи в роботі було обрано метод квадратур, метод вироджених ядер, метод найменших квадратів, метод Гальоркіна-Петрова, метод колокації [1]. Розглянемо детальніше кожен з названих методів.

1. Метод квадратур [2-4]. Побудуємо на відрізку $[a, b]$ сітку з вузлами $a \leq x_{1}<x_{2}<\ldots<x_{n} \leq b$ i перепишемо рівняння (1) у вузлах сітки:

$$
y\left(x_{i}\right)-\lambda \int_{a}^{b} K\left(x_{i}, s\right) y(s) d s=f\left(x_{i}\right), i=1,2, \ldots, n .
$$

Далі за допомогою тої чи іншої квадратурної формули апроксимуємо інтеграли в рівностях (2) кінцевими сумами:

$$
y_{i}-\lambda \sum_{j=1}^{n} A_{j} K_{i j} y_{j}=f_{i}, \quad i=1,2, \ldots, n,
$$

де $y_{i}=\tilde{y}\left(x_{i}\right), f_{i}=f\left(x_{i}\right), K_{i j}=K\left(x_{i}, x_{j}\right) ; \tilde{y}-$ наближення до шуканої функції $y ; A_{j}$ - ваги квадратурної формули.

Розв'язання системи лінійних алгебраїчних рівнянь (3) дає наближені значення шуканої функції $y(x)$ у вузлах сітки $x_{i}$. По них за допомогою інтерполяції можна побудувати наближений розв'язок інтегрального рівняння (1) в аналітичному вигляді на усьому проміжку $[a, b]$.

Нехай $\lambda=1$, а сітка $x_{1}, x_{2}, \ldots, x_{n}$ рівномірна з кроком $h$. Для апроксимації інтегралів використаємо формулу трапецій. Тоді система лінійних алгебраїчних рівнянь (3) матиме вигляд

$$
y_{i}-h \sum_{j=1}^{n} w_{i} K_{i j} y_{j}=f_{i}, \quad i=1,2, \ldots, n,
$$

де $w_{1}=w_{n}=\frac{1}{2}, w_{j}=1$ при $j=2,3, \ldots, n-1$.

2. Метод вироджених ядер [3, 4]. Як зазначалось вище, ядро інтегрального рівняння $\epsilon$ виродженим, якщо його можна представити у вигляді

$$
K(x, s)=\sum_{i=1}^{m} \alpha_{i}(x) \beta_{i}(s) .
$$

Будемо вважати, що $\left\{\alpha_{i}(x)\right\}_{i=1}^{m},\left\{\beta_{i}(s)\right\}_{i=1}^{m}$ - дві лінійно-незалежні системи неперервних на $[a, b]$ функцій.

Підставимо ядро (5) в інтегральне рівняння Фредгольма (1):

$$
y(x)-\lambda \int_{a}^{b}\left[\sum_{i=1}^{m} \alpha_{i}(x) \beta_{i}(s)\right] y(s) d s=f(x), x \in[a, b] .
$$

Поміняємо в (6) операції інтегрування та сумування місцями:

$$
y(x)-\lambda \sum_{i=1}^{m} \alpha_{i}(x) \int_{a}^{b} \beta_{i}(s) y(s) d s=f(x), \quad x \in[a, b] .
$$

Уведемо наступні позначення для інтегралів у рівнянні (7):

$$
c_{i}=\int_{a}^{b} \beta_{i}(s) y(s) d s, i=1,2, \ldots, m .
$$


Користуючись співвідношеннями (7), (8), отримаємо наступне аналітичне представлення розв'язку рівняння Фредгольма (1) з виродженим ядром:

$$
y(x)=\lambda \sum_{i=1}^{m} c_{i} \alpha_{i}(x)+f(x), \quad x \in[a, b],
$$

де $c_{i}(i=1,2, \ldots, m)$ - числові коефіцієнти, що потребують визначення. Підставляючи цей вираз в (7), матимемо:

$$
\sum_{i=1}^{m} \alpha_{i}(x)\left\{c_{i}-\int_{a}^{b} \beta_{i}(s)\left[f(s)+\lambda \sum_{j=1}^{m} c_{j} \alpha_{j}(x)\right] d s\right\}=0, x \in[a, b] .
$$

Система функцій $\left\{\alpha_{i}(x)\right\}_{i=1}^{m}$ лінійно незалежна, отже всі числові коефіцієнти в лінійній комбінації у лівій частині дорівнюють нулеві:

$$
c_{i}-\int_{a}^{b} \beta_{i}(s)\left[f(s)+\lambda \sum_{j=1}^{m} c_{j} \alpha_{j}(x)\right] d s=0, i=1,2, \ldots, m,
$$

або

$$
c_{i}-\lambda \sum_{j=1}^{m} c_{j} \int_{a}^{b} \alpha_{j}(x) \beta_{i}(s) d s=\int_{a}^{b} \beta_{i}(s) f(s) d s, \quad i=1,2, \ldots, m .
$$

Якщо ввести позначення

$$
a_{i j}=\int_{a}^{b} \alpha_{j}(x) \beta_{i}(s) d s, \quad f_{i}=\int_{a}^{b} \beta_{i}(s) f(s) d s, \quad i, j=1,2, \ldots, m,
$$

то співвідношення (10) набудуть вигляду системи лінійних алгебраїчних рівнянь відносно невідомих $c_{i}$ :

$$
c_{i}-\lambda \sum_{j=1}^{m} a_{i j} c_{i}=f_{i}, \quad i=1,2, \ldots, m .
$$

Детальніше:

$$
\left(\begin{array}{cccc}
1-\lambda a_{11} & -\lambda a_{11} & \ldots & -\lambda a_{11} \\
-\lambda a_{11} & 1-\lambda a_{22} & \ldots & -\lambda a_{11} \\
\ldots & \ldots & \ldots & \ldots \\
-\lambda a_{11} & -\lambda a_{11} & \ldots & 1-\lambda a_{m m}
\end{array}\right)\left(\begin{array}{c}
c_{1} \\
c_{2} \\
\ldots \\
c_{m}
\end{array}\right)=\left(\begin{array}{c}
f_{1} \\
f_{2} \\
\ldots \\
f_{m}
\end{array}\right)
$$

Якщо число $\lambda$ регулярне (тобто $\lambda$ не $\epsilon$ характеристичним значенням рівняння (1)), то визначник матриці системи (13) відмінний від нуля і вона має єдиний розв'язок.

Очевидно, що клас інтегральних рівнянь з виродженим ядром досить обмежений. Якщо ядро в інтегральному рівнянні невироджене, але достатньо гладке, то його можна апроксимувати близьким до нього виродженим ядром (наприклад, розклавши його в ряд Тейлора), а отримане після цього інтегральне рівняння розв'язати наведеним вище способом.

3. Метод найменших квадратів [3, 4]. Напишемо вираз для нев'язки інтегрального рівняння Фредгольма (1):

$$
R y(x)=y(x)-\lambda \int_{a}^{b} K(x, s) y(s) d s-f(x), \quad x \in[a, b] .
$$


Якщо $y(x)$ - точний розв'язок рівняння (1), то його нев'язка дорівнюватиме нулю, тобто $R y(x)=0$.

Наближений розв'язок $\tilde{y}(x)$ рівняння (1) будемо шукати в аналітичному вигляді

$$
\tilde{y}(x)=\sum_{i=1}^{n} c_{i} \varphi_{i}(x), \quad x \in[a, b],
$$

де $c_{i}(i=1,2, . ., n)$ - невідомі константи, які підлягають визначенню; $\varphi_{i}(x)$ $(i=1,2, . ., n)$ - задані лінійно-незалежні на $[a, b]$ (координатні) функції.

Позначимо для скорочення запису через $c$ вектор невідомих коефіцієнтів $c_{i}, i=1,2, . ., n$. Підставимо наближений розв'язок (15) у вираз для нев'язки (14) і положимо $\epsilon(x, c)=R \tilde{y}(x)$. Матимемо

$$
\epsilon(x, c)=\sum_{i=1}^{n} c_{i}\left[\varphi_{i}(x)-\lambda \int_{a}^{b} K(x, s) \varphi_{i}(s) d s\right]-f(x), x \in[a, b] .
$$

Сталі $c_{i}, i=1,2, . ., n$ знайдемо з умови мінімуму функціонала

тобто з умов

$$
J(c)=\int_{a}^{b} \epsilon^{2}(x, c) d x
$$

$$
\frac{\partial J}{\partial c_{i}}=0, \quad i=1,2, \ldots, n .
$$

Якщо підставити (16) в (17), отримаємо:

$$
J(c)=\int_{a}^{b}\left\{\sum_{i=1}^{n} c_{i}\left[\varphi_{i}(x)-\lambda \int_{a}^{b} K(x, s) \varphi_{i}(s) d s\right]-f(x)\right\}^{2} d x .
$$

Обчислимо частинні похідні:

$$
\begin{aligned}
\frac{\partial J}{\partial c_{i}} & =\int_{a}^{b} 2\left\{\sum_{i=1}^{n} c_{i}\left[\varphi_{j}(x)-\lambda \int_{a}^{b} K(x, s) \varphi_{j}(s) d s\right]-f(x)\right\} \times \\
& \times\left[\varphi_{i}(x)-\lambda \int_{a}^{b} K(x, s) \varphi_{i}(s) d s\right] d x, \quad i, j=1,2, \ldots, n .
\end{aligned}
$$

Прирівняємо частинні похідні до нуля і отримаємо систему лінійних алгебраїчних рівнянь з симетричною матрицею відносно невідомих $c_{i}, i=1,2, \ldots, n$ :

$$
\sum_{i=1}^{n} a_{i j} c_{j}=b_{i}, \quad i=1,2, . ., n,
$$

де

$$
\begin{gathered}
a_{i j}=\int_{a}^{b}\left[\varphi_{j}(x)-\lambda \int_{a}^{b} K(x, s) \varphi_{j}(s) d s\right] \times\left[\varphi_{i}(x)-\lambda \int_{a}^{b} K(x, s) \varphi_{i}(s) d s\right] d x ; \\
b_{i}=\int_{a}^{b} f(x)\left[\varphi_{i}(x)-\lambda \int_{a}^{b} K(x, s) \varphi_{i}(s) d s\right] d x, \quad i, j=1,2, \ldots, n .
\end{gathered}
$$

Розв'язавши систему (19), отримаємо значення невідомих коефіцієнтів $c_{i}$, $i=1,2, \ldots, n$ і знайдемо наближений розв'язок у вигляді (15), що, у свою чер- 
гу, дозволить знайти чисельні значення наближеного розв’язку в будь-якій точці на $[a, b]$.

4. Метод Гальоркіна-Петрова [3, 4]. Нехай в інтегральному рівнянні Фредгольма (1) $K(x, s) \in L_{2}(S)$ (фредгольмове ядро), $f(x) \in L_{2}[a, b]$. Розв'язок $y(x)$ рівняння (1) будемо шукати у гільбертовому просторі $L_{2}[a, b]$ зі скалярним добутком $(f, g)=\int_{a}^{b} f(x) g(x) d x$. Оберемо в $L_{2}[a, b]$ дві системи лінійнонезалежних на $[a, b]$ функцій $\varphi_{i}(x)$ та $\psi_{i}(x), i=1,2, \ldots, n$. Наближений розв'язок $\tilde{y}(x)$ рівняння (1) будемо шукати в аналітичному вигляді

$$
\tilde{y}(x)=f(x)+\sum_{j=1}^{n} c_{j} \varphi_{j}(x), \quad x \in[a, b] .
$$

Тут $c_{j}(j=1,2, \ldots, n)$ - невідомі константи, які підлягають визначенню з умови ортогональності нев'язки (14) рівняння Фредгольма (1) на наближеному розв'язку $\tilde{y}(x)$ усім лінійно-незалежним функціям $\psi_{i}(x), i=1,2, \ldots, n$ :

$$
\left(R \tilde{y}, \psi_{i}\right)=0, i=1,2, \ldots, n .
$$

Нескладно бачити, з урахуванням (14), (20), що співвідношення (21) є системою лінійних алгебраїчних рівнянь відносно невідомих коефіцієнтів $c_{j}$ :

$$
\sum_{j=1}^{n} a_{i j} c_{j}=b_{i}, \quad i=1,2, \ldots, n,
$$

де

$$
\begin{aligned}
& a_{i j}=\int_{a}^{b} \varphi_{j}(x) \psi_{i}(x) d x-\lambda \int_{a}^{b} \psi_{i}(x) \int_{a}^{b} K(x, s) \varphi_{j}(s) d s d x, \\
& b_{i}=\lambda \int_{a}^{b} \psi_{i}(x) \int_{a}^{b} K(x, s) f(s) d s d x, \quad i, j=1,2, \ldots, n .
\end{aligned}
$$

Розв'язавши систему (22), знайдемо усі невідомі коефіцієнти $c_{j}, j=1,2, \ldots, n$ і отримаємо наближений розв'язок у вигляді (20), що, у свою чергу, надасть змогу отримати чисельні результати на розглядуваному відрізку.

5. Метод колокації $[3,4]$. Будемо шукати наближений розв'язок $\tilde{y}(x)$ iнтегрального рівняння Фредгольма (1) в наступному аналітичному вигляді:

$$
\tilde{y}(x)=\sum_{j=1}^{n} c_{j} \varphi_{j}(x), x \in[a, b],
$$

де $c_{j}(j=1,2, \ldots, n)$ - невідомі числові коефіцієнти, що підлягають визначенню; $\varphi_{j}(x)(j=1,2, \ldots, n)$ - задані лінійно-незалежні на $[a, b]$ координатні функції. Підставимо вираз (23) у ліву частину (14) і отримаємо нев'язку рівняння (1) на наближеному розв'язку $\tilde{y}(x)$ :

$$
R \tilde{y}(x)=\sum_{j=1}^{n} c_{j} \varphi_{j}(x)-\lambda \int_{a}^{b} K(x, s) \sum_{j=1}^{n} c_{j} \varphi_{j}(x) d s-f(x)=
$$




$$
=\sum_{j=1}^{n} c_{j}\left[\varphi_{j}(x)-\lambda \int_{a}^{b} K(x, s) \varphi_{j}(x) d s\right]-f(x) .
$$

Згідно з методом колокації, вимагатимемо, щоб нев'язка $R \tilde{y}(x)$ оберталася до нуля у заданій системі точок відрізка $[a, b]: a \leq x_{1}<x_{2}<\ldots<x_{n} \leq b$. Тоді отримаємо систему лінійних алгебраїчних рівнянь відносно невідомих $c_{j}, j=1,2, \ldots, n$ :

$$
\sum_{j=1}^{n} c_{j}\left[\varphi_{j}\left(x_{i}\right)-\lambda \int_{a}^{b} K\left(x_{i}, s\right) \varphi_{j}\left(x_{i}\right) d s\right]=f\left(x_{i}\right), \quad i=1,2, \ldots, n .
$$

Якщо позначити елементи матриці системи (24) за

$$
\psi_{j}\left(x_{i}, \lambda\right)=\varphi_{j}\left(x_{i}\right)-\lambda \int_{a}^{b} K\left(x_{i}, s\right) \varphi_{j}(s) d s, \quad i=1,2, \ldots, n,
$$

то ця система запишеться у наступному вигляді:

$$
\sum_{j=1}^{n} \psi_{j}\left(x_{i}, \lambda\right) c_{j}=f\left(x_{i}\right), \quad i=1,2, \ldots, n .
$$

Якщо визначник системи (26) не дорівнює нулеві, то з неї можна однозначно знайти значення коефіцієнтів $c_{j}, j=1,2, \ldots, n$ i, відповідно, отримати наближений розв'язок $\tilde{y}(x)$ рівняння (1) за формулою (23).

Отже, алгоритм розв'язання інтегрального рівняння Фредгольма (1) методом колокації полягає у розрахуванні елементів матриці за формулами (25) 3 подальшим розв'язанням системи лінійних алгебраїчних рівнянь (26). Це надає змогу отримати наближений аналітичний розв'язок вихідної задачі, а 3 нього (за необхідністю) і чисельні результати.

Модельний приклад [4]. 3 використанням кожного з розглянутих вище наближених методів було проведено чисельні експерименти для розв'язання наступного модельного прикладу. Нехай у рівнянні (1) задані: межі інтегрування $a=-\pi$ та $b=\pi$, параметр $\lambda=\frac{3}{10 \pi}$, ядро $K(x, s)=\frac{1}{0.64 \cos ^{2} \frac{x+s}{2}-1}$ та права частина $f(x)=25-16 \sin ^{2}(x)$. Отже, інтегральне рівняння має вигляд:

$$
y(x)-\frac{3}{10 \pi} \int_{-\pi}^{\pi} \frac{y(s)}{0.64 \cos ^{2} \frac{x+s}{2}-1} d s=25-16 \sin ^{2}(x), \quad x \in[-\pi, \pi] .
$$

Точний розв’язок цього рівняння відомий і надається формулою

$$
y(x)=8.5+\left(\frac{128}{17}\right) \cos (2 x) .
$$

Для наведеного модельного прикладу за допомогою програмної реалізації алгоритмів розглянутих вище методів були одержані чисельні результати та проведено їх якісний порівняльний аналіз.

Результати чисельних експериментів. Зауважимо насамперед, що оцінка складності алгоритмів за часом та простором залежить від середовища та мо58 
ви програмування, на яких реалізовувались алгоритми. Так як увесь програмний код у цій роботі був реалізований на мові програмування Matlab, то кожна можливість цієї мови приймається за атомарну операцію, хоча в інших мовах та середовищах такої можливості може не бути. В зв’язку з цим оцінки обчислювальної складності та просторової складності не можна порівнювати з іншими реалізаціями, але, оскільки усі методи були реалізовані в Matlab, то правомірними є і їх порівняння, і відповідні висновки.

Наведемо спочатку загальну таблицю, у яку занесемо усі попередньо отримані результати чисельних експериментів.

Таблиия 1

Порівняльна таблиця оцінок ефективності методів

\begin{tabular}{|l|c|c|c|c|c|}
\hline \multicolumn{1}{|c|}{ Назва методу } & $\begin{array}{c}\text { Часова } \\
\text { складність }\end{array}$ & $\begin{array}{c}\text { Просторова } \\
\text { складність }\end{array}$ & Час, с & $\begin{array}{c}\text { Точність } \\
\|\Delta\|\end{array}$ & $\begin{array}{c}\text { Складність } \\
\text { реалізації }\end{array}$ \\
\hline Квадратур & $O\left(n^{2}\right)$ & $O\left(n^{2}\right)$ & 0.002 & $10^{-14}$ & 2 \\
\hline $\begin{array}{l}\text { Вироджених } \\
\text { ядер }\end{array}$ & $O\left(m^{2}\right)$ & $O(m)$ & 1.559 & 0.350 & 4 \\
\hline $\begin{array}{l}\text { Найменших ква- } \\
\text { дратів }\end{array}$ & $O\left(n^{3}\right)$ & $O\left(n^{2}\right)$ & 65.990 & 0.721 & 3 \\
\hline $\begin{array}{l}\text { Гальоркіна- } \\
\text { Петрова }\end{array}$ & $O\left(m^{2}\right)$ & $O\left(m^{2}\right)$ & 81.845 & 0.670 & 4 \\
\hline Колокації & $O\left(m^{2}\right)$ & $O\left(m^{2}\right)$ & 0.977 & 0.824 & 5 \\
\hline
\end{tabular}

Також наведемо загальний порівняльний графік для усіх розглянутих методів для спільного модельного прикладу (рис. 1).

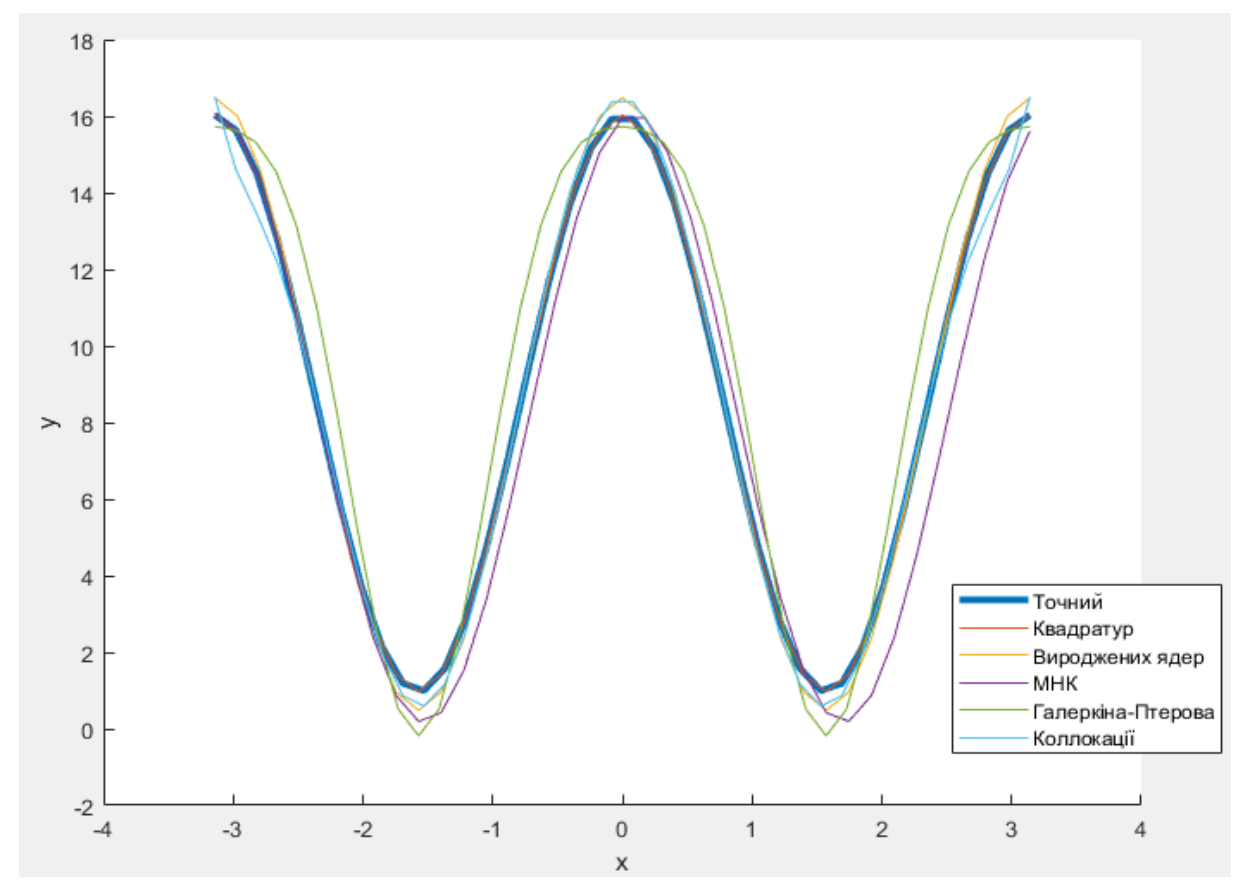

Рис. 1 - Загальний порівняльний графік 
Нормалізація оцінки. На основі показників, наведених у порівняльній таблиці з результатами експериментів, нажаль, дуже складно надати комплексну оцінку тому чи іншому методу. Для того щоб вирішити це питання, треба зробити нормалізацію критеріїв оцінювання. Нормалізовувати будемо до шкали від одного до п'яти балів.

Спочатку розглянемо оцінку складності реалізації. Оцінка надавалась за таким принципом, що чим складніше алгоритм, тим більший бал він отримає. Це було зроблено для найкращого розуміння суті оцінки. Але такий показник $\epsilon$ скоріше негативним: треба щоб більший бал відображав більш позитивні риси ніж менший. Тому тепер оцінка буде виглядати зворотною: один бал для дуже складного алгоритму та п’ять - для найпростішого.

Розглянемо оцінку складності алгоритму. Усього протягом чисельних експериментів було встановлено три оцінки складності, а саме $O\left(n^{2}\right), O\left(n^{3}\right)$, $O\left(m^{2}\right)$. Тому зробимо наступну нормалізацію. Найгіршій оцінці, тобто $O\left(n^{3}\right)$ поставимо у відповідність три бали, середній $O\left(n^{2}\right)$ - чотири, а найкращій $O\left(m^{2}\right)$ - п'ять балів. Звісно, існують і набагато кращі оцінки, але ми розглядаємо лише множину тих методів, які були розглянуті у ході роботи, тому оцінки розташувались саме таким чином.

Аналогічно, нормалізуємо оцінку просторової складності алгоритму. У цьому випадку, ми також маємо три варіанти можливих оцінок, а саме $O\left(n^{2}\right), O(m), O\left(m^{2}\right)$. Тому, слідуючи попереднім принципам, нормалізуємо ці показники так, що найгіршому випадку, тобто $O\left(n^{2}\right)$ буде відповідати оцінка три бали, а найкращому $O(m)$ - п’ять балів.

Час виконання алгоритму нормалізувати досить просто, тому що ми маємо п'ять різних показників цього параметру. Розташуємо їх у порядку зростання та найменшому дамо найвищу оцінку у п'ять балів, а найбільшому навпаки найменшу - у один бал.

За цим же принципом можна нормалізувати оцінку точності алгоритму, так як також маємо п'ять різних значень.

Запишемо отримані результати в іншу порівняльну таблицю, а також підрахуємо середній бал для кожного методу. Але також слід пам'ятати, що ефективність деяких методів дуже залежить від виду рівняння, від властивостей, що характерні цьому рівнянню, та від того, чи знаємо ми деякі характерні риси його розв'язку. Щоб врахувати ці фактори, зробимо додатковий стовпчик, де будемо ставити позначку «+» напроти таких методів, у яких $\epsilon$ деякі примітки у використанні. 
Порівняльна таблиця нормалізованих оцінок методів

\begin{tabular}{|l|c|c|c|c|c|c|}
\hline \multicolumn{1}{|c|}{ Назва методу } & $\begin{array}{c}\text { Часова } \\
\text { склад- } \\
\text { ність }\end{array}$ & $\begin{array}{c}\text { Просторо- } \\
\text { ва склад- } \\
\text { ність }\end{array}$ & $\begin{array}{c}\text { Час ви- } \\
\text { конання }\end{array}$ & $\begin{array}{c}\text { Точність } \\
\|\Delta\|\end{array}$ & $\begin{array}{c}\text { Складність } \\
\text { реалізації }\end{array}$ & $\begin{array}{c}\text { Сере- } \\
\text { дній } \\
\text { бал }\end{array}$ \\
\hline Квадратур & 4 & 3 & 5 & 5 & 4 & 4,2 \\
\hline $\begin{array}{l}\text { Вироджених } \\
\text { ядер }\end{array}$ & 5 & 5 & 3 & 4 & 2 & 3.8 \\
\hline $\begin{array}{l}\text { Найменших } \\
\text { квадратів }\end{array}$ & 3 & 3 & 2 & 2 & 3 & 2.6 \\
\hline $\begin{array}{l}\text { Гальоркіна- } \\
\text { Петрова }\end{array}$ & 5 & 4 & 1 & 3 & 2 & 3 \\
\hline Колокації & 5 & 4 & 4 & 1 & 1 & 3 \\
\hline
\end{tabular}

Висновки. Проведемо аналіз результатів, користуючись нормалізованими оцінками методів. Спочатку звернем увагу на середню оцінку методів, а потім розглянемо і порівняємо кожний детальніше.

За середньою оцінкою випереджає метод квадратур. Це пов'язано з високою точністю, гарними показниками складності за часом та за простором, а також із швидкістю виконання. Крім того, цей алгоритм не потребує попередніх підготовчих зусиль, чи якихось знань про характер розв'язку рівняння.

У той же час, метод найменших квадратів на розглянутих модельних прикладах виявився найменш ефективним майже за усіма показниками, і він потребує знання характеру розв'язку, адже, як показав чисельний експеримент, метод надзвичайно точний, коли функція проста і це відомо, і дуже втрачає ці властивості у складних випадках.

Декілька кращими видалися результати у методі Гальоркіна-Петрова, який значно випереджає метод найменших квадратів показниками складності за часом та простором, утім так само для складних прикладів його показники часу виконання та точності навіть нижче. Але для прикладу, який добре застосований до цього методу, він дає дуже точні результати.

Метод вироджених ядер надзвичайно точний для рівнянь 3 виродженими ядрами, але й навіть при їх апроксимації зберігає високу точність, маючи при цьому найкращі показники складності.

У свою чергу, метод колокації виявився надзвичайно складним у реалізації та підготовці і пошуку гарного прикладу, що й знизило йому оцінку, але все таки утримав планку точності, швидкості та складності. Втім, його точність також залежить від типу координатних функцій, і у випадку, коли це - поліноми Лежандра, від вибору порядку поліному.

Отже, далі можемо зробити висновки про те, у якому випадку застосовувати той чи інший алгоритм, а у якому - ні. 
Якщо функція ядра інтегрального рівняння Фредгольма досить складна, а також складно чи неможливо встановити характер розв'язку, слід застосовувати метод квадратур, адже він показав найкращі результати у середньому випадку, при тому, що він не має надмірних вимог до рівняння і не потребує знання поведінки розв'язку.

Обирання інших методів цілком залежить від того, яким є ядро рівняння та від кількості інформації про точний розв'язок. Так, якщо одразу можна побачити, що ядро вироджене або його легко можна привести до такого вигляду, слід обрати метод вироджених ядер. У іншому випадку, якщо відомо, що характер розв'язку близький до поліноміального, то можна сміливо використовувати метод колокації з використанням поліномів Лежандра.

Що стосується методів Гальоркіна-Петрова та метода найменших квадратів, то рекомендації щодо їх використання однакові: це добрі знання про характер розв'язку та невелика складність (особливість) функції-ядра. Порад щодо обрання того чи іншого методу надати часом складно, тому що вони показали схожі результати на одних і тих самих прикладах. Проте, якщо враховувати лише середню отриману оцінку методів, то перевагу слід віддати методу Гальоркіна-Петрова.

На останок, слід зробити зауваження, що всі отримані результати не носять стовідсоткову правдоподібність, адже є фактори, які врахувати дуже важко, але у рамках того середовища, у межах якого відбувалося дослідження, отримані результати можна вважати коректними й об'єктивними.

\section{Бібліографічні посилання}

1. Полянин, А.Д. Справочник по интегральным уравнениям [Текст] / А.Д. Полянин, А.В. Манжиров. - М.: Физматлит, 2003. - 384 с.

2. Бахвалов, Н.С. Численные методы [Текст] / Н.С. Бахвалов. - М.: Наука, 1975. - 632 с.

3. Березин, И.С. Методы вычислений. Том 2. [Текст] / И.С. Березин - М.: Гос. изд-во физ.-мат. лит., 1959. - $620 \mathrm{c}$.

4. Верлань, А.Ф. Интегральные уравнения: методы, алгоритмы, программы [Текст] / А.Ф. Верлань, В.С. Сизиков. - К.: Наукова думка, 1986. - 544 с.

Надійшла до редколегії 21.10.2019. 


\author{
Л.Л. Гарт, Н.А. Лобанцева \\ Дніпровський національний університет імені Олеся Гончара
}

\title{
ПРО ОБЧИСЛЮВАЛЬНІ АСПЕКТИ РЕАЛІЗАЦІЇ РІЗНИЦЕВИХ СХЕМ РОЗВ'ЯЗАННЯ ЗАДАЧІ ДІРІХЛЕ ДЛЯ ЕЛІПТИЧНОГО РІВНЯННЯ $З$ МІШАНИМИ ПОХІДНИМИ
}

В даній статті розглянуто обчислювальні схеми явних ітераційних методів розв'язання різницевих задач Діріхле різних порядків точності для двовимірного еліптичного диференціального рівняння 3 мішаними похідними. Виконана програмна реалізація розроблених алгоритмів та проведено якісний порівняльний аналіз результатів на прикладі розв'язання конкретних задач.

Ключові слова: задача Діріхле, еліптичне диференціальне рівняння, мішані похідні, метод скінченних різниць, різницеві схеми, похибка, збіжність.

В данной статье рассмотрены вычислительные схемы явных итерационных методов решения разностных задач Дирихле разных порядков точности для двумерного эллиптического дифференциального уравнения со смешанными производными. Выполнена программная реализация разработанных алгоритмов и проведен качественный сравнительный анализ результатов на примере решения конкретных задач.

Ключевые слова: задача Дирихле, эллиптическое дифференциальное уравнение, смешанные производные, метод конечных разностей, разностные схемы, погрешность, сходимость.

The most used in computational practice in solving elliptic boundary value problems are the finite difference method [1, 2]. This method is not only an effective numerical method for finding approximate solutions of various problems to partial differential equations, but also a very general and relatively simple method for evidence existence theorems and research the differential properties of solutions of these problems. As it known, the finite differences method essence consists of the following. The domain of continuous variation of arguments of the original problem is replaced by a discrete set of points (nodes), which is called a grid; derivatives in the differential equation and the boundary conditions are approximated by difference relations; herewith, the boundary value problem for the differential equation is replaced by a system of algebraic equations (a difference scheme).

In this paper, we discuss computational schemes of explicit iterative methods for solving Dirichlet difference problems of various orders of accuracy for two-dimensional elliptic differential equations with mixed derivatives. The developed algorithms software implementation was performed, and a qualitative comparative analysis of the results was carried out on the example of solving specific problems. For the elliptic boundary value problem with mixed derivatives, various iterative methods of solving the corresponding finite-difference schemes are implemented. For this, a software product was developed in the $\mathrm{C \#}$ programming language, which implements the above-mentioned iterative grid algorithms, to conduct capacious computational experiments, to study their practical convergence, and to carry out qualitative comparative analysis using the example of solving model problems.

() Гарт Л.Л., Лобаниева Н.А., 2019 
Keywords: Dirichlet problem, elliptic differential equation, mixed derivatives, the finite difference method, difference schemes, error, convergence.

Вступ. Диференціальні рівняння в частинних похідних мають широке застосування в математичній фізиці, гідродинаміці, акустиці, техніці та інших галузях знань. Під час математичного моделювання стаціонарних процесів різної фізичної природи, серед яких можна назвати стаціонарний розподіл тепла, дифузію, електростатичні та електромагнітні явища, деформаційні процеси, часто виникає необхідність у розв'язанні крайових задач для еліптичних диференціальних рівнянь [3].

Задача розв'язання таких рівнянь у своїй більшості складніша порівняно із звичайними диференціальними рівняннями. Крім того, складність їх розв’язання породжена великою різноманітністю в постановці початкових та крайових умов, а також вимірністю задач. Тому серед таких рівнянь лише в окремих випадках вдається отримати точні розв'язки. Для розв'язання цих задач застосовуються різні наближені методи, серед яких вирізняють аналітичні та чисельні. Для аналітичного розв'язання еліптичних крайових задач застосовують метод поділу змінних Фур'є, метод функцій Гріна і метод потенціалів, варіаційні та проекційні методи (методи Релея-Рітца, БубноваГальоркіна, Канторовича). При цьому застосування можливо лише у випадках найпростіших областей та диференціальних операторів, тому чисельні методи посідають основне місце. Серед них відомі метод скінченних різниць, метод скінченних елементів, метод інтегральних співвідношень Дородніцина, спектральні методи та ін.

Метод скінченних різниць є найбільш вживаним під час розв'язання крайових задач для еліптичних диференціальних рівнянь завдяки його універсальності та ефективності. Універсальність полягає у можливості застосування цього методу як для лінійних, так і для нелінійних крайових задач, для задач різної розмірності та з областями складної (неканонічної) форми.

Процес розв'язання диференціальних рівнянь скінченно-різницевим методом, як відомо, складається $з$ таких етапів [3]:

1) заміна області неперервного змінювання аргументу областю дискретного його змінювання;

2) заміна диференціального оператора деяким різницевим оператором, а також формулювання різницевих аналогів для крайових і початкових умов;

3) перехід до системи різницевих (алгебраїчних) рівнянь;

4) розв’язання отриманої системи різницевих рівнянь.

У роботах $[4,5]$ викладені сучасні методи різницевого розв'язання задач математичної фізики та пов'язані з цим питання теорії різницевих схем. Під час дослідження цих питань для першої еліптичної крайової задачі 3 мішаними похідними докладніше розглянута монографія [3], що присвячена теорії різницевих схем для наближеного розв'язання диференціальних рівнянь в частинних похідних еліптичного типу. У ній викладаються різні методи побудови різницевих схем для типових задач математичної фізики. 
У зазначених вище джерелах розглядалися тільки питання, пов'язані 3 побудовою і дослідженням різницевих схем, числові ж методи (прямі та ітераційні) розв'язання різницевих рівнянь, що апроксимують еліптичні крайові задачі, наведені, наприклад, в [5, 6, 7, 8]. В зазначених роботах викладаються сучасні економічні прямі методи розв'язання різницевих рівнянь Пуассона в прямокутнику з крайовими умовами різного виду. Це метод повної редукції і розділення змінних, що використовує алгоритм швидкого перетворення Фур'є, а також комбіновані методи. Серед ітераційних методів досліджуються двошарова ітераційна схема 3 чебишовським набором параметрів, тришарова схема, ітераційні методи варіаційного типу та ін. Через свою простоту та універсальність в даній роботі були обрані саме явні ітераційні методи.

Зауважимо, що для побудови різницевих схем важливо зберегти властивості монотонності і консервативності, оскільки монотонні схеми приводять до коректних систем алгебраїчних рівнянь. Різницеві схеми для еліптичних рівнянь 3 мішаними похідними, що були розглянуті в згаданих вище працях, мають необхідні властивості лише у випадку коефіцієнтів при мішаних похідних, які не змінюють свій знак. Для еліптичних рівнянь зі знакозмінними коефіцієнтами при мішаних похідних монотонні та консервативні схеми запропоновані в роботах $[1,9]$.

Постановка задачі. Розглянемо задачу Діріхле для еліптичного рівняння 3 мішаними похідними: знайти неперервну в $\bar{G}=G \cup \Gamma$ функцію $u\left(x_{1} ; x_{2}\right)$, яка задовольняє рівняння

$$
L u=\sum_{\alpha, \beta=1}^{2} \frac{\partial}{\partial x_{\alpha}}\left(k_{\alpha \beta}(x) \frac{\partial u}{\partial x_{\beta}}\right)=-f(x), x \in G,
$$

і крайову умову

$$
u(x)=g(x), x \in \Gamma,
$$

де $\bar{G}$ - прямокутник, $\bar{G}=\left\{0 \leq x_{\alpha} \leq l_{\alpha}, \alpha=1,2\right\} ; \Gamma$ - його межа; $f(x), g(x)-$ задані функції, $x=\left(x_{1} ; x_{2}\right)$.

Припустимо, що функції $f(x), g(x), k_{\alpha \beta}(x)(\alpha, \beta=1,2)$ такі, що задача (1), (2) має єдиний розв'язок, який становить достатньо гладку функцію в області $\bar{G}$, а також виконані умови симетрії

$$
k_{12}(x)=k_{21}(x), x \in \bar{G}
$$

та еліптичності

$$
c_{1} \sum_{\alpha=1}^{2} \xi_{\alpha}^{2} \leq \sum_{\alpha, \beta=1}^{2} k_{\alpha \beta} \xi_{\alpha} \xi_{\beta} \leq c_{2} \sum_{\alpha=1}^{2} \xi_{\alpha}^{2}, c_{1}>0,
$$

де $\xi=\left(\xi_{1} ; \xi_{2}\right)-$ довільний вектор.

Однією 3 основних властивостей рівняння (1) $є$ виконання принципу максимуму: неперервний в $\bar{G}$ і відмінний від константи розв'язок $u\left(x_{1} ; x_{2}\right)$ 
може досягати свого максимального за модулем значення тільки на контурі $\Gamma$. Звідси виходить, що справедлива оцінка

$$
\max _{\left(x_{1} ; x_{2}\right) \in \bar{G}}\left|u\left(x_{1} ; x_{2}\right)\right| \leq \max _{\left(x_{1} ; x_{2}\right) \in \Gamma}\left|g\left(x_{1} ; x_{2}\right)\right|,
$$

яка означає стійкість задачі (1) по крайових даних [10].

Побудова різницевої схеми. Згідно 3 загальною схемою побудови різницевих методів $[3,5]$, введемо в $u\left(x_{1} ; x_{2}\right)$ рівномірну прямокутну сітку 3 кроками $h_{1}$ та $h_{2}$ по напрямках $x_{1}$ та $x_{2}$ відповідно так, що $h_{\alpha}=l_{\alpha} / N_{\alpha}, \alpha=1,2$, де $N_{1}$ та $N_{2}$ - цілі числа:

$$
\bar{\omega}_{h}=\bar{\omega}_{h}+\gamma_{h}=\left\{\left(x_{1}^{\left(i_{1}\right)} ; x_{2}^{\left(i_{2}\right)}\right): x_{\alpha}^{\left(i_{\alpha}\right)}=i_{\alpha} h_{\alpha}, i_{\alpha}=0,1, \ldots, N_{\alpha}, \alpha=1,2\right\} \text {. }
$$

Точки $\left(x_{1}^{\left(i_{1}\right)} ; x_{2}^{\left(i_{2}\right)}\right)$ при $i_{\alpha}=1,2, \ldots, N_{\alpha}-1, \alpha=1,2$ називають внутрішніми вузлами сітки, $\bar{\omega}_{h}$ - сукупністю внутрішніх вузлів, а множину

$$
\gamma_{h}=\left\{\left(x_{1}^{(0)} ; x_{2}^{\left(i_{2}\right)}\right),\left(x_{1}^{\left(N_{1}\right)} ; x_{2}^{\left(i_{2}\right)}\right)\right\}_{i_{2}=1}^{N_{2}-1} \cup\left\{\left(x_{1}^{\left(i_{1}\right)} ; x_{2}^{(0)}\right),\left(x_{1}^{\left(i_{1}\right)} ; x_{2}^{\left(N_{2}\right)}\right)\right\}_{i_{1}=1}^{N_{1}-1}
$$

- межею сітки $\bar{\omega}_{h}$.

Розглянемо еліптичний оператор з мішаною похідною задачі (1), (2):

$$
L u=\sum_{\alpha, \beta=1}^{2} \frac{\partial}{\partial x_{\alpha}}\left(k_{\alpha \beta}(x) \frac{\partial u}{\partial x_{\beta}}\right) .
$$

В припущені, що виконуються умови еліптичності (4), оператор $\frac{\partial}{\partial x_{\alpha}}\left(k_{\alpha \alpha}(x) \frac{\partial u}{\partial x_{\alpha}}\right)$ апроксимуємо наступним виразом:

$$
\Lambda_{\alpha \alpha} y=0,5\left[\left(k_{\alpha \alpha} y_{\bar{x}_{\alpha}}\right)_{x_{\alpha}}+\left(k_{\alpha \alpha} y_{x_{\alpha}}\right)_{\bar{x}_{\alpha}}\right] \text {. }
$$

Оператор 3 мішаною похідною $\frac{\partial}{\partial x_{\alpha}}\left(k_{\alpha \beta}(x) \frac{\partial u}{\partial x_{\beta}}\right) \quad$ апроксимуємо операторами вигляду [11]

$$
\Lambda_{12}^{-} y=\left(k_{12} y_{\bar{x}_{2}}\right)_{x_{1}}, \Lambda_{21}^{-} y=\left(k_{21} y_{\bar{x}_{1}}\right)_{x_{2}} .
$$

Таким чином, різницевий оператор $\Lambda y$ матиме наступний вигляд:

$$
\Lambda y=\frac{1}{2}\left[\sum_{\alpha=1}^{2}\left[\left(k_{\alpha \alpha} y_{\bar{x}_{\alpha}}\right)_{x_{\alpha}}+\left(k_{\alpha \alpha} y_{x_{\alpha}}\right)_{\bar{x}_{\alpha}}\right]+\sum_{\alpha, \beta=1}^{2}\left(k_{\alpha \beta} y_{\bar{x}_{\beta}}\right)_{x_{\alpha}}\right] \text {. }
$$

Уведемо позначення: $f \equiv f\left(x_{1} ; x_{2}\right) \equiv f\left(x_{1}^{\left(i_{\alpha}\right)} ; x_{2}^{\left(i_{\alpha}\right)}\right), g \equiv g\left(x_{1} ; x_{2}\right) \equiv g\left(x_{1}^{\left(i_{\alpha}\right)} ; x_{2}^{\left(i_{\alpha}\right)}\right)$ при $i_{\alpha}=1,2, \ldots, N_{\alpha}-1, \alpha=1,2$. Тоді задачі Діріхле (1), (2) зіставимо наступну різницеву схему:

$$
\begin{gathered}
\Lambda y=-f, \\
y\left(x_{\alpha}^{\left(i_{\alpha}\right)} ; x_{3-\alpha}^{(0)}\right)=g\left(x_{\alpha}^{\left(i_{\alpha}\right)} ; x_{3-\alpha}^{(0)}\right) ; y\left(x_{\alpha}^{\left(i_{\alpha}\right)} ; x_{3-\alpha}^{\left(l_{\alpha}\right)}\right) \equiv g\left(x_{\alpha}^{\left(i_{\alpha}\right)} ; x_{3-\alpha}^{\left(l_{\alpha}\right)}\right), \\
i_{\alpha}=1,2, \ldots, N_{\alpha}-1, \alpha=1,2 .
\end{gathered}
$$


Запишемо (8) з використанням (7) більш детально. Так, з урахуванням введених вище позначень, для кожного вузла сітки різницевий оператор $\Lambda y=\Lambda_{11} y+\Lambda_{12} y+\Lambda_{21} y+\Lambda_{22} y$ буде мати наступний вигляд:

$$
\begin{aligned}
& \Lambda_{11} y=\left(k_{11} y_{\bar{x}_{1}}\right)_{x_{1}}+\left(k_{11} y_{x_{1}}\right)_{\bar{x}_{1}}=\frac{1}{h_{1}^{2}}\left[\left(k_{11}^{\left(-i_{1}\right)}+k_{11}\right) y^{\left(-i_{1}\right)}-\left(k_{11}^{\left(-i_{1}\right)}+2 k_{11}+k_{11}^{\left(+i_{1}\right)}\right) y+\right. \\
& \left.+\left(k_{11}+k_{11}^{\left(+i_{1}\right)}\right) y^{\left(+i_{1}\right)}\right] \\
& \Lambda_{12} y=\left(k_{12} y_{\overline{x_{2}}}\right)_{x_{1}}=\frac{1}{h_{1} h_{2}}\left[-k_{12} y+k_{12}^{\left(+i_{1}\right)} y^{\left(+i_{1}\right)}+k_{12} y^{\left(-i_{2}\right)}-k_{12}^{\left(+i_{1}\right)} y^{\left(+i_{1},-i_{2}\right)}\right] \\
& \Lambda_{21} y=\left(k_{21} y_{\bar{x}_{1}}\right)_{x_{2}}=\frac{1}{h_{1} h_{2}}\left[k_{21} y^{\left(-i_{1}\right)}-k_{21} y-k_{21}^{\left(+i_{2}\right)} y^{\left(-i_{1},+i_{2}\right)}+k_{21}^{\left(+i_{2}\right)} y^{\left(+i_{2}\right)}\right] \\
& \Lambda_{22} y=\left(k_{22} y_{\bar{x}_{2}}\right)_{x_{2}}+\left(k_{22} y_{x_{2}}\right)_{\overline{x_{2}}}=\frac{1}{h_{2}^{2}}\left[\left(k_{22}^{\left(-i_{2}\right)}+k_{22}\right) y^{\left(-i_{2}\right)}-\left(k_{22}^{\left(-i_{2}\right)}+2 k_{22}+k_{22}^{\left(+i_{2}\right)}\right) y+(12)\right) \\
& \left.+\left(k_{22}+k_{22}^{\left(+i_{2}\right)}\right) y^{\left(+i_{2}\right)}\right]
\end{aligned}
$$

Легко переконатися, що оператор $\Lambda y$ згідно з (9) - (12) визначений на множені, яка складається із семи точок (шаблон зображено на рис. 1).

Доведено, що похибка апроксимації $\psi=\Lambda_{\alpha \alpha} u-L_{\alpha \alpha} u=O\left(|h|^{2}\right)$, де $|h|^{2}=h_{1}^{2}+h_{2}^{2}$, має другий порядок [12]. Різницевий ж оператор $\Lambda_{\alpha \beta}^{-} y$ апроксимує диференціальний оператор $L_{\alpha \beta} 3$ похибкою $O\left(h_{1}+h_{2}\right)$, тому для покращення порядку апроксимації скористаємося таким різницевим оператором:

$$
\Lambda_{\alpha \beta} y=\frac{1}{2}\left(\Lambda_{\alpha \beta}^{+} y+\Lambda_{\alpha \beta}^{-} y\right)=\frac{1}{2}\left[\left(k_{\alpha \beta} y_{\bar{x}_{\beta}}\right)_{x_{\alpha}}+\left(k_{\alpha \beta} y_{x_{\beta}}\right)_{\bar{x}_{\alpha}}\right], \alpha \neq \beta,
$$

що має похибку $O\left(|h|^{2}\right)[11]$. Тут

$$
\Lambda_{12}^{+} y=\left(k_{12} y_{x_{2}}\right)_{\bar{x}_{1}}, \quad \Lambda_{21}^{+} y=\left(k_{21} y_{x_{1}}\right)_{\bar{x}_{2}} .
$$

Тоді, поклавши в (8) вирази (6) та (13), легко побачити, що різницевий оператор $\Lambda y$ має наступний вигляд:

$$
\Lambda y=\frac{1}{2} \sum_{\alpha, \beta=1}^{2}\left[\left(k_{\alpha \beta} y_{\bar{x}_{\beta}}\right)_{x_{\alpha}}+\left(k_{\alpha \beta} y_{x_{\beta}}\right)_{\bar{x}_{\alpha}}\right]
$$

та апроксимує (5) з похибкою $O\left(\left|h^{2}\right|\right)$.

Розклавши оператор (14) аналогічно минулому випадку, можна переконатися, що він теж визначений на множині, яка складається із семи точок і шаблон якої зображено на рис.1.

В [11] виділено ще один важливий апроксимаційний вираз другого порядку для оператора (5). Різницевий оператор $\Lambda y$ у цьому випадку визначений на множині, що складається із дев'яти точок (відповідний шаблон зображено на рис.2). 


$$
\begin{aligned}
\Lambda y & =\frac{1}{2} \sum_{\alpha=1}^{2}\left[\left(k_{\alpha \alpha} y_{\bar{x}_{\alpha}}\right)_{x_{\alpha}}+\left(k_{\alpha \alpha} y_{x_{\alpha}}\right)_{\bar{x}_{\alpha}}\right]+ \\
& +\frac{1}{4} \sum_{\alpha \neq \beta}^{1 \div 2}\left[\left(k_{\alpha \beta} y_{\bar{x}_{\beta}}\right)_{x_{\alpha}}+\left(k_{\alpha \beta} y_{x_{\beta}}\right)_{\bar{x}_{\alpha}}+\left(k_{\alpha \beta} y_{x_{\beta}}\right)_{x_{\alpha}}+\left(k_{\alpha \beta} y_{\bar{x}_{\beta}}\right)_{\bar{x}_{\alpha}}\right] .
\end{aligned}
$$

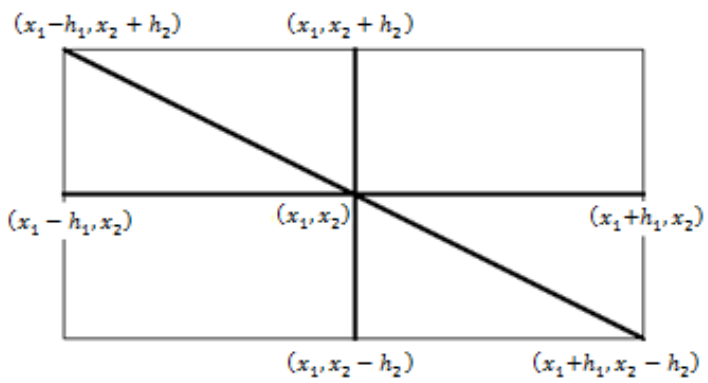

Рис. 1 - Семиточковий шаблон

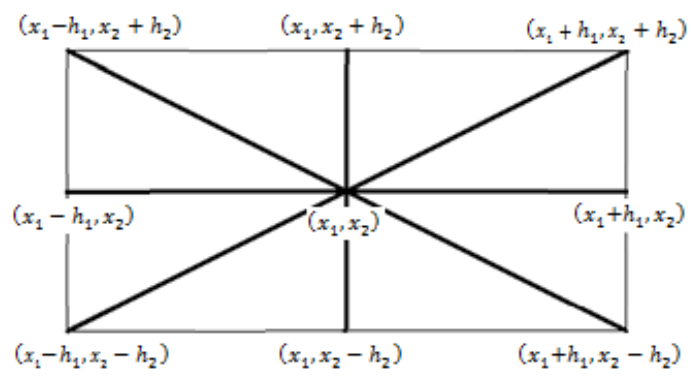

Рис. 2 - Дев'ятиточковий шаблон

Побудова різницевої схеми для коефіціснтів при мішаних похідних, що змінюють знак. Основна ідея конструювання різницевої схеми для задачі (1), (2) в цьому випадку полягає в використанні вже побудованих схем зі спеціальними значеннями коефіцієнтів при мішаних похідних. Розглянемо еліптичний оператор (5) з мішаною похідною задачі (1), (2) та припустимо, що виконуються умови еліптичності (4). Тоді для апроксимації оператора $L u$ скористаємося наступними виразами $[1,9]$ :

$$
\begin{gathered}
\Lambda y=\sum_{\alpha, \beta=1}^{2} \Lambda_{\alpha \beta} y, \Lambda_{\alpha \alpha} y=\left(a_{\alpha \alpha} y_{\bar{x}_{\alpha}}\right)_{x_{\alpha}}, \\
\Lambda_{\alpha \beta} y=\frac{1}{4}\left[\left(a_{\alpha \beta}^{-} y_{\bar{x}_{\beta}}\right)_{x_{\alpha}}+\left(a_{\alpha \beta}^{\left.-(+1)_{\alpha}\right)} y_{x_{\beta}}\right)_{\bar{x}_{\alpha}}+\left(a_{\alpha \beta}^{+} y_{x_{\beta}}\right)_{x_{\alpha}}+\left(a_{\alpha \beta}^{\left.-(+1)_{\alpha}\right)} y_{\bar{x}_{\beta}}\right)_{\bar{x}_{\alpha}}\right], \\
a_{\alpha \beta}^{ \pm}=a_{\alpha \beta} \pm\left|a_{\alpha \beta}\right|, a_{\alpha \beta}=0,5\left[k_{\alpha \beta}(x)+k_{\alpha \beta}\left(x_{\alpha}-h_{\alpha}, x_{\beta}\right)\right] .
\end{gathered}
$$

Таким чином, поклавши в (8) вирази (16) та (17), отримаємо нову різницеву схему, що задовольняє умови монотонності та консервативності. В [12] доведено, що вона має другий порядок апроксимації.

3 використанням позначень $b_{1}=0,5\left[k_{12}\left(x_{1}+h_{1} ; x_{2}\right)+k_{12}\left(x_{1}, x_{2}\right)\right]$ Ta $b_{2}=0,5\left[k_{12}\left(x_{1} ; x_{2}\right)+k_{12}\left(x_{1}-h_{1}, x_{2}\right)\right]$ можна записати наступним чином вираз 3 (17):

$$
\begin{aligned}
& \left(a_{12}^{-} y_{x_{2}}\right)_{x_{1}}=\frac{1}{h_{1} h_{2}}\left[\left(b_{1}-\left|b_{1}\right|\right)\left(y\left(x_{1}+h_{1} ; x_{2}\right)-y\left(x_{1}+h_{1} ; x_{2}-h_{2}\right)\right)-\right. \\
& \left.-\left(b_{2}-\left|b_{2}\right|\right)\left(y\left(x_{1} ; x_{2}\right)-y\left(x_{1} ; x_{2}-h_{2}\right)\right)\right]
\end{aligned}
$$

Аналогічно можна отримати інші різницеві вирази (17).

Різницеві схеми як операторні рівняння. Після заміни диференціального оператора різницевим ми перейшли від крайової задачі (1), (2) до системи лінійних алгебраїчних рівнянь порядку $\left(N_{1}-1\right) \times\left(N_{2}-1\right) \quad$ відносно наближених значень шуканого розв'язку $y\left(x_{1} ; x_{2}\right)$ у внутрішніх вузлах сітки. 
Запишемо цю систему у зручному вигляді, а саме - у вигляді операторного рівняння [12]. 3 цією метою введемо простір $H=H\left(\omega_{h}\right)$ сіткових функцій, визначених на $\omega_{h}$. При цьому в просторі $H=H\left(\omega_{h}\right)$ мають місце наступні формули для обчислення скалярного добутку та норми:

$$
(u, v)=\sum_{i=1}^{N_{1}-1} \sum_{j=1}^{N_{2}-1} u_{i j} v_{i j} h_{1} h_{2},\|u\|=\sqrt{(u, u)} .
$$

Нарівні $3 \quad H$ розглянемо простір $\dot{H}=\dot{H}\left(\overline{\omega_{h}}\right)$ сіткових функцій, які визначенні на $\overline{\omega_{h}}$ i дорівнюють нулю на межі $\gamma_{h}$. Тоді матимемо таку задачу:

$$
\begin{gathered}
\Lambda y=-f, x \in \omega_{h}, \\
y(x)=g(x), x \in \Gamma,
\end{gathered}
$$

де $A: \dot{H} \rightarrow H, \quad \Lambda y=\Lambda_{11} y+\Lambda_{12} y+\Lambda_{21} y+\Lambda_{22} y-$ різницевий оператор, побудований за допомогою будь-якої з розглянутих вище схем (7), (14), (15).

В системі (18) виділимо ті рівняння, які містять крайові значення та перенесемо їх в праву частину. Останні рівняння залишемо без змін. Тоді різницева задача (18) набуває вигляду

$$
A y=\varphi,
$$

де $A: H \rightarrow H, A=-\Lambda$. Крайові умови задачі (1) тут враховані правою частиною $\varphi$. При цьому права частина (19) відрізняється від правої частини (18) лише в примежових точках.

Відмітимо деякі важливі властивості оператора $A$ [12]. Оператор $A \epsilon$ самоспряженим, тобто для будь-яких $u, v \in H$ виконується рівність $(A u, v)=(u, A v)$. Крім того, справедлива лема [5]: для всякої сіткової функції $u(x)$, що задана на сітці $\omega_{h}$ та перетворюється в нуль на межі $\gamma_{h}$, має місце подвійна нерівність

$$
\gamma_{1}\|u\|^{2} \leq(A u, u) \leq \gamma_{2}\|u\|^{2}
$$

де $\gamma_{1}$ i $\gamma_{2}$ - сталі енергетичної еквівалентності оператора . 3 урахуванням умови еліптичності (3), вони обчислюються так [3]:

$$
\gamma_{1}=\frac{8 c_{1}}{h^{2}} \sin ^{2} \frac{\pi h}{2 l}, \gamma_{2}=\frac{8 c_{2}}{h^{2}} \cos ^{2} \frac{\pi h}{2 l},
$$

де $c_{1}$ і $c_{2}$ - сталі $з$ умови (3), $h=h_{1}=h_{2}, l=l_{1}=l_{2}$.

Двошарові ітераційні методи. Для розв'язання отриманої різницевої еліптичної задачі розглянемо двошарові ітераційні методи, а саме - метод Чебишова і метод простої ітерації. В роботах $[5,8,12]$ запропонована така явна двошарова ітераційна схема:

$$
\frac{y_{k+1}-y_{k}}{\tau_{k+1}}+A y_{k}=g, k=0,1, \ldots
$$

3 довільним початковим наближенням $y_{o} \in H$ та ітераційними параметрами $\tau_{k}$, що знаходяться за формулами 


$$
\tau_{k}=\frac{\tau_{0}}{1+\rho_{0} \mu_{k}}, \tau_{0}=\frac{2}{\gamma_{1}+\gamma_{2}}, \rho_{0}=\frac{1-\xi}{1+\xi}, \quad \xi=\frac{\gamma_{1}}{\gamma_{2}}, \mu_{k} \in \mathfrak{M}_{n}, k=0,1, \ldots, n .
$$

Тут через $\mathfrak{M}_{n}$ позначено множину коренів полінома Чебишова:

$$
\mathfrak{M}_{n}=\left\{-\cos \left(\frac{2 i-1}{2 n} \pi\right), i=0,1, \ldots, n\right\} .
$$

3 наведеної формули для $\tau_{k}$ видно, що для обчислення ітераційних параметрів потрібно задати число ітерацій $n$ :

$$
n \geq n_{0}(\varepsilon)=\frac{\ln \left(1 / \varepsilon+\sqrt{1 / \varepsilon^{2}-1}\right)}{\ln \left(1 / \rho_{1}\right)} \text { або } n_{0}(\varepsilon)=\frac{\ln (2 / \varepsilon)}{\ln \left(1 / \rho_{1}\right)}, \quad \rho_{1}=\frac{1-\sqrt{\xi}}{1+\sqrt{\xi}} .
$$

Такий метод має назву ітераиіийний чебишовський метод.

Частинним випадком чебишовського методу є метод, побудований при додатковому обмеженні $\tau_{k} \equiv \tau$, тобто в припущенні, що ітераційні параметри $\tau_{k}$ не залежать від номера ітерації $k$. Така задача виникає при знаходженні ітераційного параметра $\tau$ для стаціонарної двошарової схеми

$$
\frac{y_{k+1}-y_{k}}{\tau}+A y_{k}=g, k=0,1, \ldots
$$

Оптимальне значення параметра $\tau$ цієї схеми знайдено: $\tau=\tau_{0}=\frac{2}{\gamma_{1}+\gamma_{2}}$, a відповідний ітераційний метод має назву метод простої ітераиії. Для числа ітерацій в ньому вірна оцінка

$$
n \geq n_{0}(\varepsilon)=\frac{\ln \varepsilon}{\ln \rho_{0}} \text { або } n_{0}(\varepsilon) \approx \frac{1}{2 \xi} \ln \frac{1}{\varepsilon} .
$$

Тришарові ітераційні методи. Тришарова ітераційна схема $[8,12]$ для рівняння (19) пов'язує три ітераційних наближення $y_{k+1}, y_{k}$ i $y_{k-1}$ так, що $y_{k+1}$ визначається через $y_{k}$ і $y_{k-1}$. Явна стандартна тришарова ітераційна схема має вигляд

$$
\begin{gathered}
y_{k+1}=\alpha_{k+1}\left(E-\tau_{k+1} A\right) y_{k}+\left(1-\alpha_{k+1}\right) y_{k-1}+\alpha_{k+1} \tau_{k+1} g, \\
y_{1}=\left(E-\tau_{1} A\right) y_{0}+\tau_{1} g, \quad k=1,2, \ldots, \quad y_{0} \in H,
\end{gathered}
$$

де $y_{0}$ - довільне початкове наближення, $\alpha_{k}$ та $\tau_{k}$ - ітераційні параметри.

$\mathrm{B}[8,12]$ показано, що виходячи з умов збіжності методу, параметри $\alpha_{k}$ та $\tau_{k}$ розраховуються наступним чином:

$$
\alpha_{k+1}=\frac{2 q_{k+1}}{\rho_{0} q_{k}}, \quad \tau_{k} \equiv \tau_{0}=\frac{2}{\gamma_{1}+\gamma_{2}}, \quad q_{k}=\frac{2 \rho_{1}^{k}}{1+\rho_{1}^{2 k}}, k=1,2, \ldots, n .
$$

Такий метод має назву напівтераиійний метод Чебишова. Для числа ітерацій $n$ має місце оцінка $n \geq n_{0}(\varepsilon)$, де

$$
n_{0}(\varepsilon)=\frac{\ln 0,5 \varepsilon}{\ln \rho_{1}}, \rho_{1}=\frac{1-\sqrt{\xi}}{1+\sqrt{\xi}}, \quad \xi=\frac{\gamma_{1}}{\gamma_{2}} .
$$


Аналогічно двошаровим методам можна побудувати стаиіонарний тришаровий метод $[8,12]$ :

$$
\begin{gathered}
y_{k+1}=\alpha(E-\tau A) y_{k}+(1-\alpha) y_{k-1}+\alpha \tau g, \\
y_{1}=(E-\tau A) y_{0}+\tau g, \quad k=1,2, \ldots, \quad y_{0} \in H
\end{gathered}
$$

зі сталими (стаціонарними) параметрами вигляду

$$
\alpha=1+\rho_{1}^{2}, \quad \tau=\tau_{0}=\frac{2}{\gamma_{1}+\gamma_{2}}, \rho_{1}=\frac{1-\sqrt{\xi}}{1+\sqrt{\xi}}, \quad \xi=\frac{\gamma_{1}}{\gamma_{2}} .
$$

де $\gamma_{1}$ i $\gamma_{2}$ - сталі енергетичної еквівалентності, визначені в (20).

Опис розробленого програмного продукту. Після розгляду основних понять та принципів побудови різницевих схем для еліптичних диференціальних рівнянь 3 мішаними похідними та явних ітераційних методів для розв'язання еліптичних сіткових рівнянь, були розроблені відповідні обчислювальні алгоритми. Зазначені алгоритми спираються на методи побудови різницевих схем різних порядків точності для еліптичного рівняння 3 мішаними похідними у випадку коефіцієнтів при мішаних похідних, що не змінюють та змінюють знак, принципи побудови відповідних операторних рівнянь та наближені методи їх розв'язання (ітераційний метод Чебишова (IMЧ), метод простої ітерації (MПI), напівітераційний метод Чебишова (НМЧ) та стаціонарний ітераційний метод (CIM)).

В розробленому програмному продукті користувачеві надається можливість задати параметри сітки та значення точності розрахунків. Натиснувши на кнопку «Вирішити», отримаємо зображення побудованої сітки та результати розв'язання задачі явними ітераційними методами, зображеними у вигляді таблиці, побудованої за вузлами сітки. Для кожного методу виводяться кількість ітерацій та норма похибки, що характеризує точність розв’язку(рис. 3).

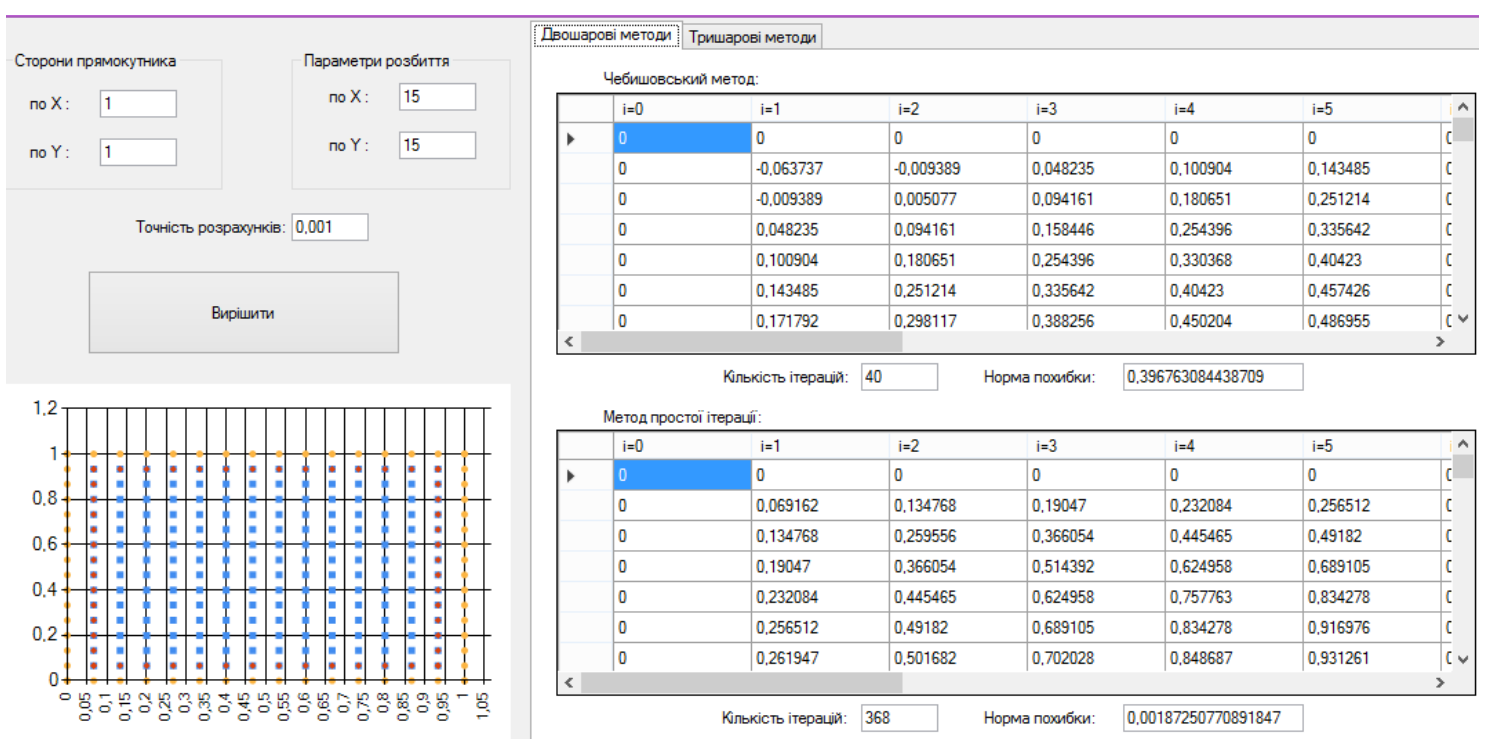

Рис. 3 - Інтерфейс продукту 
Також результати роботи програми формуються у вигляді текстового файлу. Так, за допомогою математичного пакету Maple будуються графіки отриманих розв'язків, що надає можливість візуально оцінити їх точність у порівнянні з точним розв'язком, отриманим у цьому ж пакеті.

Модельна задача 1. Розглянемо задачу знаходження неперервної в квадраті функції, яка задовольняє рівняння (1) при

$$
\begin{gathered}
f\left(x_{1} ; x_{2}\right)=-4 x_{1} \cos x_{2}+3 x_{1}^{2} x_{2} \sin x_{2}-2 x_{1}^{2}\left[\cos x_{2}-x_{2} \sin x_{2}\right]+x_{1}^{2}\left[\sin x_{2}+x_{2} \cos x_{2}\right] ; \\
k_{11}(x)=x_{1}, \quad k_{12}(x)=k_{21}(x)=x_{1} x_{2}, k_{22}(x)=x_{2}
\end{gathered}
$$

та крайові умови

$$
u(x)=g(x)=x_{1}^{2} \cos x_{2}, x \in \Gamma,
$$

де $\Gamma$ - межа $\bar{G}, x=\left(x_{1} ; x_{2}\right)$. Будемо вважати, що умови (3), (4) виконані. Точний розв'язок цієї задачі відомий в $\bar{G}$ і дорівнює

$$
u\left(x_{1} ; x_{2}\right)=x_{1}^{2} \cos x_{2} .
$$

Нескладно бачити, що властивості вихідних даних $f(x), g(x),(\alpha, \beta=1,2)$ такі, що задача (1), (2) має єдиний розв'язок, який становить гладку функцію в області . Графік розв'язку зображено на рис. 4.

Отже, перейдемо для розв'язання задачі (1), (6) методом скінченних різниць при значенні точності розрахунків $\varepsilon=0.001$. Враховуючи, що коефіцієнти при мішаних похідних не змінюють свій знак, для розв'язання задачі нами можуть бути використанні схеми (7), (14) та (15), які задовольнятимуть властивості монотонності та консервативності.

За допомогою розробленого програмного продукту було проведено експеримент з використанням різницевих схем (7), (14), (15) при різних розбиттях сітки. В табл. 1 та табл. 2 зображені загальні відомості про результати до проведених експериментів.

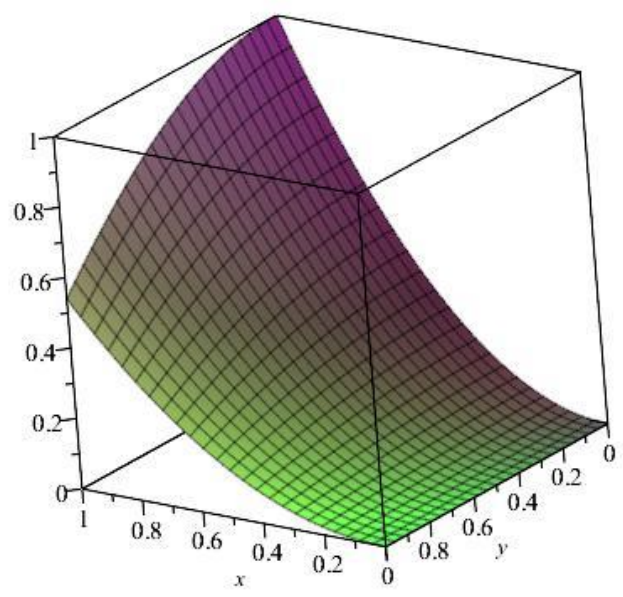

Рис.4 - Графік розв'язку

Провівши експерименти при різних значеннях параметрів сітки, можемо зробити такі висновки: для апроксимації диференціального оператора (1) краще всього обирати різницевий оператор (15) другого порядку точності, а 
для розв'язання операторного рівняння (19) найкращім вибором є тришаровий напівітераційний метод Чебишова другого порядку точності.

Таблиия 1

Результати для другої модельної задачі при розбитті сітки $5 \times 5$

\begin{tabular}{|c|c|c|c|c|c|c|c|c|c|}
\hline \multirow{2}{*}{$\begin{array}{c}\text { Ітераційний } \\
\text { метод }\end{array}$} & \multicolumn{3}{|c|}{$\begin{array}{l}\text { Перша різницева схема } \\
\text { 3 точністю } O(h)\end{array}$} & $\begin{array}{c}\text { Друга різницева схема } \\
\text { 3 точністю } O\left(h^{2}\right) \text { та } \\
\text { семиточковим } \\
\text { шаблоном }\end{array}$ & $\begin{array}{c}\text { Третя різницева схема } \\
\text { 3 точністю } O\left(h^{2}\right) \text { та } \\
\text { дев'ятиточковим } \\
\text { шаблоном }\end{array}$ \\
\cline { 2 - 11 } & $n$ & $\begin{array}{c}\text { Норма } \\
\text { похибки }\end{array}$ & $\begin{array}{c}\text { Час } \\
\text { рахун } \\
\text { ку, мс }\end{array}$ & $n$ & $\begin{array}{c}\text { Норма } \\
\text { похибки }\end{array}$ & $\begin{array}{c}\text { Час } \\
\text { рахун } \\
\text { ку, мс }\end{array}$ & $n$ & $\begin{array}{c}\text { Норма } \\
\text { похибки }\end{array}$ & $\begin{array}{c}\text { Час } \\
\text { рахун } \\
\text { ку, мс }\end{array}$ \\
\hline IMЧ & 14 & 0,128115 & 21 & 14 & 0,086434 & 28 & 14 & 0,122756 & 22 \\
\hline МПI & 47 & 0,696711 & 12 & 44 & 0,027417 & 13 & 44 & 0,001411 & 14 \\
\hline НМЧ & 14 & 0,702594 & 7 & 14 & 0,027417 & 7 & 14 & 0,001411 & 6 \\
\hline СІМ & 14 & 0,723746 & 3 & 14 & 0,027459 & 3 & 14 & 0,001411 & 4 \\
\hline
\end{tabular}

Таблиця 2

Результати для другої модельної задачі при розбитті сітки $10 \times 15$

\begin{tabular}{|c|c|c|c|c|c|c|c|c|c|}
\hline \multirow{2}{*}{$\begin{array}{c}\text { Iтераційний } \\
\text { метод }\end{array}$} & \multicolumn{3}{|c|}{$\begin{array}{l}\text { Перша різницева схема } \\
\text { 3 точністю } O(h)\end{array}$} & $\begin{array}{c}\text { Друга різницева схема } \\
\text { 3 точністю } O\left(h^{2}\right) \text { та } \\
\text { семиточковим } \\
\text { шаблоном }\end{array}$ & $\begin{array}{c}\text { Третя різницева схема } \\
\text { 3 точністю } O\left(h^{2}\right) \text { та } \\
\text { дев'ятиточковим } \\
\text { шаблоном }\end{array}$ \\
\cline { 2 - 11 } & $n$ & $\begin{array}{c}\text { Норма } \\
\text { похибки }\end{array}$ & $\begin{array}{c}\text { Час } \\
\text { рахун } \\
\text { ку, мс }\end{array}$ & $n$ & $\begin{array}{c}\text { Норма } \\
\text { похибки }\end{array}$ & $\begin{array}{c}\text { Час } \\
\text { рахун } \\
\text { ку, мс }\end{array}$ & $n$ & $\begin{array}{c}\text { Норма } \\
\text { похибки }\end{array}$ & $\begin{array}{c}\text { Час } \\
\text { рахун } \\
\text { ку, мс }\end{array}$ \\
\hline IMЧ & 38 & 0,09719 & 61 & 36 & 0,06451 & 64 & 42 & 0,042836 & 99 \\
\hline МПІ & 347 & 0,015657 & 102 & 301 & 0,003095 & 119 & 477 & 0,000134 & 234 \\
\hline НМЧ & 38 & 0,015657 & 16 & 36 & 0,003095 & 18 & 42 & 0,000134 & 30 \\
\hline СІМ & 38 & 0,015657 & 17 & 36 & 0,004396 & 19 & 42 & 0,000129 & 30 \\
\hline
\end{tabular}

Для візуалізації отриманих результатів надаються графіки розв'язків, побудованих з використанням першої, другої та третьої різницевих схем та тришарового напівітераційного методу Чебишова при розбитті сітки $5 \times 5$ (рис. 5) та при розбитті сітки $10 \times 15$ (рис. 6).
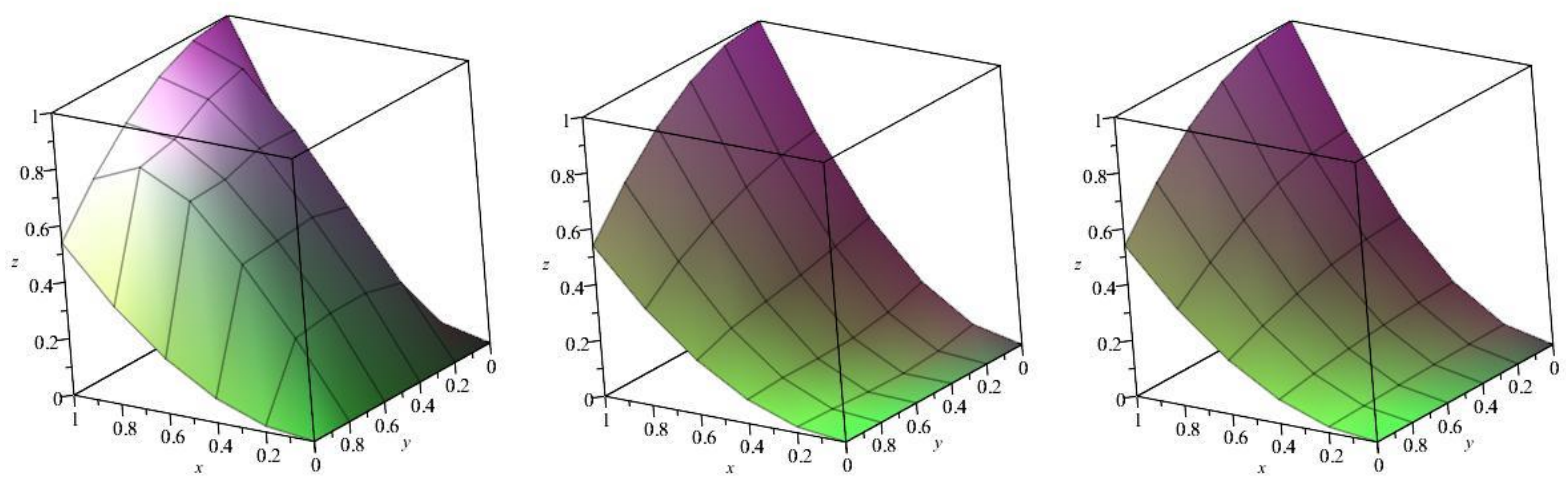

Рис. 5 - Графіки розв'язків, побудованих з використанням першої, другої та третьої різницевих схем відповідно та тришарового напівітераційного методу Чебишова 

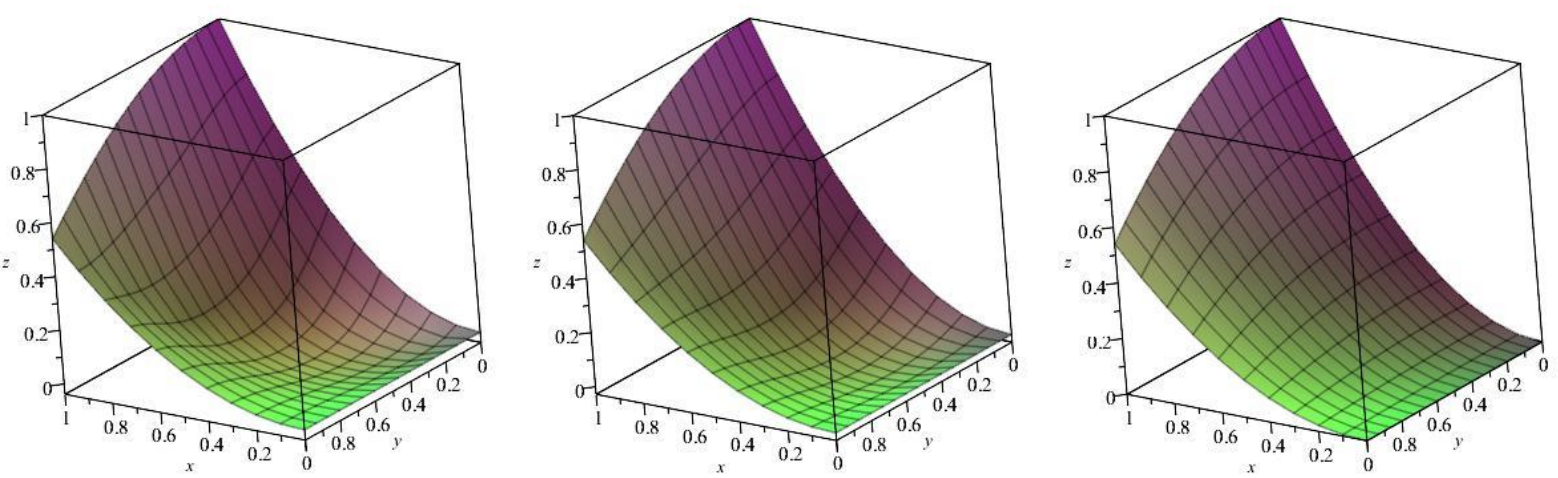

Рис. 6 - Графіки розв'язків, побудованих з використанням першої, другої та третьої різницевих схем відповідно та тришарового напівітераційного методу Чебишова

Модельна задача 2. Розглянемо задачу знаходження неперервної в квадраті функції, яка задовольняє рівняння (1) при

$$
\begin{gathered}
f\left(x_{1} ; x_{2}\right)=32 \sin \left(4 x_{1}\right) \sin \left(4 x_{2}\right)-4 \cos x_{1}\left[4 \cos \left(x_{1}+x_{2}\right) \cos x_{2}-\sin x_{2} \sin \left(x_{1}+x_{2}\right)\right]- \\
-4 \cos x_{2}\left[4 \cos \left(x_{1}+x_{2}\right) \cos x_{1}-\sin x_{1} \sin \left(x_{1}+x_{2}\right)\right] \\
k_{11}(x)=k_{22}(x)=1, \quad k_{12}(x)=k_{21}(x)=\cos \left(x_{1}+x_{2}\right)
\end{gathered}
$$

та крайові умови

$$
u(x)=g(x)=\sin \left(4 x_{1}\right) \sin \left(4 x_{2}\right), \quad x \in \Gamma,
$$

де $\Gamma$ - межа $\bar{G}, x=\left(x_{1} ; x_{2}\right)$. Будемо вважати, що умови (3), (4) виконані. Точний розв'язок цієї задачі відомий в $\bar{G}$ і дорівнює

$$
u\left(x_{1} ; x_{2}\right)=\sin \left(4 x_{1}\right) \sin \left(4 x_{2}\right) .
$$

Нескладно бачити, що властивості вихідних даних $f(x), g(x),(\alpha, \beta=1,2)$ такі, що задача (1), (2) має єдиний розв'язок, який становить гладку функцію в області . Графік розв'язку зображено на рис. 7.

У модельній задачі 2 ми розглянемо пошук розв'язку задачі (1), (2) методом скінченних різниць при значенні точності розрахунків $\varepsilon=0.001$ для коефіцієнтів при мішаних похідних, що змінюють свій знак. Оскільки в цьому випадку схеми (7), (14) та (15) не є придатними, використаємо схему (16), (17), яка вирішує проблему змінних знаків коефіцієнтів при мішаних похідних та задовольняє властивості монотонності й консервативності.

Схема (16), (17) має другий порядок апроксимації диференціального оператора (1) та має шаблон с дев'ятьма точками (рис. 2). Для проведення якісного порівняльного аналізу будемо розв'язувати задачу, використовуючи не тільки схему (16), (17), але й схему (14), з урахуванням заміни (17).

За допомогою розробленого програмного продукту було проведено експерименти, з використанням зазначених вище різницевих схем при різних розбиттях сітки. 3 результатами можна ознайомитися в таблицях 3 та 4 . 


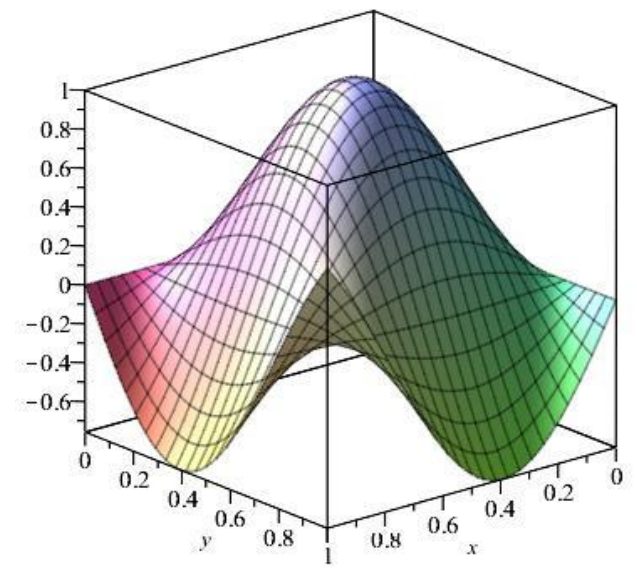

Рис. 7 - Графік розв'язку задачі

Таблиия 3

Результати для третьої модельної задачі при розбитті сітки $10 \times 10$

\begin{tabular}{|c|c|c|c|c|c|c|}
\hline \multirow{2}{*}{$\begin{array}{c}\text { Iтераційний } \\
\text { метод }\end{array}$} & \multicolumn{3}{|c|}{$\begin{array}{c}\text { Перша різницева схема } \\
\text { 3 точністю та семиточковим } \\
\text { шаблоном }\end{array}$} & \multicolumn{3}{|c|}{$\begin{array}{c}\text { Друга різницева схема } \\
\text { 3 точністю та дев’ятиточковим } \\
\text { шаблоном }\end{array}$} \\
\cline { 2 - 7 } & $n$ & $\begin{array}{c}\text { Норма } \\
\text { похибки }\end{array}$ & $\begin{array}{c}\text { Час рахунку, } \\
\text { мс }\end{array}$ & $n$ & $\begin{array}{c}\text { Норма } \\
\text { похибки }\end{array}$ & $\begin{array}{c}\text { Час } \\
\text { рахунку, мс }\end{array}$ \\
\hline IМЧ & 24 & 0,969810 & 53 & 24 & 0,468357 & 56 \\
\hline МПІ & 138 & 1,280824 & 54 & 138 & 0,02281 & 59 \\
\hline НМЧ & 24 & 1,280825 & 10 & 24 & 0,022826 & 9 \\
\hline СІМ & 24 & 1,277643 & 10 & 24 & 0,017973 & 10 \\
\hline
\end{tabular}

Таблиия 4

Результати для третьої модельної задачі при розбитті сітки

\begin{tabular}{|c|c|c|c|c|c|c|}
\hline \multirow{2}{*}{$\begin{array}{c}\text { Iтераційний } \\
\text { метод }\end{array}$} & \multicolumn{3}{|c|}{$\begin{array}{c}\text { Перша різницева схема } \\
\text { 3 точністю та семиточковим } \\
\text { шаблоном }\end{array}$} & \multicolumn{3}{|c|}{$\begin{array}{c}\text { Друга різницева схема } \\
\text { з точністю та дев'ятиточковим } \\
\text { шаблоном }\end{array}$} \\
\cline { 2 - 7 } & $n$ & $\begin{array}{c}\text { Норма } \\
\text { похибки }\end{array}$ & $n$ & $\begin{array}{c}\text { Норма } \\
\text { похибки }\end{array}$ & $\begin{array}{c}\text { Норма } \\
\text { похибки }\end{array}$ & $\begin{array}{c}\text { Час } \\
\text { рахунку, мс }\end{array}$ \\
\hline IMЧ & 56 & 0,593492 & 117 & 44 & 0,374173 & 117 \\
\hline МПІ & 581 & 0,925466 & 219 & 447 & 0,001871 & 196 \\
\hline НМЧ & 56 & 0,925466 & 34 & 44 & 0,001874 & 28 \\
\hline СІМ & 56 & 0,925228 & 38 & 44 & 0,001068 & 27 \\
\hline
\end{tabular}

Проглянувши таблиці, бачимо, що значно збільшились кількість ітерацій та час рахунку методів при розв'язання такого типу задач.

Для візуалізації отриманих результатів надаються графіки розв'язків, побудованих з використанням першої, другої та третьої різницевих схем та тришарового напівітераційного методу Чебишова при розбитті сітки $10 \times 10$ (рис. 8) та при розбитті сітки $20 \times 15$ (рис. 9). 

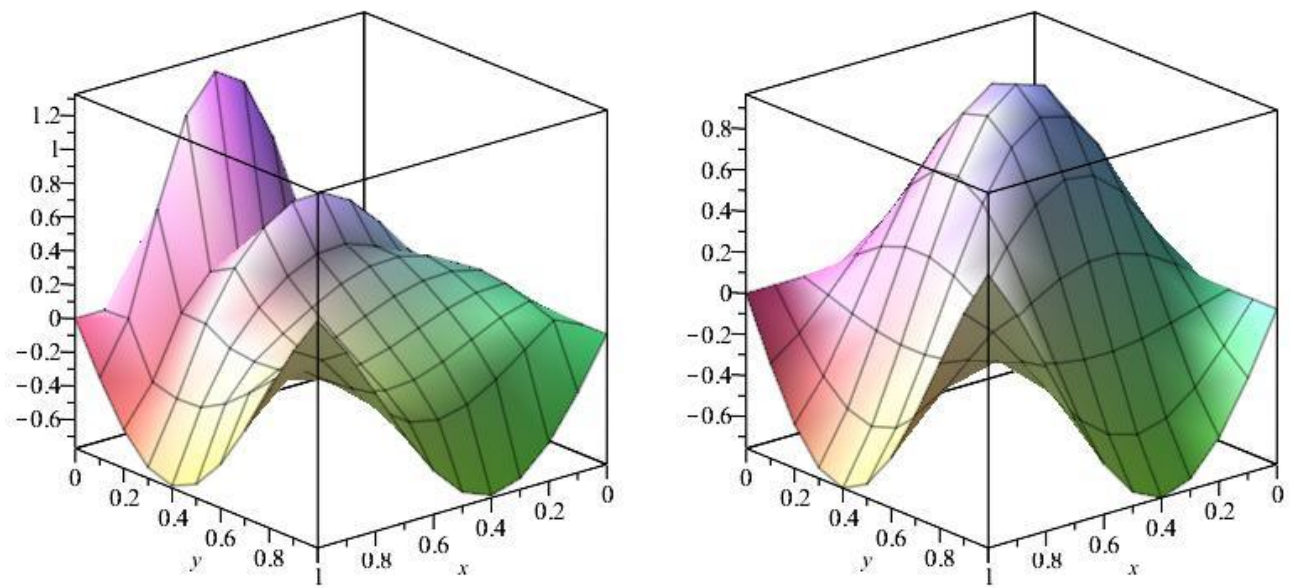

Рис. 8 - Графіки розв'язків, побудованих з використанням першої та другої різницевих схем відповідно та тришарового напівітераційного методу Чебишова
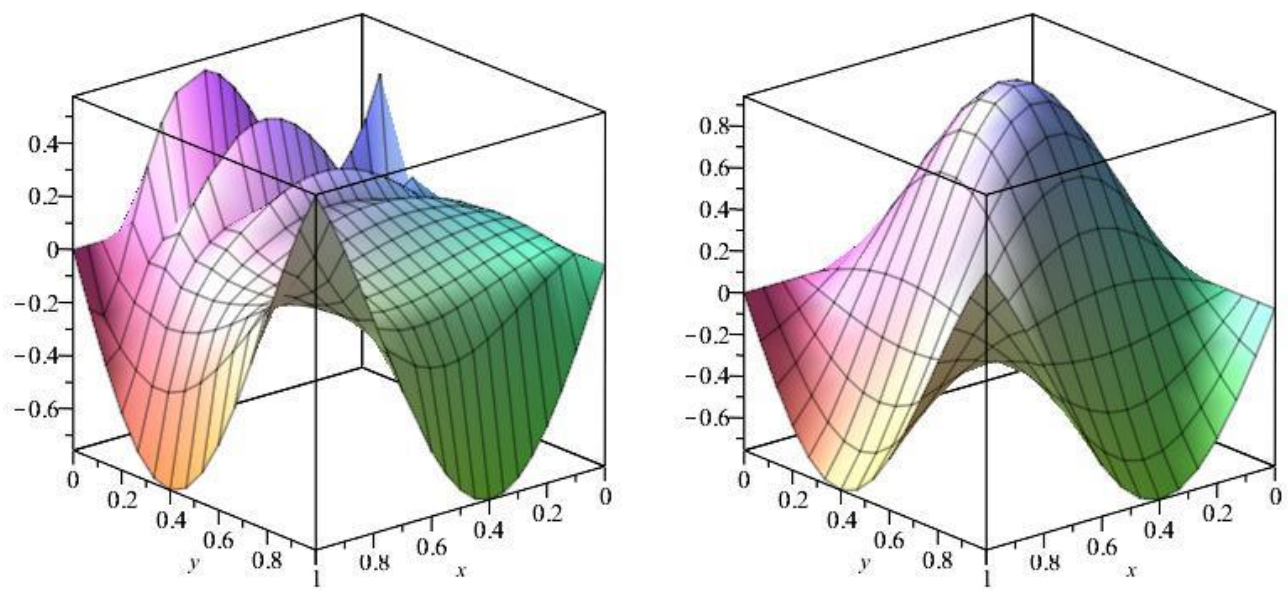

Рис. 9 - Графіки розв'язків, побудованих з використанням першої та другої різницевих схем відповідно та тришарового напівітераційного методу Чебишова

Висновки. Було проведено аналіз серед різноманітних сучасних методів розв'язання даної задачі та на його основі обраний найбільш поширений i універсальний метод - метод скінченних різниць. Тож, були побудовані обчислювальні алгоритми різницевих схем різних порядків апроксимації. При цьому було збережено важливі властивості монотонності i консервативності. Для цього були використані спеціальні різницеві схеми для еліптичних рівнянь 3 мішаними похідними для коефіціснтів $k_{\alpha \beta}$ при мішаних похідних, які змінюють свій знак. Також були побудовані обчислювальні алгоритми для розв'язання системи різницевих рівнянь, яка має специфічний вигляд.

На основі розроблених алгоритмів був створений програмний продукт та проведено порівняльний аналіз результатів роботи реалізованих методів на прикладі модельних задач різного типу.

Розглянута проблема є дуже важливою, оскільки на практиці виникають все більш і більш складні постановки задач для диференціальних рівнянь 
еліптичного типу, які вимагають як розробки нових методів, так i розширення області застосування вже існуючих методів. При цьому відбувається переоцінка порівняльних характеристик різних методів.

Результати даної роботи можуть бути застосовані під час розробки ефективних обчислювальних схем більш високих порядків точності для розв'язання еліптичних диференціальних рівнянь 3 мішаними похідними, в тому числі за крайових умов інших типів; при дослідженні різницевих схем і відповідних ітераційних алгоритмів під час розв'язання інших класів стаціонарних і нестаціонарних задач математичної фізики та оптимального керування.

\section{Бібліографічні посилання}

1. Kim, S. Microhydrodynamics: Principles and Selected Applications [Текст] / S. Kim, S. J. Karrila. - Dover, 2005.

2. Тихонов, А.Н., Самарский, А.А. Уравнения математической физики [Текст] / А.Н. Тихонов, А.А. Самарский. - М., «Наука», 1972.

3. Самарский, А.А. Разностные методы для эллиптических уравнений [Текст] / А.А. Самарский, В.Б. Андреев. - М.: Наука, 1976.

4. Matus, P. Computational methods in applied mathematics [Текст] / P. Matus, I. Rybak., 2004, no.4, pp.494-505.

5. Samarskii, A.A. The theory of difference schemes [Текст] / A.A. Samarskii. - New York: Basel. Marcel Dekker, Inc, 2001.

6. Вазов, В. Разностные методы решения дифференциальных уравнений в частных производных [Текст] / В. Вазов, Дж. Форсайт. - М., ИЛ, 1963.

7. Ладыженская, О.А. Краевые задачи математической физики [Текст] / О.А. Ладыженская. - М., 1973.

8. Самарский, А.А. Введение в теорию разностных схем [Текст] / А.А. Самарский. - М.: Наука, 1971.

9. Rybak, I.V. Monotone and conservative difference schemes for elliptic equations with mixed derivatives [Текст] / I. V. Rybak. - Dover, 2004 .

10. Балашова, С.Д. Чисельні методи. Частина 2. Методи розв'язання диференціальних та інтегральних рівнянь [Текст] / С.Д. Балашова. - Київ, 1992.

11. Сьярле, Ф. Метод конечных элементов для эллиптических задач: пер. с англ. [Текст] / Ф. Сьярле. - М.: Мир, 1980.

12. Самарский, А. А. Методы решения сеточных уравнений [Текст] / А.А. Самарский, Е.С. Николаев. - М.: Наука, 1978.

Надійшла до редколегіï 21.06.2019. 


\author{
В.Г. Городецький \\ Національний технічний університет України \\ «Київський політехнічний інститут імені Ігоря Сікорського»
}

\title{
ІДЕНТИФІКАЦІЯ МОДЕЛІ ГІДРОІМПУЛЬСНОЇ СИСТЕМИ 3 ПЕРІОДИЧНОЮ ЗОВНІШНЬОЮ ДІЄЮ
}

\begin{abstract}
Розглянуто задачу ідентифікації моделі гідроімпульсної системи у вигляді неавтономної системи звичайних диференціальних рівнянь. Використано алгоритм, який дозволяс визначити параметри моделі при відомій спостережуваній змінній та неповній інформації про зовнішню дію. При цьому спостережувана змінна може мати як регулярний так і хаотичний характер.

Ключові слова: ідентифікація, гідроімпульсна система, звичайні диференціальні рівняння, періодична зовнішня дія.
\end{abstract}

Рассмотрена задача идентификации модели гидроимпульсной системы в виде неавтономной системы обыкновенных дифференциальных уравнений. Использован алгоритм, который позволяет определить параметры модели при известной наблюдаемой переменной и неполной информации о внешнем воздействии. При этом наблюдаемая переменная может иметь как регулярный так и хаотичный характер.

Ключевые слова: идентификация, гидроимпульсная система, обыкновенные дифференциальные уравнения, периодическое внешнее воздействие.

Functioning of hydro-impulse systems, usually involves the existence of some periodic external action, that determines the type of model. In this case they use, as a mathematical model, non-autonomous system of ordinary differential equations. Sometimes external action information is incomplete or absent. This may complicate the modeling task. For example, in the operation of hydro-pulse systems, not only their constant parameters but also the type of external action may be unknown.

This study is devoted to the identification of a model of a hydro-impulse system in the form of a non-autonomous system of ordinary differential equations. The general form of the equations and one of the observed variables of the system are known, while the constant coefficients of the equations are unknown. We consider the identification problem when we know almost nothing about external action. Namely, we suppose that only its periodic character is known, and its form, period, and phase shift are unknown. Such a problem is obviously more complicated than a typical one, when the external action and the output are completely known, and only the constant coefficients of the equations of the system are to be found. As it is known, for some parameter sets and periodic external action, the observed variable may not be periodic, which makes it impossible to determine the period and other parameters of external oscillations in a simple way. Therefore, identification of the external action is also part of the formulated task. To solve this problem we use algorithm that allows to determine the model parameters with utilizing a known observed variable and incomplete information on the external action. Moreover, the observed variable can be either regular or chaotic.

Key words: identification, hydro-impulse system, ordinary differential equations, periodic external action.

(C) Городеиький В.Г., 2019 
Вступ. Розробка математичних моделей різних фізичних систем передбачає використання двох основних підходів, а саме, - розв'язок прямої або оберненої задачі [1]. Особливістю останнього є можливість використати реальні експериментальні або експлуатаційні дані про досліджуваний процес для побудови адекватної моделі. Функціонування гідроімпульсних систем, зазвичай передбачає існування деякої періодичної зовнішньої дії [2], що визначає вид моделі. В цьому випадку при використанні в якості моделей систем звичайних диференціальних рівнянь, вони повинні бути неавтономними. Ця обставина може ускладнити задачу моделювання, якщо інформація про зовнішню дію $є$ неповною, або взагалі відсутня. Наприклад, при функціонуванні гідроімпульсних систем можуть бути невідомі не тільки їх сталі параметри, але й вид зовнішньої дії.

Постановка задачі. Дане дослідження присвячене ідентифікації моделі гідроімпульсної системи у вигляді неавтономної системи звичайних диференціальних рівнянь. При цьому вважається відомим загальний вигляд рівнянь та одна із спостережуваних змінних системи, а невідомі - сталі коефіцієнти рівнянь. Щодо зовнішньої дії, то відомим вважаємо тільки іiі періодичний характер, а форма, період, фазовий зсув - невідомі. Така задача, очевидно, більш складна за типову, коли повністю відомі зовнішня дія та вихід, і треба знайти лише сталі коефіцієнти рівнянь системи.

Як буде показано далі, при деяких наборах параметрів і періодичній зовнішній дії спостережувана змінна може не бути періодичною, що не дозволяє просто визначити період та інші параметри зовнішніх коливань. Отже, ідентифікація самої зовнішньої дії $є$ також складовою сформульованої задачі.

Метод розв'язання та аналіз одержаних результатів. В якості об'єкта ідентифікації було взято одномасову модель гідромолота, запропоновану в [2]:

$$
m \ddot{x}+b \dot{x}+C(x) x=F(t) .
$$

В (1) $m$ - зведена маса гідромолота, $b$ - коефіцієнт затухання, $C(x)-$ нелінійна жорсткість, $F(t)$ - сила зовнішньої дії. Розглянемо випадок, коли $C(x)=c_{0}+c_{1} x^{2}$, де $c_{0}, c_{1}$ - сталі, а $F(t)=P \sin \left(\omega t+\varphi_{0}\right)$, де $P$ - амплітуда, $\omega$ - кругова частота коливань, $\varphi_{0}$ - початкова фаза. Було прийнято значення параметрів, близьких до реальних, а саме: $m=65, b=520, c_{0}=1,5 \cdot 10^{4}$, $c_{1}=1,5 \cdot 10^{7}, P=3,595 \cdot 10^{4}, \omega=31,416, \varphi_{0}=0$. Всі наведені параметри мають розмірність в одиницях системи СI.

Перетворимо (1) на систему

$$
\left\{\begin{array}{l}
\dot{x}_{1}=x_{2}, \\
\dot{x}_{2}=-b_{m} x_{2}-c_{0 m} x_{1}-c_{1 m} x_{1}^{3}+P_{m} \sin \left(\omega t+\varphi_{0}\right),
\end{array}\right.
$$


де $x_{1}=x, \quad b_{m}=b / m, c_{0 m}=c_{0} / m, c_{1 m}=c_{1} / m, P_{m}=P / m$. Система (2) була розв'язана методом Рунге-Кутта 4-го порядку на часовому інтервалі 5 с 3 кроком $5 \cdot 10^{-6}$ с після закінчення перехідного процесу. Розв'язки системи (2) представлені на рис. 1, а ії фазовий портрет - на рис. 2.
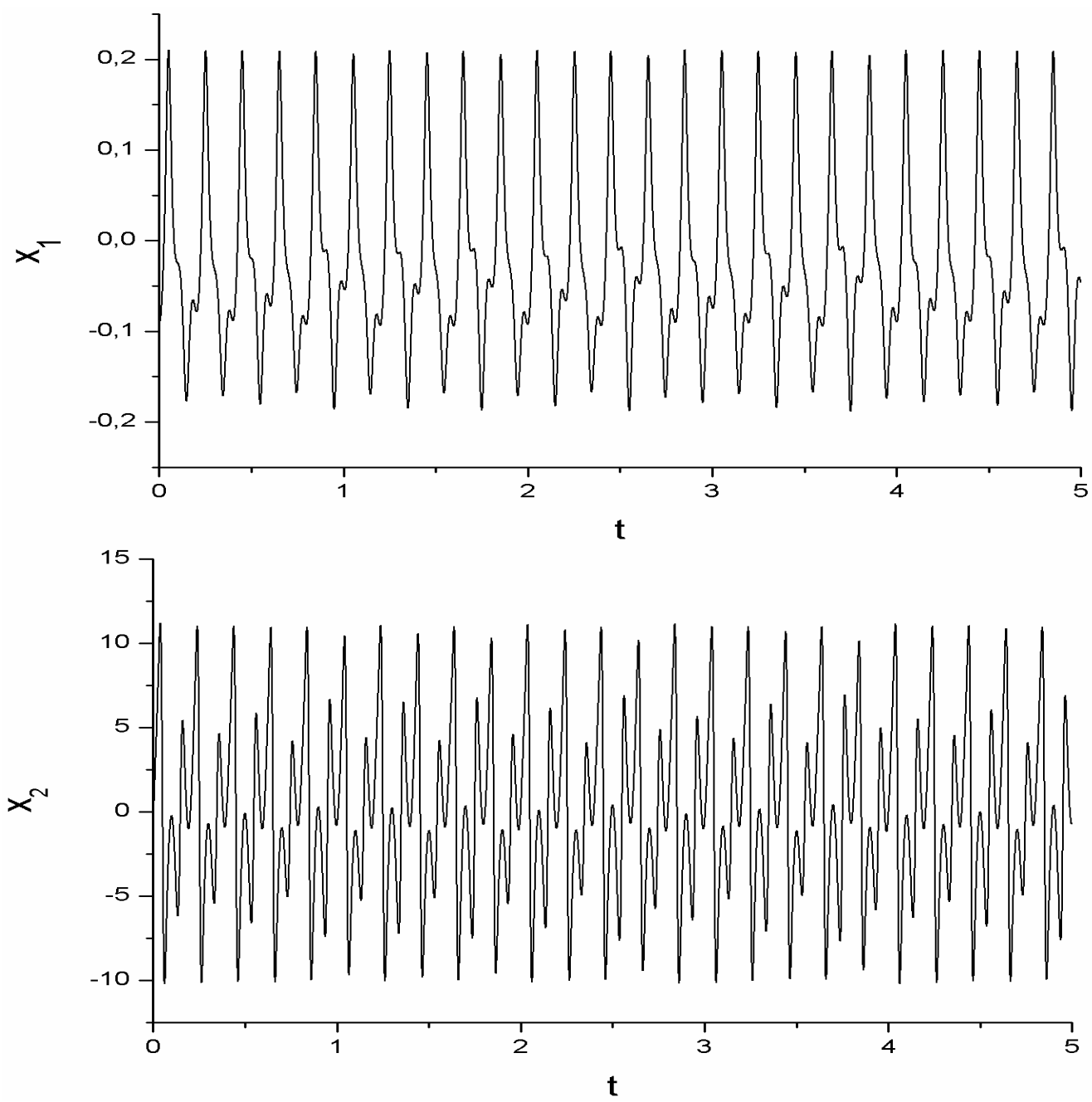

Рис. 1. Зміна у часі переміщення та швидкості зведеної маси гідромолоту в усталеному режимі

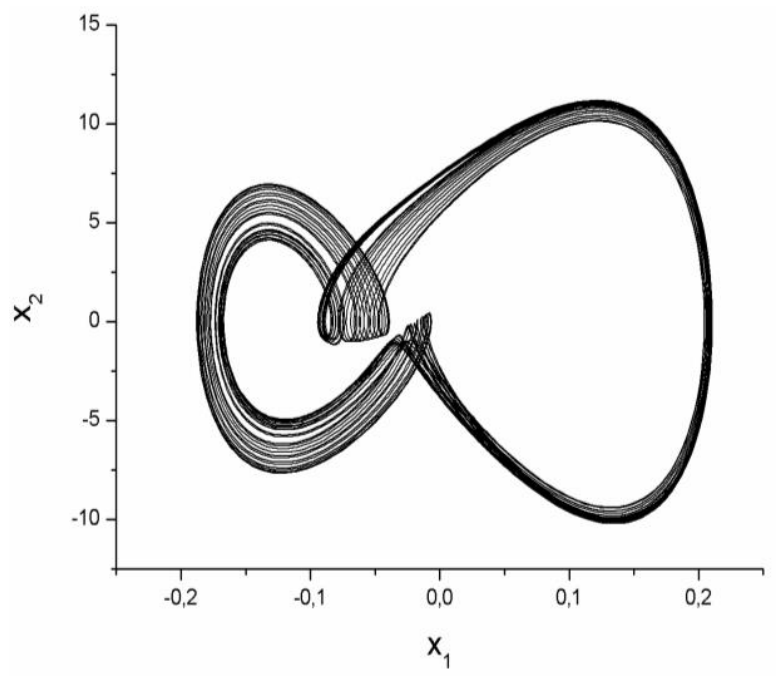

Рис. 2. Фазовий портрет системи (2) 
Як видно з фазового портрету системи (2), іï коливання не $є$ точно періодичними. Цей факт підтверджується і побудованим спектром системи, який наведено на рис. 3. Основна гармонічна складова, як видно на спектрі, має частоту 5 герц. В той же час вищі гармоніки не є точно кратними основній, що $є$ ознакою майже періодичних функцій [3] Ця особливість системи (2) ще більше проявляється при зміні параметрів. Наприклад, при зниженні коефіцієнту затухання в широкому діапазоні коливання мають ознаки хаотичних, спектр яких вже не є чітко дискретним [4]. Цей факт проілюстровано на рис. 4-6. В цьому випадку в рівнянні (1) прийнято $b=52, \varphi_{0}=0,6$, інші параметри залишилися незмінними. В результаті коефіцієнти системи (2) мають значення, наведені в таблиці 1.

Таблиия 1

Значення коефіціснтів системи (2) при $\mathrm{b}=52, \varphi_{0}=0.6$

\begin{tabular}{|c|c|c|c|}
\hline \multicolumn{4}{|c|}{ Коефіціснт } \\
\hline$b_{m}$ & $c_{0 m}$ & $c_{1 m}$ & $P_{m}$ \\
\hline 0.8 & 230.76923 & 230769.23076 & 553.07692 \\
\hline
\end{tabular}
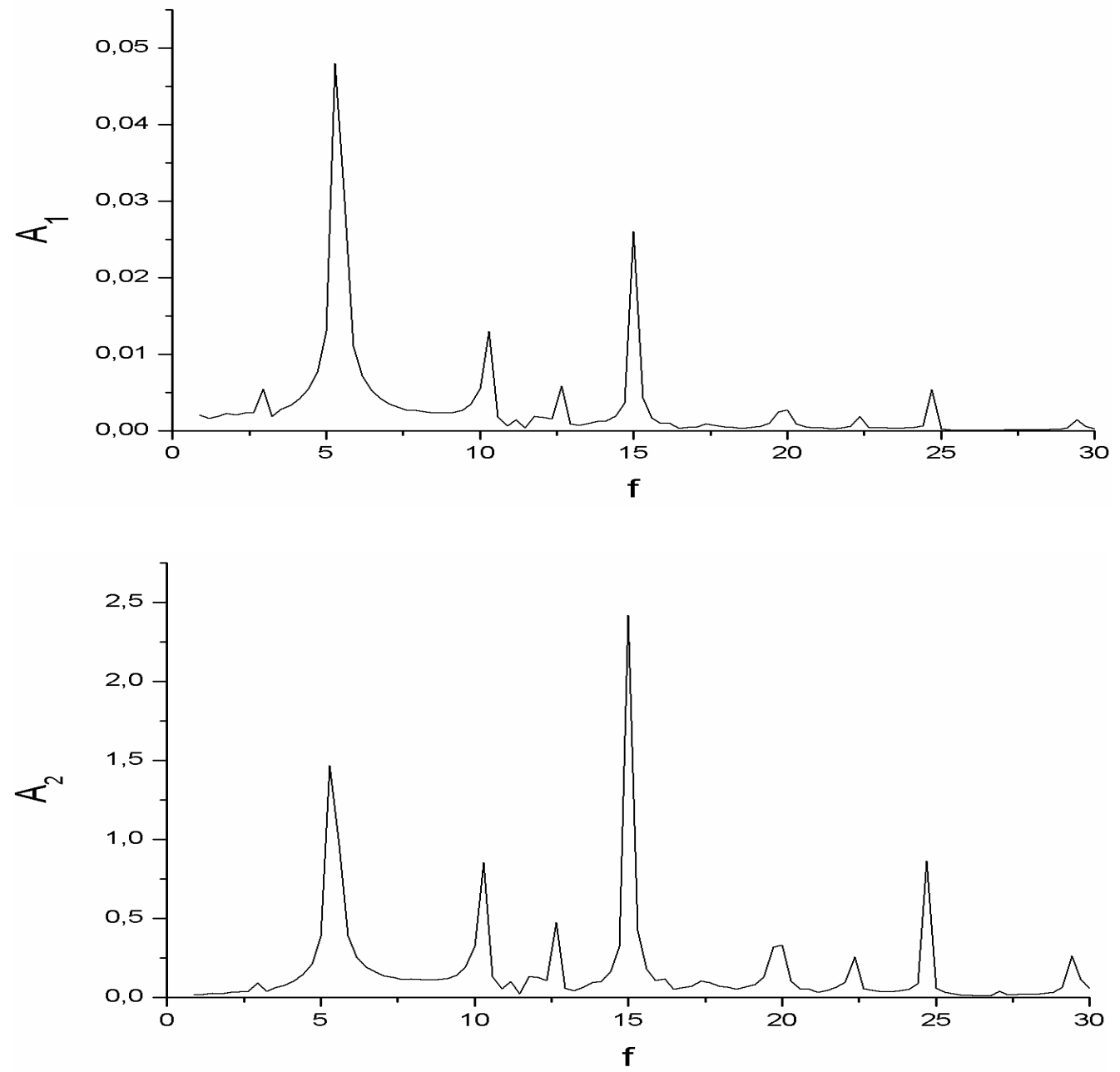

Рис. 3. Спектри функцій $x_{1}(t)$ та $x_{2}(t)$ 

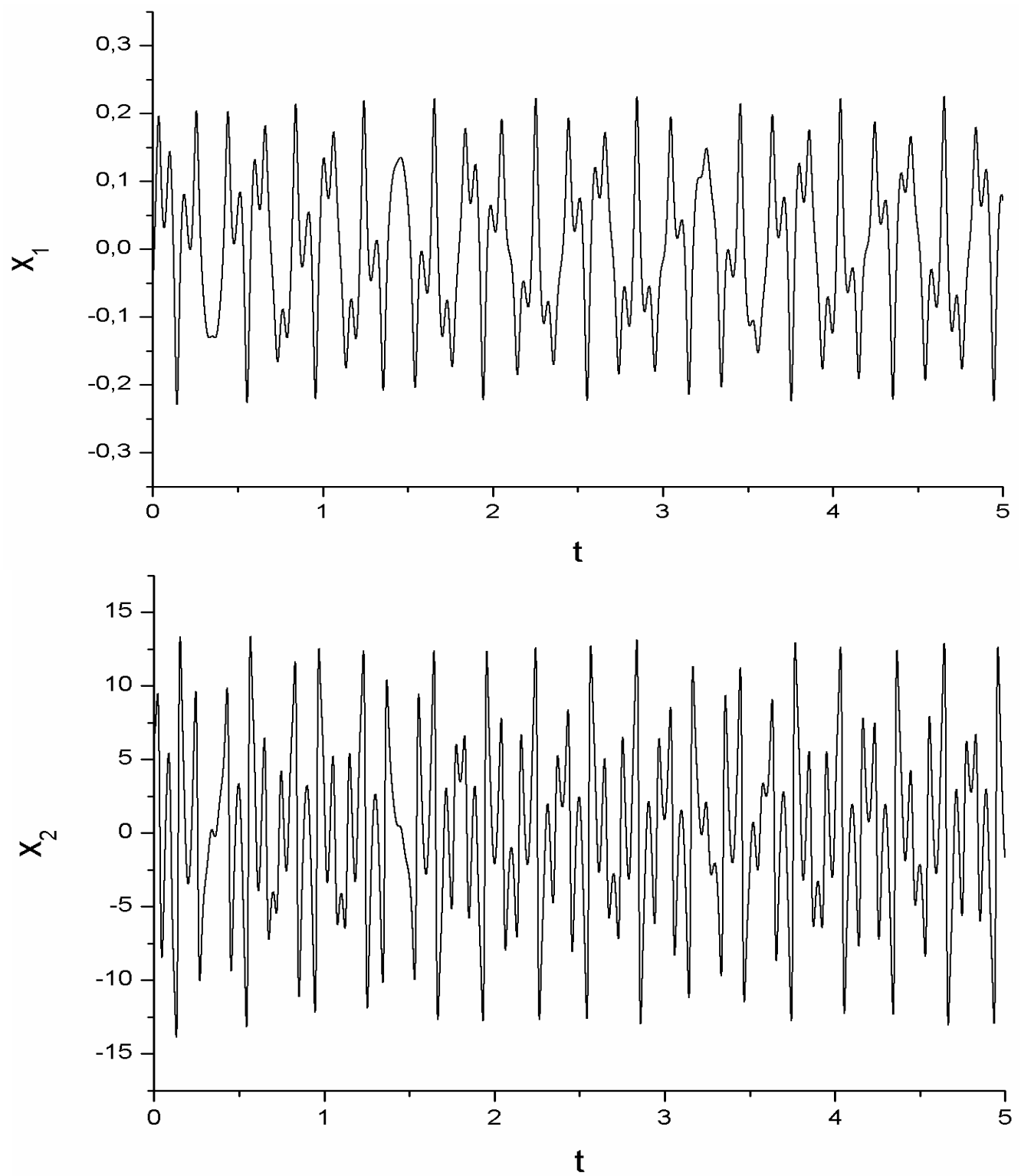

Рис. 4. Зміна у часі переміщення та швидкості зведеної маси гідромолоту

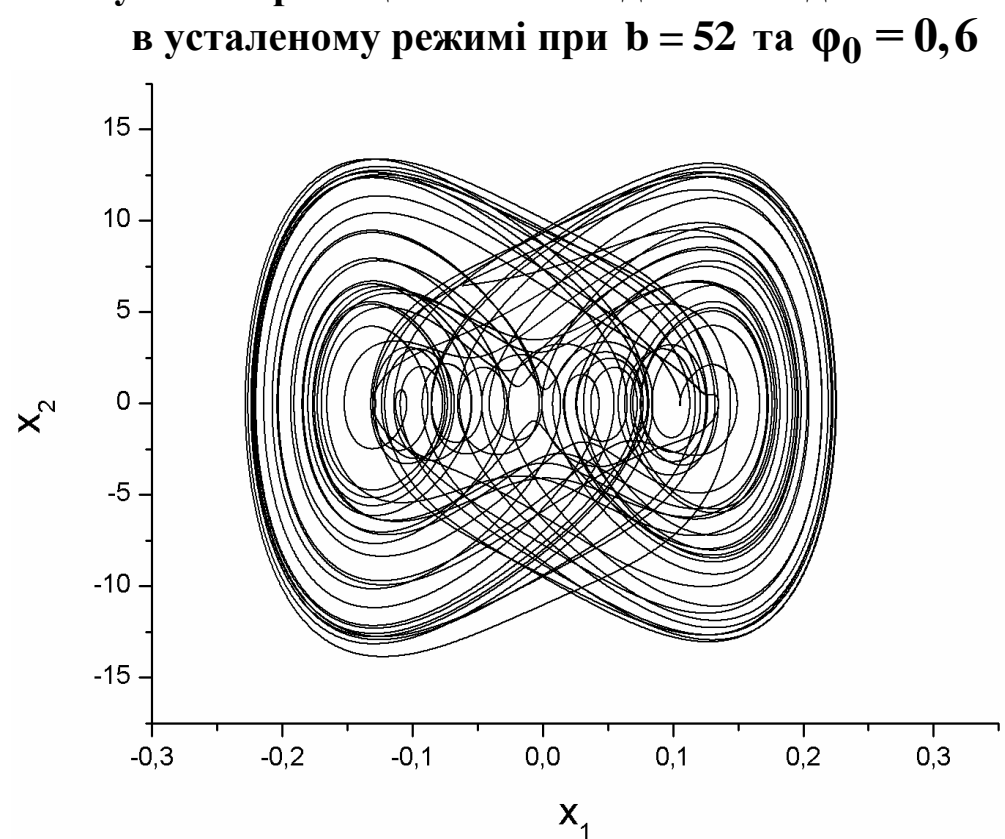

Рис. 5. Фазовий портрет системи (2) при $b=52$ 

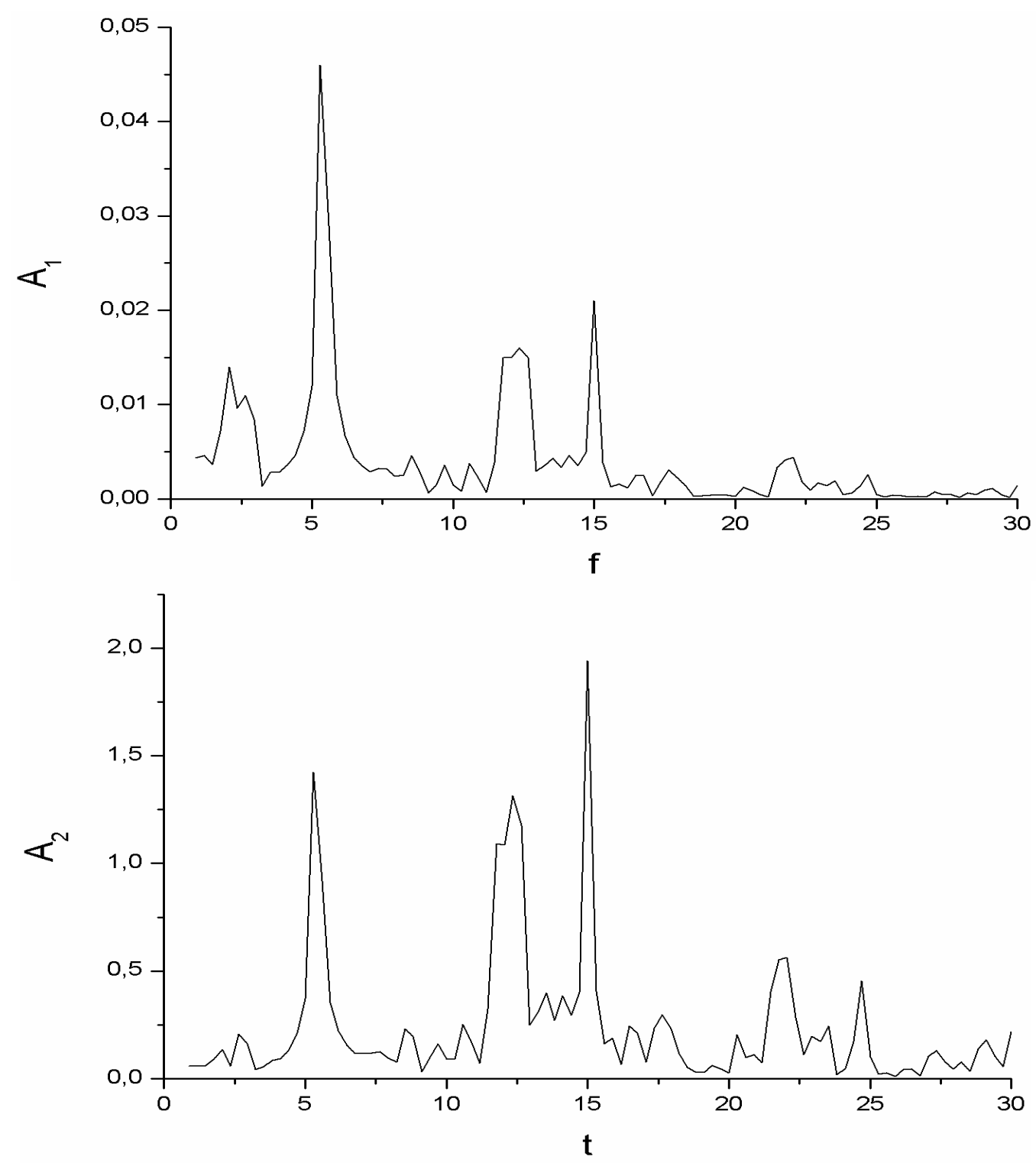

Рис. 6. Спектри функцій $\mathrm{x}_{1}(\mathrm{t})$ та $\mathrm{x}_{2}(\mathrm{t})$ системи (2) при $\mathrm{b}=52$

Якщо перед дослідником стоїть задача ідентифікації системи (2), то для іiі розв'язання в цьому разі за характером функцій $x_{1}(t)$ та $x_{2}(t)$ важко однозначно визначити навіть частоту зовнішньої дії, якщо остання невідома. Але ця проблема може бути вирішена 3 використанням метода, запропонованого в [5,6]. Для ідентифікації системи (2) були використані часові ряди, наведені на рис. 4. Вони отримані при значеннях коефіцієнтів системи (2), наведених в таблиці 1. Система розв'язувалась на часовому інтервалі 10 с 3 кроком $5 \cdot 10^{-4}$ с, тобто часовий ряд мав 20000 точок.

На першому етапі застосування алгоритму [6] були отримані значення сталих коефіцієнтів системи (2), період синусоїдальної вхідної дії та часовий ряд зміни величини $P_{m} \sin \left(\omega t+\varphi_{0}\right)$. Отримані величини коефіцієнтів наведені в таблиці 2, значення періоду співпало 3 заданим, тобто $T=0,2 c$, що відповідає 400 точкам часового ряду. 
Значення реконструйованих сталих коефіціснтів системи (2)

\begin{tabular}{|c|c|c|}
\hline$b_{m}$ & $c_{0 m}$ & $c_{1 m}$ \\
\hline 0.86511 & 235.42552 & 229859.21117 \\
\hline
\end{tabular}

На рис. 7 показано реконструкцію часового ряду $P_{m} \sin \left(\omega t+\varphi_{0}\right)$, яка має 16000 точок, а на рис. 8 - його початкову ділянку на проміжку від 0 до $T=400$ точок часового ряду. Треба відмітити, що відхилення деяких значень на рис. 7 та 8 від синусоїди пояснюються поганою обумовленістю матриці [7], яка формувалась для різних моментів часу і використовувалась для знаходження коефіцієнтів системи (2). Використовуючи дані часового ряду, наведеного на рис. 7, було отримано значення амплітуди шуканої синусоїди.

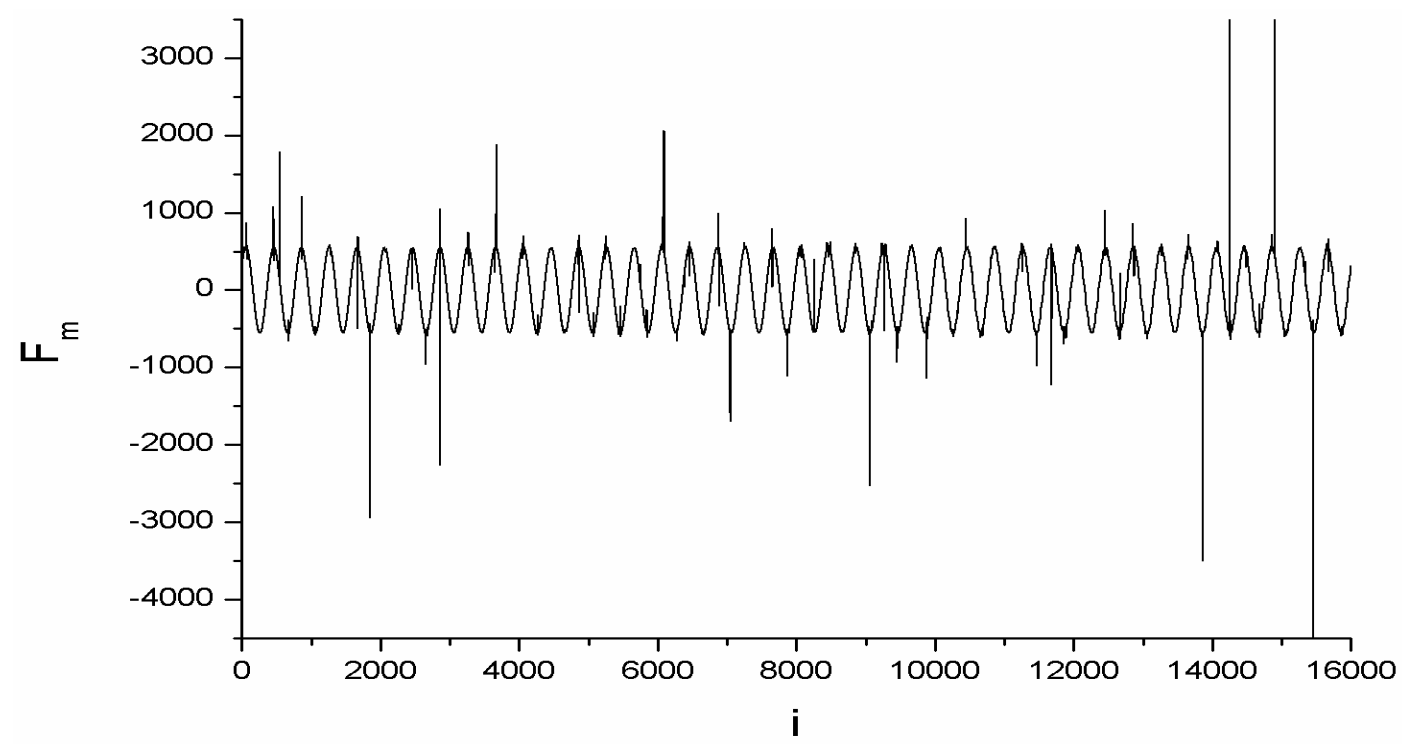

Рис. 7. Реконструйований часовий ряд функції зовнішньої дії $\mathbf{F}_{\mathbf{m}}=\mathbf{P}_{\mathbf{m}} \sin \left(\omega t+\varphi_{0}\right)$

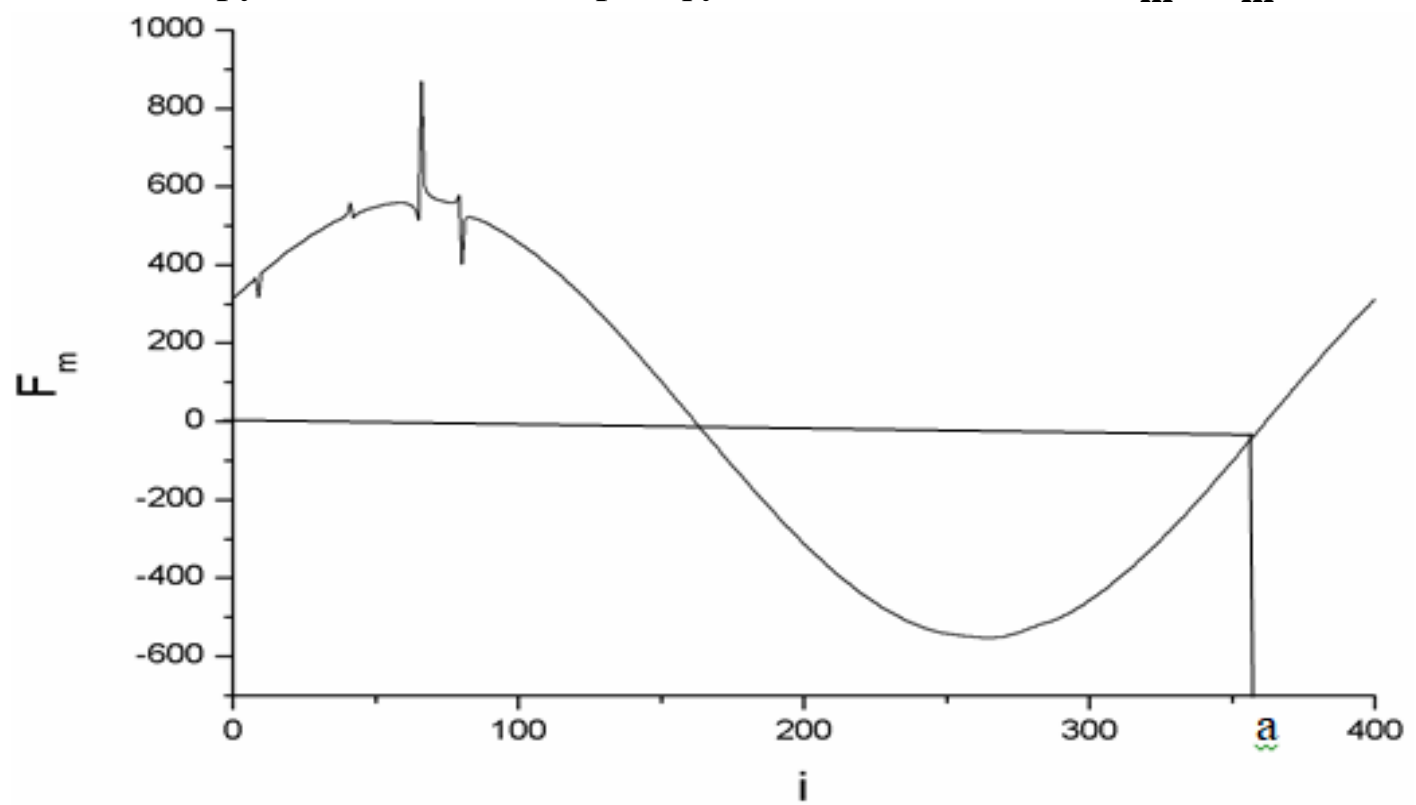

Рис. 8. Перший період реконструйованого часового ряду функції зовнішньої дії

$$
\mathbf{F}_{\mathbf{m}}=\mathbf{P}_{\mathbf{m}} \sin \left(\omega \mathrm{t}+\varphi_{0}\right)
$$


Після цього можна визначити фазовий зсув $\varphi_{0}$. Для цього достатньо, як показано на рис. 8, знайти точку на осі абсцис, яка відповідає значенню $F_{m}=0$. В точці а на рисунку $i=362$, тобто фазовий зсув складає 38 точок часового ряду, або $\varphi_{0}=0,59690$. Для порівняння остаточні значення коефіцієнтів реконструйованої системи та системи (2) наведені в таблиці 3.

Таблицяя 3

Порівняння значень коефіціснтів системи (2) та реконструйованої системи

\begin{tabular}{|c|c|c|c|c|c|c|}
\hline \multicolumn{7}{|c|}{ Значенн коефіцієнтів } \\
\hline Коефіцієнт & $b_{m}$ & $c_{0 m}$ & $c_{1 m}$ & $P_{m}$ & $\omega$ & $\varphi_{0}$ \\
\hline Система(2) & 0,8 & 230.76923 & 230769,23076 & 553,07692 & 0,2 & 0,6 \\
\hline $\begin{array}{c}\text { Реконструйова- } \\
\text { на система }\end{array}$ & 0.86511 & 235.42553 & 229859.21117 & 554,44000 & 0,2 & 0,59690 \\
\hline
\end{tabular}

При розв'язанні реконструйованої системи отримано часові ряди іiі функцій $x_{1}(t)$ та $x_{2}(t)$, їх спектри та фазовий портрет. Вони наведені на рис. 9-11.
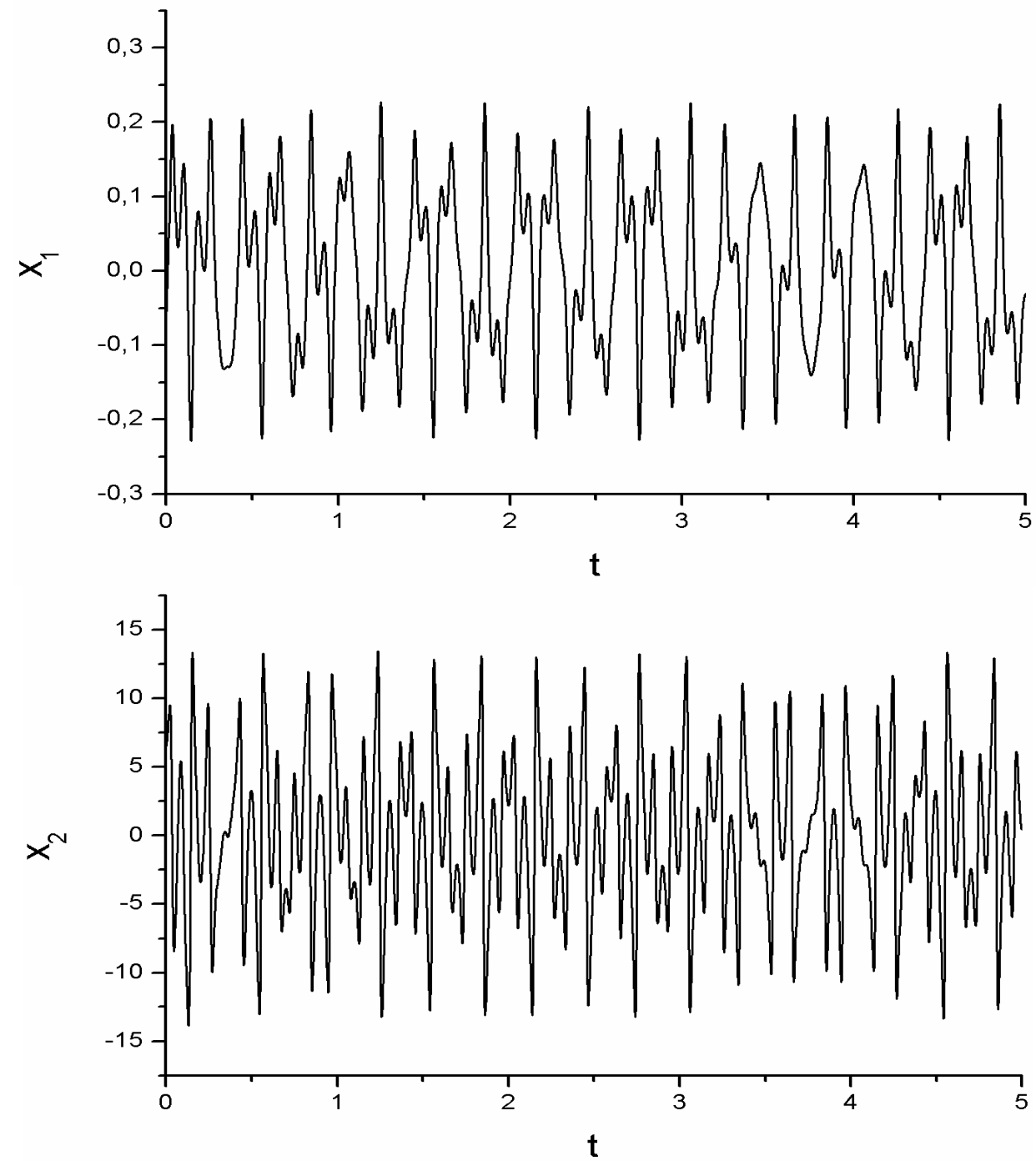

Рис. 9. Зміна у часі переміщення та швидкості реконструйованої моделі гідромолоту в усталеному режимі 


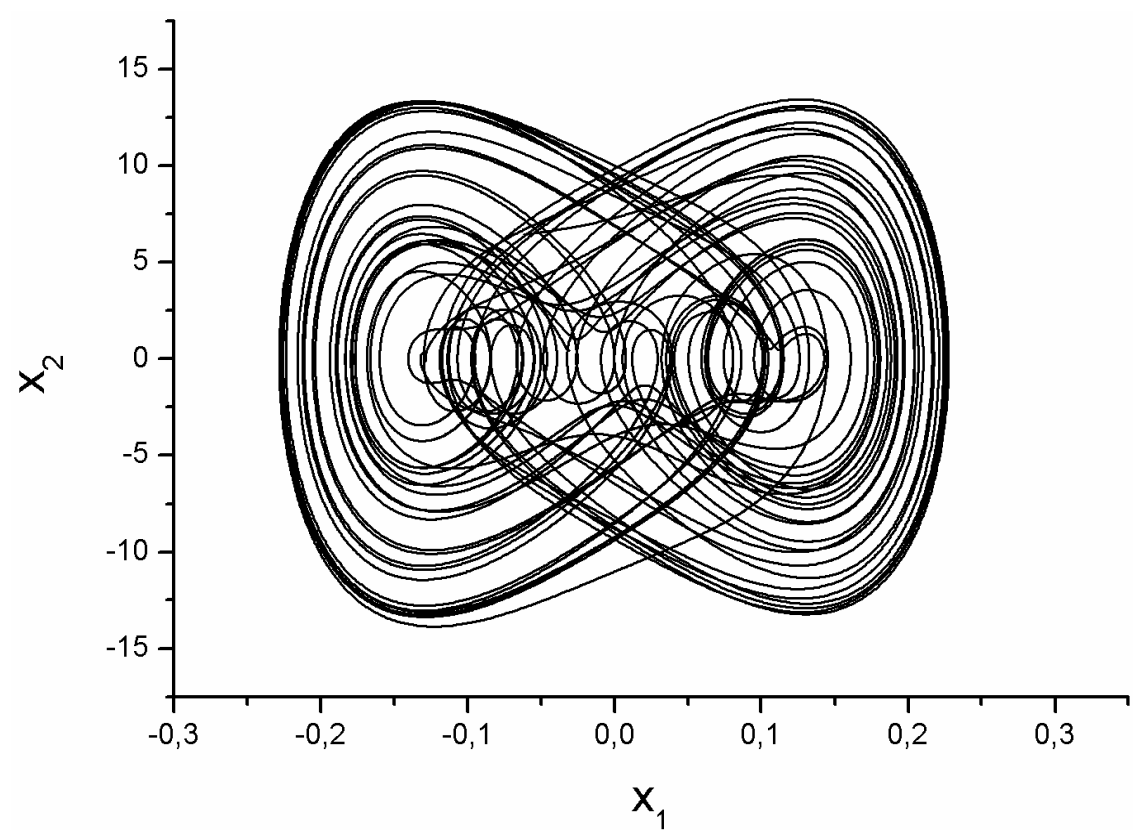

Рис. 10. Фазовий портрет реконструйованої системи


Рис. 11. Спектри функцій $\mathrm{x}_{1}(\mathrm{t})$ та $\mathrm{x}_{2}(\mathrm{t})$ реконструйованої системи 
Висновки. Згідно наведених результатів, в даній роботі продемонстрована можливість розв'язку ускладненої, в порівнянні 3 типовою, задачі ідентифікації. Звичайна постановка задачі передбачає знаходження параметрів моделі при відомих вході та виході. В даному випадку наявними $\epsilon$ дані про вихід, а інформація про вхід обмежується тільки відомим фактом про періодичність функції зовнішньої дії. Також невідомими $\epsilon$ сталі коефіцієнти рівнянь моделі. Як видно з результатів чисельних експериментів, алгоритм дозволяє достатньо точно розв'язати сформульовану задачу. Це проілюстровано отриманими часовими рядами, фазовими портретами, та спектральними характеристиками отриманих розв'язків. Такий аналіз розширює можливості моделювання систем наведеного класу, що може бути корисним при проектування різних фізичних об'єктів, виборі режимів їх функціонування.

\section{Бібліографічні посилання}

1. Tarantola, A. Inverse Problem Theory and Methods for Model Parameter Estimation [Text] / A. Tarantola // Society for Industrial and Applied Mathematics, Philadelphia (2005). - 344 p.

2. Сліденко, В.М. Математичне моделювання ударно-хвильових процесів гідроімпульсних систем гірничих машин [Текст] / В.М. Сліденко, О.М. Сліденко. - К., 2017. $-220 \mathrm{c}$.

3. Левитан, Б.М. Почти-периодические функции [Текст] / Б.М. Левитан. - М., 1953. $396 \mathrm{c.}$

4. Лоскутов, А.Ю. Введение в синергетику [Текст] / А.Ю. Лоскутов, А.С. Михайлов. М., 1990. - $272 \mathrm{c}$.

5. Городецкий, В.Г. Реконструкция некоторых нелинейных неавтономных систем по скалярному временному ряду [Текст] / В.Г. Городецкий // Вестник Запорожского национального университета. Физико-математичесике науки. - № 2. - 2016. - С. 34-42.

6. Gorodetskyi, V.G. Identification of Nonlinear Systems with Additive External Action [Text] / V.G. Gorodetskyi // Journal of Automation and Information Sciences. - v. 50. - i. 4. P. 13-24.

7. Воеводин, В.В. Матрицы и вычисления [Текст] / В.В. Воеводин, В.А. Кузнецов. - М.: Наука. - 1984. - 320 с.

Надійшла до редколегії 13.06.2019. 


\author{
Н.А. Гук, С.В. Диханов, С.Ф. Сірик \\ Дніпровський національний університет імені Олеся Гончара
}

\title{
АНАЛІЗ СТРУКТУРИ САЙТА ЗА ДОПОМОГОЮ ЖЕВ-ГРАФА
}

У роботі запропоновано методику аналізу структури веб-сайту з використанням даних про гіпертекстові зв'язки між сторінками. Розроблено математичну модель вебсайту у вигляді веб-графа. Для аналізу структури веб-графу використовусться метод кластеризації $k$-середніх, у якості кластерів обрано типи сторінок сайту. Апробацію запропонованого підходу виконано на прикладі існуючого інтернет-магазину. В результаті аналізу отримано розбиття сторінок сайту на кластери, які відповідають ієрархічним елементам структури: категоріям товарів, підкатегоріям, сторінкам товарів.

Ключові слова: веб-сайт, веб-граф, веб-аналітика, матриця суміжності, кластеризація, метод $k$ - середніх.

В работе предложена методика анализа структуры веб-сайта на основе данных о гипертекстовых связях между страницами. Разработана математическая модель вебсайта в виде веб-графа. Для анализа структуры веб-графа используется метод кластеризации $k$-средних, в качестве кластеров выбраны типы страниц сайта. Апробацию предложенного подхода выполнено на примере существующего интернетмагазина. В результате анализа получено разбиение страниц сайта на кластеры, которые соответствуют иерархическим элементам структуры: категориям товаров, подкатегориям, страницам товаров.

Ключевые слова: веб-сайт, веб-граф, веб-аналитика, матрица смежности, кластеризация, метод $k$ - средних.

A technique for analyzing the structure of a website based on data on hypertext links between pages is proposed. An analysis method based on the topology of links between pages was selected. The mathematical model of the website in the form of a web graph is developed. Structural relationships between pages are represented by binary values in the graph adjacency matrix. The problem of clustering is formulated. To analyze the structure of the web graph the clustering method $k$-means is used. A metric for determining the distance between cluster elements has been introduced. Assessment of the complexity of the algorithm is performed. Website pages correspond to hierarchical units of the structure. The structure distinguishes between pages of categories and subcategories of goods, pages of goods, and thematic articles. Types of site pages are selected as clusters. Typical pages for each cluster are selected as centroids.

An iterative algorithm for constructing a web graph has been developed. The queue is selected as the data structure for storing local information when crawling pages. Testing of the proposed approach is carried out on the example of an existing online store. A division of the site pages into clusters was obtained as a result of the analysis. A division is corresponded to hierarchical elements of the structure: product categories, subcategories, product pages.

(C) Гук Н.А., Диханов С.В., Сірик С.Ф., 2019 
The type of pages that are poorly identified by the algorithm is revealed. Using the results of clustering, you can improve the site structure during reengineering. Application of the developed methodology will improve the indexing of the site in the search engine.

Keywords: website, web graph, web analytics, adjacency matrix, clustering, $k$ - means.

Вступ. У сучасному світі існує велика кількість інформації, яку можна представити у вигляді об'єктів та відносин між ними. Прикладом таких об'єктів можуть служити ресурси, розташовані у мережі Інтернет. Веб-сайти представляють собою набір HTML-документів (сторінок), які мають певну ієрархію та пов'язані між собою.

Аналіз структури веб-сайту дозволяє вирішити ряд завдань, таких як забезпечення високого рейтингу сайту в пошуковій системі, ефективне просування ресурсу, зручність та адаптивність ресурсу для користувача.

Відомо, що світові пошукові системи Google, Yahoo!, Bing та інші формують у пошуковій видачі групи близьких за семантикою веб-документів, релевантних запиту користувача. Сайти потрапляють у пошукову видачу відповідно до свого рейтингу, який враховує кількість та якість зовнішніх посилань на сайт, релевантність тексту до пошукового запиту, та визначається за методикою вебометрії [1]. Перебування на перших сходинках гарантує залучення значної кількості відвідувачів сайту та дозволяє збільшити продаж товарів та послуг підприємства.

Аналіз структури сайту також є необхідним, коли при розробці сучасних веб-сайтів використовується механізм побудови адаптивної навігації. Під час перебування користувача на сайті виконується аналіз його поведінки, фіксуються переходи по сторінках веб-сайту, а для подальшого перегляду формуються списки веб-сторінок, близьких за змістом до вже відвіданих користувачем сторінок [2]. Крім того, при адмініструванні веб-сайтів дослідження структури необхідно для аналізу зв'язаності груп сторінок, релевантних близьким за змістом запитам користувачів. Сформовані групи веб-сторінок використовуються при реінжинірингу існуючих сайтів з метою підвищення їх зручності для навігації користувачів [3].

Для розв'язання сформульованих задач широко застосовується кластеризація веб-сторінок за тематикою або ієрархією, коли схожі сторінки об'єднуються в групи. 3 кожним днем розміри сайтів збільшуються, зростає їх структурна складність, тому розробка методів для аналізу структур веб-сайтів 3 метою покрашення їх рейтингу та зручності для користувачів $є$ актуальною задачею.

Огляд літератури. Для здійснення процедури кластеризації сторінок вебсайту існують різні підходи. Методи, які грунтуються на автоматичної обробці вмісту текстів веб-сторінок, дозволяють визначати тематику сторінки за найбільш характерними словами і використовують статистичний аналіз тексту за кількістю входжень ключових слів [4]. При аналізі текстів також широко застосовується векторна модель зображення тексту, коли текст описується характеристичним вектором у лексичному просторі 3 використанням частотного спектру слів. Побудовані вектори інтерпретуються як 
точки в багатовимірному просторі, кластеризація документів виконується 3 використанням метрики відстані між векторами. Однак при великих обсягах текстів такі методи вимагають багато часу на обробку. У разі, коли на сторінках розміщуються як текстові, так і графічні матеріали схожі за змістом, лінгвістичні методи аналізу гіпертекстової інформації застосувати неможливо.

У роботі [5] запропоновано ідею комбінованого методу класифікації вебдокументів, який враховує зміст тексту сторінки і гіперпосилання, що ведуть зі сторінки, що розглядається, на пов'язані з нею сторінки.

Найбільш широко для аналізу структури сайтів застосовуються методи, засновані виключно на аналізі топології зв'язків між сторінками веб-ресурсу. Кожен сайт являє собою набір веб-сторінок. Сторінка $\epsilon$ html-документом та має власну URL адресу, яка являє собою стандартизований спосіб запису адреси в мережі Інтернет. Сторінки сайту містять внутрішні гіперпосилання, за допомогою яких здійснюється перехід до іншої сторінки цього сайту, і зовнішні гіперпосилання, що визначають шлях до сторінок іншого сайту. Внутрішні посилання формують внутрішню структуру сайту, зовнішні посилання визначають взаємозв'язок сайту з іншими сайтами в мережі Інтернет. Вважається, що, якщо дві сторінки пов'язані гіперпосиланнями, то сторінка, що посилається, рекомендує для читання цитовану сторінку, а вказаний зв'язок носить характер рекомендації. По-друге, сторінка, яка посилається на іншу, має 3 нею тематичну схожість, тобто можна вважати, що вони $є$ тематично локалізованими.

В якості моделей зображення сайтів широко використовуються модель у вигляді графа, модель мережі Петрі, модель теорії автоматів, решітчаста модель.

Найбільш дослідженою і популярною для аналізу структури сайту є модель у вигляді орієнтованого графа, така модель представлення сайту логічна і найкраще відображає його структуру. В роботі для аналізу структури сайту - пошуку зв'язків між різними сторінками ресурсу - застосовується веб-граф [6], а в якості методу аналізу структури веб-сайту використовуються методи кластерного аналізу графів.

Постановка задачі та математична модель. Визначимо гіпертекстову модель веб-сайту $H$ як набір, що складається з двох множин:

$$
H=\{P, L\},
$$

де $P=\left\{p_{1}, \ldots, p_{n}\right\}-$ множина сторінок сайту; $L=\left\{l \mid \exists p_{1}, p_{2} \in P: p_{1}, p_{2} \in l\left(p_{1}, p_{2}\right)\right\}$ - множина гіперпосилань між сторінками. Структурі гіпертекстової моделі веб-сайту відповідає математична модель у вигляді орієнтованого незваженого графа $G=(A, E)$, у якому $A=P, E=L$. У побудованому графі $A$ - множина вершин, елементи якої описують сторінки сайту, $E$ - множина ребер графу, елементи якої відповідають гіперпосиланням між сторінками. Для аналізу структури веб-сайту необхідно виконати кластеризацію сторінок. 
Сформулюємо задачу кластеризації у такий спосіб. Розглянемо граф $G=(A, E)$. Множину всіх непустих підмножин множини $A$ позначимо $C$. Розбиттям множини $A$ вершин графа $G$ на кластери будемо називати таке відображення $\varphi: A \rightarrow C$, для якого виконується:

$$
\mathrm{E}(\varphi)=\left\{C_{j}\right\}_{j=\overline{1, k}} \subset C, \forall i, j(1 \leq i, 1 \leq k): C_{i} \cap C_{j}=\varnothing, A=\bigcup_{i=1}^{k} C_{i}
$$

Елементи множини значень $\mathrm{E}(\varphi)$ відображення $\varphi$ будемо називати кластерами. Множину всіх $\varphi$ можливих для графа $G$, будемо позначати, як $\Phi=\Phi_{G}$. 3 використанням деякої оцінки розбиття $Q(\varphi) \in R$ задачу кластеризації множини вершин $A$ графа $G$ можна зобразити у такий спосіб:

$$
\varphi^{*}=\arg \max _{\varphi \in \Phi} Q(\varphi) \text {. }
$$

Метод розв'язання задачі. Існуючі методи кластеризації умовно можна розділити на три групи. До графових методів кластеризації відносять алгоритм найкоротшого незамкнутого шляху, очевидний алгоритм, алгоритм побудови мінімального остовного дерева, алгоритми обчислення модулярності графу. До статистичних методів відносяться ЕМ-алгоритм, метод $k$-середніх та інші, до третьої групи методів - методів ієрархічної кластеризації - слід віднести агломеративну та розділову кластеризацію.

Для аналізу графових моделей також існують пакети прикладних програм, в яких реалізовані основні методи кластеризації та зручні засоби для візуалізації побудованих рішень.

В роботі для кластеризації веб-графа використовується метод $k$-середніх. Ітеративний алгоритм методу здійснює групування сторінок сайту по фіксованій кількості кластерів та полягає в наступному: випадковим чином обирається $k$ векторів, які визначаються як центроїди (найбільш типові представники) кластерів. Потім кластери $C_{1}, C_{2}, \ldots, C_{k}$ наповнюються. Для кожного $з$ векторів, які залишилися, деяким чином визначається близькість до центроїду відповідного кластера. У роботі близькість визначається як нормований скалярний добуток:

$$
\operatorname{Sim}\left(x, c^{j}\right)=\frac{\sum_{k=1}^{K} x_{k} c_{k}^{j}}{|x|\left|c^{j}\right|},
$$

де $x$ - вектор, $c^{j}$ - центроїд кластера $C_{j}, K$ - кількість кластерів.

Після визначення відстані вектор приписується до того кластеру, до якого він $\epsilon$ найбільш близьким. Вектори групуються і перенумеровуються відповідно приналежності до кластерів. Потім для кожного з нових кластерів наново обирається центроїд $c^{j}$, координати якого визначаються у такий спосіб: 


$$
c_{k}^{i}=\frac{1}{\left|c_{i}\right|} \sum_{x \in C_{i}} x_{k} .
$$

Після цього знову здійснюється процеси наповнення кластерів, обчислення нових центроїдів, поки процес формування кластерів не стабілізується. У якості критерію зупинки алгоритму обирається відсутність переходу об'єктів 3 кластера в кластер на двох сусідніх ітераціях.

Алгоритм $k$ - середніх максимізує функцію якості кластеризації $Q$ :

$$
Q\left(C_{1}, \ldots, C_{k}\right)=\sum_{i=1}^{k} \sum_{x \in C_{i}} \operatorname{Sim}\left(x, c^{j}\right) .
$$

Складність побудованого алгоритму визначається як $O(K N)$, де $\mathrm{N}$ - число вершин веб-графу, K - число кластерів. За допомогою описаного алгоритму можливо знайти лише локальну оптимальну конфігурацію кластерів, вигляд якої суттєво залежить від початкового вибору центроїдів.

До недоліків сформульованого алгоритму також слід віднести неможливість знаходження глобального оптимуму. Крім того, сформульований алгоритм для організації роботи в якості вхідного параметра вимагає вказати число кластерів. Для сформульованої задачі існує апріорна інформація про ієрархічну структуру сайту, яку можна використати для завдання кількості кластерів.

\section{Алгоритм побудови веб-графа.}

Граф, що відображає структуру веб-сайту складається з множини вершин $A=\left\{A_{i}\right\}, i=\overline{1, N}$. Головною сторінкою сайту завжди $€ A_{1}$. Кожній вершині $A_{i}$ можна поставити у відповідність множину вихідних ребер $E_{i}=\left\{e_{i j}\right\}$, де дуга $e_{i j}$ пов'язує вершини $A_{i}$ та $A_{j}$ i відповідає гіперпосиланню 3 вебсторінки $A_{i}$ на веб-сторінку $A_{j}$. Таким чином, структуру сайту можна зобразити у вигляді орієнтованого графу, вершинами якого є сторінки $A_{i}$, а дугами - гіперпосилання $e_{i j}$. При побудові графа можливі випадки, коли модель буде вироджуватися в односпрямований граф (відношення між вершинами $\epsilon$ антисиметричним), а також у дерево.

Граф структури сайту може бути представлений математично у вигляді матриці суміжності. Вхідними даними рекурсивного алгоритму формування графу $\epsilon$ посилання на головну сторінку веб-сайту і бажана кількість сканованих рівнів. Можливість завдання глибини сканування сайту зроблено для того, щоб обмежити час роботи програми для дуже великих сайтів. На виході у програми створюються 2 файли: в одному файлі містяться адреси всіх знайдених сторінок, із зазначенням рівня кожної сторінки, в другому файлі міститься список гіперпосилань у вигляді: початкова сторінка, кінцева сторінка. За необхідністю можливо додавати вагу посилання, враховуючи, наприклад, кількість посилань з однієї сторінки на іншу. 
Алгоритм починає роботу 3 пошуку головної сторінки сайту $A_{1}$, для сторінки відшукуються гіперпосилання на інші сторінки сайту $e_{i j}$, за необхідністю може бути збережено інформацію про вміст сторінки.

Пошук гіперпосилань виконується циклічно. Для збереження сторінок вебсайту використовується відповідна структура даних - черга. Кожне знайдене посилання перевіряється на приналежність до даного сервера. Якщо сторінка належить серверу, то перевіряється умова, не створена чи вже сторінка $A_{j}$, на яку посилається сторінка $A_{i}$. Якщо сторінки $A_{j}$ ще не існує, то $A_{j}$ створюється і розташовується у черзі Q для пізнішої обробки. Якщо сторінка $A_{j}$ вже існує, то для поточної сторінки $A_{i}$, що розглядається, додається посилання $e_{i j}$ i пошук триває. Після того, як всі посилання $e_{i j}$ для сторінки $A_{i}$ знайдені, з черги $Q$ обирається нова сторінка $A_{j}$, для якої виконується чергова ітерація циклу алгоритму. Алгоритм закінчує свою роботу, коли черга $Q$ порожня. За результатами роботи алгоритму можливо сформувати матрицю суміжності, яка відображає взаємозв'язок сторінок сайту.

Аналіз результатів. Запропонований підхід застосовано для аналізу структури існуючого протягом тривалого періоду сайту підприємства - iнтернет-магазину.

Для побудови веб-графу розроблено програмне забезпечення, вхідними даними для якого являються посилання на головну сторінку та глибина сканування (кількість рівнів структури, що досліджується). Під рівнями структури мається на увазі ієрархія «категорія-підкатегорія-сторінка товару». Окремим елементом структури є сторінки, на яких розташовано інформаційні матеріали про товари, зазначені сторінки можуть відповідати, як категоріям, так й сторінкам товарів.

Посилання на головну сторінку ідентифікується за доменним ім'ям. Шляхом сканування веб-ресурсу за протоколом http збирається інформація стосовно гіперпосилань між сторінками. За результатами сканування будується граф, вершинами якого $є$ адреси відшуканих сторінок із вказанням ієрархічного рівня сторінки, а дугами - гіперпосилання між сторінками. Побудований граф є орієнтованим.

У табл. 1 наведено фрагмент матриці суміжності веб-графа, великими літерами позначено сторінки ресурсу, на перетині рядків та стовпців бінарна одиниця позначає наявність зв'язку між сторінками. У наведеному фрагменті існують вершини, які відповідають сторінкам різних типів - категоріям товарів, підкатегоріям, сторінкам товарів, статтям з інформацією про товари.

Для аналізу побудованої структури було застосовано метод k- середніх, кількість кластерів вважалась відомою, дорівнювала 4 та відповідала кількості рівнів структури. Критерієм закінчення ітераційного процесу обрано стабілізацію процесу формування кластерів, яка спостерігається при переході 
до 5 ітерації. У табл. 2 наведено метричні характеристики, які відображають відстані кожного з векторів сторінок до центрів кожного $з$ кластерів.

Фрагмент матриці сумінсності веб-графа

\begin{tabular}{|c|c|c|c|c|c|c|c|c|c|c|c|c|c|c|c|c|}
\hline & $\mathrm{A}$ & $\mathrm{B}$ & $\mathrm{C}$ & $\mathrm{D}$ & $\mathrm{E}$ & $\mathrm{F}$ & $\mathrm{G}$ & $\mathrm{H}$ & $\mathrm{I}$ & $\mathrm{J}$ & $\mathrm{K}$ & $\mathrm{L}$ & $\mathrm{M}$ & $\mathrm{N}$ & $\mathrm{O}$ & $\mathrm{P}$ \\
\hline $\mathrm{A}$ & 0 & 0 & 0 & 1 & 0 & 0 & 1 & 0 & 0 & 0 & 0 & 1 & 1 & 1 & 0 & 1 \\
\hline $\mathrm{B}$ & 1 & 0 & 0 & 0 & 0 & 0 & 0 & 0 & 0 & 0 & 0 & 0 & 0 & 0 & 0 & 0 \\
\hline $\mathrm{C}$ & 1 & 0 & 0 & 0 & 0 & 0 & 0 & 0 & 0 & 0 & 0 & 1 & 0 & 0 & 0 & 0 \\
\hline $\mathrm{D}$ & 0 & 0 & 0 & 0 & 1 & 0 & 0 & 0 & 0 & 0 & 0 & 0 & 0 & 1 & 0 & 0 \\
\hline $\mathrm{E}$ & 0 & 1 & 0 & 0 & 0 & 0 & 0 & 0 & 0 & 0 & 0 & 0 & 0 & 0 & 0 & 1 \\
\hline $\mathrm{F}$ & 0 & 1 & 0 & 0 & 0 & 0 & 0 & 0 & 1 & 0 & 0 & 0 & 0 & 0 & 0 & 0 \\
\hline $\mathrm{G}$ & 0 & 1 & 0 & 0 & 0 & 0 & 0 & 0 & 0 & 0 & 1 & 0 & 0 & 0 & 0 & 0 \\
\hline $\mathrm{H}$ & 0 & 0 & 0 & 0 & 1 & 0 & 0 & 0 & 0 & 1 & 0 & 0 & 0 & 0 & 0 & 0 \\
\hline I & 0 & 0 & 0 & 0 & 0 & 1 & 0 & 1 & 0 & 0 & 1 & 0 & 0 & 0 & 0 & 0 \\
\hline $\mathrm{J}$ & 0 & 0 & 0 & 0 & 0 & 1 & 0 & 0 & 0 & 0 & 1 & 0 & 0 & 0 & 0 & 0 \\
\hline $\mathrm{K}$ & 0 & 0 & 0 & 0 & 0 & 0 & 1 & 0 & 1 & 0 & 0 & 0 & 0 & 0 & 0 & 0 \\
\hline $\mathrm{L}$ & 0 & 0 & 1 & 0 & 0 & 0 & 0 & 0 & 0 & 0 & 0 & 0 & 0 & 1 & 0 & 1 \\
\hline $\mathrm{M}$ & 0 & 0 & 1 & 0 & 0 & 0 & 0 & 0 & 0 & 0 & 0 & 1 & 0 & 0 & 0 & 0 \\
\hline $\mathrm{N}$ & 0 & 0 & 1 & 0 & 0 & 0 & 0 & 0 & 1 & 0 & 0 & 0 & 0 & 0 & 0 & 0 \\
\hline $\mathrm{O}$ & 0 & 0 & 0 & 0 & 0 & 0 & 0 & 0 & 0 & 0 & 1 & 0 & 1 & 0 & 0 & 0 \\
\hline $\mathrm{P}$ & 0 & 0 & 0 & 0 & 0 & 0 & 0 & 0 & 0 & 0 & 0 & 0 & 1 & 0 & 1 & 0 \\
\hline
\end{tabular}

Таблиия 1

Таблиия 2

Метричні характеристики кластерів

\begin{tabular}{|c|c|c|c|c|c|c|}
\hline & \multicolumn{2}{|c|}{1} & 2 & 3 & 4 & Результат кластерізації \\
\cline { 2 - 5 } & \multicolumn{2}{|c|}{ Відстань до центру кластера } & (номер кластеру) \\
\hline A & 2.236 & 2.04 & 1.542 & 1.959 & 3 \\
\hline B & 0.0 & 2.005 & 1.777 & 1.984 & 1 \\
\hline C & 2.449 & 2.272 & 1.777 & 1.76 & 4 \\
\hline D & 2.0 & 1.778 & 1.119 & 1.016 & 4 \\
\hline E & 2.236 & 2.04 & 1.334 & 1.858 & 3 \\
\hline F & 2.236 & 0.855 & 1.552 & 1.992 & 2 \\
\hline G & 2.236 & 2.04 & 1.369 & 1.426 & 3 \\
\hline H & 2.0 & 1.078 & 1.187 & 1.723 & 2 \\
\hline I & 2.0 & 2.272 & 1.59 & 2.214 & 3 \\
\hline J & 2.0 & 1.778 & 0.918 & 1.723 & 3 \\
\hline K & 2.236 & 0.671 & 2.1 & 2.39 & 2 \\
\hline L & 2.449 & 2.272 & 1.799 & 1.646 & 4 \\
\hline M & 2.449 & 2.005 & 1.498 & 1.586 & 3 \\
\hline N & 2.449 & 2.272 & 1.786 & 0.95 & 4 \\
\hline O & 2.0 & 1.778 & 0.633 & 1.646 & 3 \\
\hline P & 2.0 & 2.272 & 1.803 & 0.622 & 4 \\
\hline
\end{tabular}

Для наведеного у табл. 1 фрагменту даних в результаті кластеризації побудовано набір 34 кластерів. Аналіз розбиття на кластери показав, що об’єкти кожного з кластерів мають спільні ознаки, отримане розбиття 94 
згрупувало сторінки веб-сайту за типами: кластер 1 відповідає сторінці, яка визначає категорію товару, до кластеру 2 потрапили сторінки підкатегорій, до кластеру 3 - сторінки окремих товарів, до кластеру 4 - сторінки, на яких розміщено тематичні матеріали у вигляді статей.

Однак за результатами аналізу повного веб-графу інтернет-магазину виявлено, що ні всі сторінки відповідають типовим кластерам. Найбільш погано виконується ідентифікація сторінок, на яких розташовано статті про товари, що пов'язано з їх узагальнюючим змістом та інформаційною спрямованістю. Сторінки із статтями посилаються на сторінки товарів з різних категорій. Усунення виявленої невідповідності призведе до більш ефективної індексації сторінок сайту та дозволить суттєво покращити структуру сайту для зручності його використання. За результатами кластеризації можливо виконати реінжиніринг ресурсу та налаштувати логічну структуру сайту, що підвищить помітність ресурсу для пошукових систем та зручність для користувачеві.

Висновки. У роботі для аналізу структури веб-сайту побудовано модель сайту у вигляді графу, розроблено алгоритм автоматичної генерації матриці суміжності веб-графу. Для аналізу зв'язків сторінок сайту застосовано метод кластеризації $k$-середніх. За допомогою розробленого програмного забезпечення виконано кластеризацію сторінок за типом. Отримані результати кластеризації можна застосовувати для покращення структури сайту при реінжинірингу.

\section{Бібліографічні посилання}

1. Webometrics Ranking of World Universities: [Електронний ресурс]. - Режим доступу: http://www.webometrics.info

2. Hollink, V. Navigation behavior models for link structure optimization [Text] / V. Hollink, M. Van Someren and B. J.Wielinga // User Modelling and User-Adapted Interaction. - 2007. - Vol. 17, iss. 4. - Pp. 339-377.

3. Салин, В.С. Об одном подходе к реинжинирингу гипертекстовых структур [Текст] / В.С. Салин,С.В. Папшев // Математические методы в технике и технологиях - ММТT26: сб. тр. XXVI междунар. науч. конф. - 2013. - С. 118-120.

4. Крейнес, М.Г. Модели текстов и текстовых коллекций для поиска и анализа информации [Текст] / М.Г. Крейнес // Матем. модел. эколого-экономич. систем: экономика ТРУДЫ МФТИ. - 2017. - Том 9, № 3. - С. 132-142

5. Calado, P. Combining linkbased and content-based methods for web document classification [Text] / P. Calado, M. Cristo, E. Moura et al. // CIKM'03, Nov. - 2003. - Pp. 3-8.

6. Печников, А.А. Разработка инструментов для вебометрических исследований гиперссылок научных сайтов [Текст] / А.А. Печников, Н.Б. Луговая, Ю.В. Чуйко, И.Э. Косинец // Вычислительные технологии. - 2009. - Т. 14, № 5. - С. 66-78.

Надійшла до редколегії 24.10.2019. 


\author{
С.М. Сфремов, Т.А. Зайцева \\ Дніпровський національний університет імені Олеся Гончара
}

\title{
ОПТИМІЗАЦІЯ РОЗРАХУНКУ ГІСТОГРАМИ НАПРЯМЛЕНИХ ГРАДІЕНТІВ ДЛЯ РОЗПІЗНАВАННЯ ЗОБРАЖЕННЯ
}

В роботі розглядається оптимізація розрахунку гістограми напрямлених градіснтів для розпізнавання змісту зображення із застосуванням інтерполяції та алгоритму оптимізації швидкості розрахунків. Виконана програмна реалізація алгоритму, та на тестових прикладах проведена оцінка роботи програми.

Ключові слова: оптимізація, інтерполяція, HOG дескриптор, комп'ютерний зір, розпізнавання образів, інтегральне представлення зображень, гістограма напрямлених градієнтів.

В работе рассматривается оптимизация расчета гистограммы направленных градиентов для распознавания содержания изображения с использованием интерполяции и алгоритма оптимизации скорости расчетов. Выполнена программная реализация алгоритма и на тестовом примере продемонстрированы результаты его работы.

Ключевые слова: оптимизация, интерполяция, HOG дескриптор, компьютерное зрение, распознавание образов, интегральное представление изображений, гистограмма направленных градиентов.

The possibilities of the optimization of histogram of oriented gradients calculations for solving image content recognition problems described based on the $48 \times 48$ pixels size image example. The algorithm doesn't change in regards to the input data and suits for the histogram of the oriented gradients calculation based on any image. The algorithm idea is taken from the work of Soojin Kim and Kyeongsoon Cho [1], which is the modification of original HOG descriptor algorithm presented by Navneet Dalal and Bill Triggs [3] aimed at optimization of the calculation speed without loosing accuracy during image content recognition using HOG descriptor to generate the set of features of the image content. The algorithm is described in detail in the next sequence of actions. 1) Original HOG feature calculation. We use it as the first step since the algorithm is the optimized version of the original HOG feature calculation. 2) Solving the aliasing problem and accuracy improvement by using the interpolation technique during the HOG feature calculation process. We use one of the normalization schemes, applying interpolation as the next calculation step. 3) Solving the redundant operations and calculation speed problems by using cell-based operations and applying from one to four described types to the cells, based on which depends the detection window cell calculation. The types are applied to cell based on the blocks intersection containing the cell.

The computer program has been developed according to the selected optimized algorithm of HOG feature calculation. It was used during the image content features description and learning process and in the further computer vision research. The software implementation of the algorithm takes into account the capabilities of modern computer technology, Javascript programming language and modern needs of the image content recognition calculation speed and accuracy.

(c) Єфремов С.М., Зайцева Т.А., 2019 
The implementation of computer program logic is shown in the script examples, utilizing modularity and parallel calculation as the strong sides of Javascript, further improving HOG feature calculation speed.

Keywords: optimization, interpolation, HOG feature descriptor, computer vision, pattern recognition, integral image representation, histogram of oriented gradients.

Вступ. Сьогодні серед інтелектуальних систем значного поширення набули системи комп'ютерного зору, в яких актуальними є задачі розпізнавання зображень. На даний час розроблено ряд методів і алгоритмів синтезу та аналізу зображень, які грунтуються на різних теоретичних засадах. Гістограма напрямлених градієнтів (HOG) є сучасним методом опису характеристик змісту зображення, дескриптором, що активно використовується у сфері комп'ютерного зору, дозволяючи отримати набір чітких ознак образів на зображенні, що в свою чергу дозволяє навчання та використання нейронної сітки з ціллю близької до людської точності розпізнавання змісту зображення. Даний метод надає більшу точність та є відносно простим у реалізації відносно більшості аналогів [2], а саме тому є перспективним та широко застосовуваним у сфері комп'ютерного зору.

Класичний алгоритм побудови HOG-дескриптору призводить лише до задовільної точності розпізнавання, у порівнянні з людською. Для вирішення цієї проблеми існують різні підходів, наприклад, використання інтерполяції у процесі розрахунку HOG-дескриптора [1], техніка інтегрального представлення зображення [3], впровадження згладжування тощо. Основні складнощі при даному підході полягають у значному ускладненні розрахунків та, як наслідок, пониженні швидкості розпізнавання. Однак, за останні роки почали 3'являтись роботи, в яких автори розробляли підходи для покращення швидкості розрахунків НОG дескриптора.

В даній роботі реалізується модифікація алгоритму [1], що дозволяє оптимізувати процес розрахунків HOG-дескриптора, позбувшись надлишкових операцій при застосуванні інтерполяції, будуючи гістограми для кожної комірки лише один раз. Розроблена програмна реалізація даного алгоритму адаптована до можливостей використаної мови програмування Javascript та сучасних технологій обробки зображення.

Постановка задачі. Нехай маємо область розпізнавання на зображенні розміром $S_{x} \times S_{y}$, де $S_{x}$ - ширина зображення у пікселях, $S_{y}$ - висота зображення у пікселях. Розглянемо розбиття зображення на $C_{x} \times C_{y}$ комірок розміром $p \times p$, де $C_{x}$ - кількість комірок у ширину $\left(C_{x}=S_{x} / p\right), C_{y}-$ кількість комірок у висоту $\left(C_{y}=S_{y} / p\right), p$ - розмір комірки у пікселях.

Необхідно покращити результати оптимізації розрахунку гістограми напрямлених градієнтів для розпізнавання змісту зображення, розробити програмне забезпечення, що містить імплементацію методу побудови гістограми напрямлених градієнтів із подальшою оптимізацією розрахунків [1] на базі даного зображення із виключенням надлишкових операцій та використанні інтерполяції у процесі розрахунків. 
Основний матеріал. HOG-дескриптор базується на розрахунку нормалізованих локальних гістограм напрямлених градієнтів.

Маємо область розпізнавання $S_{x} \times S_{y}$ пікселів. Розрахуємо градієнт для кожного пікселя у області розпізнавання. Градієнт для $x$-напряму $g_{x}$, розрахуємо за рівнянням (1), градієнт для $y$-напряму $g_{y}$ за рівнянням (2), де $f(x, y)$ являє собою значення пікселю у позиції $(x, y)$ для зображення $I$.

$$
\begin{aligned}
& g_{x}=\frac{\partial I}{\partial x} f(x+1, y)-f(x-1, y) \\
& g_{y}=\frac{\partial I}{\partial y} f(x, y+1)-f(x, y-1)
\end{aligned}
$$

Далі використаємо градієнти $g_{x}$ та $g_{y}$ для розрахунку магнітуди $M$ та напрямленості $\theta$ за рівняннями (3) та (4) відповідно.

$$
\begin{gathered}
M(x, y)=\left(g_{x}{ }^{2}+g_{y}{ }^{2}\right)^{1 / 2} \\
\theta(x, y)=\operatorname{ctg}\left(\frac{g_{y}}{g_{x}}\right)
\end{gathered}
$$

Наступним кроком $є$ накопичення «weighted votes» - звішених голосів для градієнтної магнітуди до $N$ орієнтаціоних масивів у комірках розміром $p \times p$. Коли внутрішня дистанція масиву $-\theta_{\text {dist }}$ становить $20^{\circ}$ на проміжку від $0^{\circ}$ до $180^{\circ}, N=9$, де $N$ - кількість масивів для кожної комірки. Для уникнення згладжування, застосовується інтерполяція блоків із ціллю білінійно інтерполювати weighted votes між сусідніми масивами за напрямом та позицією. Наступним кроком $є$ нормалізація контрасту у кожному блоці із допомогою двох схем нормалізації(L1-norm та L2-norm відповідно) представлених у рівняннях (5) та (6), де $B_{k}-36$-ти вимірний вектор для блоку, $c$ - кожен елемент вектору, $\varepsilon$ - невелика константа для уникнення ділення на нуль.

$$
\begin{gathered}
\text { L1-norm: }\left\{\frac{c}{\left\|B_{k}\right\|+\varepsilon}\right\} \\
\text { L2-norm: }\left\{\frac{c}{\left(\left\|B_{k}\right\|^{2}+\varepsilon^{2}\right)^{1 / 2}}\right\}
\end{gathered}
$$

Вимір кожного блоку задається кількістю орієнтаційних масивів. Останнім кроком $є$ сбір векторів гістограми для всіх пересічних блоків у області розпізнавання. Коли $S_{x}=48, S_{y}=48, p=6, c=2, L=6$, де $L-$ крок блоку та $N=9$, то загальна кількість блоків у області розпізнавання становить 49 .

Для підвищення точності розпізнавання, при розрахунку HOG застосовується техніка інтерполяції з ціллю уникнення згладжування та покращення точності розпізнавання. Приклад білінійної та трилінійної інтерполяції продемонстровано на рис. 1 , де $C_{0} \sim C_{3}-$ сусідні комірки. Коли $N=9$ на від $0^{\circ}$ 
до $180^{\circ}$ та напрям градієнту для пікселю у $C_{0}=37^{\circ}$, два сусідні масиви зазначені як 1 та 2 відповідно. Оскільки у лінійній інтерполяції враховується лише напрям пікселю, weighted votes розраховуються шляхом помноження магнітуди $-M$, коефіцієнт $-G$ та зваження напряму $-W_{\theta}$. Потім weighted votes розбиваються на два масиви (масив 1 та 2 лише для $C_{0}$ ). 3 іншого боку, напрям та позиція пікселя у блоку розглядається у трилінійній інтерполяції, тому у цьому випадку weighted votes розраховуються множенням магнітуди $M$, коефіцієнту $-G$, зваженням напряму $-W_{\theta}$ та зважень для позиції пікселю ( $W_{x}$ та $W_{y}$ відповідно), а потім розбиваються на вісім масивів (масив 1 та 2 для $C_{0} \sim C_{3}$ ) (див. рис. 1.)
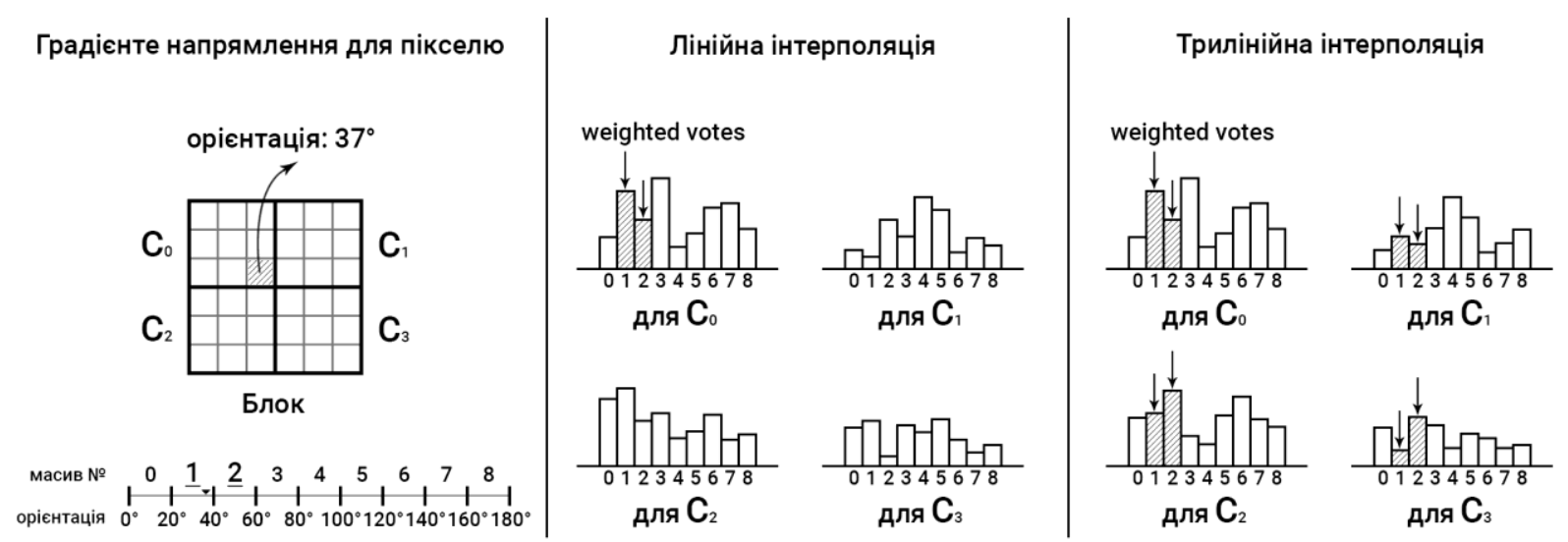

Рис. 1 Інтерполяція блоку

Незважаючи на факт, що трилінійна інтерполяція значно покращує точність, швидкість розпізнавання зменшується через високу складність розрахунків. Оскільки HOG-дескриптор розраховується із врахуванням всіх пересічних блоків у області розпізнавання, кількість розрахунків підвищується й надалі. Таблиця 1 демонструє кількість необхідних множень на області розпізнавання, враховуючи інтерполяцію та L2-norm нормалізацію, де $B_{x}$ - кількість блоків у ширину, $B_{y}$ - кількість блоків у висоту. Вочевидь, кількість необхідних множень для трилінійної інтерполяції набагато більше ніж для лінійної. Тому для підвищення швидкості розпізнавання більшість дослідників як правило ігнорують трилінійну інтерполяцію та часто застосовують лінійну інтерполяцію.

Таблиця 1

\begin{tabular}{|c|c|}
\hline Інтерполяція & Кількість множень на області розпізнавання \\
\hline Лінійна & $\left\{\left(4 \times p^{2} \times c^{2}\right)+\left(c^{2} \times N\right)+1\right\} \times B_{x} \times B_{y}$ \\
\hline Трилінійна & {$\left[\begin{array}{l}\left\{32 \times p^{2} \times(c-1)^{2}\right\}+\left\{32 \times p^{2} \times(c-1)\right\} \\
+\left(8 \times p^{2}\right)+\left(c^{2} \times N\right)+1\end{array}\right] \times B_{x} \times B_{y}$} \\
\hline
\end{tabular}


Алгоритм оптимізації швидкості розрахунків. Застосуємо алгоритм, що виконує задачу оптимізації, дозволяє повністю уникнути надлишкових операцій, уникаючи розрахунку однієї комірки двічі, що значно підвищує швидкість розпізнавання, не втрачаючи точність розпізнавання.

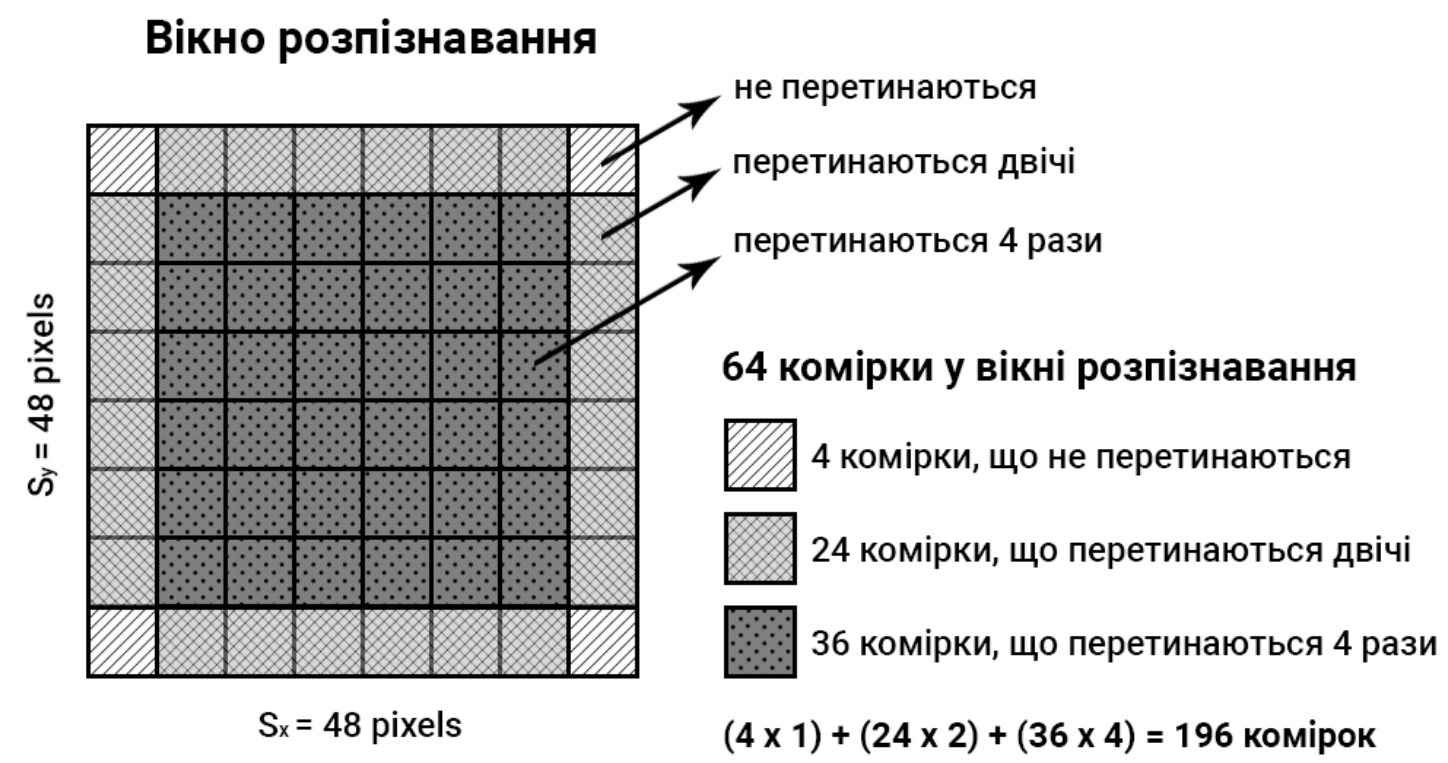

Рис. 2. Кількість необхідних комірок у розрахунку HOG-дескриптора

Надлишкові операції присутні у оригінальному алгоритмі через операції над пересічними частинами блоків. Коли $S_{x}=48, S_{y}=48, c=2$ та $L=p=6$, наприклад, 24 комірки перетинаються двічі та 36 комірок перетинаються чотири рази, як вказано на рис. 2. Хоча кількість комірок у області розпізнавання становить 64, кількість комірок, необхідних для розрахунку НOG дескриптора становить 196 блоки.

Кожен блок у області розпізнавання розбивається на чотири умовні регіони $-S B_{1} \sim S B_{4}$, як вказано на рис. 3. Оскільки інтервал кожного пересічного блоку становить одну комірку у кожному напрямі, більшість комірок належать до чотирьох заздалегідь визначених типів.

1. [масив напряму] $\leftarrow M \times G_{1} \times W_{x} \times W_{y} \times W_{\theta}$

2. [масив напряму] $\leftarrow M \times G_{2} \times W_{x} \times W_{y} \times W_{\theta}$

3. [масив напряму] $\leftarrow M \times G_{3} \times W_{x} \times W_{y} \times W_{\theta}$

4. [масив напряму] $\leftarrow M \times G_{2} \times W_{x} \times W_{y} \times W_{\theta}$

Кожній комірці присвоюється відповідний тип відповідно до кількості пересічних блоків, що містять дану комірку. Наприклад, якщо лише один блок містить комірку, вона містить один тип, при перетинанні двох блоків - 2 типи, при перетинанні чотирьох блоків - усі чотири типи. Як зазначено у відповідних формулах розрахунків, лише коефіцієнт Гауса відрізняється відповідно до типу комірки $\left(G_{1} \sim G_{4}\right.$ являють собою коефіцієнти Гауса у регіонах 
$\left.S B_{1} \sim S B_{4}\right)$. Отже рівняння трилінійної інтерполяції модифікується із ціллю розділу загальних операцій для кожного типу комірки.

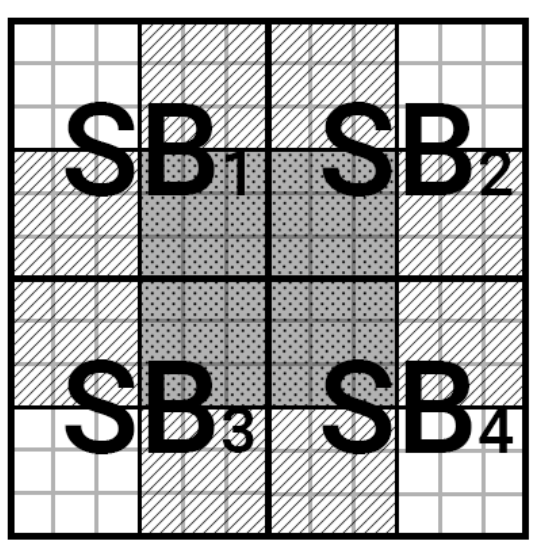

Рис. 3 Розбиття блоку на регіони

Розрахуємо трилінійну інтерполяцію для кожного з чотирьох типів регіонів комірки $-S C_{1} \sim S C_{4}$, де $\alpha$ та $\beta$ - коефіцієнти інтерполяції, $k$ - індекс групи масивів комірки. Тип 1:

$$
\begin{gathered}
S C_{1}:[N k+\alpha] \leftarrow M \times A \times G_{1} \times \beta \\
S C_{2}:\left\{\begin{array}{l}
{[N k+\alpha] \leftarrow M \times A \times G_{1} \times \beta} \\
{[N(k+1)+\alpha] \leftarrow M \times C \times G_{1} \times \beta}
\end{array}\right. \\
S C_{3}:\left\{\begin{array}{l}
{[N k+\alpha] \leftarrow M \times A \times G_{1} \times \beta} \\
{[N(k+2)+\alpha] \leftarrow M \times B \times G_{1} \times \beta}
\end{array}\right. \\
S C_{4}:\left\{\begin{array}{l}
{[N k+\alpha] \leftarrow M \times A \times G_{1} \times \beta} \\
{[N(k+1)+\alpha] \leftarrow M \times C \times G_{1} \times \beta} \\
{[N(k+2)+\alpha] \leftarrow M \times B \times G_{1} \times \beta} \\
{[N(k+3)+\alpha] \leftarrow M \times D \times G_{1} \times \beta}
\end{array}\right.
\end{gathered}
$$

Тип 2:

$$
\begin{aligned}
& S C_{1}:\left\{\begin{array}{l}
{[N(k-4)+\alpha] \leftarrow M \times C \times G_{2} \times \beta} \\
{[N(k-3)+\alpha] \leftarrow M \times A \times G_{2} \times \beta}
\end{array}\right. \\
& S C_{2}:[N(k-3)+\alpha] \leftarrow M \times A \times G_{2} \times \beta \\
& S C_{3}:\left\{\begin{array}{l}
{[N(k-4)+\alpha] \leftarrow M \times C \times G_{2} \times \beta} \\
{[N(k-3)+\alpha] \leftarrow M \times A \times G_{2} \times \beta} \\
{[N(k-2)+\alpha] \leftarrow M \times D \times G_{2} \times \beta} \\
{[N(k-1)+\alpha] \leftarrow M \times B \times G_{2} \times \beta}
\end{array}\right.
\end{aligned}
$$




$$
S C_{4}:\left\{\begin{array}{l}
{[N(k-3)+\alpha] \leftarrow M \times A \times G_{2} \times \beta} \\
{[N(k-1)+\alpha] \leftarrow M \times B \times G_{2} \times \beta}
\end{array}\right.
$$

Тип 3:

$$
\begin{gathered}
S C_{1}:\left\{\begin{array}{l}
{[N(k-28)+\alpha] \leftarrow M \times B \times G_{3} \times \beta} \\
{[N(k-26)+\alpha] \leftarrow M \times A \times G_{3} \times \beta}
\end{array}\right. \\
S C_{3}:\left\{\begin{array}{l}
{[N(k-28)+\alpha] \leftarrow M \times B \times G_{3} \times \beta} \\
{[N(k-27)+\alpha] \leftarrow M \times D \times G_{3} \times \beta} \\
{[N(k-26)+\alpha] \leftarrow M \times A \times G_{3} \times \beta}
\end{array}\right. \\
S C_{3}:\left[\begin{array}{l}
{[N(k-26)+\alpha] \leftarrow M \times A \times G_{3} \times \beta} \\
{[N(k-25)+\alpha] \leftarrow M \times C \times G_{3} \times \beta}
\end{array}\right. \\
S C_{4}:\left\{\begin{array}{l}
{[N(k-26)+\alpha] \leftarrow M \times A \times G_{3} \times \beta} \\
{[N(k-25)+\alpha] \leftarrow M \times C \times G_{3} \times \beta}
\end{array}\right.
\end{gathered}
$$

Тип 4:

$$
\begin{aligned}
& \int[N(k-32)+\alpha] \leftarrow M \times D \times G_{4} \times \beta \\
& S C_{1}:\left\{[N(k-31)+\alpha] \leftarrow M \times B \times G_{4} \times \beta\right. \\
& {[N(k-30)+\alpha] \leftarrow M \times C \times G_{4} \times \beta} \\
& {[N(k-29)+\alpha] \leftarrow M \times A \times G_{4} \times \beta} \\
& S C_{2}:\left\{\begin{array}{l}
{[N(k-31)+\alpha] \leftarrow M \times B \times G_{4} \times \beta} \\
{[N(k-29)+\alpha] \leftarrow M \times A \times G_{4} \times \beta}
\end{array}\right. \\
& S C_{3}:\left\{\begin{array}{l}
{[N(k-30)+\alpha] \leftarrow M \times C \times G_{4} \times \beta} \\
{[N(k-29)+\alpha] \leftarrow M \times A \times G_{4} \times \beta}
\end{array}\right. \\
& S C_{4}:[N(k-29)+\alpha] \leftarrow M \times A \times G_{4} \times \beta
\end{aligned}
$$

У даних рівняннях $A \sim D$ являють собою зваження для позиції пікселю $\left.W_{x} \times W_{y}\right)$, зазначених у рівняннях $(7),(8),(9)$ та (10) відповідно, де $(x, y)-$ позиція пікселю.

$$
\begin{gathered}
\left\{\begin{array}{l}
x^{\prime}=(x+0.5) / p-0.5 \\
y^{\prime}=(y+0.5) / p-0.5
\end{array} \Rightarrow A \leftarrow X_{H} \times Y_{H}\right. \\
\left\{\begin{array}{l}
x^{\prime \prime}=\text { floor }\left(x^{\prime}\right) \\
y^{\prime \prime}=\text { floor }\left(y^{\prime}\right)
\end{array} \Rightarrow B \leftarrow X_{H} \times\left(1-Y_{H}\right)\right.
\end{gathered}
$$




$$
\begin{gathered}
\left\{\begin{array}{l}
x_{1}=x^{\prime}-x^{\prime \prime} \\
y_{1}=y^{\prime}-y^{\prime \prime} \\
x_{2}=1-x_{1} \\
y_{2}=1-y_{1}
\end{array} \Rightarrow C \leftarrow\left(1-X_{H}\right) \times Y_{H}\right. \\
\left\{\begin{array}{l}
X_{H}=\max \left(x_{1}, x_{2}\right) \\
Y_{H}=\max \left(y_{1}, y_{2}\right)
\end{array} \Rightarrow D \leftarrow\left(1-X_{H}\right) \times\left(1-Y_{H}\right)\right.
\end{gathered}
$$

Слід зауважити, що $G_{1} \sim G_{4}$ та $A \sim D$ розраховані заздалегідь, оскільки вони вже визначені за $p$ та $c$. Модифіковані рівняння трилінійної інтерполяції використовуються у подальшому розрахунку HOG дескриптора за запропонованим алгоритмом.

Програмна реалізація алгоритму. Швидкість розрахунків при програмній реалізації залежить не лише від реалізованого алгоритму, але й від оптимального використання операцій, наданих мовою програмування Javascript.

Оскільки алгоритм оптимізації розрахунків базується на операціях на рівні комірки, необхідно розбити вхідне зображення на масив комірок, відповідно до вхідних параметрів ( $p \times p-$ розмір комірки, $S_{x} \times S_{y}$ - розмір області розпізнавання). Виконаємо розрахунок, створивши функцію getImageCells схематично представлений на рис. 4. Слід зауважити, що розбиття коду на функції (модульність) - $є$ невід'ємним стандартом мови програмування Javascript.



Рис. 4 Функція розбиття зображення на комірки

Оскільки проходження по двомірному масиві - досить важка операція, зменшимо кількість надлишкових операцій втричі, включивши до проходження по пікселям зображення розрахунок коефіцієнтів Гауса (calculateGaussian) та коефіцієнтів $A \sim D$ (calculateAD).

Маючи масив комірок та розраховані коефіцієнти для кожного пікселя, наступним кроком є розрахунок HOG дескриптора, що потребує повторного проходження по кожному пікселю, але тепер на рівні комірки. Виконаємо ро- 
зрахунок, створивши функцію getHOGfeature, що містить у собі необхідну логіку для подальшої реалізації методу.

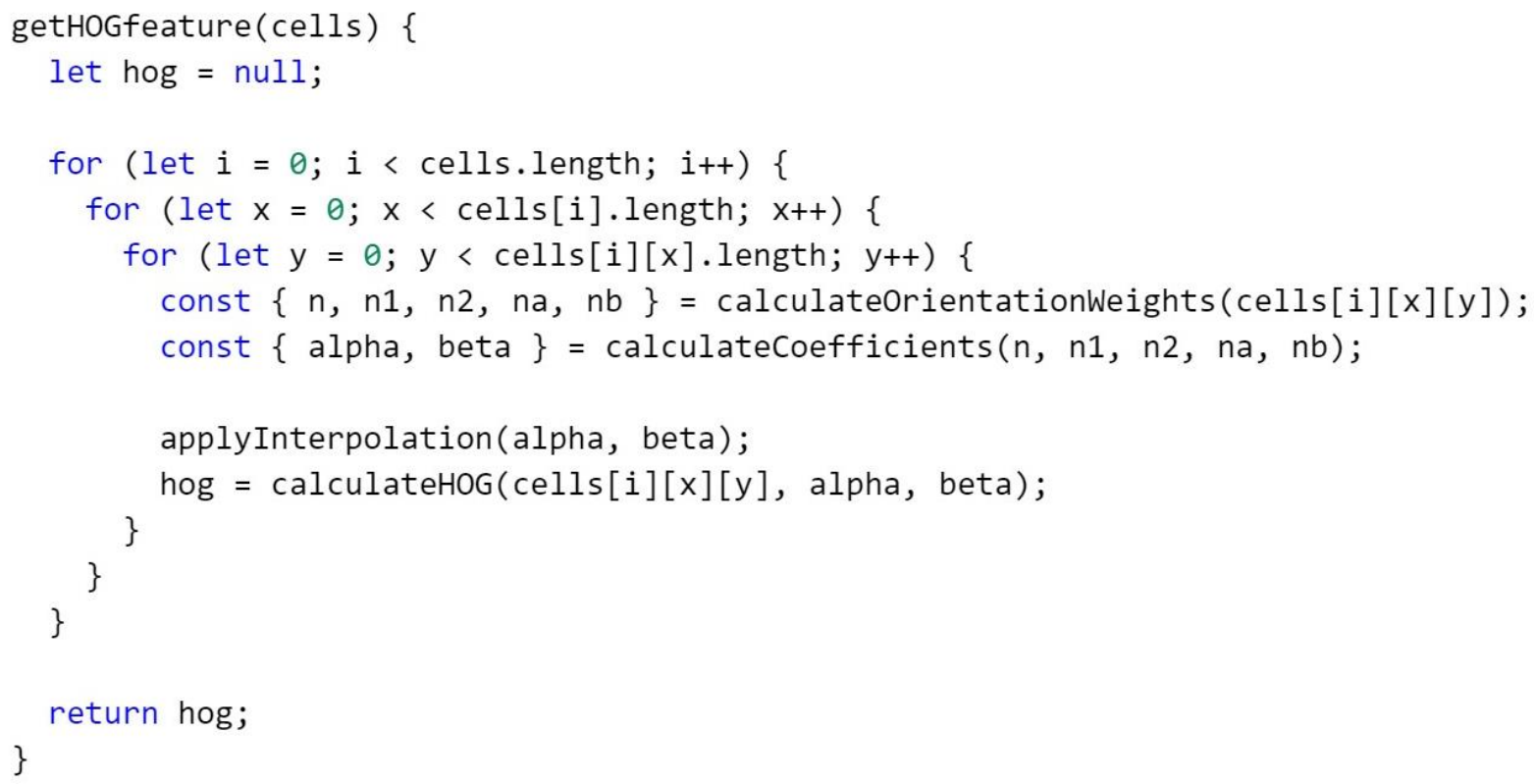

Рис. 5 Функція розрахунку HOG дескриптора

Розрахунок HOG дескриптора включає в себе розрахунок зважених голосів для трилінійної інтерполяції (calculateOrientationWeights), коефіцієнти А та В для трилінійної інтерполяції (calculateCoefficients), трилінійної інтерполяції (applyInterpolation) та безпосередньо гістограми напрямлених градієнтів (calculateHOG).

Функція calculateHOG містить у собі розрахунок відповідно до одного 3 чотирьох запропонованих типів комірки. Наприклад, коли піксель знаходиться у позиції $(0,0)$ у 0-ій комірці, роздивляється тільки тип 1 , оскільки 0 -ва комірка належить лише одному блоку, тому не причепна до перетинання, а коли піксель знаходиться у позиції $(7,0)$ у 1-ій комірці, належить до типу 2 у 0-му блоці та до типу 1 у 1-му блоці.

Незважаючи на ускладнення реалізації через більш складну логіку алгоритму оптимізації, даний метод надає можливість позбавитися від значної кількості надлишкових операцій, що прискорює розрахунок гістограми напрямлених градієнтів.

Таким чином отримуємо HOG дескриптор, що достатньо швидкий у розрахуванні та завдяки наявності інтерполяції при розрахунку, надає кращу точність при розпізнавання, ніж класичний $\mathrm{HOG}$ дескриптор.

Висновки. Для програмної реалізації, було обрано та програмно реалізовано метод оптимізації, представлений у роботі [1]. Було покращено результати оптимізації розрахунку HOG-дескриптора для розпізнавання змісту зображення. Для того, щоб повністю позбавитись надлишкових операцій, НОG дескриптор розраховувався на рівні операцій над коміркою. Такий підхід до- 
зволив розгляну кожну комірку лише один раз, що значно покращило швидкість розрахунку та, як наслідок, швидкість розпізнавання образів.

Тестування програмної реалізації на вище зазначеному наборі вказало, що даний підхід не тільки надає високу точність розпізнавання, але й покращує швидкість проведення розрахунків, побудови гістограми напрямлених градієнтів.

Програмна реалізація виконана на мові програмування Javascript та відповідає стандартам відповідного програмного забезпечення.

\section{Бібліографічні посилання}

1. Soojin, Kim. Fast Calculation of Histogram of Oriented Gradient Feature by Removing Redundancy in Overlapping Block [Text] / Soojin Kim, Kyeongsoon Cho // Journal of Information Science and Engineering. - 2014 - Volume 30. - C.1719-1731.

2. Navneet, Dalal. Histograms of Oriented Gradients for Human Detection [Text] / Navneet Dalal, Bill Triggs // 2005 IEEE Computer Society Conference on Computer Vision and Pattern Recognition (CVPR'05) - 2005. - Volume 1. - C. 886-893.

3. Южаков, Г.Б. Алгоритм быстрого построения дескрипторов изображения, основанных на технике гистограмм ориентированных градиентов [Текст] / Г.Б Южаков // Труды МФТИ. - 2013. - №3. - С. 84-91.

Надійшла до редколегіï 30.09.2019. 


\author{
О.М. Кісельова ${ }^{1}$, О.М. Притоманова ${ }^{1}$, С.В. Дзюба ${ }^{2}$ В.Г. Падалко \\ ${ }^{1}$ Дніпровський начіональний університет імені Олеся Гончара \\ 2 Придніпровський науковий центр НАН Украӥни та МОН Украӥни
}

\title{
РОЗВ'ЯЗАННЯ ДВОЕТАПНОЇ НЕПЕРЕРВНО-ДИСКРЕТНОЇ ЗАДАЧІ ОПТИМАЛЬНОГО РОЗБИТТЯ-РОЗПОДІЛУ З НЕЧІТКИМИ ПАРАМЕТРАМИ
}

Запропоновано метод розв'язання двоетапної неперервно-дискретної задачі оптимального розбиття-розподілу 3 нечіткими параметрами у цільовому функціоналі, який базусться на застосуванні методу нейролінгвістичної ідентифікації невідомих залежностей для відновлення чітких значень нечітких параметрі, методів теорії оптимального розбиття множин та методу потенціалів розв'язання транспортної задачі.

Ключові слова: нескінченновимірне математичне програмування, оптимальне розбиття-розподілення, недиференційовна оптимізація, нейронечіткі технології.

Предложен метод решения двухэтапной непрерывно-дискретной задачи оптимального разбиения-распределения с нечеткими параметрами в целевом функционале, который основан на применении метода нейролингвистической идентификации неизвестных зависимостей для восстановления четких значений нечетких параметров, методов теори оптимального разбиения множеств и метода потенциалов решения транспортной задачи.

Ключевые слова: бесконечномерное математическое программирование, оптимальное разбиение-распределение, недифференцируемая оптимизация, нейронечеткие технологии.

The theory of optimal set partitioning from an n-dimensional Euclidean space $E_{n}$ is an important part of infinite-dimensional mathematical programming.

The mostly reason of high interest in development of the theory of optimal set partitioning is that its results can be applied to solving the classes of different theoretical and applied optimization problems, which are transferred into continuous optimal set partitioning problem.

This paper investigates the further development of the theory of optimal set partitioning from $E_{n}$ in the case of a two-stage continuous-discrete problem of optimal partitioningdistribution with non-determined input data, which is frequently appear in solving practical problems.

The two-stage continuous-discrete problem of optimal partition-distribution under constraints in the form of equations and determined position of centers of subsets is generalized by proposed continuous-discrete problem of optimal partition-distribution in case if some parameters are presented in incomplete, inaccurate or unreliable form. These parameters can be represented as linguistic variables and the method of neurolinguistic identification of unknown complex, nonlinear dependencies can be used in purpose to recovery them.

(С) Кісельова О.М., Притоманова О.М., Дзюба С.В., Падалко В.Г., 2019 
A method for solving the two-stage continuous-discrete optimal partitioning-distribution problem with fuzzy parameters in target functional which based on usage of neurolinguistic identification of unknown dependencies for recovering precise values of fuzzy parameters, methods of the theory of optimal set partitioning and the method of potentials for solving a transportation problem is proposed.

Keywords: infinite-dimensional mathematical programming, optimal partitioningallocation, non-differentiable optimization, neurofuzzy technologies.

Вступ. Необхідність у вивченні неперервних моделей оптимального розбиття множин (ОРМ) $n$-вимірного евклідового простору $E_{n}$ викликана тим, що до таких моделей зводяться в математичній постановці багато абсолютно різних за своєю природою оптимізаційних теоретичних та прикладних задач [1]. Активно розвивається в даний час такий клас неперервних задач OРM, як задачі ОРМ в умовах невизначеності (стохастичні, нечіткі) [2].

Ця стаття присвячена подальшому розвитку теорії оптимального розбиття множин із $E_{n}$ на випадок двоетапної неперервно-дискретної задачі оптимального розбиття-розподілу в умовах невизначеності вхідних даних, які часто зустрічаються на практиці. Відзначимо, що класична скінченновимірна транспортна задача розглядається в роботі [3], дискретні двоетапні виробничо-транспортні задачі розглядаються в роботі [4]. В роботі [5] представлена класична скінченновимірна транспортна задача в умовах невизначеності.

Запропонована неперервно-дискретна задача оптимального розбиттярозподілу узагальнює двоетапну неперервно-дискретну задачу оптимального розбиття-розподілу при обмеженнях у вигляді рівностей та заданим положенням центрів підмножин, яка розглянута в [6], на випадок, коли деякі параметри задачі можуть бути задані неповно, неточно, недостовірно. Тоді дані параметри можна розглядати як лінгвістичні змінні. Для їх відновлення використовується метод нейролінгвістичній ідентифікації невідомих складних, нелінійних залежностей [7].

В даній статті запропоновано метод розв'язання сформульованої задачі, який базується на використанні методу нейролінгвістичної ідентифікації невідомих залежностей для відновлення чітких значень тих параметрів задачі, які задані нечітко, методів теорії оптимального розбиття множин та методу потенціалів розв’язання транспортної задачі.

Постановка задачі. Нехай $\Omega$ - обмежена, замкнута, вимірна за Лебегом множина в $n$-вимірному евклідовому просторі $E_{n}$.

Сукупність вимірних за Лебегом підмножин $\Omega_{1}, \ldots, \Omega_{N} 3 \Omega \subset \mathrm{E}_{n}$ будемо називати можливим розбиттям множини $\Omega$ на його підмножини $\Omega_{1}, \ldots, \Omega_{N}$, що не перетинаються, якщо

$$
\bigcup_{i=1}^{N} \Omega_{i}=\Omega, \operatorname{mes}\left(\Omega_{i} \cap \Omega_{j}\right)=0, i \neq j, i, j=1, \ldots, N,
$$

де mes( $)$ означає міру Лебега.

Позначимо клас всіх можливих розбиттів множини $\Omega$ на підмножини $\Omega_{1}, \ldots, \Omega_{N}$, що не перетинаються, через $\Sigma_{\Omega}^{N}$, тобто 


$$
\Sigma_{\Omega}^{N}=\left\{\left(\Omega_{1}, \ldots, \Omega_{N}\right): \bigcup_{i=1}^{N} \Omega_{i}=\Omega, \operatorname{mes}\left(\Omega_{i} \cap \Omega_{j}\right)=0, i \neq j, i, j=1, \ldots, N\right\} .
$$

Введемо функціонал

$$
\begin{aligned}
& F\left(\left\{\Omega_{1}, \ldots, \Omega_{i}, \ldots, \Omega_{N}\right\},\left\{v_{11}, \ldots, v_{i j}, \ldots, v_{N M}\right\}\right)= \\
& \quad \sum_{i=1}^{N} \int_{\Omega_{i}} c_{i}^{I}\left(x, \tau_{i}^{I}\right) \rho(x) d x+\sum_{i=1}^{N} \sum_{j=1}^{M} c_{i j}^{I I}\left(\tau_{i}^{I}, \tau_{j}^{I I}\right) v_{i j} .
\end{aligned}
$$

В (1) функції $c_{i}^{I}\left(x, \tau_{i}^{I}\right), i=1, \ldots, N, \epsilon$ функціями відстані між точками $x$ i $\tau_{i}^{I}$ для І-го етапу та визначаються як одна з метрик [2]:

$$
\begin{aligned}
& c\left(x, \tau_{i}\right)=\left\|x-\tau_{i}\right\|_{2}=\sqrt{\sum_{k=1}^{n}\left(x^{(k)}-\tau_{i}^{(k)}\right)^{2}}-\text { евклідова, } \\
& c\left(x, \tau_{i}\right)=\left\|x-\tau_{i}\right\|_{1}=\sum_{k=1}^{n}\left|x^{(k)}-\tau_{i}^{(k)}\right|-\text { манхеттенська, } \\
& c\left(x, \tau_{i}\right)=\left\|x-\tau_{i}\right\|_{0}=\max _{k=1, \ldots, n}\left\{\left|x^{(k)}-\tau_{i}^{(k)}\right|\right\}-\text { Чебишева; }
\end{aligned}
$$

функції $c_{i j}^{I I}\left(\tau_{i}^{I}, \tau_{j}^{I I}\right), i=1, \ldots, N, j=1, \ldots, M, \epsilon$ функціями відстані між точками $\tau_{i}^{I}$ i $\tau_{j}^{I I}$ для II-го етапу, які визначаються аналогічно функціям відстані I-го етапу.

Для практичних задач відстані між споживачами і підприємствами I-го етапу, а також відстані між підприємствами I-го та II-го етапів можуть істотно відрізнятися від відстаней, що розраховуються за допомогою «формальних» метрик (2)-(4). Ці відмінності можуть бути задані нечітко за допомогою множника - вектора нечітких параметрів $\tilde{a}=\left(\tilde{a}_{1}, \ldots, \tilde{a}_{N}\right)$ для кожної функції $c_{i}^{I}\left(x, \tau_{i}^{I}\right), i=1, \ldots, N$ та вектора нечітких параметрів $\tilde{w}=\left(\tilde{w}_{11}, \ldots, \tilde{w}_{N M}\right)$ для кожної функції $c_{i j}^{I I}\left(\tau_{i}^{I}, \tau_{j}^{I I}\right), i=1, \ldots, N, j=1, \ldots, M$.

Тоді функціонал (1) запишемо у виді

$$
\begin{aligned}
& F\left(\left\{\Omega_{1}, \ldots, \Omega_{i}, \ldots, \Omega_{N}\right\},\left\{v_{11}, \ldots, v_{i j}, \ldots, v_{N M}\right\}, \tilde{a}, \tilde{w}\right)= \\
& =\sum_{i=1}^{N} \int_{\Omega_{i}} \tilde{a}_{i} c_{i}^{I}\left(x, \tau_{i}^{I}\right) \rho(x) d x+\sum_{i=1}^{N} \sum_{j=1}^{M} \tilde{w}_{i j} c_{i j}^{I I}\left(\tau_{i}^{I}, \tau_{j}^{I I}\right) v_{i j} .
\end{aligned}
$$

Перш ніж формулювати математичну постановку двоетапної неперервнодискретної лінійної однопродуктової задачі оптимального розбиттярозподілу на випадок заданих координат центрів підмножин і при обмеженнях у вигляді рівностей, знімемо нечіткість у функціоналі (5) за допомогою методу нейролінгвістичної ідентифікації з [7].

Для спрощення опису методу нейролінгвістичної ідентифікації для відновлення значень нечітких параметрів $\tilde{a}_{1}, \ldots, \tilde{a}_{N}, \tilde{w}_{11}, \ldots, \tilde{w}_{N M}$ позначимо їх відновленні значення як $y$ та розглянемо функціональну залежність виходу y від входів $z_{1}, \ldots, z_{q}$ об’єкта ідентифікації у виді: 


$$
y=y\left(z_{1}, \ldots, z_{q}\right),
$$

тут $z_{1}, \ldots, z_{q}$ - фактори, що впливають на $y$, та можуть бути задані нечітко. Для задачі ідентифікації передбачаються відомими області визначення входів $z_{1}, \ldots, z_{q}$, область зміни виходу $y$ для (6), а також експертноекспериментальна інформація про залежність (6) у вигляді вибірки даних про входи і вихід об'єкта ідентифікації.

Задача ідентифікації (відновлення) складної нелінійної залежності виду (6) розглядається як побудова моделі об'єкта за експертно-експериментальними даними про взаємозв'язки <входи> - <вихід> та вирішується, як правило, в два етапи [7]:

- структурна ідентифікація: формування нечіткої бази знань про об’єкт і побудова на ії основі нечіткої моделі об'єкта з кількома входами і одним виходом, яка грубо відтворює залежність виходу від входів за допомогою лінгвістичних правил «ЯКЩО-ТО», що генеруються з експериментальних даних;

- параметрична ідентифікація (настройка): пошук таких параметрів нечіткої моделі, які мінімізують відхилення модельних значень від експериментальних.

У результаті застосування методу нейролінгвістичної ідентифікації отримуємо точне (чітке) значення вихідної змінної $y$, яке розраховується за такими формулами:

$$
\begin{gathered}
y=\frac{\sum_{k=1}^{L} d_{k} \cdot \mu{ }^{*}{ }_{D_{k}}(y)}{\sum_{k=1}^{L} \mu{ }_{D_{k}}(y)}, \\
\mu_{D_{k}}^{*}(y)=\left\{\begin{array}{l}
\sum_{j=1}^{s_{k}} p_{j}^{* k}\left(z_{1}, z_{2}, \ldots, z_{q}\right), \quad \text { якщо } \sum_{j=1}^{s_{k}} p_{j}^{* k}\left(z_{1}, z_{2}, \ldots, z_{q}\right) \leq 1, \\
1 \quad p_{j}^{*{ }_{j}^{k}}\left(z_{1}, z_{2}, \ldots, z_{q}\right)=v_{j}^{* k} \prod_{i=1}^{q} \mu_{i j}^{* k}\left(z_{i}\right),
\end{array}\right. \\
\mu^{*}{ }_{i j}^{k}\left(z_{i}\right)=\frac{1+\left(\frac{z_{i}-t{ }_{i j}^{* k}}{e_{i j}^{* k}}\right)^{2}, i=1, \ldots, q, j=1, \ldots, s_{k}, \mathrm{k}=1,2, \ldots, \mathrm{L},}{\text { випадках, }}
\end{gathered}
$$

де у формулах (7)-(10):

- $\mu^{*} D_{k}(y)$ - функція належності вихідної змінної $y$ класу $D_{k}, k=1,2, \ldots, L$, $L$ - кількість класів (лінгвістичних термів) вихідної змінної $y, d_{k}$ - центр класу $D_{k}$; 
- $p{ }_{j}^{*}\left(z_{1}, z_{2}, \ldots, z_{q}\right)$ - нечіткі продукційні правила, які отримуються з експертно-експериментальної інформації про залежність (6), $j$ - номер правила у $k$-у класі, $j=1,2, \ldots, s_{k}, s_{k}$ - кількість правил у $k$-ом класі; $v_{j}^{* k}$ - вага $j$-го правила у $k$-у класі виходу;

- $\mu_{i j}^{*}\left(z_{i}\right)$ - дзвонова функція належності змінної $z_{i}$ iї лінгвістичному терму у $j$-у правилі $k$-го класу виходу вихідної змінної $y, t * i j$ - координата максимуму і $e_{i j}^{*}$ - коефіцієнт концентрації цієї функції належності.

Зауваження. Значення $v^{*_{j}^{k}}$ - ваг правил у (9) та параметрів $t_{i j}^{k}, e_{i j}^{* k}$ функції належності (10) відмічені зірочкою як оптимальні, тобто такі, що отримані у результаті етапу параметричної ідентифікації методу нейролінгвістичної ідентифікації, для яких відхилення експериментальних даних від модельних, отриманих після настройки нечіткої моделі об’єкта (6), досягає мінімального значення. Значення $\mu^{*}{ }_{D_{k}}(y), \quad p_{j}^{* k}\left(z_{1}, z_{2}, \ldots, z_{q}\right)$ та $\mu{ }_{i j}^{k}\left(z_{i}\right)$ у (7)-(10) обчислюються при оптимальних значеннях $v_{j}^{*}, t{ }_{i j}^{k}, e_{i j}^{* k}$.

Таким чином, після відновлення значень нечітких параметрів $\tilde{a}_{1}, \ldots, \tilde{a}_{N}$, $\tilde{w}_{11}, \ldots, \tilde{w}_{N M} \quad$ у функціоналі (5) за допомогою описаного методу нейролінгвістичної ідентифікації, отримуємо їх відновлені (чіткі) значення $a_{1}, \ldots, a_{N}, w_{11}, \ldots, w_{N M}$.

Сформулюємо тепер математичну постановку двоетапної неперервнодискретної лінійної однопродуктової задачі оптимального розбиттярозподілу на випадок заданих координат центрів підмножин і при обмеженнях у вигляді рівностей та відновленими значеннями ії нечітких параметрів.

Задача 1. Знайти таке розбиття множини $\Omega$ на $N$ вимірних за Лебегом підмножин $\Omega_{*_{1}}, \ldots, \Omega_{*_{N}}$ i такий невід'ємний вектор $v_{*}=\left(v_{*_{11}}, \ldots, v_{* i j}, \ldots, v_{*_{N M}}\right) \in E_{N M}$, які забезпечують

$$
\min _{\left\{\Omega_{1}, \ldots, \Omega_{N}\right\},\left\{v_{1}, \ldots v_{N M}\right\}} F\left(\left\{\Omega_{1}, \ldots, \Omega_{N}\right\},\left\{v_{11}, \ldots v_{N M}\right\}\right)
$$

за умов

$$
\begin{aligned}
& \sum_{j=1}^{M} v_{i j}=\int_{\Omega_{i}} \rho(x) d x, i=1, \ldots, N ; \sum_{i=1}^{N} v_{i j}=b_{j}^{I I}, j=1, \ldots, M ; \\
& \left\{\Omega_{1}, \ldots, \Omega_{N}\right\} \in \Sigma_{\Omega}^{N} ; v_{i j} \geq 0, i=1, \ldots, N, j=1, \ldots, M ; \\
& x=\left(x^{(1)}, \ldots, x^{(n)}\right) \in \Omega ; \quad \in \underbrace{\Omega \times \ldots \times \Omega}_{N}=\Omega^{N}, \tau^{I I}=\left(\tau_{1}^{I I}, \ldots, \tau_{M}^{I I}\right) \in \Omega^{M},
\end{aligned}
$$

де 
ISSN 2074-5893 Питання прикладної математики і математичного моделювання. Випуск 19

$$
\begin{aligned}
& F\left(\left\{\Omega_{1}, \ldots, \Omega_{i}, \ldots, \Omega_{N}\right\},\left\{v_{11}, \ldots, v_{i j}, \ldots, v_{N M}\right\}\right)= \\
& =\sum_{i=1}^{N} \int_{\Omega_{i}} a_{i} c_{i}^{I}\left(x, \tau_{i}^{I}\right) \rho(x) d x+\sum_{i=1}^{N} \sum_{j=1}^{M} w_{i j} c_{i j}^{I I}\left(\tau_{i}^{I}, \tau_{j}^{I I}\right) v_{i j} .
\end{aligned}
$$

У функціоналі (11) кожний з параметрів $a_{i}, w_{i j}, i=1, \ldots, N, j=1, \ldots, M$, позначений раніше, як вихід $y$, що залежить від входів $z_{1}, \ldots, z_{q}$, у методі нейролінгвістичної ідентифікації, розраховується за формулами (7)-(10).

Тут $b_{j}^{I I}, j=1, \ldots, M,-$ задані невід’ємні числа, причому виконуються умови розв'язуваності задачі

$$
S=\int_{\Omega} \rho(x) d x=\sum_{i=1}^{N} \int_{\Omega_{i}} \rho(x) d x=\sum_{i=1}^{N} \sum_{j=1}^{M} v_{i j}=\sum_{j=1}^{M} b_{j}^{I I}, 0 \leq b_{j}^{I I} \leq S, j=1, \ldots, M .
$$

Зауважимо, що в термінах класичної транспортної задачі вектор $v=\left(v_{11}, \ldots v_{N M}\right)$ має значення обсягів транспортування продукції з пунктів першого етапу $\tau_{i}^{I}, i=1, \ldots, N$, до пунктів $\tau_{j}^{I I}, j=1, \ldots, M$, кінцевого споживання (другого етапу).

Функція $\rho(x)$ - дійсна, обмежена, вимірна, невід’ємна на $\Omega$; $\tau_{i}^{I}=\left(\tau_{i}^{I(1)}, \ldots, \tau_{i}^{I(n)}\right), i=1, \ldots, N,-$ деяка задана еталонна точка для підмножини $\Omega_{i}$, яку позначають центром цієї підмножини; $\tau_{j}^{I I}=\left(\tau_{j}^{I I(1)}, \ldots, \tau_{j}^{I I(n)}\right), j=1, \ldots, M,-$ деяка задана точка множини $\Omega$.

Тут і надалі інтеграли розуміються в сенсі Лебега. Будемо вважати, що міра множини граничних точок підмножин $\Omega_{i}, i=1, \ldots, N$, дорівнюють нулю.

Пару $\left(\left\{\Omega_{*_{1}}, \ldots, \Omega_{*_{N}}\right\},\left\{v_{*_{11}}, \ldots v_{*_{N M}}\right\}\right)$, що є розв'язкам задачі 1 , назвемо оптимальною.

Введемо характеристичну функцію

$$
\lambda_{i}(x)=\left\{\begin{array}{l}
1, x \in \Omega_{i}, \\
0, x \in \Omega \backslash \Omega_{i},
\end{array}\right.
$$

підмножини $\Omega_{i}, i=1, \ldots, N$.

Розглянемо функціонал

$$
I(\lambda(\cdot), v)=\sum_{i=1}^{N} \int_{\Omega} a_{i} c_{i}^{I}\left(x, \tau_{i}^{I}\right) \rho(x) \lambda_{i}(x) d x+\sum_{i=1}^{N} \sum_{j=1}^{M} w_{i j} c_{i j}^{I I}\left(\tau_{i}^{I}, \tau_{j}^{I I}\right) v_{i j},
$$

де вектор-функція $\lambda(x)$ має вид $\lambda(x)=\left(\lambda_{1}(x), \ldots, \lambda_{i}(x), \ldots, \lambda_{N}(x)\right)$, а вектор $v$ має вид $v=\left(v_{11}, \ldots, v_{i j}, \ldots, v_{N M}\right) . \quad$ Очевидно, що $I(\lambda(\cdot), v)=F\left(\left\{\Omega_{1}, \ldots, \Omega_{N}\right\},\left\{v_{11}, \ldots, v_{N M}\right\}\right)$.

Перепишемо задачу 1 в термінах характеристичної функції $\lambda_{i}(x)$ підмножини $\Omega_{i}, i=1, \ldots, N$, у такому виді. 
Задача 2. Знайти

$$
\min _{(\lambda(\cdot), v)} I(\lambda(\cdot), v),
$$

за умов

$$
\begin{gathered}
\sum_{j=1}^{M} v_{i j}=\int_{\Omega} \rho(x) \lambda_{i}(x) d x, i=1, \ldots, N ; \sum_{i=1}^{N} v_{i j}=b_{j}^{I I}, j=1, \ldots, M ; \\
\lambda_{i}(x)=0 \vee 1 \text { майже всюди (м.в.) для } x \in \Omega, i=1, \ldots, N ; \\
\sum_{i=1}^{N} \lambda_{i}(x)=1 \text { м.в. для } x \in \Omega ; v_{i j} \geq 0, i=1, \ldots, N, j=1, \ldots, M .
\end{gathered}
$$

Від нескінченновимірної задачі 2 з булевими значеннями змінних $\lambda_{i}(\cdot)$, $i=1, \ldots, N$, перейдемо до відповідної задачі зі значеннями $\lambda_{i}(\cdot)$ з відрізку $[0,1]$.

Задача 3. Зайти

$$
\min _{(\lambda(\cdot), v) \in \Gamma_{1} \times Q} I(\lambda(\cdot), v)
$$

де

$$
\begin{aligned}
& \Gamma_{1}=\left\{\lambda(x)=\left(\lambda_{1}(x), \ldots, \lambda_{N}(x)\right) \in \Gamma \text { м.в. для } x \in \Omega ;\right. \\
& \left.\sum_{j=1}^{M} v_{i j}=\int_{\Omega} \rho(x) \lambda_{i}(x) d x, i=1, \ldots, N ; \sum_{i=1}^{N} v_{i j}=b_{j}^{I I}, j=1, \ldots, M\right\} . \\
& \Gamma=\left\{\lambda(x): 0 \leq \lambda_{i}(x) \leq 1, x \in \Omega, i=1, \ldots, N ; \sum_{i=1}^{N} \lambda_{i}(x)=1 \text { м.в. для } x \in \Omega\right\} ; \\
& Q=\left\{v=\left(v_{11}, \ldots, v_{i j}, \ldots, v_{N M}\right): v_{i j} \geq 0, i=1, \ldots, N, j=1, \ldots, M\right\} .
\end{aligned}
$$

При кожному фіксованому $v \in Q$ задача 3 , як доведено в [1], має розв'язок, і у множині оптимальних розв'язків задачі 3 містяться оптимальні розв'язки задачі 2 , що дозволяє в подальшому перейти до розгляду задачі 3.

Метод розв'язання задачі. Введемо функціонал Лагранжа для задачі 3 таким чином:

$$
L(\{\lambda(\cdot), v\}, \Psi)=I(\lambda(\cdot), v)+\sum_{i=1}^{N} \psi_{i}\left(\int_{\Omega} \rho(x) \lambda_{i}(x) d x-\sum_{j=1}^{M} v_{i j}\right)+\sum_{j=1}^{M} \eta_{j}\left(b_{j}^{I I}-\sum_{i=1}^{N} v_{i j}\right),
$$

де $\Psi=\left(\psi_{1}, \ldots, \psi_{i}, \ldots, \psi_{N} ; \eta_{1}, \ldots, \eta_{j}, \ldots, \eta_{M}\right)-(N+M)$-вимірний вектор дійсних чисел довільного знаку; $\lambda(x)=\left(\lambda_{1}(x), \ldots, \lambda_{N}(x)\right) \in \Gamma \quad$ м.в. для $x \in \Omega$; $v=\left(v_{11}, \ldots, v_{i j}, \ldots, v_{N M}\right)-N \times M-$ вимірний вектор дійсних невід'ємних чисел.

Пару елементів $\left(\left\{\lambda_{*}(\cdot), v_{*}\right\}, \Psi^{*}\right)$ назвемо сідловою точкою функціоналу (13) на множині $\{\Gamma \times Q\} \times \Lambda$, де

$$
\begin{gathered}
Q=\left\{v=\left(v_{11}, \ldots, v_{i j}, \ldots, v_{N M}\right): v_{i j} \geq 0, i=1, \ldots, N, j=1, \ldots, M\right\}, \\
\Lambda=\left\{\Psi=(\psi ; \eta) \in E_{N+M}: \psi=\left(\psi_{1}, \ldots, \psi_{N}\right) \in E_{N}, \eta=\left(\eta_{1}, \ldots, \eta_{M}\right) \in E_{M}\right\},
\end{gathered}
$$


якщо $L\left(\left\{\lambda_{*}(\cdot), v_{*}\right\}, \Psi\right) \leq L\left(\left\{\lambda_{*}(\cdot), v_{*}\right\}, \Psi^{*}\right) \leq L\left(\{\lambda(\cdot), \tau\}, \Psi^{*}\right)$ для $\lambda(\cdot) \in \Gamma, v \in Q$,

$$
\Psi \in \Lambda \text {, }
$$

або $L\left(\left\{\lambda_{*}(\cdot), v_{*}\right\}, \Psi^{*}\right)=\min _{\{\lambda(\cdot), v\} \in \Gamma \times Q} \max _{\Psi \in \Lambda} L(\{\lambda(\cdot), v\}, \Psi)=\max _{\Psi \in \Lambda} \min _{\{\lambda(\cdot), v\} \in \Gamma \times Q} L(\{\lambda(\cdot), v\}, \Psi)$.

Введемо функціонали

$$
\begin{gathered}
X(\{\lambda(\cdot), v\})=\max _{\Psi \in \Lambda} L(\{\lambda(\cdot), v\}, \Psi),\{\lambda(\cdot), v\} \in \Gamma \times Q, \\
G(\Psi)=\min _{\{\lambda(\cdot), v\} \in \Gamma \times Q} L(\{\lambda(\cdot), v\}, \Psi), \Psi \in \Lambda .
\end{gathered}
$$

Розглянемо задачі

$$
\begin{gathered}
X(\{\lambda(\cdot), v\}) \rightarrow \min ,\{\lambda(\cdot), v\} \in \Gamma \times Q . \\
G(\Psi) \rightarrow \max , \Psi \in \Lambda .
\end{gathered}
$$

Задачу (14) назвемо прямою, а задачу (15) - двоїстою до задачі (14).

Неважко показати, слідуючи [2], що задачі (14), (15) пов'язані співвідношенням двоїстості $X_{*}=G^{*}$ і розв'язок пари двоїстих задач (14) і (15), (кожна 3 яких розв'язувана) еквівалентний відшуканню сідлової точки функціонала Лагранжа (13) на множині $\{\Gamma \times Q\} \times \Lambda$.

Для відшукання сідлової точки функціонала Лагранжа (13), виходячи з [1], запишемо двоїсту задачу (15) у вигляді

$$
\begin{gathered}
G(\Psi)=G_{2}(\Psi)=\int_{\Omega} \min _{k=1, \ldots, N}\left(a_{k} c_{k}^{I}\left(x, \tau_{k}^{I}\right)+\psi_{k}\right) \rho(x) d x+ \\
+\sum_{j=1}^{M} b_{j}^{I I} \min _{k=1, \ldots, N}\left(w_{i k} c_{k j}^{I I}\left(\tau_{k}^{I}, \tau_{j}^{I I}\right)-\psi_{k}\right) \rightarrow \max _{\psi}, \\
\psi=\left(\psi_{1}, \ldots, \psi_{N}\right) \in E_{N} .
\end{gathered}
$$

Таким чином, перша компонента $\lambda_{*}(\cdot)=\left(\lambda_{*_{1}}(\cdot), \ldots, \lambda_{*_{i}}(\cdot), \ldots, \lambda_{*_{N}}(\cdot)\right)$ оптимального розв'язку задачі 3 визначається для всіх $i=1, \ldots, N$, та майже всіх $x \in \Omega$ таким чином:

$$
\lambda_{* i}(x)= \begin{cases}1, & \text { якщо } a_{i} c_{i}^{I}\left(x, \tau_{* i}^{I}\right)+\psi_{i}^{*} \leq a_{k} c_{k}^{I}\left(x, \tau_{* k}^{I}\right)+\psi_{k}^{*}, i \neq k, k=1, \ldots, N, \\ 0 & \text { в інших випадках, }\end{cases}
$$

у якості $\psi_{1}^{*}, \ldots, \psi_{N}^{*}$ вибирається оптимальний розв'язок двоїстої задачі (15), приведеної до виду (16), (17).

Друга компонента $v_{*}=\left(v_{*_{11}}, \ldots, v_{* i j}, \ldots, v_{*_{N M}}\right)$ відшукується як оптимальний розв'язок наступної скінченновимірної транспортної задачі методом потенціалів [3]:

$$
\sum_{i=1}^{N} \sum_{j=1}^{M} w_{i j} c_{i j}^{I I}\left(\tau_{* i}^{I}, \tau_{j}^{I I}\right) v_{i j} \rightarrow \min _{v}
$$

за умов 


$$
\begin{gathered}
\sum_{j=1}^{M} v_{i j}=\int_{\Omega} \rho(x) \lambda_{*_{i}}(x) d x, i=1, \ldots, N, \\
\sum_{i=1}^{N} v_{i j}=b_{j}^{I I}, j=1, \ldots, M, \\
v_{i j} \geq 0, i=1, \ldots, N, j=1, \ldots, M,
\end{gathered}
$$

причому виконується умова балансу

$$
\int_{\Omega} \rho(x) d x=\sum_{i=1}^{N} \int_{\Omega_{i}} \rho(x) d x=\sum_{j=1}^{M} b_{j}^{I I} .
$$

Далі наведемо алгоритм розв'язання задачі 3, складовими якого $є$ один 3 варіантів $r$-алгоритму Н.3. Шора 3 [8], який застосовується для числового розв'язку двоїстої задачі (16)-(17), 3 урахуванням недиференційовності функції $G_{2}(\psi)$, і метод потенціалів 3 [3], що застосовується для розв'язання задачі (18)-(22) відшукання значення другої компоненти $v_{*}$ оптимального розв'язку задачі 3 .

Алгоритм розв'язання задачі. Перш ніж сформулювати алгоритм розв'язання задачі 3 , визначимо $i-\mathrm{y}, i=1, \ldots, N$, компоненту вектора узагальненого градіента $g_{G_{2}}(\psi)=\left(g_{G_{2}}^{\psi_{1}}(\psi), \ldots, g_{G_{2}}^{\psi_{i}}(\psi), \ldots, g_{G_{2}}^{\psi_{N}}(\psi)\right)$ функції $G_{2}(\psi)$ задачі (16) в точці $\psi=\left(\psi_{1}, \ldots, \psi_{N}\right)$ таким чином:

$$
g_{G_{2}}^{\psi_{i}}(\psi)=\int_{\Omega} \rho(x) \lambda_{i}(x) d x+\sum_{j=1}^{M}\left(b_{j}^{I I} q_{i j}\right), i=1, \ldots, N,
$$

де $\lambda_{i}(x)=$

$= \begin{cases}1, & \text { якщо } a_{i} c_{i}^{I}\left(x, \tau_{i}^{I}\right)+\psi_{i}^{*} \leq a_{k} c_{k}^{I}\left(x, \tau_{k}^{I}\right)+\psi_{k}, i \neq k, \text { м.в. для } x \in \Omega, k=1, \ldots, N, \\ 0 & \text { в інших випадках; }\end{cases}$

$$
q_{i j}=\left\{\begin{array}{l}
-1, \quad w_{i j} c_{i j}^{I I}\left(\tau_{i}^{I}, \tau_{j}^{I I}\right)-\psi_{i}=\min _{k=1, \ldots, N}\left(w_{k j} c_{k j}\left(\tau_{k}^{I}, \tau_{j}^{I I}\right)-\psi_{k}\right), i=1, \ldots, N, j=1, \ldots, M, \\
0 \quad \text { в інших випадках. }
\end{array}\right.
$$

Далі опишемо алгоритм.

Алгоритм.

Попередній етап. Область $\Omega$ укладаємо в $n$-вимірний паралелепіпед П, сторони якого паралельні вісям декартової системи координат, вважаємо $\rho(x)=0$ для $x \in \Pi \backslash \Omega$. Паралелепіпед покриваємо прямокутною сіткою і задаємо початкове наближення $\psi=\psi^{(0)}$. Обчислюємо значення $\lambda^{(0)}(x)$ в вузлах сітки за формулами (24) при $\psi=\psi^{(0)}$ та значеннями параметрів $a_{1}, \ldots, a_{N}$, відновленими за допомогою методу нейролінгвістичної ідентифікації за формулами (7)-(10). Обчислюємо значення вектору узагальненого градієнта $g_{G_{2}}(\psi)$ в вузлах сітки за формулою (23) при $\psi=\psi^{(0)}, \lambda(x)=\lambda^{(0)}(x)$.

Крок 1. Обчислюємо за формулою 
ISSN 2074-5893 Питання прикладної математики і математичного моделювання. Випуск 19

$$
\psi^{(1)}=\psi^{(0)}+h_{0} g_{G_{2}}\left(\psi^{(0)}\right),
$$

де $h_{0}$ - величина кроку, яка розраховується із умови максимуму функції $G_{2}(\psi)$ за напрямком узагальненого градієнта $g_{G_{2}}\left(\psi^{(0)}\right)$.

Крок 2. Нехай в результаті обчислень після $k, k=2,3, \ldots$, кроків алгоритму отримані значення $\psi^{(k)}, \lambda^{k-1}(x)$ в вузлах сітки.

Крок $(k+1)-\check{u}$.

1) обчислюємо значення $\lambda^{(k)}(x)$ у вузлах сітки за формулами (24) при $\psi=\psi^{(k)}$ та значеннями параметрів $a_{1}, \ldots, a_{N}$, відновленими за допомогою методу нейролінгвістичної ідентифікації за формулами (7)-(10);

2 ) обчислюємо значення вектору $g_{G_{2}}(\psi)$ в вузлах сітки за формулам (23) при $\psi=\psi^{(k)}, \lambda(x)=\lambda^{(k)}(x)$;

3) проводимо обчислення за ітераційною формулою $\psi^{(k+1)}=\psi^{(k)}+h_{k} B_{k+1}^{\psi} \tilde{g}_{G_{2}}^{\psi}$, де $B_{k+1}^{\psi}$ - оператор відображення перетвореного простору в основний простір $E_{N}$, причому $B_{0}^{\psi}=I_{N}$ (одинична матриця), $\tilde{g}_{G_{2}}^{\psi}=B_{k+1}^{*} g_{G_{2}}\left(\psi^{(k)}\right), h_{k}-$ величина кроку, яка визначається з умови максимуму функції $G_{2}(\psi)$ у напрямку узагальненого градієнта $g_{G_{2}}\left(\psi^{(k)}\right)$ в перетвореному просторі;

4) якщо умова

$$
\left\|\psi^{(k+1)}-\psi^{(k)}\right\| \leq \varepsilon, \varepsilon>0
$$

не виконується, переходимо до $(k+2)$-го кроку алгоритму, якщо виконується, то до п.5;

5) вважаємо $\psi^{*}=\psi^{l}, \lambda_{*}(x)=\lambda^{(l)}(x)$, де $l$-номер ітерації, на якій виконалася умова (25);

6) розв'язуючи транспортну задачу методом потенціалів при $\lambda(x)=\lambda_{*}(x)$, $\psi=\psi^{*}$ та значеннях параметрів $w_{11}, \ldots, w_{N M}$, відновлених за допомогою методу нейролінгвістичної ідентифікації за формулами (7)-(10), знаходимо $v_{*}=\left(v_{*_{11}}, \ldots, v_{*_{N M}}\right)$;

7) обчислюємо оптимальне значення цільового функціоналу $G_{2}(\psi)$ двоїстої задачі (16)-(17) при $\psi=\psi^{*}$ та, для контролю правильності розрахунків, оптимальне значення цільового функціонала (12) задачі 3 за формулою

$$
I\left(\lambda_{*}(\cdot), v_{*}\right)=\sum_{i=1}^{N} \int_{\Omega} a_{i} c_{i}^{I}\left(x, \tau_{i}^{I}\right) \rho(x) \lambda_{*_{i}}(x) d x+\sum_{i=1}^{N} \sum_{j=1}^{M} w_{i j} c_{i j}^{I I}\left(\tau_{i}^{I}, \tau_{j}^{I I}\right) v_{* i j},
$$

де значення параметрів $a_{1}, \ldots, a_{N}, w_{11}, \ldots, w_{N M}$ відновлені за допомогою методу нейролінгвістичної ідентифікації невідомих складних, нелінійних залежностей за формулами (7)-(10). 


\section{Завершення роботи алгоритму.}

Висновки. Ця стаття присвячена подальшому розвитку теорії ОРМ $n$-вимірного евклідового простору $E_{n}$ на випадок двоетапної неперервнодискретної лінійної задачі оптимального розбиття-розподілу з нечіткими параметрами при обмеженнях у формі рівностей та заданим положенням центрів підмножин.

Запропоновано метод розв'язання даної задачі, заснований на застосуванні методу нейролінгвістичної ідентифікації невідомих залежностей для відновлення чітких значень нечітких параметрів, методів теорії оптимального розбиття множин та методу потенціалів розв'язання транспортної задачі.

\section{Бібліографічні посилання}

1. Киселева, Е.М. Непрерывные задачи оптимального разбиения множеств: теория, алгоритмы, приложения [Текст] / Е.М. Киселева, Н.3. Шор. - К.: Наукова думка, 2005. $564 \mathrm{c}$.

2. Кісельова, О.М. Становлення та розвиток теорії оптимального розбиття множин. Теоретичні і практичні застосування: монографія [Текст] / О.М. Кісельова. - Д.: Ліра, 2018. - 532 c.

3. Гольштейн, Е.Г. Задачи линейного программирования транспортного типа [Текст] / Е.Г. Гольштейн, Д.Б. Юдин. - М.: Наука, 1969. - 382 с.

4. Стецюк, П.I. Двоетапна транспортна задача та iї AMPL-реалізація [Текст] / П.I. Стецюк, В.І. Ляшко, Г.В. Мазютинець // Наукові записки НаУКМА. Комп'ютерні науки. - 2018. - Т. 1. - С. 14-20.

5. Згуровский, М.3. Модели и методы принятия решений в нечетких условиях [Текст] / М.З. Згуровский, Ю.П. Зайченко. - К.: Наукова думка, 2011. - 288 с.

6. Кісельова, О.М. Про розв'язок двоетапної неперервно-дискретної задачі оптимального розбиття-розподілення [Текст] / О.М. Кісельова., О.М. Притоманова, С.А. Ус, В.В. Матяш // Математичне та програмне забезпечення інтелектуальних систем. Тези доповідей XVI Міжнародної науково-практичної конференції, листопад 21-23. - Д.: Ліра, 2018. C. 99-101.

7. Kiseleva, Elena M. Algorithm for Solving a Continuous Problem of Optimal Partitioning with Neurolinguistic Identification of Functions in Target Functional [Text] / Elena M. Kiseleva, Olga M. Prytomanova, Sergey V. Zhuravel // Journal of Automation and Information Sciences. - 2018. - Volume 50. - Issue 3. - PP. 1-20. DOI: 10.1615/JAutomatInfScien.v50.i3.10.

8. Киселева, Е.М. Непрерывные задачи оптимального разбиения множеств и $r$-алгоритмы [Текст] / Е.М. Киселева, Л.С. Коряшкина. - К.: Наукова думка, 2015. - 400 с.

Надійшла до редколегії 23.10. 2019. 


\author{
О.М. Кісельова ${ }^{1}$, О.М. Притоманова ${ }^{1}$, С.В. Дзюба ${ }^{2}$, В.Г. Падалко ${ }^{1}$ \\ ${ }^{1}$ Дніпровський наиіональний університет імені Олеся Гончара \\ ${ }^{2}$ Придніпровський науковий центр НАН Украӥни та МОН Украӥни
}

\title{
ПОБУДОВА МУЛЬТИПЛІКАТИВНО ЗВАЖЕНОЇ ДІАГРАМИ ВОРОНОГО 3 НЕЧІТКИМИ ПАРАМЕТРАМИ
}

Запропоновано алгоритм побудови мультиплікативно зваженої діаграми Вороного при наявності нечітких параметрів 3 оптимальним розміщенням точокгенераторів в обмеженій множині $n$-вимірного евклідового простору $E_{n}$. Алгоритм розроблений на основі синтезу методів розв'язання задач теорії оптимального розбиття множин 3 нейронечіткими технологіями і модифікаціями $r$-алгоритма Н.3. Шора для розв'язання негладких оптимізаційних задач.

Ключові слова. Мультиплікативно зважена діаграма Вороного, задача оптимального розбиття множин, оптимальне розміщення точок-генераторів, нейронечіткі технології, $r$-алгоритм Н.3. Шора, негладкі оптимізаційні задачі.

Предложен алгоритм построения мультипликативно взвешенной диаграммы Вороного при наличии нечетких параметров с оптимальным размещением точекгенераторов в ограниченном множестве $n$-мерного евклидова пространства $E_{n}$. Алгоритм разработан на основе синтеза методов решения задач теории оптимального разбиения множеств с нейронечеткими технологиями и модификациями $r$-алгоритма Н.3. Шора для решения негладких оптимизационных задач.

Ключевые слова. Мультипликативно взвешенная диаграмма Вороного, задача оптимального разбиения множеств, оптимальное размещение точекгенераторов, нейронечеткие технологии, $r$-алгоритм Н.3. Шора, негладкие оптимизационные задачи.

An algorithm for constructing a multiplicatively weighted Voronoi diagram in the presence of fuzzy parameters with optimal location of a finite number of generator points in a bounded set of n-dimensional Euclidean space $E_{n}$ is proposed in the paper. The algorithm is based on the formulation of a continuous set partitioning problem from $E_{n}$ into non-intersecting subsets with a partitioning quality criterion providing the corresponding form of Voronoi diagram.

Algorithms for constructing the classical Voronoi diagram and its various generalizations, which are based on the usage of the methods of the optimal set partitioning theory, have several advantages over the other used methods: they are out of the dependence of $E_{n}$ space dimensions, which containing a partitioned bounded set into subsets, independent of the geometry of the partitioned sets, the algorithm's complexity is not growing under increasing of number of generator points, it can be used for constructing the Voronoi diagram with optimal location of the points and others. The ability of easily construction not only already known Voronoi diagrams but also the new ones is the result of this general-purpose approach.

The proposed in the paper algorithm for constructing a multiplicatively weighted

(C) Кісельова О.М., Притоманова О.М., Дзюба С.В., Падалко В.Г., 2019 
Voronoi diagram in the presence of fuzzy parameters with optimal location of a finite number of generator points in a bounded set of $\mathbf{n}$-dimensional Euclidean space $E_{n}$ is developed using a synthesis of methods for solving optimal set partitioning problems, neurofuzzy technologies and modifications of the Shor's r-algorithm for solving nonsmooth optimization problems.

Keywords: multiplicatively weighted Voronoi diagram, optimal set partitioning problem, optimal location of generator points, neurofuzzy technologies, Shor's r-algorithm, non-smooth optimization problems.

Вступ. В даний час налічується кілька сотень літературних джерел, присвячених діаграмам Вороного та їх додаткам у різних областях [1]. Діаграми Вороного для двох і тривимірних просторів використовуються в самих різних областях прикладних наук. Незважаючи на те, що велика кількість 3 відомих алгоритмів побудови діаграм Вороного заданої скінченної множини $M$ точок площини (простору), які називають точками-генераторами, мають складність $O(|M| \log (|M|))$, всі ці алгоритми досить складні. Крім того, часто в практичних задачах параметри діаграм Вороного можуть бути описані нечітко.

У роботах $[2,3]$ запропоновано алгоритми побудови стандартної (класичної) діаграми Вороного з чіткими параметрами і різних їі узагальнень, які засновані на застосуванні методів теорії оптимального розбиття множин (OРM) і мають ряд переваг у порівнянні з відомими, описаними в науковій літературі $[1,4,5]$. А саме: не залежать від розмірності простору $E_{n}$, що містить обмежену множину, яка підлягає розбиттю; не залежить від геометрії множин, які підлягають розбиттю; складність алгоритмів побудови діаграм Вороного на основі описаного підходу не збільшується при збільшенні кількості точок-генераторів; можуть бути застосовні до побудови не тільки діаграм Вороного заданої кількості точок-генераторів з фіксованим їх розташуванням, а й з оптимальним розміщенням цих точок в обмеженій множині простору $E_{n}$ та інші. Результатом такого універсального підходу є можливість легко будувати не тільки вже відомі діаграми Вороного, а й конструювати нові.

Універсальність пропонованого в роботах $[2,3]$ підходу до побудови діаграм Вороного підтверджується ще і тим, що моделі і методи розв'язання неперервних задач оптимального розбиття множин можуть бути узагальнені на випадок нечіткого завдання вихідних параметрів задачі або вимоги нечіткого розбиття множини, в результаті чого і результуючі діаграми Вороного можуть носити нечіткий характер.

У даній роботі розроблено алгоритм побудови мультиплікативно зваженої діаграми Вороного при наявності нечітких параметрів 3 оптимальним розміщенням скінченної кількості $N$ точок-генераторів в обмеженій множині $\Omega 3$ $n$-вимірного евклідового простору $E_{n}(n \geq 2)$. Алгоритм розроблений на основі синтезу методів розв'язання задач теорії ОРМ [7]) з нейронечіткими технологіями [8]) та модифікаціями $r$-алгоритму Н.3. Шора для розв'язання негладких задач оптимізації $[9,10]$.

Постановка задачі. Класичною діаграмою Вороного скінченної множини $M=\left\{\tau_{1}, \tau_{2}, \ldots, \tau_{N}\right\} \subset E_{n}$ точок-генераторів $\tau_{i}=\left(\tau_{i}^{(1)}, \tau_{i}^{(2)}, \ldots, \tau_{i}^{(n)}\right), i=1,2, \ldots, N$ в $n$ - 
вимірному евклідовому просторі $\mathrm{E}_{n}(n \geq 2)$ називається сукупність багатогранників Вороного

$$
\operatorname{Vor}\left(\tau_{i}\right)=\left\{x \in \mathrm{E}_{n}: c\left(x, \tau_{i}\right) \leq c\left(x, \tau_{j}\right), j=1,2, \ldots, N, j \neq i\right\}, \quad i=1,2, \ldots, N,
$$

вихідних точок $\tau_{1}, \tau_{2}, \ldots, \tau_{N}$, де функції $c_{i}\left(x, \tau_{i}\right) \in$ функціями відстані між точками $x$ i $\tau_{i}$ та можуть визначатися в $E_{n}$ як евклідова метрика.

$\mathrm{y}$ мультиплікативно зваженій діаграмі Вороного множини $M=\left\{\tau_{1}, \tau_{2}, \ldots, \tau_{N}\right\} \subset E_{n}$

$$
M W \operatorname{Vor}(\mathrm{M})=\bigcup_{\tau_{i} \in \mathrm{M}} M W \operatorname{Vor}\left(\tau_{i}\right)
$$

кожний багатогранник Вороного

$M W \operatorname{Vor}\left(\tau_{i}\right)=\left\{x \in E_{n}: c\left(x, \tau_{i}\right) / w_{i} \leq c\left(x, \tau_{j}\right) / w_{j}, j=1,2, \ldots, N, j \neq i\right\}, i=1,2, \ldots, N$,

представляє собою множину простору, зважена відстань від яких до точкигенератора $\tau_{i} \in \mathrm{M}$ не перевищує зваженої відстані до будь-якої іншої вихідної точки ( $w_{i}>0, i=1,2, \ldots, N,-$ задані вагові коефіцієнти).

Одним з наочних способів отримання мультиплікативно зваженої діаграми Вороного є вирощування кристалів [6]. У разі, коли всі кристали починають рости одночасно, але ростуть з різною швидкістю, кожна точка $\tau_{i} \in M$ отримує ваговий коефіцієнт і, при вимірюванні відстані до неї, потрібно помножити функцію, яка задає відстань, на цей ваговий коефіцієнт.

Діаграми Вороного з нечіткими параметрами з'являються, наприклад, у тому випадку, коли вагові коефіцієнти функцій відстані двох точок, що визначають елементи діаграми Вороного, задані нечітко. Задамо для кожної функції $c_{i}\left(x, \tau_{i}\right)$ з (1) нечітку вагу $\tilde{w}_{i}$, яка залежить від зовнішніх факторів, які теж можуть бути задані нечітко, причому вид цієї залежності заздалегідь невідомий.

Тоді запишемо (1) у виді $M W \operatorname{Vor}\left(\tau_{i}\right)=\left\{x \in E_{n}: c\left(x, \tau_{i}\right) / \tilde{w}_{i} \leq c\left(x, \tau_{j}\right) / \tilde{w}_{j}, j=1,2, \ldots, N, j \neq i\right\}, i=1,2, \ldots, N$,

Для формулювання математичної постановки задачі побудови мультиплікативно зваженої діаграми Вороного з оптимальним розміщенням скінченної кількості $N$ точок-генераторів у обмеженій множині $\Omega$ з $n$-вимірного евклідового простору $E_{n}(n \geq 2)$ на основі методів розв'язання задач ОРМ знімемо нечіткість у (2) за допомогою методу нейролінгвістичної ідентифікації невідомих складних нелінійних залежностей з [8].

Для застосування указаного методу для відновлення значень нечітких параметрів $\tilde{w}_{1}, \ldots, \tilde{w}_{N}$, не обмежуючи узагальнення міркувань, позначимо їх відновленні значення як $w$ та розглянемо функціональну залежність виходу $w$ від входів $y_{1}, \ldots, y_{q}$ об’єкта ідентифікації у виді:

$$
w=w\left(y_{1}, \ldots, y_{q}\right),
$$


тут $y_{1}, \ldots, y_{q}$ - фактори, що впливають на $w$, та, як указувалося раніше, можуть бути теж задані нечітко.

Після застосування методу нейролінгвістичної ідентифікації невідомих складних нелінійних залежностей, розробленого у [8], отримаємо точне (чітке) значення вихідної змінної $w$, яке розраховується за такими формулами:

$$
\begin{aligned}
& w=\frac{\sum_{k=1}^{L} d_{k} \cdot \mu^{*}{ }_{D_{k}}(w)}{\sum_{k=1}^{L} \mu{ }^{*}(w)}, \\
& \mu_{D_{k}}^{*}(w)=\left\{\begin{array}{l}
\sum_{j=1}^{s_{k}} p_{j}^{* k}\left(y_{1}, y_{2}, \ldots, y_{q}\right), \quad \text { якщо } \sum_{j=1}^{s_{k}} p_{j}^{* k}\left(y_{1}, y_{2}, \ldots, y_{q}\right) \leq 1, \\
1 \quad \text { в інших випадках, }
\end{array}\right. \\
& p_{j}^{* k}\left(y_{1}, y_{2}, \ldots, y_{q}\right)=v_{j}^{* k} \prod_{i=1}^{q} \mu_{i j}^{* k}\left(y_{i}\right), \\
& \mu_{i j}^{* k}\left(y_{i}\right)=\frac{1}{1+\left(\frac{y_{i}-b_{i j}^{* k}}{e^{* k}{ }_{i j}^{k}}\right)^{2}}, i=1, \ldots, q, j=1, \ldots, s_{k}, \mathrm{k}=1,2, \ldots, \mathrm{L},
\end{aligned}
$$

де у формулах (4)-(7):

- $\mu^{*} D_{k}(w)$ - функція належності вихідної змінної $w$ класу $D_{k}, k=1,2, \ldots, L$, $L$ - кількість класів (лінгвістичних термів) вихідної змінної $w, d_{k}$ - центр класу $D_{k}$;

- $p_{j}^{* k}\left(y_{1}, y_{2}, \ldots, y_{q}\right)$ - нечіткі продукційні правила, які отримуються з експертно-експериментальної інформації про залежність (6), $j$ - номер правила у $k$-у класі, $j=1,2, \ldots, s_{k}, s_{k}$ - кількість правил у $k$-у класі; $v_{j}^{*}$ - вага $j$-го правила у $k$-у класі виходу $w$;

- $\mu_{i j}^{*}\left(y_{i}\right)$ - дзвонова функція належності змінної $y_{i}$ іiі лінгвістичному терму у $j$-у правилі $k$-го класу виходу вихідної змінної $w, b{ }_{i j}^{k}$ - координата максимуму і $e^{* k}$ - коефіцієнт концентрації цієї функції належності.

Необхідно зауважити, що значення $v_{j}^{* k}$ - ваг правил у (6) та параметрів $b_{i j}^{*}, e^{*}{ }_{i j}^{k}$ функції належності (7) відмічені зірочкою як оптимальні, тобто такі, що отримані у результаті етапу параметричної ідентифікації методу нейролінгвістичної ідентифікації, для яких відхилення експериментальних даних від модельних, отриманих після настройки нечіткої моделі об'єкта (3), дося- 
гає мінімального значення. Значення $\mu_{D_{k}}^{*}(w), p_{j}^{* k}\left(y_{1}, y_{2}, \ldots, y_{q}\right)$ та $\mu_{i j}^{* k}\left(y_{i}\right)$ у (4)-(7) обчислюються при оптимальних значеннях $v_{j}^{* k}, b_{i j}^{* k}, e_{i j}^{*}$.

Таким чином, після відновлення значень нечітких параметрів $\tilde{w}_{1}, \ldots, \tilde{w}_{N}$ в (2) за допомогою описаного методу нейролінгвістичної ідентифікації, отримуємо їх відновлені (чіткі) значення $w_{1}, \ldots, w_{N}$.

Сформулюємо тепер математичну постановку задачі побудови мультиплікативно зваженої діаграми Вороного з оптимальним розміщенням скінченної кількості $N$ точок-генераторів у обмеженій множині $\Omega$ з $n$-вимірного евклідового простору $E_{n}(n \geq 2)$ на основі методів розв'язання задач ОРМ та відновленими значеннями ії нечітких параметрів.

Нехай $\Omega$ - деяка задана обмежена множина з $E_{n}, \tau_{l}, \tau_{2}, \ldots, \tau_{N}-$ скінченна множина точок-генераторів в $\Omega$. У тих випадках, коли розташування точок $\tau_{1}, \tau_{2}, \ldots, \tau_{N}$ в $\Omega$ невідомо і їх потрібно розмістити (вибрати) в $\Omega$, можна ввести ще один варіант діаграми Вороного на множині $\Omega \subset \mathrm{E}_{n}$, а саме діаграму Вороного скінченної множини точок, оптимально розміщених в обмеженій множині.

Під мультиплікативно зваженою діаграмою Вороного скінченної кількості $N$ точок-генераторів $\tau_{1}, \tau_{2}, \ldots, \tau_{N}$ у обмеженій множині $\Omega \subset \mathrm{E}_{n}$, будемо розглядати таку сукупність многогранників Вороного

$$
M W \operatorname{Vor}\left(\tau_{i}\right)=\left\{x \in E_{n}: c\left(x, \tau_{i}\right) / w_{i} \leq c\left(x, \tau_{j}\right) / w_{j}, j=1,2, \ldots, N, j \neq i\right\}, i=1,2, \ldots, N,
$$

точок $\tau_{1}, \tau_{2}, \ldots, \tau_{N}$, оптимально розміщених в обмеженій множині, для яких сумарна зважена відстань від точок множини $\Omega$ до відповідних точокгенераторів $\tau_{1}, \tau_{2}, \ldots, \tau_{N} \epsilon$ найменшою, тобто функціонал

$$
J\left(\left\{\tau_{1}, \ldots, \tau_{N}\right\}\right)=\sum_{i=1}^{N} \int_{\operatorname{Vor}\left(\tau_{i}\right)}\left(c\left(x, \tau_{i}\right) / w_{i}\right) d x
$$

приймає мінімальне значення.

Метод розв'язання задачі. Викладемо підхід до побудови мультиплікативно зваженої діаграми Вороного скінченної кількості точок-генераторів $\tau_{1}, \tau_{2}, \ldots, \tau_{N}$, оптимально розміщених в обмеженій множині $\Omega \subset \mathrm{E}_{n}, 3$ нечіткими параметрами, заснований на застосуванні математичного апарату нейронечітких технологій [8] і теорії ОРМ [11]. Для цього спочатку сформулюємо відповідну неперервну задачу оптимального розбиття множини з $\mathrm{E}_{n}$ на підмножини з невідомими заздалегідь координатами деяких характерних для кожної підмножини точок, які називаються центрами підмножин, яка є узагальненням задачі з [11].

Нехай $\Omega$ - обмежена, вимірна за Лебегом множина в $n$-вимірному евклідовому просторі $\mathrm{E}_{n}$. Сукупність вимірних за Лебегом підмножин $\Omega_{1}, \ldots, \Omega_{N}$ з $\Omega \subset \mathrm{E}_{n}$ назвемо можливим розбиттям множини $\Omega$ на його підмножини $\Omega_{1}, \ldots, \Omega_{N}$, що не перетинаються, якщо 


$$
\bigcup_{i=1}^{N} \Omega_{i}=\Omega, \operatorname{mes}\left(\Omega_{i} \cap \Omega_{j}\right)=0, i, j=1,2, \ldots, N \quad(i \neq j),
$$

де $m e s(\cdot)$ означає міру Лебега.

Позначимо через $\sum_{\Omega}^{N}$ клас всіх можливих розбиттів множини $\Omega$ на підмножини, що не перетинаються, $\Omega_{1}, \ldots, \Omega_{N}$, тобто

$$
\sum_{\Omega}^{N}=\left\{\left(\Omega_{l}, \ldots, \Omega_{N}\right): \bigcup_{i=1}^{N} \Omega_{i}=\Omega, \operatorname{mes}\left(\Omega_{i} \cap \Omega_{j}\right)=0, i, j=1,2, \ldots, N \quad(i \neq j)\right\} .
$$

Введемо функціонал

$$
F\left(\left\{\Omega_{1}, \ldots, \Omega_{N}\right\},\left\{\tau_{1}, \ldots, \tau_{N}\right\}\right)=\sum_{i=1}^{N} \int_{\Omega_{i}}\left(c\left(x, \tau_{i}\right) / w_{i}\right) d x,
$$

де $c\left(x, \tau_{i}\right)$ - задана дійсна обмежена на $\Omega \times \Omega$ функція, вимірна за $x=\left(x^{(l)}, \ldots, x^{(n)}\right) \in \Omega$ для будь-якої фіксованої точки $\tau_{i}=\left(\tau_{i}^{(l)}, \ldots, \tau_{i}^{(n)}\right) \in \Omega$ для усіх $i=1,2, \ldots, N ; w_{i}>0(i=1,2, \ldots, N)$ - задані вагові коефіцієнти.

Тут і надалі інтеграли розуміються в сенсі Лебега. Будемо вважати, що міра множини граничних точок множин $\Omega_{i}, i=1, . ., N$, дорівнює нулю.

Задача А. Знайти $\min _{\substack{\left\{\Omega_{1}, \ldots, \Omega_{N}\right\} \in \Sigma_{N}^{N},\left\{\tau_{1}, \ldots, \tau_{N}\right\} \in \Omega^{N}}} F\left(\left\{\Omega_{1}, \ldots, \Omega_{N}\right\},\left\{\tau_{1}, \ldots, \tau_{N}\right\}\right)$,

де функціонал $F\left(\left\{\Omega_{1}, \ldots, \Omega_{N}\right\},\left\{\tau_{1}, \ldots, \tau_{N}\right\}\right)$ представлений у виді (11); координати $\tau_{i}^{(1)}, \ldots, \tau_{i}^{(n)}$ центрів $\tau_{i}=\left(\tau_{i}^{(l)}, \ldots, \tau_{i}^{(n)}\right) \in \Omega_{i}, i=1,2, \ldots, N$, заздалегідь невідомі та їх потрібно визначити.

Пару $\left(\left\{\Omega_{1}^{*}, \ldots, \Omega_{N}^{*}\right\},\left\{\tau_{1}^{*}, \ldots, \tau_{N}^{*}\right\}\right)$, що доставляє мінімум функціоналу (11) на множині $\Sigma_{\Omega}^{N} \times \Omega^{N}$, назвемо оптимальним розв'язком задачі А. При цьому розбиття $\left\{\Omega_{l}^{*}, \ldots, \Omega_{N}^{*}\right\} \in \Sigma_{\Omega}^{N}$ назвемо оптимальним розбиттям множини $\Omega \subset \mathrm{E}_{n}$ на $N$ підмножин, а сукупність $\tau^{*}=\left(\tau_{1}^{*}, \ldots, \tau_{N}^{*}\right) \in \Omega^{N}$ центрів $\tau_{i}^{*} \in \Omega_{i}^{*}$, $i=1,2, \ldots, N-$ оптимальними центрами підмножин $\Omega_{i}^{*}$ в задачі А.

Для розв'язання задачі А для кожного фіксованого $w_{i}(i=1,2, \ldots, N)$ введемо характеристичні функції підмножин $\Omega_{i}$ :

$$
\lambda_{i}(x)=\left\{\begin{array}{l}
1, x \in \Omega_{i}, \\
0, x \in \Omega \backslash \Omega_{i}, i=1, \ldots, N,
\end{array}\right.
$$

та перепишемо задачу А у термінах характеристичних функцій в такому виді.

Задача В. Знайти

$$
\min _{(\lambda(\cdot), \tau) \in \Gamma \times \Omega^{\mathrm{N}}} \int_{\Omega} \sum_{i=1}^{N}\left(\mathrm{c}\left(x, \tau_{i}\right) / w_{i}\right) \lambda_{i}(x) d x,
$$

де 


$$
\begin{gathered}
\Gamma=\left\{\lambda(\mathrm{x})=\left(\lambda_{1}(\mathrm{x}), \ldots, \lambda_{\mathrm{N}}(\mathrm{x})\right): \sum_{\mathrm{i}=1}^{\mathrm{N}} \lambda_{\mathrm{i}}(\mathrm{x})=1 \text { майже всюди (м.в.) для } \mathrm{x} \in \Omega,\right. \\
\left.\lambda_{\mathrm{i}}(\mathrm{x})=0 \vee 1 \text { м.в. для } \mathrm{x} \in \Omega, \mathrm{i}=1, \ldots, \mathrm{N}\right\} ; \tau=\left(\tau_{1}, \ldots, \tau_{\mathrm{N}}\right) \in \underbrace{\Omega \times \ldots \times \Omega}_{\mathrm{N}}=\Omega^{\mathrm{N}} .
\end{gathered}
$$

Для задачі В у роботі [7] доведена наступна теорема 1, що встановлює вид оптимального розв'язку $\left(\lambda_{*}(\cdot), \tau_{*}\right)$.

Теорема 1. Компоненти характеристичної вектор-функції $\lambda_{*}(x)=\left(\lambda_{*_{1}}(x), \ldots, \lambda_{*_{i}}(x), \ldots, \lambda_{*_{N}}(x)\right)$, яка відповідає оптимальному розв'язку $\left(\Omega_{* 1}, \ldots, \Omega_{*_{i}}, \ldots, \Omega_{*_{N}}\right)$ задачі $\mathbf{A}$ для $i=1, \ldots, N$ та маже всіх $x \in \Omega$ мають вид:

$$
\lambda_{*_{i}}(x)=\left\{\begin{aligned}
& 1, \text { якщо } c\left(x, \tau_{*_{i}}\right) / w_{i} \leq c\left(x, \tau_{*_{j}}\right) / w_{j}, \\
& i \neq j \text { м.в. для } x \in \Omega, j=1, \ldots, N, \text { тоді } x \in \Omega_{*_{i}}, \\
& 0 \text { в інших випадках, }
\end{aligned}\right.
$$

в якості $\tau_{*_{1}}, \ldots, \tau_{*_{N}}$ обирається оптимальний розв'язок задачі, яка $\epsilon$ двоїстою до задачі В:

$$
G(\tau)=\int_{\Omega} \min _{i=1, \ldots, N}\left[c\left(x, \tau_{i}\right) / w_{i}\right] d x \rightarrow \min , \tau \in \Omega^{N} .
$$

Тепер наведемо теорему 2, засновану на результатах з робіт [7, 12], яка підводить підсумок нашим міркуванням і буде використана в подальшому при формулюванні алгоритму розв'язання задачі А.

Теорема 2. Компоненти характеристичної вектор-функції $\lambda_{*}(x)=\left(\lambda_{*_{1}}(x), \ldots, \lambda_{*_{i}}(x), \ldots, \lambda_{*_{N}}(x)\right)$, яка відповідає оптимальному розв'язку $\left(\Omega_{*_{1}}, \ldots, \Omega_{*_{i}}, \ldots, \Omega_{*_{N}}\right)$ задачі $\mathbf{A}$ для $i=1, \ldots, N$ та майже всіх $x \in \Omega$ мають вид:

$$
\lambda_{*_{i}}(x)=\left\{\begin{aligned}
1, & \text { якщо } c\left(x, \tau_{*_{i}}\right) / w_{i} \leq c\left(x, \tau_{*_{j}}\right) / w_{j}, \\
& i \neq j \text { м.в. для } x \in \Omega, j=1, \ldots, N, \text { тоді } x \in \Omega_{*_{i}}, \\
0 & \text { в інших випадках, }
\end{aligned}\right.
$$

в якості $\tau_{*_{1}}, \ldots, \tau_{*_{N}}$ обирається оптимальний розв'язок задачі

$$
G(\tau)=\int_{\Omega} \min _{i=1, \ldots, N}\left[c\left(x, \tau_{i}\right) / w_{i}\right] d x \rightarrow \min , \tau \in \Omega^{N} .
$$

Тут кожний параметр $w_{i}, i=1, \ldots, N$, указаний раніше як вихід $w$, що залежить від входів $y_{1}, \ldots, y_{q}$ У вигляді $w=w\left(y_{1}, \ldots, y_{q}\right)$, розраховується за формулам (4)-(7).

Алгоритм розв'язання задачі А. Для опису алгоритму визначимо $i$-у, $i=1, \ldots, N, \quad$ компоненту вектора узагальненого градієнта $g_{G}^{\tau}(\tau)=\left(g_{G}^{\tau_{1}}(\tau), \ldots, g_{G}^{\tau_{i}}(\tau), \ldots, g_{G}^{\tau_{N}}(\tau)\right)$ функції $(13)$ в точці $\tau$ таким чином:

$$
g_{G}^{\tau_{i}}(\tau)=\int_{\Omega} g_{c}^{\tau_{i}}(x ; \tau) \lambda_{i}(x) d x, \quad i=1, \ldots, N,
$$

де $g_{c}^{\tau_{i}}(x, \tau)-i$-а компонента $N$-вимірного вектора узагальненого градієнта 
$g_{c}^{\tau}(x, \tau)$ функції $c\left(x, \tau_{i}\right)$ в точці $\tau$.

В формулі (14) $\lambda_{i}(x), i=1, \ldots, N$, визначається таким чином:

$$
\lambda_{i}(x)=\left\{\begin{aligned}
1, & \text { якщо } c\left(x, \tau_{i}\right) / w_{i} \leq c\left(x, \tau_{j}\right) / w_{j}, \\
& i \neq j \text { м.в. для } x \in \Omega, j=1, \ldots, N, \text { тоді } x \in \Omega_{i}, \\
0 & \text { в інших випадках, }
\end{aligned}\right.
$$

де $w_{i}, i=1, \ldots, N$, розраховуються за формулам (4)-(7).

Алгоритм. Область $\Omega$ укладаємо в $n$-вимірний паралелепіпед П, сторони якого паралельні вісям декартової системи координат. Паралелепіпед П покриваємо прямокутною сіткою і задаємо початкове наближення $\tau=\tau^{(0)}$. Обчислюємо значення $\lambda^{(0)}(x)$ в вузлах сітки за формулами (15) 3 урахуванням формул (4)-(7) для обчислення параметрів $w_{i}$, при $\tau=\tau^{(0)}$; значення $g_{G}(\tau)$ - за формулою (14) при $\lambda(x)=\lambda^{(0)}(x), \tau=\tau^{(0)}$; обираємо початковий пробний крок $r$-алгоритму $h_{0}>0$ та знаходимо

$$
\tau^{1}=\mathrm{P}_{\Pi}\left(\tau^{0}-h_{0} \frac{H_{1} g_{G}\left(\tau^{0}\right)}{\sqrt{\left(H_{1} g_{G}\left(\tau^{0}\right), g_{G}\left(\tau^{0}\right)\right)}}\right),
$$

$\mathrm{P}_{\Pi}-$ оператор проектування на П.

Переходимо до другого кроку.

Нехай в результаті обчислень після $k(k=1,2, \ldots$,$) кроків алгоритму$ отримані значення $\tau^{(k)}, \lambda^{(k-1)}(x)$ в вузлах сітки.

Опишемо $(k+1)$-й крок.

1. Обчислюємо значення $\lambda^{(k)}(x)$ в вузлах сітки за формулами (15), з урахуванням формул (4)-(7) для обчислення параметрів $w_{i}$, при $\tau=\tau^{(k)}$.

2. Знаходимо значення $g_{G}(\tau)$ за формулами (14) при $\lambda(x)=\lambda^{(k)}(x)$, $\tau=\tau^{(k)}$.

3. Проводимо $(k+1)$-й крок r-алгоритму в $H$-формі, ітераційна формула якого має вид

$$
\tau^{k+1}=\mathrm{P}_{\Pi}\left(\tau^{k}-h_{k} \frac{H_{k+1} g_{G}\left(\tau^{k}\right)}{\sqrt{\left(H_{k+1} g_{G}\left(\tau^{k}\right), g_{G}\left(\tau^{k}\right)\right)}}\right),
$$

4. Якщо умова

$$
\left\|\tau^{k}-\tau^{k+1}\right\| \leq \varepsilon, \varepsilon>0,
$$

не виконується, переходимо до $(k+2)$-го кроку алгоритму, в протилежному випадку - до п. 5.

5. Приймаємо $\lambda_{*}(x)=\lambda^{(l)}(x), \tau_{*}=\tau^{(l)}$, де $l$ - номер ітерації, на якій викона- 
лася умова (16).

6. Обчислюємо оптимальне значення цільової функції $G(\tau)$ з (13) за формулою

$$
G(\tau)=\int_{\Omega} \min _{i=1, \ldots, N}\left[c\left(x, \tau_{i}\right) / w_{i}\right] d x,
$$

при $\tau=\tau_{*}$ та $w_{i}, i=1, \ldots, N$, обчислених за формулами (14)-(17).

\section{Алгоритм описаний.}

Таким чином, в результаті розв'язку задачі А описаним алгоритмом, який заснований на наведеній вище теоремі 2, одержуємо сукупність багатогранників Вороного (3) точок-генераторів $\tau_{i}, i=1, \ldots, N$ :

$$
\operatorname{Vor}\left(\tau_{i}\right)=\left\{x \in \Omega \subset \mathrm{E}_{n}: c\left(x, \tau_{i}\right) / w_{i} \leq c\left(x, \tau_{j}\right) / w_{j}, i \neq j, j=1, \ldots, N\right\},
$$

але на відміну від стандартної діаграми Вороного (1), в якій точки $\tau_{1}, \ldots, \tau_{N}$ фіксовані і параметри $w_{i}, i=1, \ldots, N$ чіткі, для відшукання координат точокгенераторів $\tau_{1}, \ldots, \tau_{N}$, оптимально розміщених в $\Omega \subset E_{n}, \quad$ потрібно розв’язання скінченновимірної задачі оптимізації

$$
G(\tau)=\int_{\Omega} \min _{i=1, \ldots, N}\left[c\left(x, \tau_{i}\right) / w_{i}\right] d x \rightarrow \min , \tau \in \Omega^{N}=\underbrace{\Omega \times \ldots \times \Omega}_{N},
$$

3 недиференційовною цільовою функцією $G(\tau)$ та параметрами $w_{i}, i=1, \ldots, N$, відновленими за допомогою методу нейролінгвістичої ідентифікації невідомих складних нелінійних залежностей.

Висновки. Запропоновано метод і алгоритм побудови мультиплікативно зваженої діаграми Вороного при наявності нечітких параметрів 3 оптимальним розміщенням скінченної кількості точок-генераторів в обмеженій множині $n$-вимірного евклідового простору $E_{n}$. Метод заснований на формулюванні відповідної неперервної задачі оптимального розбиття множини на підмножини, що не перетинаються, з розміщенням центрів цих підмножин при наявності нечітких параметрах в цільовому функціоналі та 3 критерієм якості розбиття, що забезпечує відповідний вид діаграми Вороного з нечіткими параметрами. Метод розв'язання названої вище задачі оптимального розбиття множин заснований на застосуванні математичного апарату, розробленого в [12], при цьому для зняття нечіткості в задачі ОРМ використаний метод нейролінгвістичній ідентифікації, розроблений в [8].

\section{Бібліографічні посилання}

1. Preparata, F. Computational geometry: an introduction / F. Preparata, M. Sheimos. Springer. First Edition edition, 1993. - 390 p.

2. Kiseleva, E.M. Theory of continuous optimal set partitioning problems as a universal mathematical formalism for constructing Voronoi diagrams and their generalizations I. Theoretical foundations / E.M. Kiseleva, L.S. Koriashkina // Cybernetics and Systems Analysis, vol. 51, № 3, pp. 325-335 (2015). DOI 10.1007/s10559-015-9725-x.

3. Kiseleva, E.M. Theory of continuous optimal set partitioning problems as a universal mathematical formalism for constructing voronoi diagrams and their generalizations. II. 
Algorithms for constructing Voronoi diagrams based on the theory of optimal set partitioning / E.M. Kiseleva, L.S. Koriashkina // Cybernetics and Systems Analysis, vol. 51, № 4, pp. 489499 (2015). DOI: 10.1007/s10559-015-9740-y.

4. Aurenhammer, F. Voronoi Diagrams and Delaunay Triangulations. / F. Aurenhammer, R. Klein, D.-T. Lee. - World Scientific Pub Co Inc, 2013. - 337 p.

5. Okabe, A. Spatial Tessellations: Concepts and Applications of Voronoi / A. Okabe, B. Boots, K. Sugihara, S.N. Chiu // West Sussex, England: John Wiley and Sons Ltd, second ed., 2000. $-696 \mathrm{p}$.

6. Trubin, Stanislav I. Information Space Mapping with Adaptive Multiplicatively Weighted Voronoi Diagrams / Stanislav I. Trubin // Thesis (M.S.) - Origon State University. - 2007.

7. Киселева, Е.М. Непрерывные задачи оптимального разбиения множеств: теория, алгоритмы, приложения. / Е.М. Киселева, Н.3. Шор. - К.: Наукова думка, 2005. -564 с.

8. Kiseleva, E.M. Algorithm for Solving a Continuous Problem of Optimal Partitioning with Neurolinguistic Identification of Functions in Target Functional / E.M. Kiseleva, O.M. Pritomanova, S.V. Zhuravel // Journal of Automation and Information Science, vol. 50, № 3, pp. 1-20 (2018). DOI: 10.1615/JAutomatInfScien.v50.i3.10.

9. Шор, Н.3. Методы минимизации недифференцируемых функций и их приложения / Н.3. Шор. - К.: Наук. думка, 1979. - 200 с.

10.Stetsyuk, P.I. Shor's r-Algorithms: Theory and Practice / P.I. Stetsyuk // In: Optimization Methods and Applications: In Honor of the 80th Birthday of Ivan V. Sergienko. Ed. by Butenko S., Pardalos P.M, Shylo V. Springer. - 2017. - P. 495-520.

11. Киселева, Е.М. Модели и методы решения непрерывных задач оптимального разбиения множеств: линейные, нелинейные, динамические / Е.М. Киселева, Л.С. Коряшкина. - К.: Наукова думка, 2013. - 606 с.

12. Kiseleva, E. An Algorithm to Construct Generalized Voronoi Diagrams with Fuzzy Parameters Based on the Theory of Optimal Partitioning and Neuro-Fuzzy Technologies / E. Kiseleva, L. Hart, O. Prytomanova, O. Kuzenkov - URL: http://ceur-ws.org/Vol2386/paper12.pdf.

Надійшла до редколегії 10.10. 2019. 


\author{
Є.В. Косенко, А.С. Шевельова \\ Дніпровський наиіональний університет імені Олеся Гончара
}

\title{
ПРО ЕКСТРЕМАЛЬНУ ЗАДАЧУ ІДЕНТИФІКАЦЇ̈ ВЛАСТИВОСТЕЙ СЕГНЕТОЕЛЕКТРИКІВ
}

Розглянуто екстремальну задачу визначення фізичних параметрів сегнетоелектричних кристалів за характером зміни в часі струму перемикання. Наведено алгоритм спільної ідентифікації таких невимірюваних параметрів, як міжфазний поверхневий натяг та кінетичний коефіцієнт. Сформульовано жорстку задачу Коші для системи звичайних диференціальних рівнянь і знайдено її розв'язок однокроковим ітераційним методом Розенброка. Проведено числовий експеримент для конкретних сегнетоелектричних матеріалів.

Ключові слова: ідентифікація параметрів, задача мінімізації, метод покоординатного спуску, жорстка задача Коші для системи звичайних диференціальних рівнянь, сегнетоелектричні кристали.

Рассмотрена экстремальная задача определения физических параметров сегнетоэлектрических кристаллов по характеру изменения во времени тока переключения. Приведен алгоритм совместной идентификации таких неизмеримых параметров, как межфазное поверхностное натяжение и кинетический коэффициент. Сформулирована жесткая задача Коши для системы обыкновенных дифференциальных уравнений и найдено ее решение одношаговым итерационным методом Розенброка. Проведен численный эксперимент для конкретных сегнетоэлектрических материалов.

Ключевые слова: идентификация параметров, задача минимизации, метод покоординатного спуска, жесткая задача Коши для системы обыкновенных дифференциальных уравнений, сегнетоэлектрические кристаллы.

Ferroelectricity is a phenomenon exhibited by crystals with a spontaneous polarization and hysteresis effects associated with dielectric changes when an electric field is given. Ferroelectricity is a characteristic of certain materials that have a spontaneous electric polarization, which can be reversed by the application of an external electric field. The ferroelectric sensor is a simple device, which can measure and produce some form of the output of mechanical, electrical and optical product. Today, developmental sensors use computing, communications and connectivity to the web, mobile smart devices and integration clouds added to the sensor capabilities.

Dependence of the switching current of the polarization of the ferroelectric on time and the electric field, the law of conservation of the full dipole moment in the ferroelectric crystal make up a system of equations that define the dependence of the switching current on the time and the electric field.

The one-step implicit iterative Rosenbrock method for the solution of the Cauchy problem for stiff systems of ordinary differential equations is applied. It is based on the generalized Runge-Kutta schemes with up to four stages.

Coordinate descent is based on the idea that the minimization of a multivariable function can be achieved by minimizing it along one direction at a time, i.e., solving univariate optimization problems in a loop. Golden-section search is used for the function of a single variable.

(c) Косенко С. В. , Шевельова А. С. , 2019 
Keywords: parameter identification problem, minimization problem, coordinate descent method, Cauchy problem for stiff system of ordinary differential equations, ferroelectric crystals.

Вступ. Сегнетоелектрики - це матеріали, що мають одночасно як характеристики діелектриків так і провідників. В них при відсутності зовнішнього електричного поля і за певного діапазону температур може виникати спонтанна поляризація (явище, яке пов'язане зі зміщенням в матеріалі зв'язаних електричних зарядів). Показово, що сегнетоелектрики можуть бути п’єзоелектриками і піроелектриками (матеріалами, в яких спонтанна поляризація проявляється незалежно від зовнішніх факторів) [1].

На сьогоднішній день сегнетоелектрики знайшли широке застосування в багатьох областях сучасної техніки - радіотехніці, акустиці, оптоелектроніці, піро- і п'єзотехніці як запам'ятовуючі динамічні і статичні пристрої обчислювальної техніки, сенсори акустичних і теплових хвиль (в тому числі піроприймачі), п'єзоелементи, модулятори лазерного випромінювання. Перспективи створення сегнетоелектричних матеріалів 3 прогнозованими фізичними властивостями, а також можливості використання модифікованих зовнішніми впливами сегнетоелектриків стимулюють дослідження ефектів в сегнетоелектричних кристалах.

Сегнетоелектричний кристал складається 3 доменів - областей спонтанної поляризації. Домен - просторова область, всередині якої певна фізична характеристика однакова, проте відрізняється від такої ж характеристики в сусідній області. Домени розділені між собою доменними стінками. Спонтанні поляризації всіх елементарних елементів одного домену спрямовані однаково, в той же час, поляризації, які відповідають різним доменам, орієнтовані в різних напрямках, тому сумарна величина макроскопічної поляризації кристала залишається рівною нулю.

Властивістю п’єзоелектриків є їхня здатність змінювати напрямок поляризації на протилежний, у результаті чого виникає струм перемикання [2-4]. Дослідження ефектів в сегнетоелектричних кристалах, що впливають на кінетику доменної структури і перемикання поляризації, представляє інтерес, як $з$ точки зору фундаментальної науки, так і з точки зору практичних застосувань.

Струм перемикання поляризації сегнетоелектрика 3 віссю поляризації вздовж осі $z$ з використанням теорії Колмогорова-Аврамі-Ішібіші [5, 6] обчислюється за формулою:

$$
j(t)=-\frac{2 P_{z 10}\left(\frac{\xi_{0}}{\tau}-\frac{\xi(t)}{\tau}-\xi^{\prime}(t)\right)(1-Z(t))}{\left(\frac{P_{z 2}}{P_{z 10}}-1-\xi(t)\right)}
$$

де $\xi(t)$ - переполяризація в момент часу $t, Z(t)$ - функція, що показує частину заповнення об’єму п’єзоелектрика переполяризованими областями. 
Фізичні сталі, які входять до формули (1) мають такий фізичний сенс: $\xi_{0}-$ початкове значення переполяризації, $P_{z 2}, P_{z 10}$ - рівноважні значення поляризації, $\tau$ - часовий параметр конкретного сегнетоелектрика.

Залежність струму перемикання поляризації сегнетоелектрика від часу та електричного поля має вигляд [7]:

$$
\frac{d}{d t}\left[\frac{1}{\xi(t)} \frac{d}{d t}\left(\frac{j(t)}{\xi(t)}\right)\right]=-\frac{4 \omega P_{z 10}}{t_{0}^{2}} I(\xi(t)) .
$$

де $I(\xi(t))$ - швидкість нуклеації доменів [1], $t_{0}$ - характерний час росту зародка нового домена [7], $\omega$ - об'єм однієї елементарної комірки сегнетоелектричного кристалу. Нуклеація (зародкоутворення) доменів - це стадія появи нового домену. У сегнетоелектриків із $180^{\circ}$-доменами вектори спонтанної поляризації направлені протилежно.

Для знаходження функції $Z(t)$, а відповідно й струму перемикання $j(t)$, необхідно розв'язати таке диференціальне рівняння [8]:

$$
\frac{d}{d t}\left[\frac{1}{\xi(t)} \frac{d}{d t}\left(\frac{1}{\xi(t)} \frac{d Z(t)}{d t}\right)\right]=\frac{2 \omega}{t_{0}^{2}} I(\xi(t)),
$$

Рівняння закону збереження повного дипольного моменту в сегнетоелектричному кристалі, який враховує, що зароджування нових доменів має місце тільки на вільних місцях, можна записати у вигляді

$$
\frac{d \xi(t)}{d t}=\frac{\xi_{0}}{\tau}-\frac{\xi(t)}{\tau}-\frac{(P-1-\xi(t))}{1-Z(t)} \frac{d Z(t)}{d t},
$$

де $P=P_{z 2} / P_{z 10}$.

Залежність $I(\xi(t))$ для випадку перемикання в сегнетоелектриках із $180^{\circ}$ доменами має вигляд [7]

$$
I(\xi(t))=I_{0} \sqrt{\xi(t)} \cdot \exp \left(-\frac{\alpha}{\xi(t)}\right)
$$

де

$$
I_{0}=\frac{N_{v} \beta_{0} \omega P_{z 10} \sqrt{H}}{\sqrt{k_{B} T \chi \varepsilon_{0}}}, \alpha=\frac{\pi H \sigma^{2} \chi \varepsilon_{0}}{2 k_{B} T P_{z 10}^{2}},
$$

$N_{v}$ - число елементарних комірок в одиниці об'єму кристала, $N_{v} \sim 1 / \omega, \beta_{0}$ -кінетичний коефіцієнт, $H$ - висота домену циліндричної форми, $k_{B}$ - стала Больцмана, $T$ - температура середовища, в якому знаходиться сегнетоелектричний кристал, $\chi$ - діелектрична сприйнятливість, $\varepsilon_{0}$ - діелектрична проникність вакууму, $\sigma$ - міжфазний поверхневий натяг.

У роботі [7] було показано, що струм перемикання однозначно пов'язаний 3 такими параметрами, як міжфазний поверхневий натяг $\sigma$ та кінетичний ко- 
ефіцієнт $\beta_{0}$, що описують зміщення атомів з однієї підгратки сегнетоелектричного кристалу в іншу. Ці параметри не є безпосередньо вимірюваними.

Порівнюючи теоретичні залежності струму перемикання з експериментальними даними, можна визначити константи $I_{0}$ та $\alpha$, що входять у вираз для потоку зародків $I(\xi(t))$. Вже за цими величинами можна визначити ряд констант сегнетоелектриків ( $\sigma, \beta_{0}$ та ін.).

Постановка задачі ідентифікації параметрів. Розв'язати задачу умовної мінімізації

$$
f\left(\alpha, I_{0}\right)=\sum_{k=0}^{n}\left(j\left(t_{k}\right)-j_{*}\left(t_{k}\right)\right)^{2} \rightarrow \min , \alpha \in\left[\alpha^{-}, \alpha^{+}\right], I_{0} \in\left[I_{0}^{-}, I_{0}^{+}\right],
$$

де $j_{*}\left(t_{k}\right)$ - вимірювані (відомі) значення струму перемикання в моменти часу $t_{k}, k=\overline{1, n}$, константи $\alpha^{-}, \alpha^{+}, I_{0}^{-}, I_{0}^{+}$задані.

Сформулюємо систему диференційних рівнянь для знаходження функції $j(t)$.

Якщо підставити (1) в (2), одержимо

$$
\frac{d}{d t}\left[\frac{1}{\xi(t)} \frac{d}{d t}\left(\frac{\left(\xi_{0} / \tau-\xi(t) / \tau-\xi^{\prime}(t)\right)(1-Z(t))}{(P-1-\xi(t)) \xi(t)}\right)\right]=\frac{2 \omega}{t_{0}^{2}} I(\xi(t)) .
$$

Початковими умовами для цього диференціального рівняння $є$ умови рівності нулю струму перемикання, його похідних за часом та переполяризації.

Перейдемо від диференціального рівняння третього порядку (8) до системи диференційних рівнянь першого порядку.

Введемо функції $y_{0}(t)=\xi(t), y_{1}(t)=Z(t), y_{2}(t)=\xi^{\prime}(t)$, тоді

$$
\frac{d y_{3}(t)}{d t}=\frac{d}{d t}\left[\frac{1}{\xi(t)} \frac{d}{d t}\left(\frac{Z^{\prime}(t)}{\xi(t)}\right)\right]=\frac{2 \omega}{t_{0}^{2}} I(\xi(t)) .
$$

Позначимо

$$
y_{3}(t)=\frac{1}{\xi(t)} \frac{d}{d t}\left(\frac{Z^{\prime}(t)}{\xi(t)}\right),
$$

тоді

$$
\frac{d}{d t}\left(\frac{Z^{\prime}(t)}{\xi(t)}\right)=y_{0}(t) y_{3}(t)
$$

і маємо таке друге диференціальне рівняння:

$$
\frac{d y_{2}(t)}{d t}=y_{0}(t) y_{3}(t)
$$

Позначимо

$$
y_{2}(t)=\frac{Z^{\prime}(t)}{\xi(t)}=\xi^{\prime}(t), \text { тоді } Z^{\prime}(t)=y_{0}(t) y_{2}(t),
$$


або

$$
\frac{d y_{1}(t)}{d t}=y_{0}(t) y_{2}(t)
$$

3 формули (4), з урахуванням введених позначень, випливає:

$$
\frac{d y_{0}(t)}{d t}=\frac{\xi_{0}}{\tau}-\frac{y_{0}(t)}{\tau}-\frac{\left(P-1-y_{0}(t)\right)}{1-y_{1}(t)} y_{0}(t) y_{2}(t) \text {. }
$$

Отже, маємо задачу Коші для системи чотирьох звичайних диференціальних рівнянь для вектору стану $Y(t)=\left\{y_{0}(t), y_{1}(t), y_{2}(t), y_{3}(t)\right\}$ :

$$
\frac{d}{d t} Y(t)=\left\{\begin{array}{c}
\frac{\xi_{0}}{\tau}-\frac{y_{0}(t)}{\tau}-\frac{\left(P-1-y_{0}(t)\right)}{1-y_{1}(t)} y_{0}(t) y_{2}(t), \\
y_{0}(t) y_{1}(t), \\
y_{0}(t) y_{3}(t), \\
\frac{2 \omega}{t_{0}^{2}} I_{0} \sqrt{y_{0}(t)} \exp \left(\frac{-\alpha}{y_{0}(t)}\right) .
\end{array},\right.
$$

3 початковими умовами:

$$
y_{0}(0)=10^{-10}, y_{1}(0)=0, y_{2}(0)=0, y_{3}(0)=0 \text {. }
$$

Розв'язання жорсткої системи звичайних диференціальних рівнянь для визначення струму перемикання. Задача (9)-(10) є задачею Коші з жорсткою системою звичайних диференціальних рівнянь.

Жорсткою системою звичайних диференціальних рівнянь (ЗДУ) називається така система ЗДУ, чисельне розв'язання якої явними методами (наприклад, методами Рунге-Кутти або Адамса) є незадовільним через різке збільшення кількості обчислень (при малому кроці інтегрування) або через різке зростання похибки (так званого, вибуху похибки) при недостатньо малому кроці інтегрування [9]. Для жорстких систем характерно те, що для них неявні різницеві схеми дають кращий результат, ніж явні методи. Явище жорсткості полягає в тому, що розв’язок системи ЗДУ містить як повільну складову, яка суттєво змінюється в усій області значень часу, так і швидку складову, яка відрізняється від нуля тільки у малому діапазоні зростання часу від 0 .

Для чисельного розв'язування жорстких систем звичайних диференціальних рівнянь можуть застосовуватися чисто неявні багатокрокові схеми, неявні методи Рунге-Кутти, однокрокові ітераційні методи Розенброка, явні різницеві схеми Федули, неявні методи Ракитського [10, 11].

Система ЗДУ (9) є автономною, тобто їі права частина не містить змінну $t$. Для розв’язання задачі (9)-(10) був застосований метод Розенброка, який базується на неявній схемі Рунге-Кутти 4-го порядку. Розрахункові формули методу такі:

$$
Y_{i+1}=Y_{i}+\frac{13}{6} \mathbf{k}_{\mathbf{1}}+\frac{1}{6} \mathbf{k}_{\mathbf{2}}-2 \mathbf{k}_{\mathbf{3}}+\frac{2}{3} \mathbf{k}_{\mathbf{4}}
$$


де

$$
\left\{\begin{array}{l}
\mathbf{k}_{\mathbf{1}}=h \cdot[E-h \cdot J]^{-1} \cdot F\left(Y_{n}\right) ; \\
\mathbf{k}_{\mathbf{2}}=h \cdot[E-h \cdot J]^{-1} \cdot F\left(Y_{n}-\mathbf{k}_{\mathbf{1}}\right) ; \\
\mathbf{k}_{\mathbf{3}}=h \cdot[E-h \cdot J]^{-1} \cdot F\left(Y_{n}+\frac{1}{8} \mathbf{k}_{1}+\frac{3}{8} \mathbf{k}_{2}\right) ; \\
\mathbf{k}_{\mathbf{4}}=h \cdot[E-h \cdot J]^{-1} \cdot F\left(Y_{n}+\frac{3}{8} \mathbf{k}_{1}+\frac{19}{24} \mathbf{k}_{2}-\frac{1}{6} \mathbf{k}_{\mathbf{3}}\right) ;
\end{array}\right.
$$

$F(Y)=\left(f_{1}(Y), f_{2}(Y), f_{3}(Y), f_{4}(Y)\right)$ - вектор правих частин (9)-(10), $E$ - одинична матриця; $J\left(Y_{i}\right)=\frac{\partial F\left(Y_{i}\right)}{\partial y_{k}}-$ матриця Якобі системи, яка обчислена при $t=t_{i}$

Реалізовано автоматичний вибір кроку інтегрування $h$.

Застосування різницевої схеми (11)-(12) дає таблицю значень векторфункції $Y(t)=\left\{y_{0}(t), y_{1}(t), y_{2}(t), y_{3}(t)\right\}$ у вузлах $t_{k}, k=\overline{1, n}$, за якими можна обчислити

$$
j\left(t_{k}\right)=-\frac{2 P_{z 10}\left(\xi_{0} / \tau-y_{0}\left(t_{k}\right) / \tau-y_{2}\left(t_{k}\right)\right)\left(1-y_{1}\left(t_{k}\right)\right)}{\left(P-1-y_{0}\left(t_{k}\right)\right)} .
$$

Розв’язання задачі мінімізації. Задача мінімізації (7) розв'язувалась методом покоординатного спуску з використанням методу золотого перерізу [12].

Для обчислення кожного значення цільової функції потрібно розв'язувати задачу Коші (9)-(10). Обчислення ж похідних цільової функції є окремою задачею і може бути виконано тільки наближено. У таких випадках можуть бути корисні методи нульового порядку, тобто методи, які не потребують обчислення похідних. Одним 3 них є метод покоординатного спуску, в якому багатовимірний пошук замінюється послідовністю одновимірних пошуків 3 будь-стратегією мінімізації функції однієї змінної. За метод одновимірного пошуку було обрано метод золотого перерізу.

Нехай $n=2, \lambda_{1}^{-}=\alpha^{-}, \lambda_{1}^{+}=\alpha^{+}, \lambda_{2}^{-}=I_{0}^{-}, \lambda_{2}^{+}=I_{0}^{+}$, де $\alpha^{-}, \alpha^{+}, I_{0}^{-}, I_{0}^{+}-$границі шуканих змінних. Позначимо через $\Omega=\left\{\left(\alpha, I_{0}\right): \alpha^{-} \leq \alpha \leq \alpha^{+}, I_{0}^{-} \leq I_{0} \leq I_{0}^{+}\right\}$.

Алгоритм розв'язання задачі.

Початковий етап. Вибрати число $\varepsilon>0$ для зупинки алгоритму, початкову точку $x^{(0)}=\left(\alpha^{(0)}, I_{0}^{(0)}\right) \in \Omega$, покласти $z_{1}=x^{(0)}, k=i=1$ і перейти до основного етапу.

Основний етап.

Крок 1. Знайти кроковий множник $\lambda_{(k-1) n+i-1}$ iз розв’язання методом золотого перерізу задачі одновимірної мінімізації 


$$
f\left(x^{(k-1) n+i-1}+\lambda e_{i}\right) \rightarrow \min , \lambda \in E^{1} .
$$

Покласти $x^{(k-1) n+i}=x^{(k-1) n+i-1}+\lambda_{(k-1) n+i-1} e_{i}$. Перевірити умову $x^{(k-1) n+i} \in \Omega$. При невиконанні цієї умови спроектувати точку $x^{(k-1) n+i}$ на множину $\Omega$.

Якщо $i<n$, то замінити $i$ на $i+1$ та повернутися до кроку 1 , якщо $i=n$, то перейти до кроку 2.

Крок 2. Покласти $z_{k+1}=x^{(k n)}$. Якщо $\left\|z_{k+1}-z_{k}\right\|<\varepsilon$, то зупинитися. У протилежному випадку покласти $k=k+1, i=1$ та перейти до кроку 1 .

Чисельний експеримент та аналіз результатів. Числові розрахунки проведені для ідентифікації параметрів сегнетоелектичних кристалів TGS (Тригліцинсульфат). Фізичні константи при розрахунках вибирались відповідно властивостям сегнетокристалів TGS, а саме $\alpha^{-}=0.15, \alpha^{+}=0.3, I_{0}^{-}=8 \cdot 10^{30}$, $I_{0}^{+}=12 \cdot 10^{30}, \tau=10^{-6}, t \in\left[0,10^{-5}\right], \xi_{0}=1.5 \cdot 10^{6}, P=1.5, t_{0}=10^{-13}$.

Розв'язання задачі ідентифікації починалось 3 початкової точки $\left(\alpha^{(0)}, I_{0}^{(0)}\right)=\left(0.12,9.7 \cdot 10^{30}\right)$. На рис. 1,2 наведені графіки функцій $y_{0}(t)$, $y_{1}(t)$ та $y_{2}(t), y_{3}(t)$, відповідно, при таких значеннях параметрів $\alpha$ та $I_{0}$ (табл. 1).

Таблиия 1

\begin{tabular}{|c|c|c|}
\hline $\begin{array}{c}\text { Номер кривої } \\
\text { на графіку }\end{array}$ & $\alpha$ & $I_{0} / 10^{30}$ \\
\hline 1 & 0.1764 & 9.7 \\
\hline 2 & 0.252785 & 9.7 \\
\hline 3 & 0.205579 & 9.7 \\
\hline 4 & 0.220668 & 1.0472 \\
\hline 5 & 0.220668 & 9.5277 \\
\hline 6 & 0.220668 & 8.00384 \\
\hline
\end{tabular}

Криві 6 на рисунках відповідають оптимальним значенням $\left(\bar{\alpha}, \bar{I}_{0}\right)=(0.220668,8.00384)$, для яких відхилення (8) експериментальних даних від теоретичних досягає мінімального значення.

Знаючи оцінки точних значень $\alpha$ та $I_{0}$ за формулами (6) можна знайти кінетичний коефіцієнт $\beta_{0}$ i величину поверхневого натягу доменних стінок в сегнетоелектричних кристалах $\sigma$.

Зазначимо, що за такою методикою можуть бути визначені ці параметри не тільки для сегнетоелектриків із $180^{\circ}$-доменами, а й для багатовісних сегнетоелектриків [1]. 

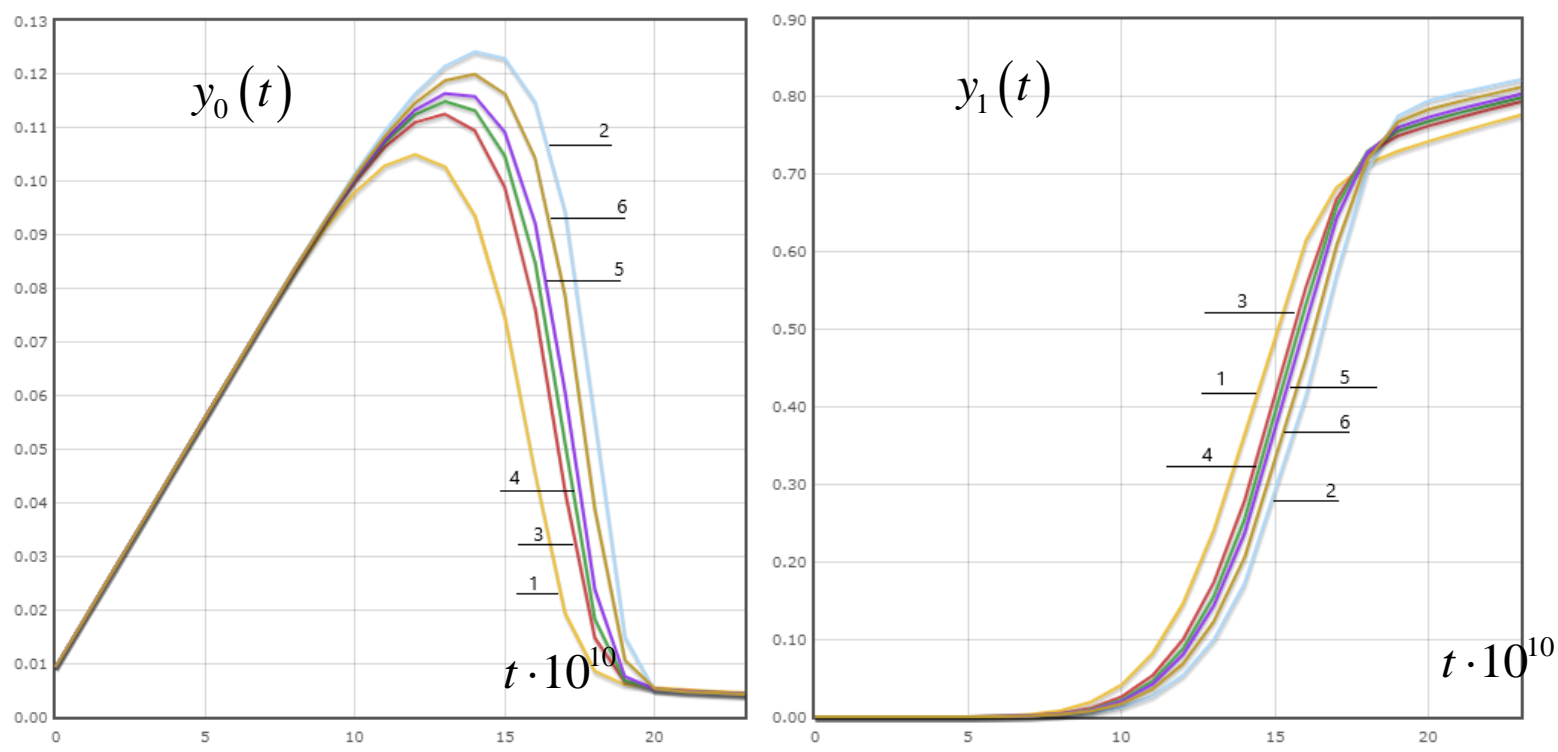

Рис. 1. Графіки функцій $y_{0}(t), y_{1}(t)$

при різних значеннях параметрів $\alpha$ та $I_{0} / 10^{30}$
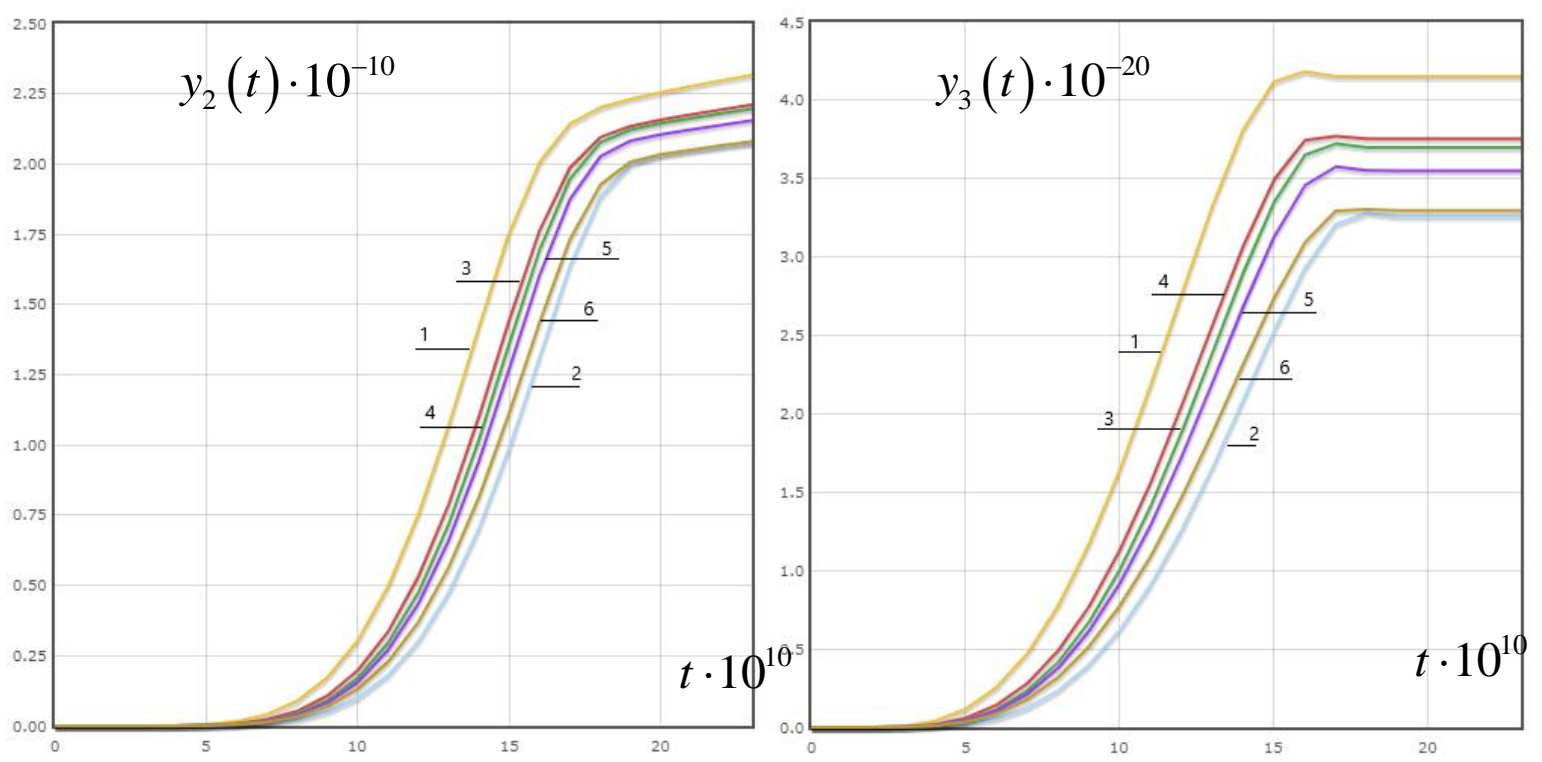

Рис. 2. Графіки функцій $y_{2}(t), y_{3}(t)$

при різних значеннях параметрів $\alpha$ та $I_{0} / 10^{30}$

Висновки. Було сформульовано постановку задачі ідентифікації невимірюваних параметрів сегнетоелектриків. Розв'язано жорстку систему звичайних диференціальних рівнянь із застосуванням однокрокового ітераційного методу Розенброка. Розроблено алгоритм та його програмну реалізацію, який дозволяє розв'язувати поставлені задачі ідентифікації параметрів сегнетоелектриків та реалізує методи пошуку мінімуму для задачі багатовимірної умовної оптимізації з використанням одновимірної оптимізації. Проведено числовий експеримент для конкретних сегнетоелектричних матеріалів. 


\section{Бібліографічні посилання}

1. Струков Б. А. Физические основы сегнетоэлектрических явлений в кристаллах [Текст] / Б. А. Струков, А. П. Леванюк. - М.: Наука, 1995. - 304 с.

2. Wang C. L. Switching characters of asymmetric ferroelectric films [Text] / C. L. Wang, L. Zhang, W. L. Zhong, P. L. Zhang // Physics Letters A. - 1999. - 254, Issue 5. - P. 297 300. - https://doi.org/10.1016/S0375-9601(99)00129-2.

3. Ishibashi Y. Note on ferroelectric domain switching [Text] / Y. Ishibashi, Y. Takagi // J. Phys. Soc. Jpn. - 1970. - 31. - P. 506-510. - https://doi.org/10.1143/JPSJ.31.506.

4. Ishibashi Y. Superstructure in the ferroelectric phase of ammonium Rochelle salt [Text] / Y. Ishibashi, Y. Takagi // J. Phys. Soc. Japan. - 1971. - 31. - P. 506. https://doi.org/10.1143/JPSJ.31.952

5. Кукушкин С. А. Кинетика переключения в сегнетоэлектриках [Текст] / С. А. Кукушкин, А. В. Осипов // Физика твердого тела. - 2001. - 43. - С. 88-98.

6. Захаров М. А. Теория переключения многоосных сегнетоэлектриков (основные стадии) [Текст] / М. А. Захаров, С. А. Кукушкин, А. В. Осипов // Физика твердого тела. 2005. - 47, Вып. 4. - С. 673-678.

7. Kukushkin S. A. Theory of the Switching in Ferroelectrics [Text] / S. A. Kukushkin, A. V. Osipov // Ferroelectrics. - 2002. - 280, № 1. - P. 3-33.

8. Проблемы механики деформируемых твердых тел и горных пород. Сборник статей к 75-летию Е. И. Шемякина [Текст] / Под. ред. Д. Д. Ивлева и Н. Ф. Морозова. - М.: Физматлит, 2006. - 864 с.

9. Хайрер Э. Решение обыкновенных дифференциальных уравнений. Жесткие и дифференциально-алгебраические задачи [Текст] / Э. Хайрер, Г. Ваннер - М.: Мир, 1999. $685 \mathrm{c}$.

10. Фельдман Л.П. Чисельні методи в інформатиці [Текст] / Л. П. Фельдман, А. І. Петренко, О. А. Дмитрієва. - К.: Видавнича група ВНV, 2006. - 480 с.

11. Бігун Я. Й. Числові методи: навч.посібник [Текст] / Я. Й. Бігун. - Чернівці: Чернівец. нац. нн-т ім. Ю. Федьковича, 2019. - 436 с.

12. Васильев Ф. П. Численные методы решения экстремальных задач [Текст] / Ф. П. Васильев. - М.: Наука, 1988.-552 с.

Надійшла до редколегії 22.10. 2019. 


\author{
T. Nakonechnaya \\ Oles Honchar Dnipro National University
}

\title{
THE CYCLIC INEQUALITY OF N.P. KORNEICHUK AND IT'S GENERALIZATION
}

In this paper there is given a generalization of well-known cyclic inequality of N.P. Korneichuk on the case of $\boldsymbol{n}$ independent variables. This result is of independent interest and can be used to obtain estimated results of splines-approximation in classes with bounded modulus of continuity.

Key words: cyclic inequality, extreme problem, Lagrange principle.

Наведена стаття містить узагальнення відомої циклічної нерівності Н.П. Корнійчука на випадок $n$ незалежних змінних. Отриманий результат має також самостійний інтерес та його можна застосувати для отримання оціночних результатів сплайн-апроксимації на класах функцій з обмеженим модулем неперервності.

Ключові слова: циклічна нерівність, екстремальна задача, принцип Лагранжу.

В данной статье приводится обобщение известного циклического неравенства Н.П. Корнейчука на случай $n$ независимых переменных. Данный результат представляет самостоятельный интерес и может быть использован для получения оценочных результатов сплайн-аппроксимации на классах с ограниченных модулем непрерывности.

Ключевые слова: циклическое неравенство, экстремальная задача, принцип Лагранжа.

Introduction. N.P. Korneichuk in his monograph "Splines in approximation theory" noted the advantages of splines over other approximation methods. Two aspects can be pointed out in which these advantages have been most convincing:

1) Interpolation splines in a number of important cases provide the minimum possible approximation error on the class of functions. Interpolation polynomials do not provide even the best order.

2) Splines - the apparatus is more convenient than polynomials from a computational or even practical point of view.

The main attention in the fifth chapter of his monograph, N.P. Korneichuk focused on issues related to estimating the error of spline-interpolation through the modulus of continuity $\omega(\delta)$. In the same chapter, an upper bound was obtained for the approximation of piecewise constant functions on a class $H^{\omega}$. To establish this estimate, N.P. Korneichuk had to prove the following elementary inequality. We cite this inequality together with the proof.

Lemma (N.P. Korneichuk). For all $u \geq 0$ and $0<p \leq 3$ we have the inequality

$$
2^{p}\left(u^{p}+u\right) \leq(1+u)^{p+1}
$$

which with $p>3$ and some $u>0$ is no longer fulfilled.

(C) Nakonechnaya T., 2019 
Really, let us consider the function

$$
\eta(u, p)=(1+u)^{p+1}-2^{p}\left(u^{p}+u\right), u \geq 0, p>0,
$$

and we'll show that

$$
\eta(u, p) \geq 0, u \geq 0,3 \geq p>0 .
$$

Assuming $u>0$ (with $u=0$ inequality (2) is obvious), we note that $\eta(u, p)=u^{p+1} \eta\left(\frac{1}{u}, p\right)$,

and therefore it is sufficient to prove non-negativity $\eta(u, p)$ with $u \geq 1$ and $0<p \leq 3$.

Thus

$$
\eta(1, p)=\eta_{u}^{\prime}(1, p)=0, \lim _{u \rightarrow \infty} \eta(u, p)=+\infty, p>0,
$$

then necessary inequality will be established if we show that for $u>1$ and $0<p<3$

$$
\eta_{u u}^{\prime \prime}(u, p)>0
$$

But

$$
\eta_{u u}^{\prime \prime}(u, p)=p\left[(p+1)(1+u)^{p-1}-2^{p}(p-1) u^{p-2}\right]
$$

and in the case $0<p \leq 1$ everything is trivial. If $1<p<3$, then (3) follows from fact

$$
\eta_{u u}^{\prime \prime}(1, p)=p 2^{p-1}(3-p)>0
$$

and, besides, for $u \geq 1$ and $1<p<3$

$$
\frac{\partial^{3} \eta(u, p)}{\partial u^{3}}=p(p-1)\left[(p+1)(1+u)^{p-2}-2^{p}(p-2) u^{p-3}\right]>0 .
$$

Last inequality at $1<p \leq 2$ is obvious, and for $u \geq 1$ and $2<p<3$ follows from the relation

$$
(1+p)(1+u)^{p-2}>(1+p) 2^{p-2}>2^{p}(p-2)>2^{p}(p-2) u^{p-3} .
$$

Relation (2), and with it the first part of the statement of lemma, is proved. If $p>3$, then $\eta_{u u}^{\prime \prime}(u, p)<0$ and in the neighborhood of the line $u=1$ function $\eta(u, p)$ takes negative values.

We reformulate this inequality in a more convenient form for us; for this, put $u=x / y$, where $x>0, y>0$.

Lemma 1. For all $x \geq 0, y \geq 0$ and $0<p \leq 3$ we have the inequality

$$
(x+y)^{p+1} \geq 2^{p}\left(x y^{p}+y x^{p}\right),
$$

which with $p>3$ and some $x>0, y>0$ is no longer fulfilled.

The main results. This article summarizes the inequality of N.P. Korneichuk in the case of $n$ independent variables. The following theorem will be true. 
Theorem 1. For all $x_{i}>0(i=1,2, \ldots n), n \in N, n \geq 2$ and $q \in\left(0 ; \frac{n+1}{n-1}\right)$ the next inequality will be true

$$
\left(\frac{1}{n} \sum_{k=1}^{n} x_{k}\right)^{q+1} \geq \frac{1}{n} \sum_{k=1}^{n} x_{k}^{q} \frac{1}{n-1}\left(\sum_{i=1}^{n} x_{i}-x_{k}\right),
$$

which with $q>\frac{n+1}{n-1}$ and some $x_{i}>0(i=1,2, \ldots n)$ is no longer fulfilled. If $q=\frac{n+1}{n-1}$, then inequality (5) holds only for the values $n=2,3$.

Proof. We'll obtain the decision of inequality (5) as a solution to the extreme problem

$$
\left(\frac{1}{n} \sum_{k=1}^{n} x_{k}\right)^{q+1} \rightarrow \inf , q>0, x_{k}>0,(1 \leq k \leq n)
$$

under the following condition

$$
\frac{1}{n} \sum_{k=1}^{n} x_{k}^{q} \frac{\left(\sum_{i=1}^{n} x_{i}-x_{k}\right)}{n-1}-1=0 .
$$

The set of admissible elements is compact; the functional is continuous, which means that by Weierstrass's theorem a solution to the problem exists. First, let the $0<q<\frac{n+1}{n-1}$. Then Lagrange Function have the form:

$$
L=\lambda_{0}\left(\frac{1}{n} \sum_{k=1}^{n} x_{k}\right)^{q+1}+\lambda_{1}\left(\frac{1}{n(n-1)} \sum_{k=1}^{n} x_{k}^{q}\left(\sum_{i=1}^{n} x_{i}-x_{k}\right)-1\right)
$$

The necessary condition for the existence of an extremum is as follows:

$$
\begin{gathered}
\frac{\partial L}{\partial x_{k}}=0,(k=1,2, \ldots . n) \Leftrightarrow \\
\lambda_{0} \frac{q+1}{n}\left(\frac{1}{n} \sum_{k=1}^{n} x_{k}\right)^{q}+\frac{\lambda_{1}}{n(n-1)}\left(q x_{k}^{q-1}\left(\sum_{i=1}^{n} x_{i}-x_{k}\right)+\sum_{i=1}^{n} x_{i}^{q}-x_{k}^{q}\right)=0 .
\end{gathered}
$$

If $\lambda_{0}=0$ then and $\lambda_{1}=0$ that contradicts the Lagrange principle. Put $\lambda_{0}=1$. Subtracting from all subsequent equations the first equation of system (4), we obtain the following system: 


$$
\left\{\begin{array}{l}
\lambda_{0} \frac{q+1}{n}\left(\frac{1}{n} \sum_{k=1}^{n} x_{k}\right)^{q}+\frac{\lambda_{1}}{n(n-1)}\left(q x_{1}^{q-1}\left(\sum_{i=1}^{n} x_{i}-x_{1}\right)+\sum_{i=1}^{n} x_{i}^{q}-x_{1}^{q}\right)=0, \\
\frac{\lambda_{1}}{n(n-1)}\left(q \sum_{i=1}^{n} x_{i}\left(x_{k}^{q-1}-x_{1}^{q-1}\right)-(q+1)\left(x_{k}^{q}-x_{1}^{q}\right)\right)=0, \quad k=2,3, \ldots n .
\end{array}\right.
$$

It is clear that the solution to this system has the form $x_{k}=x_{1}(k=2,3, \ldots n)$. According to condition (6), we obtain, that $x_{1}^{q+1}=1$, hence, $x_{1}=1$ and $\lambda_{1}=-1$. Thus, the point $N(1,1, \ldots .1,-1)$ is the point of the possible minimum of the Lagrange function, and the point $\hat{x}=(1,1, \ldots, 1)$ will be a valid element. Now it is necessary to verify that sufficient conditions are satisfied, that is, to prove that the inequality $\left.d^{2} L\right|_{N}>0$ holds for $q \in\left(0 ; \frac{n+1}{n-1}\right)$. Calculating the second-order derivatives of the Lagrange function, we obtain:

$$
\begin{aligned}
& \frac{\partial^{2} L}{\partial x_{k}^{2}}=\frac{q(q+1)}{n^{2}}\left(\frac{1}{n} \sum_{k=1}^{n} x_{k}\right)^{q-1}+\frac{\lambda_{1} q(q-1)}{n(n-1)} x_{k}^{q-2} \sum_{i=1}^{n} x_{i}-\frac{\lambda_{1} q(q-1)}{n(n-1)} x_{k}^{q-1},(k=1,2, \ldots . . n) \\
& \frac{\partial^{2} L}{\partial x_{k} x_{j}}=\frac{q(q+1)}{n^{2}}\left(\frac{1}{n} \sum_{k=1}^{n} x_{k}\right)^{q-1}+\frac{\lambda_{1} q}{n(n-1)}\left(x_{k}^{q-1}+x_{j}^{q-1}\right), \quad k, j=1,2, \ldots n ; \quad k \neq j .
\end{aligned}
$$

Consequently,

$$
\begin{aligned}
& \left.\frac{\partial^{2} L}{\partial x_{k}^{2}}\right|_{N}=\frac{(n+1) q}{n^{2}}\left(1-q \frac{n-1}{n+1}\right), \quad k=1,2, \ldots n \\
& \left.\frac{\partial^{2} L}{\partial x_{k} \partial x_{j}}\right|_{N}=-\frac{(n+1) q}{n^{2}}\left(1-q \frac{n-1}{n+1}\right), \quad k, j=1,2, \ldots n, \quad k \neq j .
\end{aligned}
$$

Thus, we arrive at the equality

$$
\left.d^{2} L\right|_{N}=\frac{(n+1) q}{n^{2}}\left(1-q \frac{n-1}{n+1}\right)\left(2 \sum_{k=1}^{n} d x_{k}^{2}-\left(\sum_{k=1}^{n} d x_{k}\right)^{2}\right) .
$$

Further, from condition (6) it follows that

$$
d\left(\frac{1}{n} \sum_{k=1}^{n} x_{k}^{q} \frac{\sum_{i=1}^{n} x_{i}-x_{k}}{n-1}-1\right)=0 \Leftrightarrow \frac{1}{n}\left(\sum_{k=1}^{n} q x_{k}^{q-1} \frac{\left(\sum_{i=1}^{n} x_{i}-x_{k}\right)}{n-1}+\sum_{i=1}^{n} x_{i}^{q}-x_{k}^{q}\right) d x_{k}=0 .
$$


It is clear that the resulting equality will be true at the point $\widehat{x}=(1,1, \ldots, 1)$. Thus, we obtain the following relation: $\frac{q+1}{n} \sum_{k=1}^{n} d x_{k}=0$. Hence,

$$
\left.d^{2} L\right|_{N}=\frac{2(n+1)}{n^{2}} q\left(1-q \frac{n-1}{n+1}\right) \sum_{k=1}^{n} d x_{k}^{2}>0, \quad \text { for } \quad 0<q<\frac{n+1}{n-1} .
$$

We prove that for $q>\frac{n+1}{n-1}(n \geq 2)$ there are such $x_{i}^{*}>0(i=1,2, \ldots n)$ that

$$
\left(\frac{1}{n} \sum_{k=1}^{n} x_{k}^{*}\right)^{q+1}<\frac{1}{n} \sum_{k=1}^{n} x_{k}^{*} q \frac{1}{n-1}\left(\sum_{i=1}^{n} x_{i}^{*}-x_{k}^{*}\right) \text {. }
$$

Let $x_{1}^{*}=1+\varepsilon, x_{2}^{*}=x_{3}^{*}=\ldots=x_{n}^{*}=1$, where $\varepsilon \in\left[0 ; \frac{n-1}{q+1}\left(q-\frac{n+1}{n-1}\right)\right)$. Consider the function

$$
F(q, \varepsilon)=\frac{1}{n} \sum_{k=1}^{n} x_{k}^{*} q \frac{1}{n-1}\left(\sum_{i=1}^{n} x_{i}^{*}-x_{k}^{*}\right)-\left(\frac{1}{n} \sum_{k=1}^{n} x_{k}^{*}\right)^{q+1}=1+\frac{(1+\varepsilon)^{q}+\varepsilon-1}{n}-\left(1+\frac{\varepsilon}{n}\right)^{q+1} .
$$

We prove that there is $0<\varepsilon^{*}<\frac{n-1}{q+1}\left(q-\frac{n+1}{n-1}\right)$ such, that $F\left(q, \varepsilon^{*}\right)>0$. Easy to see that $F(q, 0)=0$. Besides,

$$
F_{\varepsilon}^{\prime}(q, \varepsilon)=\frac{1}{n}\left(q(1+\varepsilon)^{q-1}+1-(q+1)\left(1+\frac{\varepsilon}{n}\right)^{q}\right),
$$

thus, $F_{\varepsilon}^{\prime}(q, 0)=0$. Thus, it remains for us to prove that for all $\varepsilon$ of the above interval, the inequality $F_{\varepsilon}^{\prime \prime}(q, \varepsilon)>0$ holds.

Really,

$$
\begin{gathered}
F_{\varepsilon}^{\prime \prime}(q, \varepsilon)=\frac{q(q-1)}{n}(1+\varepsilon)^{q-2}-\frac{q(q+1)}{n^{2}}\left(1+\frac{\varepsilon}{n}\right)^{q-1}= \\
=\frac{q(q+1)}{n^{2}(1+\varepsilon)^{1-q}}\left(\frac{(q-1) n}{(q+1)(1+\varepsilon)}-\left(\frac{1+\frac{\varepsilon}{n}}{1+\varepsilon}\right)^{q-1}\right)>\frac{q(q+1)}{n^{2}(1+\varepsilon)^{1-q}}\left(1-\left(\frac{1+\frac{\varepsilon}{n}}{1+\varepsilon}\right)^{q-1}\right) \geq 0 .
\end{gathered}
$$

Let now $q=\frac{n+1}{n-1}$. The case, when $n=2$ was considered in [1].

Let now $n=3$, then $q=2$. We need to make sure that for non-negative values of variables $x_{1}, x_{2}, x_{3}$ the next inequality will be true: 
Really,

$$
\left(\frac{1}{3} \sum_{k=1}^{3} x_{k}\right)^{3} \geq \frac{1}{3} \sum_{k=1}^{3} x_{k}^{2} \frac{1}{2}\left(\sum_{i=1}^{3} x_{i}-x_{k}\right) .
$$

$$
\begin{aligned}
& \left(\frac{1}{3} \sum_{k=1}^{3} x_{k}\right)^{3}-\frac{x_{1}^{2}\left(x_{2}+x_{3}\right)+x_{2}^{2}\left(x_{1}+x_{3}\right)+x_{3}^{2}\left(x_{1}+x_{2}\right)}{6}= \\
& \frac{1}{27}\left(x_{1}^{3}+x_{2}^{3}+x_{3}^{3}-\frac{1}{2}\left(x_{1} x_{2}\left(x_{1}+x_{2}\right)+x_{1} x_{3}\left(x_{1}+x_{3}\right)+x_{2} x_{3}\left(x_{2}+x_{3}\right)+6 x_{1} x_{2} x_{3}\right) \geq\right. \\
& \geq \frac{2}{9} x_{1} x_{2} x_{3} \geq 0,
\end{aligned}
$$

which follows from the elementary inequality $a^{3}+b^{3} \geq a b(a+b), a \geq 0, b \geq 0$.

Let now $n \geq 4$. Let us prove that there are such $y_{i}>0(i=1,2, \ldots n)$, for which the next inequality is true

$$
\left(\frac{1}{n} \sum_{k=1}^{n} y_{k}\right)^{\frac{2 n}{n-1}}<\frac{1}{n} \sum_{k=1}^{n} y_{k}^{\frac{n+1}{n-1}} \frac{1}{n-1}\left(\sum_{i=1}^{n} y_{i}-y_{k}\right) .
$$

Let $y_{1}=1+\varepsilon, y_{2}=y_{3}=\ldots=y_{n-1}=1, y_{n}=1-\varepsilon$, where $|\varepsilon|<1$. We introduce the function

$$
\begin{aligned}
& F(n, \varepsilon)=\frac{1}{n} \sum_{k=1}^{n} y_{k}^{\frac{n+1}{n-1}} \frac{1}{n-1}\left(\sum_{i=1}^{n} y_{i}-y_{k}\right)-\left(\frac{1}{n} \sum_{k=1}^{n} y_{k}\right)^{\frac{2 n}{n-1}}= \\
& =\frac{1}{n}\left((1+\varepsilon)^{\frac{n+1}{n-1}}\left(1-\frac{\varepsilon}{n-1}\right)+(1-\varepsilon)^{\frac{n+1}{n-1}}\left(1+\frac{\varepsilon}{n-1}\right)-2\right),
\end{aligned}
$$

and prove that there is $0<\left|\varepsilon^{*}\right|<1$ such, that for all $n \geq 4$ the inequality $F\left(n, \varepsilon^{*}\right)>0$ takes place. It is easy to see that $F(n, 0)=0$. Besides,

$$
\begin{gathered}
\left.F_{\varepsilon}^{\prime}(n, \varepsilon)\right|_{\mathcal{E}=0}=\left.\frac{1}{n-1}\left((1+\varepsilon)^{\frac{2}{n-1}}\left(1-\frac{2}{n-1} \varepsilon\right)-(1-\varepsilon)^{\frac{2}{n-1}}\left(1+\frac{2}{n-1} \varepsilon\right)\right)\right|_{\mathcal{E}=0}=0, \\
\left.F_{\mathcal{E}}^{\prime \prime}(n, \varepsilon)\right|_{\mathcal{E}=0}=\left.C(n) \varepsilon\left((1-\varepsilon)^{\frac{3-n}{n-1}}-(1+\varepsilon)^{\frac{3-n}{n-1}}\right)\right|_{\mathcal{E}=0}=0,
\end{gathered}
$$

where $C(n)=\frac{2(n+1)}{(n-1)^{2}}$. It can be directly verified that if $n \geq 4$, then $F_{\varepsilon}^{\prime \prime}(n, \varepsilon)>0$ for $0<|\varepsilon|<1$. As $F_{\mathcal{\varepsilon}}^{\prime}(n, 0)=0$, then function $F_{\mathcal{\varepsilon}}^{\prime}(n, \varepsilon)$ changes sign from «-» on «+» when crossing a point $\varepsilon=0$. It follows that $\min _{|\varepsilon|<1} F(n, \varepsilon)=F(n, 0)=0$. 
Thus, indeed, there is at least one $0<\varepsilon^{*}<1$, for which $F\left(n, \varepsilon^{*}\right)>0$ for $n \geq 4$.

Conclusions. In this paper there is given a generalization of well-known cyclic inequality of N. P. Korneichuk on the case of $n$ independent variables. The proof of this result differs from the proof of the original result in that it required a study on the conditional extremum of the function of $n$ variables, which required very complex calculations and transformations. This result is of independent interest and can be used to obtain estimated results of spline-approximation in classes with bounded modulus of continuity.

\section{Bibliographic references}

1. Корнейчук, Н.П. Сплайны в теории приближения [Текст]/ Н.П. Корнейчук. - М., 1984. $-452 \mathrm{c.}$

2. Алексеев, В.М. Оптимальное управление [Текст] / В.М. Алексеев, В.М. Тихомиров, С.В. Фомин. - М.,1979. - 495 с.

Received 15.10.2019. 
М.С. Сердюк, С.Ф. Сірик, О.О. Сокол

Дніпровський національний університет імені Олеся Гончара

\section{АВТОМАТИЧНА КОЛОРИЗАЦІЯ ЦИФРОВИХ НАПІВТОНОВИХ ЗОБРАЖЕНЬ 3 ВИКОРИСТАННЯМ НЕЙРОННИХ МЕРЕЖ}

Розглянуто задача автоматичної колоризації монохромних зображень та метод ії розв'язання 3 використанням згорткової нейронної мережі. Розглянута структура нейронної мережі для колоризації на основі моделі VGG16. Представлена комп'ютерна система для здійснення автоматичної колоризації зображень у відтінках сірого.

Ключові слова: обробка зображень, колоризація, згортка, згорткова нейронна мережа.

Рассмотрена задача автоматической колоризации монохромных изображений и метод ее решения с использованием сверточной нейронной сети. Рассмотрена структура нейронной сети для колоризации на основе модели VGG16. Представлена компьютерная система для осуществления автоматической колоризации изображений в оттенках серого.

Ключевые слова: обработка изображений, колоризация, свертка, сверточная нейронная сеть.

The problem of automatic colorization of monochrome images is considered. methods of colorizing are used in film industry to restore chromaticity of old movies and photographic materials, in computer vision problems, in medical images processing etc. Modern techniques of colorization contain many manual operations, take a lot of time and are expensive. Many methods of colorization require human participation to correctly determine colors, since there is no one-to-one accordance between grayscale and color. In this paper we discuss method for fully automatic colorization of monochrome images using a convolutional neural network. This approach has reduced using of manual operations to minimum. Structure of the neural network for coloration based on the VGG16 model is considered in the paper. Types of layers that are appropriate for solving the problem of colorization are determined and analyzed. Proposed structure consists of 13 convolutional layers and three upsampling layers. The subsample layers are replaced with the necessary zero addition with a step of $2 \times 2$. All layers' filters have $3 \times 3$ size. The activation function of all convolutional layers is ReLU and hyperbolic tangent of the last layer. The presented model is implemented in a software system for automatic image colorization. The software system includes two parts. The first part implements construction and training of the neural network. The second part uses obtained neural network to generate colorized images from grayscale images. Network training was carried out on a sample of Caltech-256, which contains 256 categories of objects. After training the system was tested on series of grayscale images. Testing showed that the system performs enough plausible colorization of certain types objects. Acceptable results were obtained in the colorization of images of nature, ordinary animals, portrait photos. In unsuccessful cases objects were painted in brown shades. Unsuccessful results were obtained for images that contained only parts of objects or these objects were represented in the training sample in too different colors.

Keywords: image processing, colorization, convolution, convolutional neural network.

(C) Сердюк М.С., Сірик С.Ф., Сокол О.О., 2019 
Вступ. Колоризація - це процес додавання кольору до напівтонових зображень чи відео. Колоризація монохромних зображень активно використовується в кіноіндустрії для відновлення колірності старих кінофільмів та фотографічних матеріалів. Методи колоризації зображень використовують в задачах комп'ютерного зору, в таких галузях, як обробка зображень 3 приладів нічного бачення для покращення сприйняття, обробка медичних знімків, реставрація старих фото тощо. Сучасні техніки колоризації містять багато ручних операції, займають багато часу та дорого коштують.

Процес колоризації базується на пошуку відображення множини відтінків сірого на множину кольорів, наприклад, колірного простору RGB. Основною проблемою $є$ те, що не існує взаємно однозначної відповідності між відтінком сірого та кольором. Існує невизначеність між можливими кольорами одного об'єкту, що ускладнює процес колоризації. Отже, багато методів потребують участі людини для правильного визначення кольорів.

Тому актуальною $є$ розробка системи колоризації напівтонового зображення, яка б відрізнялась високим ступенем автоматизації процесу та генерувала колірне зображення із монохромного з мінімальним втручанням з боку користувача.

Аналіз існуючих методів. Усі методи колоризації можна розділити на три групи за необхідністю втручання людини: повністю автоматичні методи, напівавтоматичні та неавтоматичні, які потребують значної участі людини.

Ідея розфарбовувати чорно-білі зображення з'явилася практично одночасно $з$ появою перших фотокарток та фільмів. До появи цифрових технологій колоризація монохромних фотографій здійснювалась вручну з використанням масляних або акварельних фарб та кольорових олівців. Інші техніки передбачали використання трафаретів для нанесення кольорів. 3 появою та вдосконаленням комп'ютерної техніки робота по додаванню кольорів спростилась. В наш час колоризація цифрових зображень «вручну» здійснюється за допомогою графічних редакторів, які надають користувачеві можливість використовувати багато різних пензлів та палітр кольорів. Важливим етапом процесу колоризації $є$ сегментація зображення на регіони, у яких пікселі імовірно відносяться до одного об'єкту або кольорової гами. Задача є досить складною і повністю лягає на плечі користувача при використанні ручних технологій колоризації. 3 іншого боку, перевагою методу розфарбовування «вручну» $є$ повний контроль над процесом передачі кольору.

Методи напівавтоматичної колоризації потребують часткової участі людини та зазвичай вимагають певних зразків кольору, які потім автоматично розподіляються по всьому зображенню. Необхідність зразків кольорів витікає 3 того факту, що не тільки штучні матеріали, такі як, наприклад, пластик, можуть бути різноманітного кольору, але й природні об'єкти також. Так, листя може бути зеленим влітку, але жовтим, червоним або коричневим восени. Тому ідея надати користувачеві можливість попередньо обрати кольори для подальшого використання досить обгрунтована. В роботі [6] досліджено алгоритми, що використовують для колоризації надані користувачем зразки ко- 
льору у певних регіонах зображення. Зокрема, вибір кольору базується на положенні, що сусідні пікселі у просторі-часі зі схожою яскравістю мають бути схожими за кольором. Формалізація даного твердження з використанням квадратичної функції дозволила отримати задачу оптимізації, яку можна ефективно розв'язати стандартними способами. Даний метод дозволяє отримати правдоподібні результати колоризації, проте інколи необхідно позначити велику кількість зразків кольору.

Інша група напівавтоматичних методів для генерації кольорового зображення використовує так зване довідкове зображення. В роботі [11] запропоновано метод, що дозволяє колоризувати монохромні зображення переносом інформації, що стосується кольору, з так званого довідкового зображення. Для цього перевіряється яскравість пікселів, розташованих поруч із цільовим пікселем, та у шуканий піксель переносяться кольори відповідних сусідніх за умови, якщо їх яскравість співпадає. Ця техніка показала високі результати на зображеннях, у яких регіони, пофарбовані у різні кольори, також мають різні рівні яскравості або текстури. В інших випадках користувачеві необхідно спрямовувати пошук відповідностей між пікселями, уточнюючи зразки, які б вказували на відповідні регіони на двох зображеннях. Метод дозволяє отримати хороші результати, але для їх отримання митцю необхідно знайти зразки зображень, які б мали бажані кольори на регіонах з текстурами, схожими до тих, що мають бути колоризованими. Також складним може бути вибіркове налаштування результату у певних зонах.

В роботі [3] запропоновано вдосконалення описаної техніки шляхом додаткового аналізу у вхідному зображенні текстури регіону. Спочатку у довідковому зображенні помічаються декілька початкових «довідкових» зон. Далі будується відображення між малими околами пікселів та точками в просторі характеристик, сконструйованому для того, щоб розрізняти пікселі з різних регіонів, основаних на локальному частотному аналізі у каналі яскравості. Для колоризації монохромного зображення необхідно класифікувати кожний із вхідних пікселів, щоб знайти, якій з визначених раніше рис вони відповідають найліпше. Пікселю надається колір із відповідної області. Отримане зображення зі зразками кольору передається на вхід оптимізованого алгоритму Левіна [6], після чого генерується фінальне зображення. Проблемною залишається ідентифікація нечітких та складних границь в процесі сегментації зображення, часто цю задачу доводиться розв'язувати вручну.

У роботі [7] запропоновано підхід, який передає статистику кольору декількох опорних зображень, здобутих шляхом веб-пошуку, на вихідне зображення у відтінках сірого. Цей метод дає гарний результат, коли вихідне та опорні зображення мають подібний контент. Однак пошук опорних зображень вимагає багато часу та може бути проблемним для рідкісних об'єктів або складних сцен.

У роботах [2], [4], [12] розглядаються повністю автоматичні методи колоризації, які базуються на використанні нейронних мереж. На основі обробки великих об'ємів даних будується нейронна мережа, що встановлює відповід- 
ність між відтінком сірого та кольором у просторі CIE Lab. Методи відрізняються в архітектурі їх згорткових нейронних мереж та цільовими функціями. В [12] використовується цільова функція у контексті задачі класифікації із збалансованими рідкими випадками, алгоритм в [4] використовує незбалансовану цільову функцію в контексті задачі класифікації, а в [2] використовується цільова функція в контексті задачі регресії. Певною проблемою цих алгоритмів є невизначеність границь кольору у складних для аналізу випадках.

Отже, існує багато різних методів колоризації, проте всі вони мають певні недоліки. Методи, що потребують зразків кольору, неможливо використовувати в автоматичних системах, часом вони вимагають значного втручання користувача. Методи автоматичної колоризації погано розв'язують задачу сегментації і тому часто генерують неприйнятні результати. Найбільш перспективними в цьому сенсі $є$ методи на основі використання нейронних мереж.

Метою даної роботи є проектування моделі згорткової нейронної мережі, яка б якісно перетворювала напівтонові зображення на кольорові, та розробка автоматизованої системи, яка б реалізувала таку нейронну мережу, давала змогу здійснити їі навчання та мала функцію автоматичної обробки вхідних монохромних зображень 3 можливістю отримання найвирогідніших їх колірних представлень.

Постановка задачі. Задача колоризації полягає в тому, щоб для кожного пікселя вихідного зображення у відтінках сірого знайти значення червоної, зеленої та синьої складових у моделі RGB відповідного кольорового зображення. Формально модель колоризації може бути представлена у вигляді:

$$
y=\varphi(x)
$$

де $x$ - вихідне зображення, що уявляє собою матрицю $n \times m$, елементами якої є значення яскравостей пікселів, $x \in \mathbb{R}^{n \times m \times 1} ; \varphi$ - деяке перетворення (наприклад, нейронна мережа); $y$ - колоризоване $R G B$-зображення, $y \in \mathbb{R}^{n \times m \times 3}$. Задача полягає в тому, щоб знайти таке перетворення $\varphi(x)$, щоб отримані кольорові зображення були якомога більш реалістичними. Відзначимо, що задача не має єдиного розв'язку, оскільки різним кольоровим зображенням $y$ може відповідати одне и те ж зображення $x$ у відтінках сірого. Тому під реалістичністю зображення $y$ будемо розуміти не відповідність оригінальному зображенню (яке може і не існувати), а візуальне сприйняття людиною.

Метод розв'язання задачі. В якості перетворення $\varphi$ будемо розглядати згорткову нейронну мережу. Існує багато різновидів нейронних мереж, які $є$ спробами змоделювати процеси, що відбуваються в мозку людини, і які використовуються в різних практичних цілях: в задачах прогнозування, для розпізнавання образів, в задачах керування тощо. Але саме згорткові нейронні мережі добре зарекомендували себе в обробці зображень. Як відомо, звичайні нейронні мережі отримують вхідні дані (вектор), після чого трансформують їх, пропускаючи через ряд прихованих шарів. Кожний прихований шар складається з множини нейронів, які зв'язані зі всіма нейронами попере- 
днього шару, тобто кожний такий повнозв'язний шар можна представити як лінійний оператор, що з'єднує кожен вхідний нейрон з кожним вихідним та надає кожному зв'язку певний параметр - вагу. Останній повнозв'язний шар $\epsilon$ вихідним, він генерує результат [8]. Проблемою звичайних нейронних мереж при використанні в задачах обробки зображень є велика кількість параметрів вже на зображеннях малих розмірів, оскільки кожен піксель зображення пов'язують 3 кожним нейроном. Так, для обробки зображення розміром 30х30 пікселів необхідно використати близько 0.5 мільйона параметрів. При збільшенні розмірів вхідного зображення кількість параметрів збільшується експоненціально до дуже великих значень. Величезна кількість параметрів може швидко привести до перенавчання - сильної адаптації мережі до навчальної вибірки [13]. Проблему надмірної кількості параметрів у задачах обробки зображень вирішують згорткові нейронні мережі. 3 технічної точки зору згорткові мережі уможливлюють обробку великих зображень через фільтрацію зв'язків між нейронами, з огляду на близькість оброблюваних пікселів. Два пікселя, що розташовані поруч, мають більшу вірогідність бути пов'язаними між собою, ніж два пікселя, що знаходяться поодаль один від одного. Замість того, щоб з'єднувати всі вхідні дані з всіма нейронами у певному шарі, згорткові нейронні мережі з'єднують кожен нейрон даного шару лише 3 малою підгрупою входів (наприклад, секції $3 \times 3$ або 5х5). Звідси, кожен нейрон відповідає лише за обробку певної секції зображення.

Згорткова нейронна мережа складається з серії шарів декількох типів. Зображення пропускається через ці шари, за допомогою повнозв'язного шару породжується вихід, в якості якого може виступати клас або вірогідність класу, який краще за все описує зображення.

Основним будівельним блоком згорткових нейронних мереж є згортковий шар. Параметри шару складаються з набору фільтрів для навчання, які мають невелике рецептивне поле. Під час проходу вперед кожен фільтр ковзає за шириною та висотою вхідних даних, при цьому обчислюється скалярний добуток даних фільтру та входу (виконується операція згортки):

$$
y_{j}=\sum_{i} w_{i} x_{i},
$$

де $x_{i}$ - вхідні значення, $w_{i}-$ вагові коефіцієнти фільтру, та формується двовимірна карта активацій, в якій записані відгуки цього фільтру на всіх просторових позиціях. Кожен згортковий шар уявляє собою набор таких фільтрів, що навчаються та мають однакові розміри. В результаті мережа навчається, а фільтри активуються за наявності тих чи інших візуальних ознак, таких як, наприклад, краї або деяка орієнтація кольорової плями [5]. Складання активаційних карт усіх фільтрів уздовж виміру глибини формує повний вихідний об'єм згорткового шару.

Розмір вихідного об'єму згорткового шару контролюють чотири параметри: глибина, просторовий розмір, крок та нульове доповнення. Глибина відповідає кількості фільтрів у шарі, просторовий розмір визначає ширину та висоту фільтру, крок задає крок, з яким ковзає кожен фільтр, а нульове доповнення дозволяє контролювати розміри карти активацій, доповнюючи вхід- 
ний об'єм нулями навколо його границь, що дозволяє у бажаних випадках зберегти просторовий розмір вхідного об'єму.

Інший шар, що використовується у послідовності перетворень, є шар лінійної ректифікації (ReLU). У контексті нейронних мереж це шар активацій. Скалярний результат згортки попадає на функцію активації $f(x)=\max (0, x)$, яка здійснює операцію відсікання від'ємної частини скалярної величини. Використання такої функції активації дозволяє прискорити процес навчання та одночасно спростити обчислення в порівнянні з традиційними функціями типу гіперболічного тангенсу або сігмоїди. Саме така функція та ії модифікаціï (Noisy ReLU, Leaky ReLU та ін.) на сьогоднішній день найбільш часто використовуються в згорткових нейронних мережах.

Підвибірковий шар - ще один шар, який застосовується в архітектурі згорткової нейронної мережі між послідовностями згорткових шарів. Основна задача полягає в послідовному зменшенні просторових габаритів зображення 3 метою зменшення кількості вхідних параметрів для наступного шару i, відповідно, обчислювальних операцій у мережі, що запобігає перенавчанню. Також операція підвибірки забезпечує інваріантність щодо розміщення об'єкту на зображенні. Підвибіркові шари працюють незалежно від глибини даних на вході та масштабують весь об'єм просторово. Існує декілька нелінійних функцій, які використовуються для реалізації даної концепції, серед яких найбільш популярною є максимізаційна підвибірка. Ця функція ділить вхідну матрицю на певні регіони, що не перекриваються, та для кожного регіону виводить найбільше значення з нього. Найпопулярнішими є підвибіркові шари 3 фільтрами розміру 2 х 2 та кроком 2 . Такі шари знижують розмірність кожного зрізу глибини вхідних даних в два рази за шириною та висотою, відкидаючи при цьому 75\% елементів активації. При кожній операції максимуму в цьому випадку обирається максимальна величина 3 4-х чисел (рис.1). Глибина при цьому залишається незмінною.

Один зріз глибини

\begin{tabular}{|l|l|l|l|}
\hline 4 & 7 & 6 & 3 \\
\hline 5 & 1 & 2 & 8 \\
\hline 3 & 1 & 1 & 2 \\
\hline 1 & 5 & 3 & 2 \\
\hline
\end{tabular}

Операція максимізаційної підвибірки з фільтром 2 х2 та кроком 2

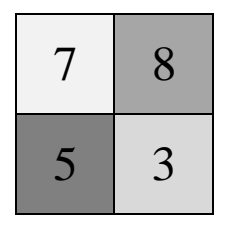

\section{Рис.1. Приклад роботи операції максимізаційної підвибірки}

Окрім максимізаційної підвибірки існують інші підвибіркові операції, такі як середнє арифметичне та середнє квадратичне. Але на практиці максимізаційна підвибірка працює ефективніше. 
Отже, загальна структура згорткової нейронної мережі зазвичай має такий вигляд:

$$
I N P U T \rightarrow((C O N V \rightarrow \operatorname{ReLU}) * N \rightarrow P O O L ?) * M \rightarrow(F C \rightarrow \operatorname{ReLU}) * K \rightarrow F C,
$$

де INPUT - вхідне зображення, $C O N V$ - згортковий шар, $R e L U$ - шар лінійної ректифікації, $P O O L$ ? - можливий підвибірковий шар, $F C$ - повнозв'язний шар, знак «*» позначає повторюваність блоку певну кількість разів.

Головною відмінністю нейронних мереж, що використовуються для колоризації, від інших мереж є те, що для них $\epsilon$ важливим положення пікселя у просторі. Розмір зображення та відношення сторін при роботі зі згортковими мережами залишається незмінним, в той час як інші мережі можуть спотворювати зображення без помітного впливу на результат роботи мережі. Наприклад, нейронна мережа, що проводить класифікацію, може нехтувати деякою його просторовою деформацією. Відзначимо, що підвибірковий шар ущільнює інформацію про наявні в зображенні характеристики, проте одночасно зменшує розмір зображення та спотворює відносну відстань між об'єктами на зображенні. Тому для зменшення розміру опрацьованих зображень пропонується використовувати крок розміром 2х2, що також підвищує щільність інформації, проте не деформує іiі (рис.2).
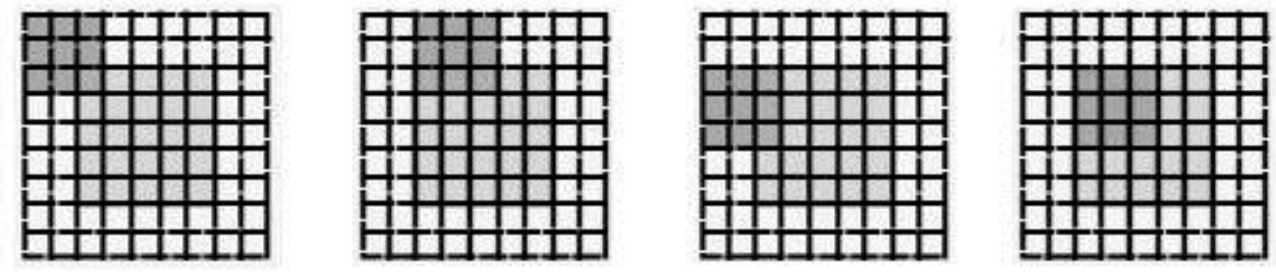

Рис.2. Приклад дії кроку (3x3) з нульовим доповненням розміру (2х2)

Для збереження відношення та розмірів сторін у зображенні будемо використовувати шар підвищення частоти дискретизації, на якому здійснюється нульове доповнення до вхідного зображення (рис.3).
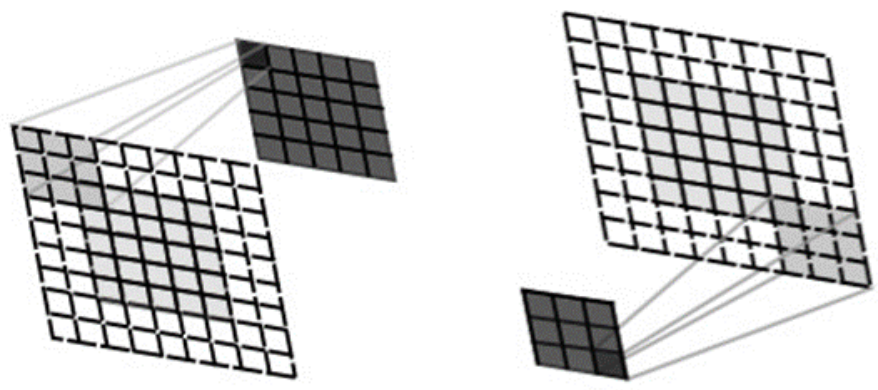

Рис.3. Приклад роботи згортки (ліворуч) та підвищення частоти дискретизації (праворуч).

Модель нейронної мережі. За основу структури нейронної мережі було обрано нейронну мережу VGG16 [10], яка представлена у двох варіантах: перший містить 16 шарів, другий - 19. Головна ідея цієї мережі полягає в тому, що усі згорткові шари даної мережі роблять лише згортки розміром 3х3 та 
вибірки розміром 2х2. Ця мережа демонструє важливість глибини нейронної мережі - чим глибша мережа, тим кращий результат. Недоліком такої мережі $\epsilon$ те, що вона зазвичай дуже велика та містить близько 160 мільйонів параметрів, більшість 3 яких припадає на повнозв’язані шари.

В розроблюваній мережі пропонується також використовувати прості згортки, але підвибірки замінити на необхідне нульове доповнення 3 кроком (2x2). Таким чином, структура нейронної мережі, що пропонується, складається з 13 згорткових шарів (CONV) та трьох шарів підвищення дискретизації. Фільтри усіх шарів мають розмір 3х3, функція активації усіх згорткових шарів $\operatorname{Re} L U$, за виключенням останнього. Нижче наведена структура мережі, що пропонується. Числа в описі згорткових шарів визначають кількість фільтрів відповідного шару. Отже, структура мережі має наступний вигляд:

1. INPUT: вхідне зображення розміром 256 х 256 х 1, тобто з одним каналом яскравості.

2. $C O N V-64$, нульове доповнення до розміру вихідного зображення.

3. $C O N V-64$, нульове доповнення до розміру вихідного зображення, крок 2.

4. $C O N V-128$, нульове доповнення до розміру вихідного зображення.

5. CONV - 128, нульове доповнення до розміру вихідного зображення, крок 2.

6. $C O N V-256$, нульове доповнення до розміру вихідного зображення.

7. $C O N V-256$, нульове доповнення до розміру вихідного зображення, крок 2.

8. $C O N V-512$, нульове доповнення до розміру вихідного зображення.

9. $C O N V-256$, нульове доповнення до розміру вихідного зображення.

10. $C O N V-128$, нульове доповнення до розміру вихідного зображення.

11. Шар підвищення дискретизації з фактором 2.

12. $C O N V-64$, нульове доповнення до розміру вихідного зображення.

13. Шар підвищення дискретизації з фактором 2.

14. $C O N V-32$, нульове доповнення до розміру вихідного зображення.

15. $C O N V-2$, функція активації гіперболічного тангенсу, нульове доповнення до розміру вихідного зображення.

16.Шар підвищення дискретизації з фактором 2.

Така архітектура є досить простою, проте, як показала практична реалізація, достатньо ефективною для отримання правдоподібної колоризації.

Програмна реалізація системи автоматичної колоризації. Розроблена система колоризації зображень складається з двох частин, одна з яких здійснює побудову та тренування нейронної мережі, а інша використовує отриману нейронну мережу для генерації кольорових зображень 3 вхідних зображень у відтінках сірого. Для розробки системи використано мову програмування Python, а також нейромережеві бібліотеки Tensorflow та Keras. Графічний інтерфейс користувача додатку було розроблено за допомогою мови Kv. 
Тренування нейронної мережі відбувалося за допомогою хмарного сервісу Paperspace [9], який надає послуги віддаленої робочої станції для важких обчислень та складних візуалізацій. Для тренування була використана вибірка Caltech-256 [1], яка містить 256 категорій об’єктів та додаткову категорію, що можна описати як шум, тобто зображення, що важко віднести до будь-якої категорії. У кожній категорії знаходиться щонайменше 80 об'єктів. Всього вибірка містить 30608 зображень. Категорії включають в себе такі класи об’єктів як «тварини», «люди», «комахи», «рослини» та інше. Для мінімізації в процесі навчання використовується середньоквадратична функція. Після того, як модель натренована, скрипт зберігає їі структуру та отримані ваги в окремому файлі, який в подальшому використовується для генерації інших кольорових зображень.

Для здійснення колоризації користувач має завантажити зображення до системи. Варто зауважити, що хоч користувач може обрати будь-яке зображення, нейронна мережа приймає лише зображення розміру $256 \times 256$. Тому спочатку зображення буде зменшено по меншій стороні до 256 пікселів, а потім обрізано таким чином, щоб сторони мали відношення 1:1. Процес колоризації займає приблизно 1-2 хвилини на комп'ютері з 4Гб оперативної пам'яті та двоядерним процесором. Результат відображається у відповідному віджеті та може бути збережений у файлі.

Аналіз результатів. Розроблена система була протестована на низці зображень у відтінках сірого. Тестування показало, що система виконує досить правдоподібну колоризацію певних об'єктів. Так, прийнятні результати були отримані при колоризації пейзажів, звичайних тварин, портретних фото. Порівняння 3 оригінальними зображеннями показало, що кольори в більшості випадків були визначені вдало, але мали дещо холодніші відтінки. В той же час колоризація дає гірші результати, коли вхідне зображення містить схожі, але дещо інші об'єкти. Так, наприклад, на зображенні пустелі система не розпізнала правильно пісок та надала йому блакитного відтінку, тобто розпізнала його як водну поверхню. Також треба відзначити, що система погано колоризує дрібні деталі зображень та речі, що можуть бути різних кольорів (м'яч, рюкзак та ін.). Крім того можна зробити загальне припущення, що коли система не може правильно класифікувати об'єкт, вона фарбує його в коричневий колір або відтінки септії як найбільш схожі на всі інші кольори. При колоризації фото з зображеннями людей система правильно розфарбувала обличчя та волосся людей, проте надала одежі лише коричневі відтінки. Варто зазначити, що система показала низькі результати для зображень, які містять лише фрагменти об'єктів або дані об'єкти були представлені у навчальній вибірці занадто різними кольорами. Такі зображення набували кольорів сепії або залишалися коричневими.

Висновки. В роботі була проаналізована задача колоризації зображень та можливість іiі розв'язання за допомогою згорткової нейронної мережі. Була розглянута структура згорткової нейронної мережі та визначені типи шарів, які доцільно використовувати для розв'язання задачі колоризації, запропоно- 
вано структура мережі на основі моделі VGG16. Практичним результатом роботи є програмна система, яка складається 3 двох частин. Перша частина включає скрипт для побудови та навчання згорткової нейронної мережі. Друга частина містить додаток, що інкапсулює відповідну нейронну мережу та здійснює автоматичну колоризацію зображень у відтінках сірого. Тестування показало, що на багатьох типах зображень система генерує досить правдоподібні кольори.

\section{Бібліографічні посилання}

1. Griffin, G. Holub, AD. Perona, P. The Caltech 256. [Електронний ресурс] - Режим доступу: http://www.vision.caltech.edu/Image_Datasets/Caltech256/

2. Iizuka, S. Let there be Color!: Joint End-to-end Learning of Global and Local Image Priors for Automatic Image Colorization with Simultaneous Classification [Text] / S. Iizuka, E. Simo-Serra, H. Ishikawa. ACM Transactions on Graphics (Proc. of SIGGRAPH 2016) 35(4) (2016)

3. Irony, R. Colorization by example [Text]/ R. Irony, D. Cohen-Or, D. Lischinski // Eurographics Symp. on Rendering, vol. 2. Citeseer, 2005, pp. 277-280.

4. Larsson, G. Learning representations for automatic colorization [Text] / G. Larsson, M. Maire, G. Shakhnarovich // In: European Conference on Computer Vision, pp. 577-593. Springer (2016).

5. Krizhevsky, A. Imagenet classification with deep convolutional neural networks [Text] / A. Krizhevsky, I. Sutskever, G.E Hinton // Advances in neural information processing systems. - [S. 1.: s. n.], 2012. - P. 1097-1105.

6. Levin, A. Colorization using Optimization [Electronic resource] / A. Levin, D. Lischinski, Y. Weiss // ACM SIGGRAPH 2004 Papers, 2004, pp. 689-694.

7. Liu, X. Intrinsic colorization [Text] / X. Liu, L. Wan, Y. Qu, T.-T. Wong, S. Lin, C.-S. Leung, and P.-A. Heng, // In TOG, vol. 27, no. 5. ACM, 2008, p. 152.

8. Nielsen, M. Neural Networks and Deep Learning [Електронний ресурс] - Режим доступу: http://neuralnetworksanddeeplearning.com/index.html

9. Paperspace: the first cloud built for the future. Powering next-generation application and cloud ML/AI pipelines. [Електронний ресурс] - Режим доступу: https://www.paperspace.com.

10. Simonyan, K. Very deep convolutional networks for large-scale image recognition [Text] // K. Simonyan, A. Zisserman. In Proc. Int. Conf. Learn. Represent., 2015.

11. Welsh, T. Transferring color to greyscale images [Text]/ T. Welsh, M. Ashikhmin, K. Mueller // ACM SIGGRAPH 2002 Conference Proceedings (2002) pp. 277-280.

12. Zhang, R. Colorful Image Colorization. [Electronic resource] / R. Zhang, P. Isola, A. A. Efros - Access mode: https://arxiv.org/abs/1603.08511.

13. Свёрточные нейронные сети: взгляд изнутри [Електронний ресурс] - Режим доступу: http://ru.datasides.com/code/cnn-convolutional-neural-networks

Надійшла до редколегії 25.02. 2019 


\section{МОДЕЛЮВАННЯ ПРОЦЕСІВ ТЕПЛОМАСООБМІНУ В ПЛІВКОВИХ ТЕЧІЯХ НЕЛІНІЙНО-В' ЯЗКОЇ РІДИНИ}

Розглядається задача про тепломасообмін в плівці нелінійно-в'язкої рідини, що стікає по поверхні тіла обертання. Пропонусться методика наближеного розв'язання рівнянь руху і тепломассоопереноса в рідкій плівці, що основана на методах малого параметра і локальної подібності.

Ключові слова: рідка плівка, метод малого параметра, нелінійно-в'язка рідина, тепломасообмін.

Рассматривается задача о тепломассообмене в пленке нелинейно-вязкой жидкости, стекающей по поверхности тела вращения. Предлагается методика приближенного решения уравнений движения и тепломассоопереноса в жидкой пленке, основанная на методах малого параметра и локального подобия.

Ключевые слова: жидкая пленка, метод малого параметра, нелинейно-вязкая жидкость, тепломассообмен.

The problem of heat and mass transfer in a liquid film of a nonlinearly viscous fluid flowing down the surface of a body of revolution under the influence of gravity is considered. The axis of the body is located at a certain angle to the vertical, and the film of liquid flows down from its top. It is assumed that the thermal and diffusion Prandtl numbers are large and the main changes in the temperature and diffusion fields occur in thin boundary layers near the solid wall and near the free surface separating the liquid and gas. A curvilinear orthogonal coordinate system $(\xi, \eta, \zeta)$ connected with the surface of the body is introduced. To describe the flow of a liquid film, a model of a viscous incompressible liquid is used, which is based on differential equations in partial derivatives - the equations of motion and continuity. As boundary conditions, the conditions of adhesion are used on the surface of a solid body, as well as the conditions of continuity of stresses and the normal component of the velocity vector - on the surface separating the liquid and gas. To simulate heat and mass transfer in a liquid film, the equations of thermal and diffusion boundary layers with boundary conditions of the first and second kind are used. To close the system of differential equations, the Ostwald-de-Ville rheological model is used.

To simplify the system of differential equations, the small parameter method is used, in which the relative film thickness is selected. It is assumed that the generalized Reynolds number is of the order of unity. The solution of the equations of continuity and motion (taking into account the main terms of the expansion) is obtained in an analytical form. To determine the unknown film thickness, an initial-boundary-value problem is formulated for a first-order partial differential equation. The solution to this problem is found numerically using a running count difference scheme. To reduce the dimension of the problem for the equations of the boundary layer, the local similarity method is used. To integrate simplified equations, the finite-difference method is used.

Key words: liquid film, small parameter method, nonlinearly viscous liquid, heat and mass transfer.

(C) I.C. Тонкошкур, 2019 
Вступ. Моделювання плівкових течій рідини по твердим поверхням становить інтерес у зв'язку з широким застосуванням таких течій в тепломасообмінних апаратах, при нанесенні лакофарбових і полімерних покриттів на різні поверхні і в інших технологічних процесах. В технічних пристроях часто використовують течії реологічно складних рідин.

Математичному моделюванню тепломассообміну в рідких плівках присвячена значна кількість теоретичних досліджень (наприклад, $[1,3,4,6]$ ), але при цьому число робіт, в яких досліджуються тривимірні течії рідини, є доволі обмеженим. В даній роботі пропонується методика наближеного розрахунку просторових течій нелінійно-в'язкої рідини по поверхні тіла обертання 3 урахуванням процесів тепломасообміну.

Постановка задачі. Розглядається задача про тепломасообмін в ламінарної плівці в'язкої рідини, що стікає під дією сили тяжіння по поверхні тіла обертання. Тіло розташоване під деяким кутом до вертикалі. Припускається, що теплове і дифузійне числа Прандтля великі і основні зміни температурного і дифузійного полів відбуваються в тонких примежових шарах поблизу твердої стінки і близько вільної поверхні, що розділяє рідину і газ.

Введемо криволінійну ортогональну систему координат ( $\xi, \eta, \zeta)$, зв'язану з поверхнею тіла: координата $\xi$ відраховується від вершини тіла уздовж твірної, $\eta$ - полярний кут в площині, перпендикулярній осі тіла обертання, $\zeta$ - відстань по нормалі до поверхні. Рівняння поверхні тіла задається у вигляді,

$$
r=r_{w}(\xi),
$$

де $r_{w}$ - відстань від точки поверхні до осі тіла.

Для опису течії рідкої плівки застосовується модель в'язкої нестисливої рідини, яка заснована на рівняннях імпульсу і нерозривності. У векторній формі ці рівняння мають вигляд

$$
\begin{gathered}
\rho \frac{d \bar{V}}{d t}=-\operatorname{grad} p+\operatorname{Div} \bar{\tau}+\rho \bar{g}, \\
\operatorname{div} \bar{V}=0,
\end{gathered}
$$

де $\bar{V}$ - вектор швидкості руху рідини, $p$ - тиск, $\rho$ - густина рідини, $\bar{\tau}-$ тензор в'язких напружень, $\bar{g}$ - інтенсивність сили тяжіння.

В якості крайових умов використовуються умова прилипання на поверхні твердого тіла, а також умови неперервності напружень і нормальної складової вектора швидкості - на поверхні, що розділяє рідину і газ

$$
\begin{array}{cc}
\bar{V}=0 & \text { при } \zeta=0, \\
\overline{\bar{\tau}} \bar{N}-\left(p-p_{0}\right) \bar{N}=2 \sigma \chi \bar{N}+\nabla_{\Gamma} \sigma, \\
\bar{V} \bar{N}=0 & \text { при } \zeta=F .
\end{array}
$$


Тут $F=F(\xi, \zeta)$ - рівняння вільної поверхні, $p_{0}$ - атмосферний тиск в газі, $\bar{N}=\bar{N}(\xi, \eta)-$ одинична нормаль до $\Gamma, \chi$ - середня кривизна поверхні $\Gamma, \sigma-$ коефіцієнт поверхневого натягу, $\nabla_{\Gamma} \sigma-$ поверхневий градієнт коефіцієнта $\sigma$. Для визначення компонентів тензора в'язких напружень $\tau_{i j}$ використовується степеневий реологічний закон [4]:

$$
\tau_{i j}=2 k\left(2 I_{2}\right)^{\frac{n-1}{2}} \dot{e}_{i j}, \quad I_{2}=\sum_{i=1}^{3} \sum_{j=1}^{3} \dot{e}_{i j} \dot{e}_{j i},
$$

де $k, n$ - сталі величини. Компоненти тензора швидкостей деформацій визначаються за формулою

$$
2 \dot{e}_{i j}=\frac{1}{h_{j}} \frac{\partial V_{i}}{\partial x_{j}}+\frac{1}{h_{i}} \frac{\partial V_{j}}{\partial x_{i}}+2 \delta_{i j} \sum_{k=1}^{3} \frac{V_{k}}{h_{k}} \frac{\partial \ln h_{i}}{\partial x_{k}}-\frac{1}{h_{i} h_{j}}\left(V_{i} \frac{\partial h_{i}}{\partial x_{j}}+V_{j} \frac{\partial h_{j}}{\partial x_{i}}\right),
$$

де $\delta_{i j}$ - символи Кронекера, $V_{i}$ - складові вектора швидкості в напрямках осей координат, $h_{i}$ - коефіцієнти Ламе.

Для моделювання процесів стаціонарного теплообміну в рідкій плівці, використовується рівняння просторового теплового примежового шару на поверхні тіла обертання

$$
\frac{u}{h_{1}} \frac{\partial T}{\partial \xi}+\frac{w}{h_{2}} \frac{\partial T}{\partial \eta}+\frac{v}{h_{3}} \frac{\partial T}{\partial \zeta}=a \frac{\partial^{2} T}{\partial \zeta^{2}}
$$

де $u, w, v$ - компоненти вектора швидкості $\bar{V}$ вздовж координат $\xi, \eta, \zeta, T-$ температура рідини, $a$ - коефіцієнт температуропровідності.

За крайові умови беруться умови першого або другого роду на поверхні твердого тіла, а також умови на зовнішній межі примежового шару

$$
\begin{array}{cc}
T=T_{w} \quad \text { або } \frac{\partial T}{\partial \zeta}=q_{w} & \text { при } \zeta=0, \\
T \rightarrow T_{E} & \text { при } \zeta \rightarrow F .
\end{array}
$$

Аналогічну задачу для моделювання масообміну в рідкій плівці можна подати у вигляді

$$
\begin{array}{rr}
\frac{u}{h_{1}} \frac{\partial C}{\partial \xi}+\frac{w}{h_{2}} \frac{\partial C}{\partial \eta}+\frac{v}{h_{3}} \frac{\partial C}{\partial \zeta}=D \frac{\partial^{2} C}{\partial \zeta^{2}}, \\
C=C_{E} & \text { при } \zeta=F, \\
C \rightarrow C_{W} & \text { при } \zeta \rightarrow 0,
\end{array}
$$

де $C$ - концентрація домішки в рідині, $D$ - коефіцієнт дифузії, індекси «ш» і «Е» відносяться до поверхні твердого тіла і вільної межі відповідно.

Метод розв'язання. Для спрощення системи диференціальних рівнянь (1)-(2) з крайовими умовами (3)-(5) застосовується метод малого параметра, в якості якого обрана відносна товщина плівки $\varepsilon=h_{0} / l_{0} \quad\left(h_{0}, l_{0}\right.$ - характерні поперечний і поздовжній розміри). Припускається, що узагальнене число Рейнольдса $\operatorname{Re}=\rho h_{0}{ }^{n} U_{0}^{2-n} / \mu^{n}$ має порядок одиниці (тобто $\left.\varepsilon \operatorname{Re}<<1\right)$ [2]. 
Розв'язок задачі (в нульовому наближенні) для складових вектора швидкості і функції тиску має вигляд:

$$
\begin{gathered}
u=-\frac{n}{n+1} \varphi_{1}(\eta) B F^{\frac{n+1}{n}}\left(1-\left(1-\frac{\zeta}{F}\right)^{\frac{n+1}{n}}\right), \\
w=-\frac{n}{n+1} \varphi_{2}(\eta) B F^{\frac{n+1}{n}}\left(1-\left(1-\frac{\zeta}{F}\right)^{\frac{n+1}{n}}\right), \\
v=\left(\varphi_{1}(\eta) \frac{\partial F}{\partial \xi}+\frac{\varphi_{2}(\eta)}{r_{w}} \frac{\partial F}{\partial \eta}\right) B F^{\frac{n+1}{n}}\left[\frac{\zeta}{F}+\frac{n}{n+1}\left(\left(1-\frac{\zeta}{F}\right)^{\frac{n+1}{n}}-1\right)\right]+ \\
+\frac{n}{n+1} \frac{\varphi_{3}}{\xi} F^{\frac{2 n+1}{n}}\left[\frac{\zeta}{F}+\frac{n}{2 n+1}\left(\left(1-\frac{\zeta}{F}\right)^{\frac{2 n+1}{n}}-1\right)\right], \\
P=-\varphi_{4}(\eta) F\left(1-\frac{\zeta}{F}\right),
\end{gathered}
$$

де $\varphi_{i}(\eta)$ і $B$ - відомі функції, що залежать від геометричних и фізичних параметрів.

Невідома товщина плівки $F$ визначається в результаті розв'язання крайової задачі

$$
\begin{gathered}
\varphi_{1} \frac{\partial F}{\partial \xi}+\frac{\varphi_{2}}{r_{w}} \frac{\partial F}{\partial \eta}+\varphi_{3} F=0, \\
F\left(\xi_{0}, \eta\right)=\mu_{1}(\eta), \quad F(\xi, 0)=\mu_{2}(\xi) .
\end{gathered}
$$

Система рівнянь (12)-(13) розв'язується чисельно з використанням різницевої схеми біжучого обчислення. Функція $\mu_{1}(\xi) \in$ заданою, а $\mu_{2}(\xi)$ знаходиться в результаті розв'язання задачі на лінії розтікання $\eta=0$, на якій виконується умова $\varphi_{2}(0)=0$.

Відзначимо, що в примежовому шарі навколо твердої поверхні вирази для компонентів вектора швидкості, які входять в рівняння (6), можна значно спростити, провівши лінеаризацію при малих значеннях координати $\zeta$. Аналогічне спрощення можливе і поблизу вільної межі при $\zeta \rightarrow F$.

Для розв'язання крайових задач (6)-(8) і (9)-(11) застосовується локальноавтомодельний підхід [5], який дозволяє звести початкову просторову задачу до ряду двовимірних (для кожного поперечного перерізу $\xi=c o n s t$ ).

Введемо наступну заміну незалежних змінних

$$
\xi_{1}=\xi, \quad \eta_{1}=\eta, \quad \varsigma_{1}=\frac{\varsigma}{\alpha(\xi)},
$$

де $\alpha(\xi)$ - деяка задана функція. Похідні від шуканої функції $\mathrm{A}(\xi, \eta, \zeta)$ по координатам $\xi, \zeta$ можуть бути представлені у наступному вигляді 


$$
\frac{\partial A}{\partial \xi}=\frac{\partial A}{\partial \xi_{1}}+\frac{\partial A}{\partial z}\left(-\frac{\varsigma}{\alpha^{2}(\xi)} \frac{\partial \alpha}{\partial \xi}\right), \quad \frac{\partial A}{\partial \zeta}=\frac{\partial A}{\partial z} \frac{1}{\alpha(\xi)} .
$$

Будемо припускати, що у системі координат $\xi_{1}, \eta_{1}, \zeta_{1}$ рівняння примежового шару має властивість локальної подібності, тобто $\partial A / \partial \xi_{1}=0$.

Тоді з попередніх рівностей можна одержати співвідношення

$$
\frac{\partial A}{\partial \xi}=-\frac{\zeta}{\alpha(\xi)} \frac{d \alpha}{d \xi} \frac{\partial A}{\partial \zeta}
$$

Для даних крайових задач функція $\alpha(\xi)$ вибиралась у вигляді $\alpha=\xi^{n}$, де $n=1 / 3,1 / 2$ для рівнянь теплопровідності і дифузії відповідно. За допомогою цих перетворень рівняння (6) можна звести до вигляду

$$
\frac{\partial^{2} T}{\partial \lambda^{2}}+\frac{A_{1}}{3} \lambda^{2} \frac{\partial T}{\partial \lambda}-\frac{A_{2}}{\cos \alpha} \lambda \frac{\partial T}{\partial \eta}=0
$$

де

$$
\lambda=\left(\frac{U_{0}}{a h_{0}}\right)^{1 / 3} \frac{\varsigma}{\xi^{1 / 3}}, \quad A_{0}=-B\left(\frac{F}{h_{0}}\right)^{\frac{1}{n}}, \quad A_{1}=\varphi_{1} A_{0}, A_{2}=\varphi_{2} A_{0} .
$$

Аналогічні перетворення проводяться і $з$ рівнянням (9). Для інтегрування одержаних рівнянь 3 відповідними крайовими умовами застосовується скінченно-різницевий метод.

Аналіз одержаних результатів. На рис. 1,2 наведені результати розрахунків за викладеною методикою для конуса з кутом $\alpha=30^{\circ}$ при куті скосу потоку $\gamma=10^{\circ}$ і значеннях фізичних параметрів $R e=1, F r=1, n=0.5 ; 1 ; 2 ; 10$. На рис. 1.а представлені профілі температури $\theta=\mathrm{T} / \mathrm{T}_{\mathrm{E}}$ в примежовому шарі навколо твердої поверхні для точки з координатами $\left(\xi=2 ; \eta=0^{\circ}\right)$ при різних значеннях параметра нелінійності $n$. Аналогічні профілі концентрації домішки $\theta_{\mathrm{C}}=\mathrm{C} / \mathrm{C}_{\mathrm{E}}$ поблизу вільної межі наведені на рис. $1 . б$ (координата $\lambda$ відкладається від вільної межі всередину плівки).
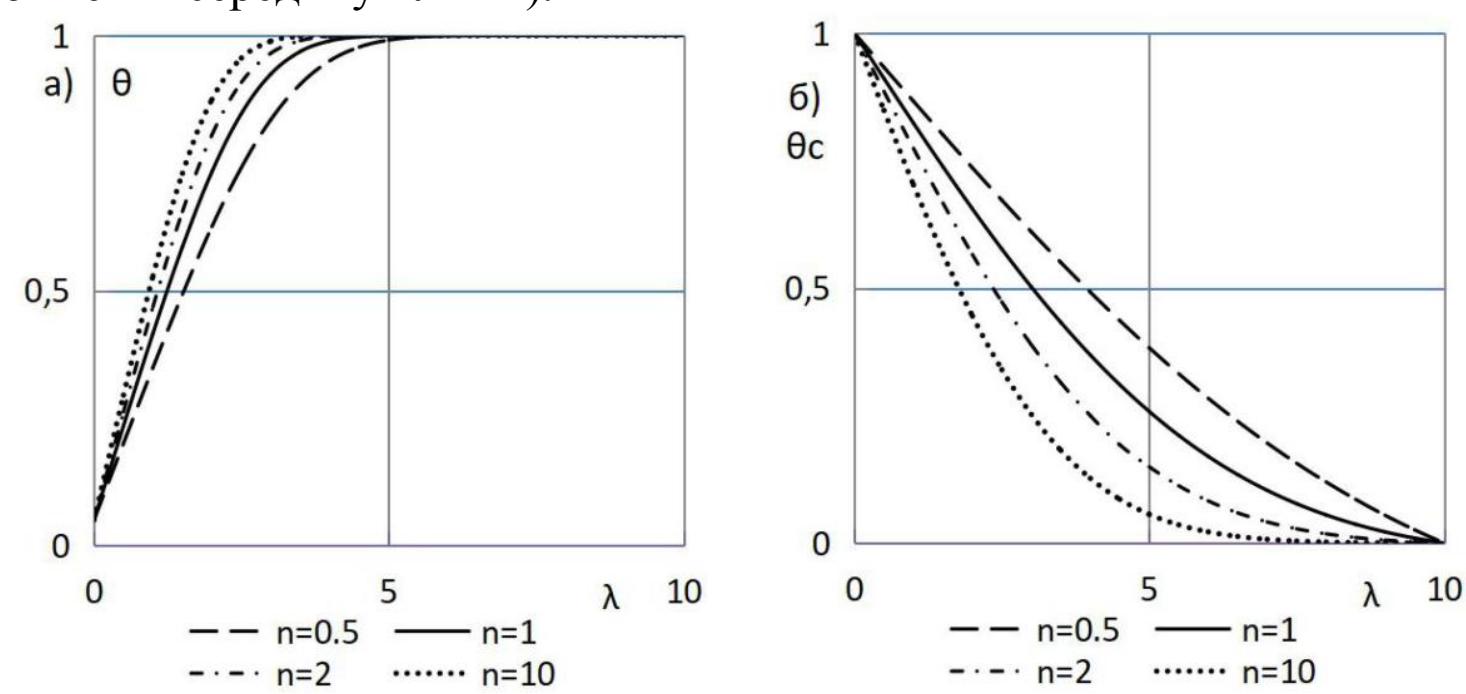

Рис. 1 Профілі температури $\theta$ і концентрації домішки $\theta_{\mathrm{C}}$ в примежовому шарі 
На рис. 2а показані розподіли величини похідної $\theta^{\prime}(0)$, що характеризує теплові потоки на твердій поверхні, вздовж твірної $\eta=0^{\circ}$ для крайової умови першого роду $\theta_{\mathrm{w}}=0.05$. Такі ж розподіли температури $\theta(0)$ для крайової умови другого роду $\theta^{\prime}{ }_{\mathrm{w}}=0.1$ наведені на рис 26 .
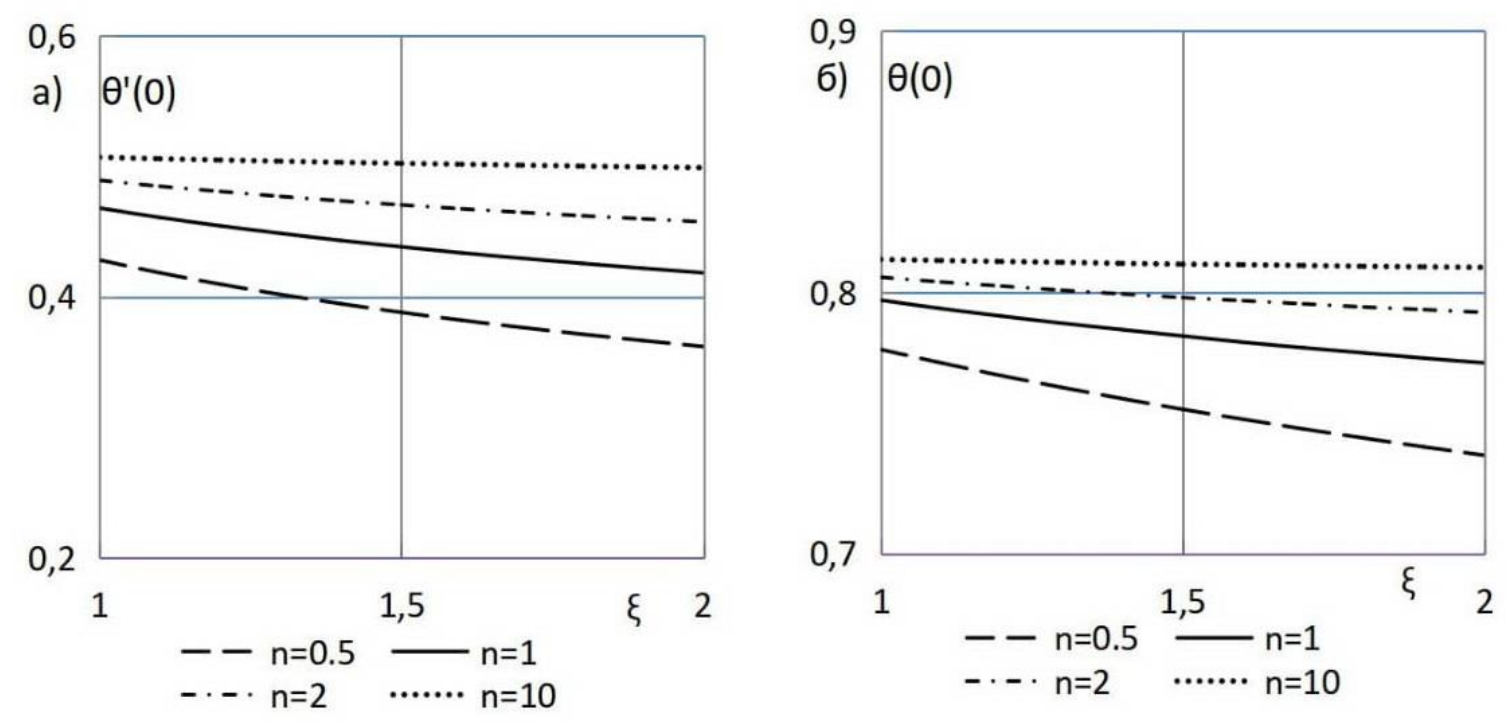

Рис. 2. Розподіли теплових характеристик вздовж твірної тіла

Висновки. За допомогою методів малого параметра і локальної подібності розроблена методика розв'язання задачі про тепломасообмін в плівці нелінійно-в'язкої рідини, що рухається по поверхні тіла обертання під дією сили тяжіння. Сформульовано спрощені крайові задачі для визначення товщини плівки, а також для характеристик тепло- і масообміну в рідкій плівці. Отримано аналітичні вирази для профілів швидкості.

\section{Бібліографічні посилання}

1. Бояджиев, Х. Массоперенос в движущихся пленках жидкости [Текст] / Х. Бояджиев, В. Бешков. - М.: Мир, 1988. - 136 с.

2. Тонкошкур, И.С. Математическое моделирование течения жидкой пленки по конической поверхности [Текст] / И.С. Тонкошкур // Питання прикладної математики і математичного моделювання. - Д.: ДНУ, 2010. - С. 284-291.

3. Холпанов, Л.П. Гидродинамика и тепломассообмен с поверхностью раздела [Текст] / Л.П. Холпанов, В.Я. Шкадов . - М.: Наука, 1990. - 271 с.

4. Шульман, 3.П. Реодинамика и тепломассообмен в пленочных течениях [Текст]/ 3.П. Шульман, В.Н. Байков.- Минск: Наука и техника, 1979.- 296 с.

5. Kaups, K. Prediction of turbulent boundary layers on cones at incidence [Text] / K. Kaups and T. Cebeci // AIAA Journal. - 1977. - Vol. 15, No. 5. - P. 727-730

6. Shevchuk, I.V. Convective Heat and Mass Transfer in Rotating Disk Systems [Text] / I.V. Shevchuk. - Berlin, Heidelberg: Springer-Verlag, 2009, XIX. - 236 p.

Надійшла до редколегії 25.09.2019 


\section{МОДЕЛЮВАННЯ ГРАВІТАЦІЙНИХ ТЕЧІЙ В'ЯЗКОПЛАСТИЧНОЇ РІДИНИ ПО КОНІЧНІЙ ПОВЕРХНІ}

Розглянуто задачу про плівкову течію в'язкопластичної рідини по поверхні конуса 3 довільним гладким поперечним перерізом під дією сили тяжіння. За допомогою метода малого параметра одержано наближений розв'язок рівнянь динаміки рідкої плівки по конічній поверхні.

Ключові слова: рідка плівка, метод малого параметра, конічна поверхня, в'язкопластична рідина.

Рассмотрена задача о пленочном течении вязкопластической жидкости по поверхности конуса с произвольным гладким поперечным сечением под действием силы тяжести. С помощью метода малого параметра получено приближенное решение уравнений динамики жидкой пленки по конической поверхности.

Ключевые слова: жидкая пленка, метод малого параметра, коническая поверхность, вязкопластичные жидкость.

The problem of a stationary waveless gravitational flow of a viscoplastic fluid over the surface of a cone with an arbitrary smooth cross section is considered. It is assumed that the axis of the body is located at a certain angle to the vertical, and the film of liquid flows down from its top. A curvilinear orthogonal coordinate system $(\xi, \eta, \zeta)$ associated with the body surface is introduced: $\xi$ is the coordinate along the generatrix of the body, $\eta$ is the polar angle in the plane perpendicular to the axis of the body of revolution, $\zeta$ is the distance along the normal to the surface.

To describe the flow of a liquid film, a viscous incompressible fluid model is used, which is based on partial differential equations - the equations of motion and continuity. The following boundary conditions are used: sticking conditions on the solid surface; on the surface separating liquid and gas, the conditions for continuity of stresses and normal component of the velocity vector. To close the system of differential equations, the ShvedovBingham rheological model is used.

To simplify the system of differential equations, the small parameter method is used. The small parameter is the relative film thickness. It is assumed that the generalized Reynolds number has an order equal to one. The solution of the equations of continuity and motion (taking into account the principal terms of the expansion) was obtained in an analytical form. The obtained formulas for the components of the velocity and pressure vector generalize the known relations for flat surfaces. To determine the unknown film thickness, an initial-boundary value problem was formulated for a first-order partial differential equation. The solution to this problem is found with the help of the finite difference method.

The results of calculations by the proposed method for cones with a cross section in the form of a circle and a square with rounded corners are presented. Calculations show that the plasticity parameter and the cross-sectional shape significantly affect the velocity and distribution profiles of the thickness of the viscous layer over the surface of the body.

Key words: liquid film, small parameter method, conical surface, viscoplastic liquid.

(C) Тонкошкур I.C., Калініченко К.В., 2019 
Вступ. Течії неньютоновскіх рідин по твердих поверхнях широко застосовуються в різних технологічних процесах енергетики, металургії, в хімічній, будівельній та інших галузях промисловості. При цьому в технічних пристроях часто реалізуються суттєво тривимірні течії рідини по криволінійним поверхням.

Дослідження просторових течій рідини по твердій поверхні проводились в роботах [1-4]. В [3,4] розглядались течії нелінійно-в'язкої і в'язкопластичної рідини поблизу твердих тіл, що обертаються навколо своєї осі. В роботі [2] проведено чисельне дослідження течій неньютоновскіх рідин у зігнутому каналі. В [1] запропонована методика наближеного розрахунку плівкових течій в'язкопластичної рідини Шведова-Бінгама по поверхні тіла обертання. В даній роботі ця методика поширюється на клас конічних тіл 3 довільним гладким поперечним перерізом.

Постановка задачі. Розглядається задача про просторову безхвильову стаціонарну течію в'язкопластичної рідини по конічній поверхні під дією сили тяжіння. Припускається, що вісь конуса розташована під деяким кутом до вертикалі, а плівка рідини стікає від його вершини вниз. Введемо криволінійну ортогональну систему координат $(\xi, \eta, \zeta)$, зв'язану з поверхнею тіла: координата $\xi$ відраховується від вершини конуса уздовж твірної, $\eta$ - полярний кут в площині, перпендикулярній осі тіла обертання, $\zeta$ - відстань по нормалі до поверхні. Рівняння поверхні тіла в сферичній системі координат $(r, \theta, \varphi)$ задається у вигляді

$$
\theta=\theta(\varphi),
$$

де $\theta$ - кут між твірною і віссю конуса.

Для опису течії рідкої плівки приймається модель в'язкої нестисливої рідини, що заснована на рівняннях імпульсу і нерозривності. У векторній формі ці рівняння мають вигляд

$$
\begin{aligned}
& \rho \frac{d \bar{V}}{d t}=-\operatorname{grad} p+\operatorname{Div} \bar{\tau}+\rho \bar{g}, \\
& \operatorname{div} \bar{V}=0,
\end{aligned}
$$

де $\bar{V}$ - вектор швидкості руху рідини, $p$ - тиск, $\rho$ - густина рідини, $\bar{\tau}-$ тензор в'язких напружень, $\bar{g}$ - інтенсивність сили тяжіння.

В якості крайових умов використовуються умова прилипання на поверхні конуса, а також умови неперервності напружень і нормальної складової вектора швидкості - на поверхні, що розділяє рідину і газ.

$$
\begin{array}{cr}
\bar{V}=0 & \text { при } \zeta=0, \\
\overline{\bar{\tau}} \bar{N}-\left(p-p_{0}\right) \bar{N}=2 \sigma \chi \bar{N}+\nabla_{\Gamma} \sigma, \\
\bar{V} \bar{N}=0 & \text { при } \zeta=F .
\end{array}
$$


Тут $F=F(\xi, \zeta)$ - рівняння вільної поверхні $\Gamma, p_{0}$ - атмосферний тиск в газі, $\bar{N}=\bar{N}(\xi, \eta)$ - одинична нормаль до $\Gamma, \chi$ - середня кривизна поверхні $Г$, $\sigma$-коефіцієнт поверхневого натягу, $\nabla_{\Gamma} \sigma-$ поверхневий градієнт коефіцієнта $\sigma$.

Для замикання системи рівнянь (1)-(2) використовується реологічна модель вязкопластичної рідини Шведова-Бінгама [5]:

$$
\begin{array}{ll}
\tau_{i j}=2\left[\frac{\tau_{0}}{\sqrt{2 I_{2}}}+\mu_{p}\right] \dot{e}_{i j} & \text { при }|\tau|>\tau_{0}, \\
\dot{e}_{i j}=0 & \text { при }|\tau| \leq \tau_{0},
\end{array}
$$

де $\tau_{i j}$ - компоненти тензора в'язких напружень $\bar{\tau}, \tau_{0}$ - граничне напруження зсуву, $\mu_{p}$ - коефіцієнт пластичної в’язкості, $I_{2}$ - другий інваріант тензора швидкостей деформацій $\dot{e}_{i j}$.

Метод розв'язання. Система диференціальних рівнянь (1)-(2) з крайовими умовами (3)-(5) спрощується за допомогою метода малого параметра, в якості якого обрана відносна товщина плівки $\varepsilon=h_{0} / l_{0} \quad\left(h_{0}, l_{0}\right.$ - характерні поперечний і поздовжній розміри).

Вводяться безрозмірні змінні за формулами:

$$
\begin{gathered}
\xi=\xi^{\prime} l_{0}, \quad \eta=\eta^{\prime}, \quad \zeta=\varepsilon l_{0} \zeta^{\prime}, \\
u=U_{0} u^{\prime}, \quad w=U_{0} w^{\prime}, \quad v=\varepsilon U_{0} v^{\prime}, \\
p=\rho U_{0}^{2} p^{\prime}, \quad \sigma=\sigma_{0} \sigma^{\prime}, \quad F=\varepsilon l_{0} F^{\prime} .
\end{gathered}
$$

Тут $u, w, v$ - складові вектора швидкості, відповідні координатам $(\xi, \eta, \zeta)$, $U_{0}, \sigma_{0}$ - характерні значення швидкості руху і коефіцієнта поверхневого натягу. Введемо також допоміжну функцію $P(\xi, \eta, \zeta)$, зв'язану з тиском $p$ співвідношенням:

$$
p=p_{0}-2 \sigma \chi+\rho U_{0}^{2} P
$$

Подамо невідомі функції (складові вектора швидкості і тиск) у вигляді розкладів в ряд по $\varepsilon$

$$
A=A^{0}+\varepsilon A^{1}
$$

і підставимо їх в систему отриманих рівнянь.

В роботі розглядаються течії рідкої плівки, для яких число Рейнольдса $\operatorname{Re}=\rho h_{0} U_{0} / \mu$ має порядок одиниці, тобто $\varepsilon \operatorname{Re}<<1$. Враховуючи головні члени розкладань, отримаємо спрощену систему рівнянь (надалі для скорочення запису знак «'» опущений)

$$
\frac{\partial u}{\partial \xi}+\frac{1}{\xi \psi(\eta)} \frac{\partial w}{\partial \eta}+\frac{\partial v}{\partial \zeta}+\frac{1}{\xi} u=0, \frac{\partial P}{\partial \zeta}=\frac{(\overline{e n})}{F r},
$$


ISSN 2074-5893 Питання прикладної математики і математичного моделювання. Випуск 19

$$
\frac{\partial \tau_{31}}{\partial \zeta}=-\frac{\operatorname{Re}}{F r}\left(\overline{e e}_{1}\right), \quad \frac{\partial \tau_{32}}{\partial \zeta}=-\frac{\operatorname{Re}}{F r}\left(\overline{e e}_{2}\right)
$$

Крайові умови:

$$
\begin{gathered}
u=w=v=0 \quad \text { при } \zeta=0, \\
\tau_{31}=\tau_{32}=P=0, v-u \frac{\partial F}{\partial \xi}-\frac{w}{\xi \psi(\eta)} \frac{\partial F}{\partial \eta}=0 \quad \text { при } \zeta=F .
\end{gathered}
$$

Тут $F r=U_{0}^{2} /\left(g h_{0}\right)$ - число Фруда; $\bar{e}-$ одиничний вектор, що задає напрям дії сили тяжіння; $\bar{e}_{1}, \bar{e}_{2}, \bar{n}$ - базисні вектори криволінійної системи координат $(\xi, \eta, \zeta) ; g-$ прискорення вільного падіння. Поверхня $\zeta=F_{1}(\xi, \eta)$, що розділяє в'язку і пластичну області течії рідини, визначається параметром пластичності $S=\tau_{0} h_{0} /\left(\mu U_{0}\right)$.

Розв'язок задачі (в нульовому наближенні) для складових вектора швидкості має вигляд:

у в'язкій області течії (при $\zeta<F_{1}$ )

$$
\begin{aligned}
& u=\varphi_{1}\left[\frac{\zeta^{2}}{2}-(F-\bar{S}) \zeta\right], \quad w=\varphi_{2}\left[\frac{\zeta^{2}}{2}-(F-\bar{S}) \zeta\right], \\
& v=-\varphi_{3}\left[\frac{\zeta^{3}}{6}-(F-\bar{S}) \frac{\zeta^{2}}{2}\right]+\left(\varphi_{1} \frac{\partial F}{\partial \xi}+\frac{\varphi_{2}}{\xi \psi(\mu)} \frac{\partial F}{\partial \eta}+\bar{S} \varphi_{5}\right) \frac{\zeta^{2}}{2},
\end{aligned}
$$

у пластичній області (при $\zeta \geq F_{1}$ )

$$
\begin{gathered}
u=-\frac{1}{2} \varphi_{1}(F-\bar{S})^{2}, \quad u=-\frac{1}{2} \varphi_{1}(F-\bar{S})^{2}, \\
v=\frac{1}{3} \varphi_{3}(F-\bar{S})^{3}+\frac{1}{2}\left(\varphi_{1} \frac{\partial F}{\partial \xi}+\frac{\varphi_{2}}{\xi \psi(\mu)} \frac{\partial F}{\partial \eta}+\bar{S} \varphi_{5}\right)(F-\bar{S})^{2},
\end{gathered}
$$

для функції тиску

$$
P=\varphi_{4}(\zeta-F)
$$

де $F_{1}=F-\bar{S}$ - товщина в'язкого шару, $\bar{S}=S$ / $\left(\varphi_{1}^{2}+\varphi_{2}^{2}\right), \varphi_{i}-$ відомі функції, які залежать від геометричних і фізичних параметрів:

$$
\begin{gathered}
\varphi_{1}=-\frac{\operatorname{Re}}{F r}\left(\bar{e}, \bar{e}_{1}\right), \quad \varphi_{2}=-\frac{\operatorname{Re}}{F r}\left(\bar{e}, \bar{e}_{2}\right), \quad \varphi_{4}=\frac{(\bar{e}, \bar{n})}{F r}, \\
\varphi_{3}=\frac{\partial \varphi_{1}}{\partial \xi}+\frac{1}{\xi \psi(\eta)} \frac{\partial \varphi_{2}}{\partial \eta}+\frac{1}{\xi} \varphi_{1}, \quad D=\left(\varphi_{1}^{2}+\varphi_{2}^{2}\right)^{-1}, \\
\varphi_{5}=D\left[\varphi_{1}^{2} \frac{\partial \varphi_{1}}{\partial \xi}+\varphi_{1} \varphi_{2} \frac{\partial \varphi_{2}}{\partial \xi}+\frac{1}{\xi \psi(\eta)}\left(\varphi_{1} \varphi_{2} \frac{\partial \varphi_{1}}{\partial \eta}+\varphi_{2}^{2} \frac{\partial \varphi_{2}}{\partial \eta}\right)\right],
\end{gathered}
$$

Невідома товщина плівки $F$ визначається в результаті розв'язання крайової задачі

$$
\varphi_{1} \frac{\partial F}{\partial \xi}+\frac{\varphi_{2}}{\xi \psi(\eta)} \frac{\partial F}{\partial \eta}+\frac{1}{3} \varphi_{3} F+\bar{S}\left(\frac{1}{2} \varphi_{5}-\frac{1}{3} \varphi_{3}\right)=0
$$


ISSN 2074-5893 Питання прикладної математики і математичного моделювання. Випуск 19

$$
F(1, \eta)=1, \quad F\left(\xi, \eta_{p}\right)=F_{0}(\xi),
$$

де $\eta_{p}$ - координата, що визначає лінію розтікання $\eta=\eta_{p}$. Система рівнянь (6)-(7) розв'язується чисельно з використанням різницевої схеми біжучого обчислення. Функція $F_{0}(\xi)$ знаходиться в результаті розв'язання задачі на лінії розтікання $\eta=\eta_{p}$.

Для конічних тіл 3 некруговим поперечним перерізом течія може мати декілька ліній розтікання і стікання. При розв'язанні крайової задачі (6)-(7) розрахункова область розбивається на $n$ прямокутних підобластей $\Omega_{i}$, обмежених двома сусідніми лініями стікання

$$
\Omega_{i}=\left\{\eta_{c m, i} \leq \eta \leq \eta_{c m, i+1}, \quad \xi_{1} \leq \xi \leq \xi_{2}\right\},
$$

де $n$ - число ліній розтікання. В кожній такій підобласті розв'язок будується незалежно від інших областей. Інтегрування починається $з$ лінії розтікання $\eta=\eta_{p}$, на якій $\varphi_{2}=0$ і вихідне рівняння вироджується в звичайне диференціальне рівняння. Значення шуканої величини на цій лінії використовується в якості початкової умови при знаходженні розв'язків в підобластях $\Omega_{i}^{1}$ і $\Omega_{i}^{2}$, обмежених лінією розтікання і найближчими лініями стікання.

Аналіз одержаних результатів. За описаною методикою проведені розрахунки течії рідкої плівки по поверхні конічних тіл з поперечним перерізом у вигляді кола, еліпса і багатокутника із закругленими кутами. Результати розрахунків для кругового конуса з кутом $\theta=30^{\circ}$ при куті скосу потоку $\gamma=10^{\circ}$ i значеннях фізичних параметрів $R e=1, F r=1$ представлені на рисунках 1. На рис. 1.а показані профілі поздовжньої складової вектора швидкості $u$ в шарі плівки для точки поверхні з координатами $\left(\xi=2 ; \eta=45^{\circ}\right)$ при значеннях параметра пластичності $S=0 ; 0.1 ; 0.2 ; 0.3$, на рис. 1.6 - розподіли товщини плівки $F$ в поперечних перерізах $\xi=1 ; 1.5 ; 2$.
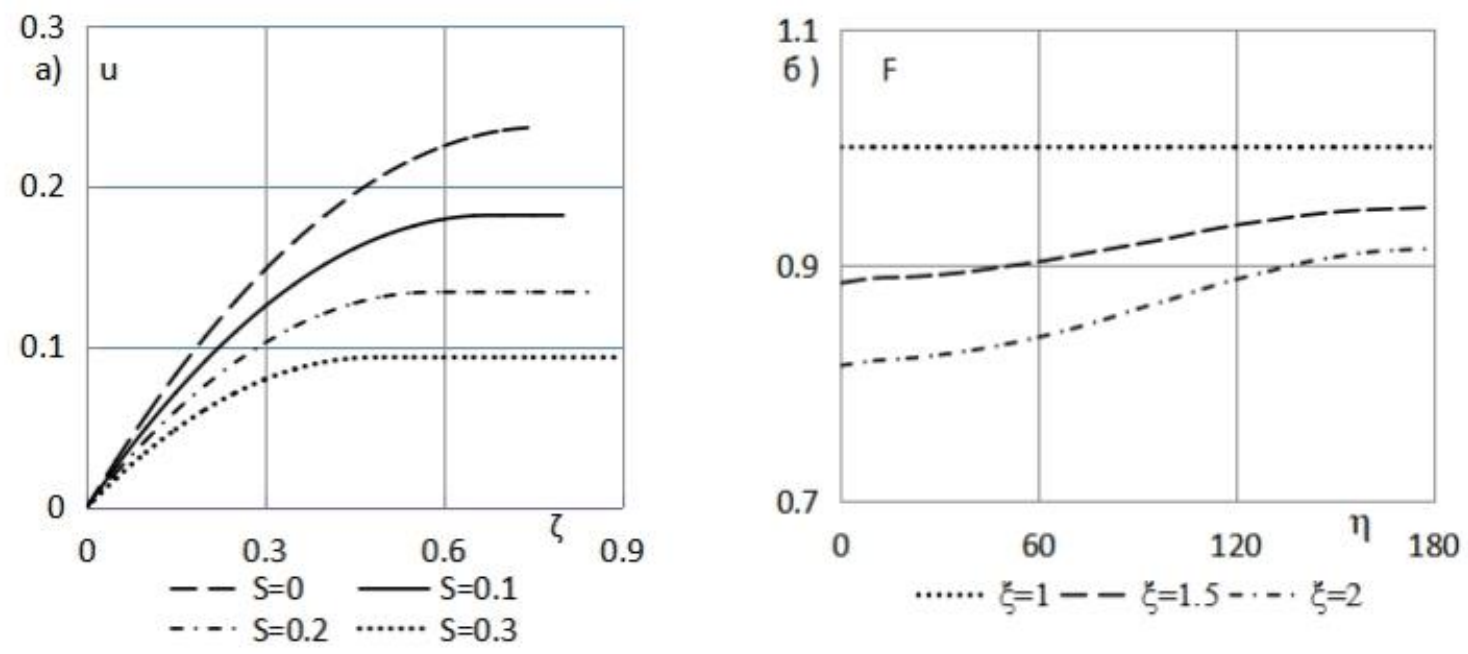

Рис. 1 Профілі поздовжньої складової вектора швидкості $u$ i розподіли товщини плівки $F$ в поперечному перерізі кругового конуса 
На рис. 2 наведені розподіли товщини плівки $F$ в перерізі $\xi=2$ конуса 3 поперечним перерізом у вигляді квадрата із закругленими кутами при значеннях геометричних параметрів $\theta_{\mathrm{K}}=30^{\circ} ; r=0.25 ; \gamma=0^{\circ}, 10^{\circ}, 15^{\circ}\left(\theta_{\text {к }}\right.$ кут конуса, вписаного в піраміду; $r$ - радіус закруглення в площині поперечного перерізу). Розрахунки показують, що параметр пластичності $S$ і форма поперечного перерізу істотно впливають на профілі швидкості і розподіли товщини в'язкого шару по поверхні тіла.

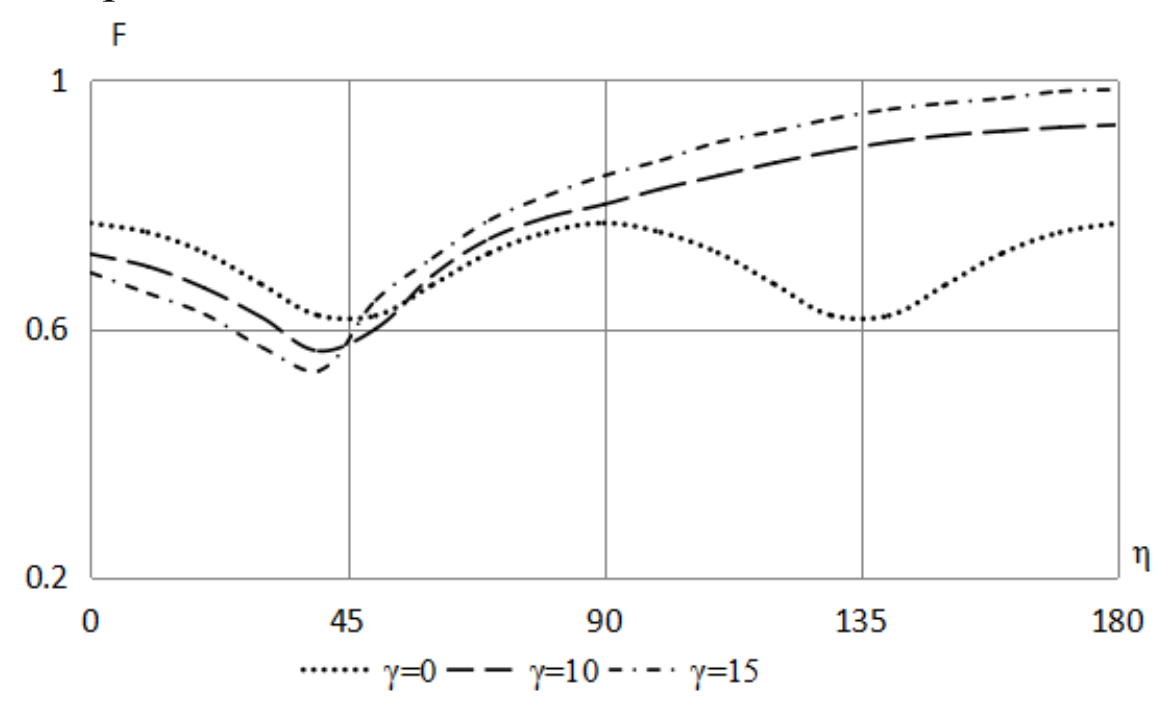

Рис. 2. Розподіли товщини плівки $F$ в поперечному перерізі пірамідального тіла

Висновки. За допомогою методу малого параметра розроблено методику наближеного розрахунку плівкових течій в'язкопластичної рідини ШведоваБінгама по поверхні конічного тіла 3 довільним гладким поперечним перерізом. Одержано аналітичні вирази для компонентів вектора швидкості. Сформульовано крайову задачу для визначення товщини плівки. Наведено результати розрахунків для тіл з різними поперечними перерізами.

\section{Бібліографічні посилання}

1. Дудник, А.С. Моделирование течения вязкопластической жидкости по поверхности тела вращения [Текст]/ А.С. Дудник, И.С. Тонкошкур // Питання прикладної математики і математичного моделювання. - Дніпропетровськ: Ліра, 2014. - С. 98-104.

2. Кадыйров, А.И. Исследование гидродинамики при ламинарном течении не ньютоновских жидкостей в изогнутом канале [Текст] / А.И.Кадыйров, Е.К. Вачагина // Теплофизика и аэромеханика - 2012. - Вып. 3. - С. 279-289.

3. Рябчук, Г.В. Течение нелинейно-вязкой жидкости по поверхности вращающегося плоского диска [Текст] / Г.В. Рябчук, А.Г. Щукина // Изв. РАН. Механика жидкости и газа - 2003. - № 6. - С. 155-161.

4. Шаповалов, В.М. Влияние гравитационных сил на течение среды Шведова-Бингама в валковой сушилке [Текст] / В. М. Шаповалов, С. О. Зубович // Известия вузов. Химия и химическая технология. - 2006. - Т. 49, N 6. - С. 59-61.

5. Шульман, 3.П. Реодинамика и тепломассообмен в пленочных течениях [Текст] / 3.П. Шульман, В.Н. Байков.- Минск: Наука и техника, 1979.- 296 с. 


\section{ИСПОЛЬЗОВАНИЕ ПРОГНОЗНЫХ ЗНАЧЕНИЙ В ПРОМЕЖУТОЧНЫХ ТОЧКАХ ПРИ ПРОГНОЗИРОВАНИИ ХАОТИЧЕСКИХ ВРЕМЕННЫХ РЯДОВ НА МНОГО ШАГОВ ВПЕРЕД}

В предлагаемой работе излагается (в рамках парадигмы прогнозирования на основе кластеризации) подход к прогнозированию хаотических временных рядов на много шагов вперёд хотя бы для тех точек, для которых такой прогноз возможен. Здесь используется прогноз по прогнозным значениям в промежуточных точках промежутка прогнозирования и предлаются алгоритмы оценки достоверности указанных прогнозных значений.

Ключевые слова: хаотические временные ряды; многошаговое прогнозирование; прогнозирование на основе кластеризации.

У запропонованій роботі наводиться (в рамках парадигми прогнозування на основі кластеризації) підхід до прогнозування хаотичних часових рядів на багато кроків вперед хоча б для тих точок, для яких такий прогноз можливий. Тут використовусться прогноз по прогнозним значенням в проміжних точках проміжку прогнозування та пропонуються алгоритми оцінки достовірності зазначених прогнозних значень. Вище перераховані завдання передбачають використання алгоритмів кластеризації, заснованих на апараті теорії графів, для відшукання характерних послідовностей (мотивів) в певній частині прогнозованого ряду i їх використанням при отриманні прогнозу. При прогнозуванні на багато кроків вперед використовуються отримані за допомогою алгоритму прогнозні значення в проміжних точках. А саме, використання запропонованої авторами концепції шаблонів непослідовних спостережень при формуванні векторів вибірки, що підлягас кластеризації на етапі виявлення мотивів, дозволяс отримати безліч (нехай і скорельованих) прогнозів для однієї точки; аналіз безлічі прогнозів дозволяє відкинути свідомо помилкові прогнози. Крім того побудовано три оцінки для прогнозованих точок: оцінка зверху оцінка, отримана шляхом прикладання мотивів до всіх точок спостережень; оцінка знизу - оцінка, отримана шляхом прикладання мотивів тільки до тих точок, на які можна опиратися, ці точки нам будуть відомі; апроксимація оцінки - оцінка, отримана шляхом прикладання мотивів тільки до тих точок на які можна спиратися, при цьому точки опори будуть відбиратися за значенням їх інваріантної міри.

В якості основних планованих результатів дослідження можна вказати наступні: (1) встановлення характеру залежності числа непрогнозованих точок і середньої помилки прогнозу для точок, для яких прогноз можливий, в функції від довжини проміжку прогнозування; (2) алгоритми оцінки достовірності отриманих прогнозних значень в проміжних точках проміжку прогнозування та оцінка їх впливу на якість прогнозування; (3) розробка алгоритмів, що дозволяють прогнозувати хаотичні часові ряди на багато кроків вперед.

Ключові слова: хаотичні часові ряди; багатокрокове прогнозування; прогнозування на основі кластеризації.

(C) Турчина В.А., Березин В.В., 2019 
The proposed work (within the clustering prediction paradigm) presents an approach to predicting chaotic time series by many steps at least for those points for which such a forecast is possible. This is used to forecast the forecast values at intermediate points of the forecasting interval and proposes algorithms for estimating the reliability of these forecast values. The above tasks require the use of clustering algorithms based on the apparatus of graph theory to find characteristic sequences (motives) in a known part of the predicted series and their use in obtaining the forecast. When predicting many steps forward, the predicted values at intermediate points are obtained using the algorithm. Namely, the use of the concept of inconsistent observation patterns proposed by the authors in the formation of sample vectors to be clustered at the stage of motive identification allows one to obtain many (albeit correlated) forecasts for one point; analysis of many forecasts allows you to drop obviously erroneous forecasts. In addition, three estimates for the projected points were constructed: the top estimate is the estimate obtained by applying motives to all observed points; lower estimate - an estimate obtained by applying motives only to those points on which you can rely; we will know these points; approximation of the lower estimate - the estimate obtained by applying motives only to those points on which you can rely, while the support points will be selected according to the value of their invariant measure.

The following can be indicated as the main planned research results: (1) establishing the nature of the dependence of the number of unpredictable points and the average forecast error for points for which a forecast is possible, as a function of the length of the forecast interval; (2) algorithms for assessing the reliability of the obtained forecast values at intermediate points of the forecasting interval and evaluating their impact on the quality of forecasting; (3) the construction of a system of algorithms that allows predicting chaotic time series many steps forward.

Key words: chaotic time series; multi-step forecasting; predictive clustering.

Введение. При прогнозировании хаотических рядов на много шагов вперёд в рамках парадигмы прогнозирования на основе кластеризации, следует учитывать, что (в отличие от классических прогнозных моделей) прогноз можно получить не в каждой требуемой точке; для некоторых точек (непрогнозируемые точки) просто может не существовать достаточно близких мотивов. При этом следует ясно понимать, что допуская некоторый процент непрогнозируемых точек, мы тем самым увеличиваем и число шагов, за которое можно получить прогноз для остальных точек.

В настоящей работе задачу прогнозирования хаотического ряда на много шагов вперёд предлагается решать путём использования прогноза по прогнозным значениям. При этом для каждой промежуточной прогнозной точки предлагается осуществить оценку достоверности её прогнозного значения с использованием характеристик множества прогнозов (отвечающих различным мотивам), полученных для данной точки, а также (восстановленных по ряду) характеристик инвариантной меры динамической системы, породившей рассматриваемый временной ряд. Целью настоящего исследования является создание (в рамках парадигмы прогнозирования на основе кластеризации) подхода к прогнозированию хаотических временных рядов на много шагов вперёд с использованием оценок достоверности прогнозных значений в промежуточных точках промежутка прогнозирования. 
Постановка задачи. Пусть задана совокупность наблюдений хаотического временного ряда $y_{0}, y_{1}, \ldots, y_{t}$. Обозначим через $y_{t+1}, y_{t+2}, \ldots, y_{t+p}$ совокупность следующих наблюдений в ряде. А через $y_{t+1}, y_{t+2}, \ldots, y_{t+p}$ оценённые значения последующих наблюдений. Задача состоит в минимизации ошибки прогнозирования

$$
\begin{gathered}
I=M\left(y_{(n+k)}-y_{(n+k)}\right)^{2} \rightarrow \min , k \geq 1 ; \\
y_{(n+k)}=f\left(y_{n}, y_{n-1}, \ldots, y_{n-p}, P\left(y_{n}\right), \ldots, P\left(y_{n+k}\right)\right) ; \\
P\left(y_{n+k}\right)=P\left(y_{n}, \ldots, y_{n-k-1}\right) .
\end{gathered}
$$

Метод решения. Из множества наблюдений временного ряда строим векторы обучающей выборки. Для этого построим сначала все возможные шаблоны. Под шаблоном здесь понимается фиксированная последовательность расстояний между позициями наблюдений в наблюдаемой последовательности, которые займут соседние позиции в формируемом векторе обучающей выборки. Пусть необходимая размерность векторов обучающей выборки равна $m$, тогда для построения шаблона нужно найти $m-1$ значений расстояний между номерами наблюдений. Построим все шаблоны [1], для которых расстояние между наблюдением не будет превышать $\alpha$. Шаблон будет иметь такой вид:

$$
\left(k_{1}, k_{2} \ldots, k_{m-1}\right) ; 0<k_{i} \leq \alpha ; i=\overline{1, m-1} ; k \in Z, \alpha \in Z .
$$

Всего таких шаблонов $\alpha^{m-1}$. Вектор будет иметь вид $\left(y_{i}, y_{i+k_{1}}, \ldots, y_{i+k_{1}+k_{2}+\ldots+k_{m-1}}\right)$. Множество векторов, составленных по таким шаблонам, будет составлять обучающую выборку. Векторы обучающей выборки разделяем на кластеры с помощью алгоритма Уишарта. Существенным здесь является то, что использование векторов, составленных из последовательных наблюдений, оказалось менее эффективным, чем использование векторов, составленных в соответствии с множеством шаблонов. Пример построения обучающей выборки приведен на рис. 1.

Алгоритм кластеризации Уишарта. Алгоритм основан на аппарате теории графов и использовании непараметрической функции плотности вероятности $k$ ближайших соседей

$$
\bar{p}(x)=\frac{k}{V_{k}(x) N},
$$

где $V_{k}(x)$ - объем $d_{k}(x)$ с центром в $x$ который содержит $k$ наблюдений из выборки $\left(x^{i}, i=\overline{1, n}\right)$.

Пусть $G\left(Z_{n}, U_{n}\right)$ - граф отношений «сходства», множество вершин $Z_{n}$ которого, отвечает точкам выборки, а множество рёбер

$$
U_{n}=\left\{(i, j): d_{k}\left(x^{i}, x^{j}\right) \leq d_{k}\left(x^{i}\right), i \neq j\right\} .
$$

Кластер $c_{i}$ будем считать значимым по высоте $h>0$, если 
$\max \left\{\left|\bar{p}\left(x^{i}\right)-\bar{p}\left(x^{j}\right)\right| \forall x^{i}, x^{j} \in c_{i}\right\} \geq h$.

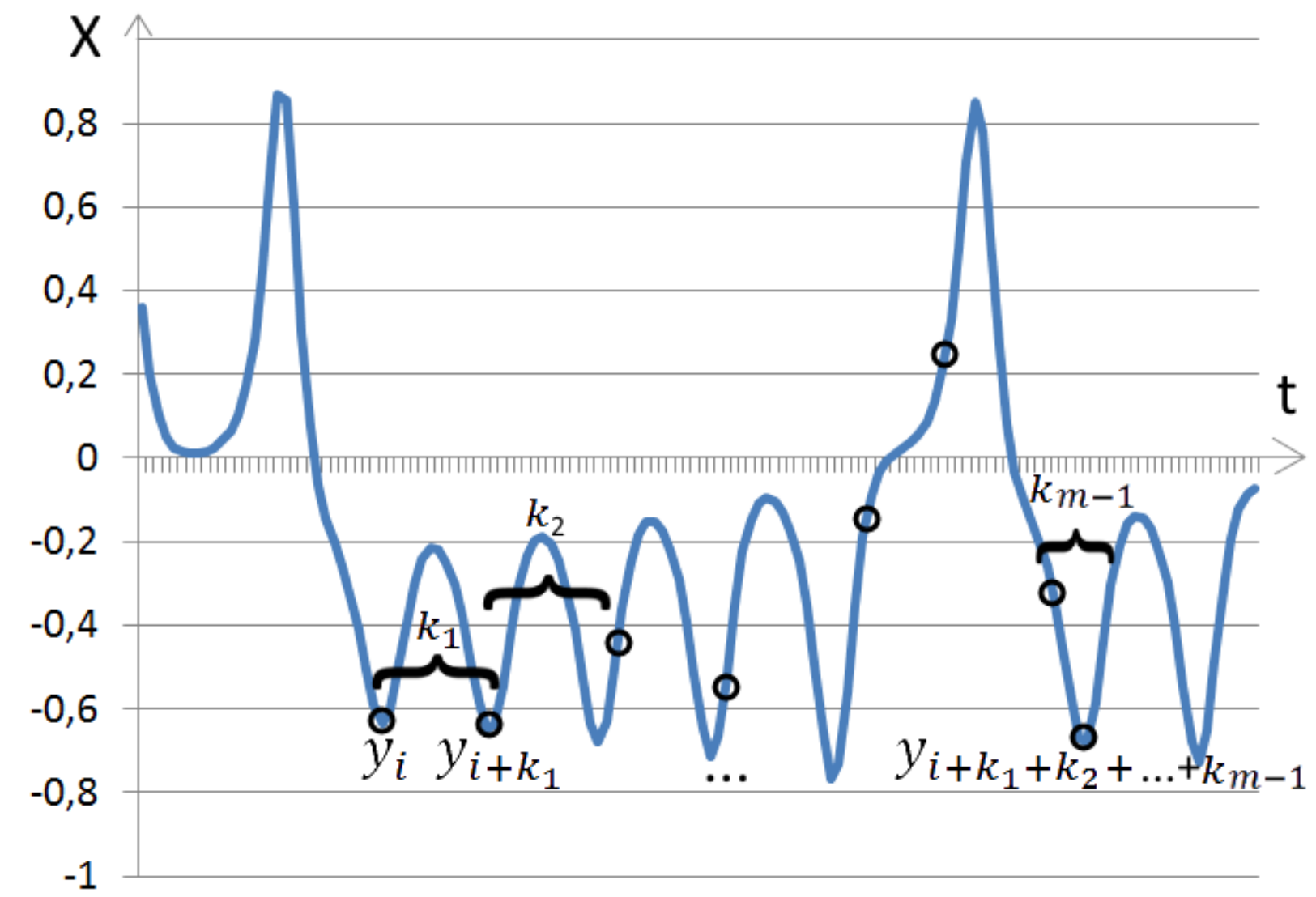

Рис. 1. Построение обучающей выборки с помощью шаблона

Кластер, который не является значимым по высоте, считаем фоновым. Номер кластера, содержащего вектор $x^{i}$, обозначим $w\left(x^{i}\right)$. Тогда находить унимодальные кластеры можно по следующему алгоритму:

1. Найти расстояние $d_{k}\left(x^{i}\right)$ для каждого вектора выборки до его $k$ ближайшего соседа и провести сортировку выборки в порядке возрастания $d_{k}\left(x^{i}\right)$

2. Положить $i=1$;

3. Для подграфа $G\left(Z_{i}, U_{i}\right)$ возможны следующие варианты:

Если $x^{i}$ - изолированная вершина графа $G\left(Z_{i}, U_{i}\right)$, начать формирование нового кластера. В случае $w\left(x^{i}\right)=i$, перейти к этапу 4 ;

Если вершина $x^{i}$ связана только с вершинами $l$-го кластера, и он уже сформирован, то положить $w\left(x^{i}\right)=0$. Если кластер $l$ не сформирован, положить $w\left(x^{i}\right)=l$. Перейти к этапу 4 .

Если вершина $x^{i}$ связана с вершинами из кластеров $l_{1}<l_{2}<\ldots<l_{t}, t>1$, и все эти кластера сформированы, тогда положить $w\left(x^{i}\right)=0$ и перейти к этапу 4. 
Если количество значимых по высоте кластеров больше 1 или $l_{1}=0$, то принять $w\left(x^{i}\right)=0$. Значимые кластера пометить сформированными, а не значимые - удалить, положив $w\left(x^{i}\right)=0$ для всех векторов, которые входили в эти кластера.

Если количество значимых по высоте кластеров $\geq 1$ или $l_{1}>0$, то включить все кластеры в $l_{1}$, положив $w\left(x^{j}\right)=l_{1}$ для всех векторов, которые в них входят. Принять $w\left(x^{i}\right)=l_{1}$;

4. Положить $i=i+1$. Если $i \leq n$, перейти к этапу 3 .

Преимуществами этого метода является небольшое количество параметров алгоритма. После того, как все кластеры найдены, находим центры каждого из них, как среднее арифметическое компонент всех векторов данного кластера. Также сохраняем информацию о шаблоне построения вектора, поскольку для различных шаблонов различные кластеризации.

Алгоритм подсчета ячеек. При явном разбиении большого куба, в котором находится аттрактор системы, на гиперкубик, значительная часть гиперкубиков будет пустой. Также при большой размерности системы, кубиков будет большое количество. Но значительная часть из них нам не нужна, так как не будет нести никакой информации об аттракторе. Пользуясь выше описанными рассуждениями, будет использован алгоритмом подсчета ячеек [4]. Суть алгоритма заключается в следующем: необходимо найти отношение каждой компоненты точки аттрактора и $\varepsilon$, и оставить только целую часть, превратив точки $x_{i}$ в новые векторы $n_{i}$. Тогда для всех точек $x_{i}$, попавших в одну ячейку, полученные векторы $n_{i}$ будут совпадать.

Алгоритм прогнозирования на много шагов вперед. Рассмотрим алгоритм выполнения прогнозирования «скачками» на много шагов вперед [2]. После кластеризации, в каждом кластере будут находиться подобные участки, примеры которых приведены на рис.2.

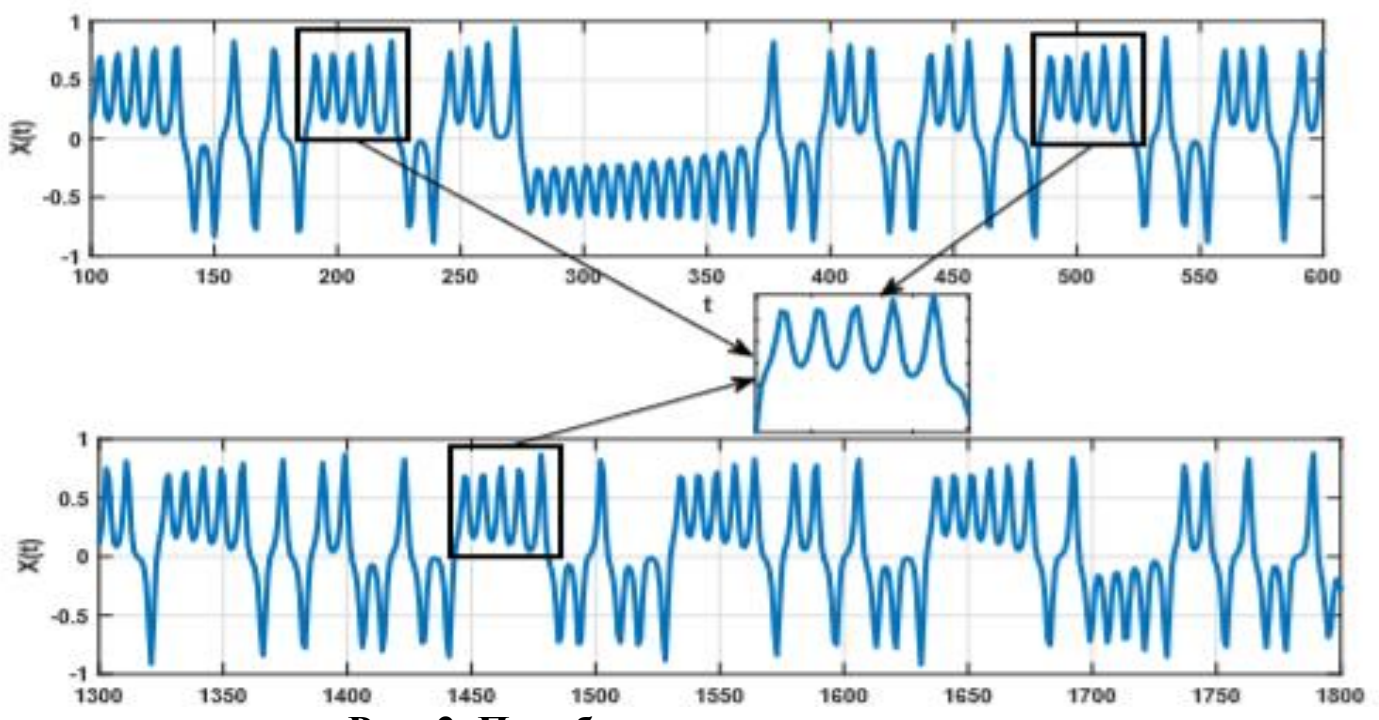

Рис. 2. Подобные участки в ряде 
Пусть необходимо получить прогнозное значение для наблюдения $y_{i}$, которое находится через $n$-точек от последней известной точки. Найдем это значение используя шаблон $\left(k_{1}, k_{2} \ldots, k_{m-1}\right)$, причем - расстояние между $k_{m-1}$ и $k_{m-2}$ должно быть равно $n$. Позиция компоненты $k_{m-2}$ должна совпадать с позицией последнего известного наблюдения. Среди всех кластеров, соответствующих тому же шаблону, найдем такой, для которого расстояние $d$ между вектором $x$, полученным из центра кластера, кроме последней точки, и вектором $\bar{x}$, построенным с использованным шаблоном из реальных значений, будет минимальной.

Для того чтобы выполнять прогнозирования на несколько «скачков», необходимо вектор $\bar{x}$ строить с учетом всех шагов, которые уже были сделаны ранее и использовать полученные прогнозные значения. Также ограничение вводится на использование шаблонов. Предположим, что необходимо выполнить прогнозирование комбинацией прыжков $y_{1}, y_{2}, \ldots, y_{t}$, тогда на последнем прыжке возможно лишь использование шаблона $\left(\ldots, s_{t-2}, s_{t-1}, s_{t}\right)$.

При оценке качества прогноза необходимо найти прогнозные значения $y_{t}, y_{t+1}, \ldots, y_{t+n}$ для всех наблюдений тестирующего множества $y_{t}, y_{t+1}, \ldots, y_{t+n}$.

При этом оценивается среднеквадратичная погрешность RMSE:

$$
R M S E=\sqrt{\frac{\sum_{t=1}^{n}\left(y_{t}-y_{t}\right)^{2}}{n}} * 100 .
$$

Также оцениваеться количество непрогнозируемых наблюдений.

Прогнозирование с использованием характеристик инвариантной меры.

Рассмотрим не одну траектории [4], а целый ансамбль, начальные данные для которого распределены в фазовом пространстве с определенной плотностью вероятностей (то есть сначала вводится некоторая вероятностная мера). «Включим» временную эволюцию, которая будет характеризоваться динамикой отображения $x \rightarrow \varphi^{t}(x)$. При этом вероятность оказаться в бесконечно малой окрестности точки $x$ для любой траектории с рассматриваемого ансамбля и в окрестности ее образа $\varphi^{t}(x)$ должны совпадать, то есть $P(x) d x=P\left(\varphi^{t}(x), t\right) d \varphi^{t}(x)$.

Через преобразование пространства размер этой бесконечно малой окрестности, вообще говоря, изменится, а потому изменится и плотность вероятности. Преобразование пространства $x \rightarrow \varphi^{t}(x)$ порождает преобразование плотности вероятности $P(x) d x=P(x, t)=L(P(x), t)$. Если же при таком преобразовании плотность остается неизменной, ее называют инвариантной.

При прогнозировании на несколько шагов вперед, прогноз естественным образом должен осуществляться по уже спрогнозированным значением. Но 
не все точки, для которых был получен прогноз и на которые можно опереться, для получения следующего прогноза, считаются равноэффективными. Некоторые приводят к большему накоплению ошибки, некоторые к меньшемy.

Для точек, находящихся между последней точкой, которая была спрогнозирована, и которую необходимо спрогнозировать, имеем дополнительную информацию, а именно значение инвариантной меры того гиперкуба фазового пространства, к которому принадлежит эта точка.

Будем считать достоверными прогнозы только те, для которых значение инвариантной меры больше некоторого порога $\alpha$. Такой алгоритм будем считать модифицированным.

Построение оценки сверху. Оценка сверху представляет собой функцию ошибки, зависящую от количества шагов прогнозирования. Для построения оценки сверху будем использовать алгоритм прогнозирования на много шагов вперед, без использования дополнительной информации о спрогнозированных промежуточных точках.

Построение оценки снизу. Оценка снизу представляет собой функцию, зависящую от количества шагов прогнозирования, но промежуточные точки, на которые мы будем опираться, будут выбираться путём сравнивания с реальным значением точек. Если спрогнозированная точка будет лежать в $\varepsilon$ окрестности точки, для которой мы этот прогноз получили, то дальше эта точка пригодна для получения прогноза по прогнозу.

Аппроксимация оценки. Аппроксимацию оценки будем строить, используя ранее описанный алгоритм прогнозирования с использованием характеристик инвариантной меры. Необходимо также найти такие гиперпараметры модифицированного алгоритма, чтобы аппроксимация оценки совпадала с оценкой снизу.

Анализ полученных результатов. Описанный подход, был применён к временному ряду, полученному интегрированием системы Лоренца (который является типичным примером хаотического временного ряда). Система Лоренца (со стандартными «хаотическими» параметрами) интегрировалась с помощью метода Рунге-Кутта 4-го порядка (с шагом интегрирования 0.1), в результате чего получен временной ряд, который в дальнейшем будем называть рядом Лоренца. Для ряда Лоренца первые 3000 наблюдений отбрасываются, чтобы гарантировать, что движение траекторий происходит в окрестности соответствующего странного аттрактора.

Был спрогнозирован ряд на 50 шагов вперед и построены выше описанные оценки:

Оценки сверху и снизу представлены на рис.3. 


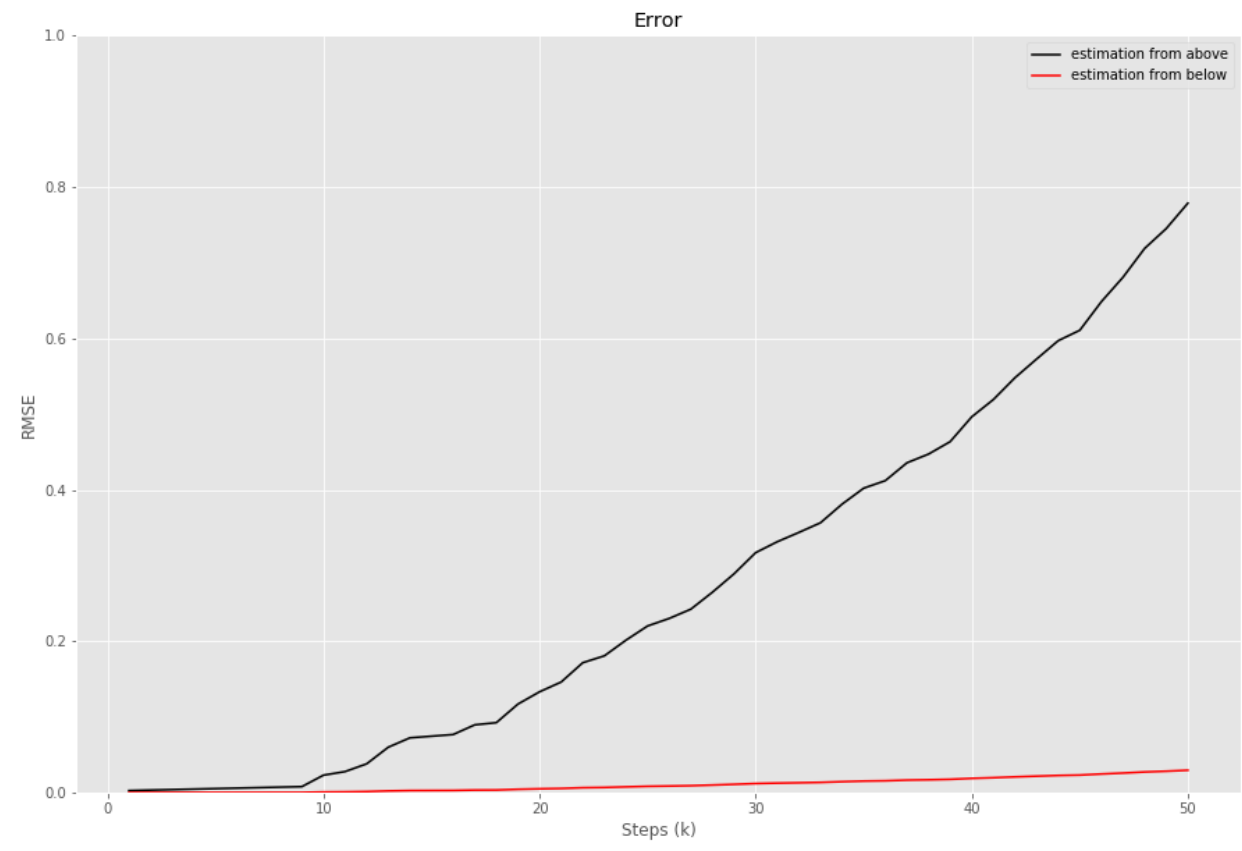

Рис. 3. Оценка сверху и снизу

Аппроксимация оценки при $\alpha \in[0.5,0.7)$ представлена на рис.4.

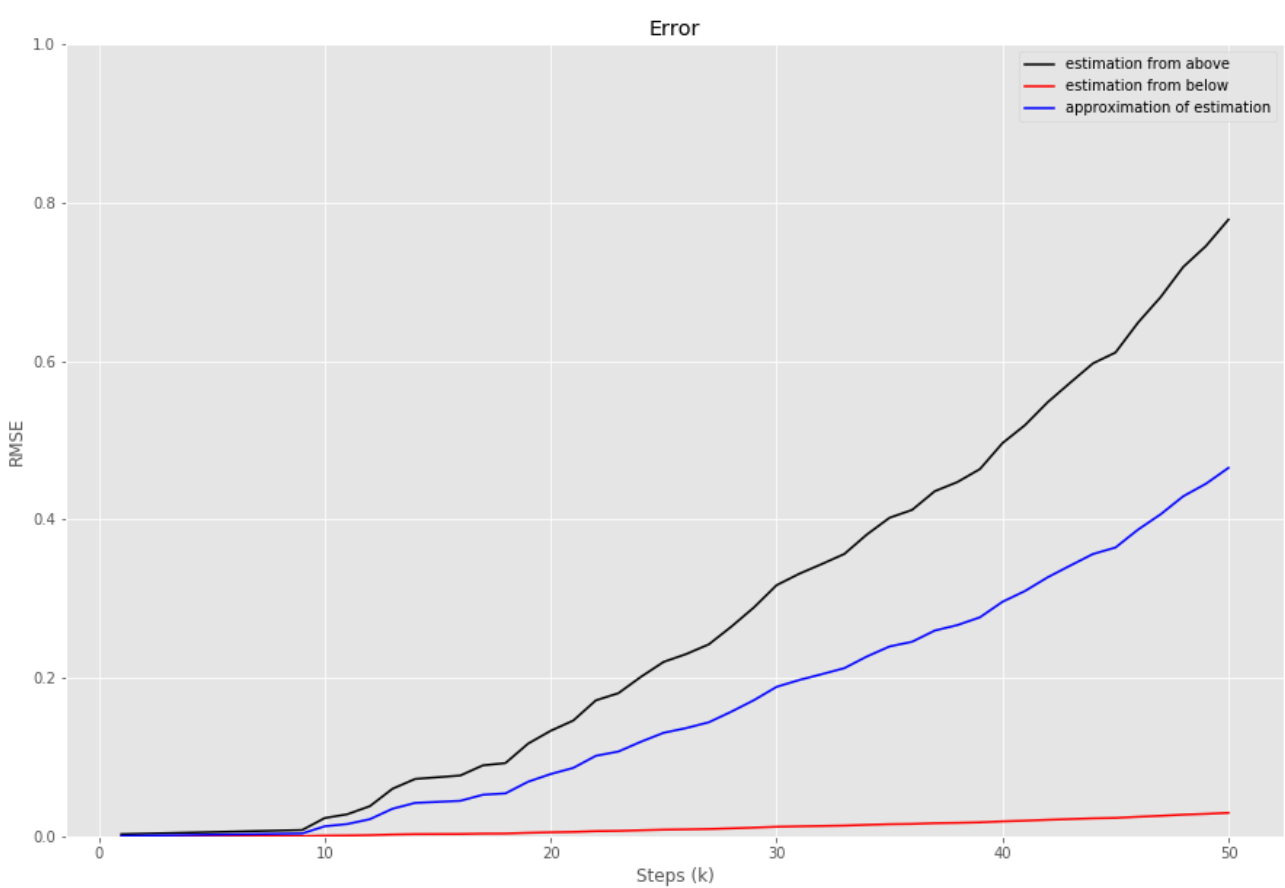

Рис.4. Аппроксимация оценки при $\alpha \in[0.5,0.7)$

Аппроксимация оценки при $\alpha \in[0.7,0.9)$ представлена на рис. 5 . 


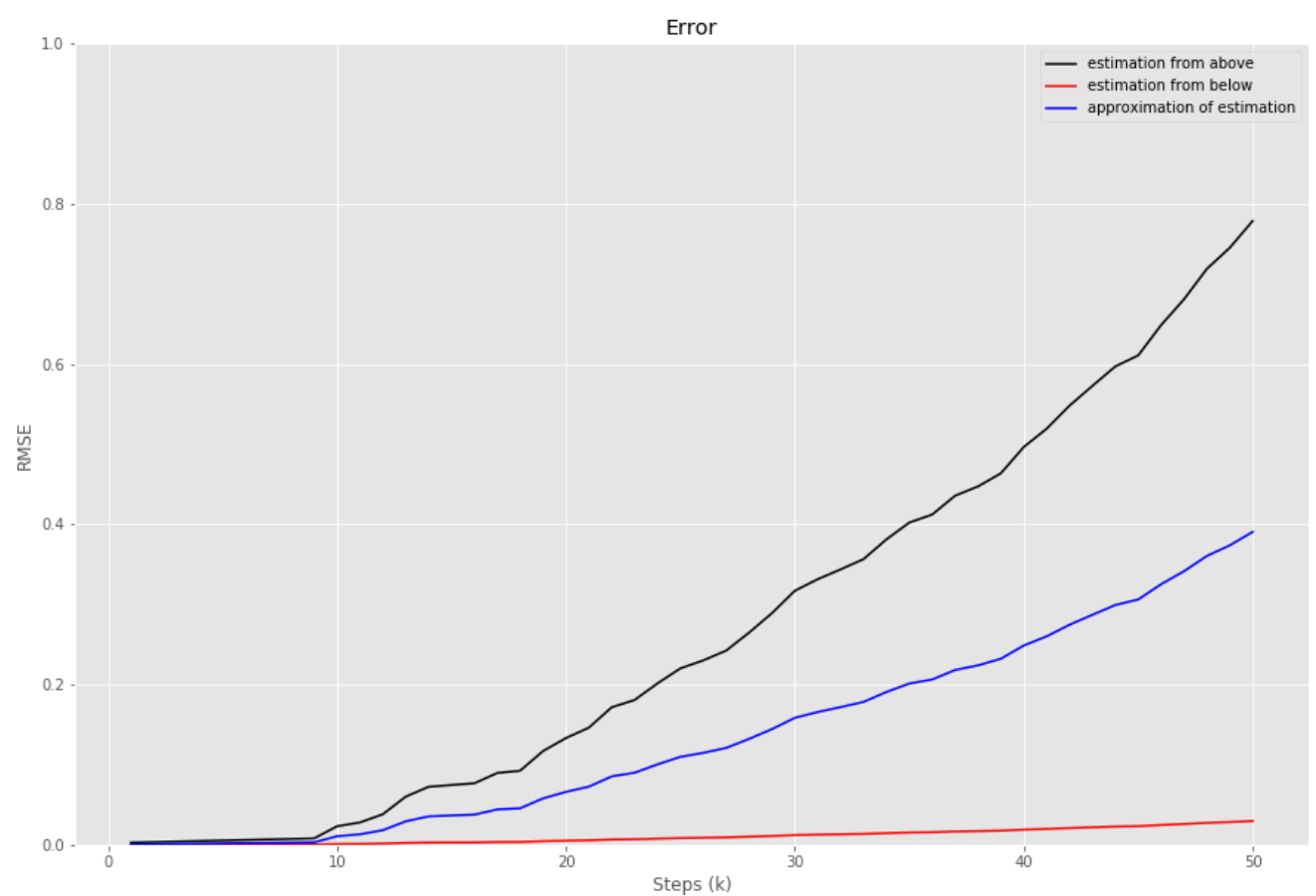

Рис.5. Аппроксимация оценки при $\alpha \in[0.7,0.9)$

Аппроксимация оценки при $\alpha \in[0.9,1)$ представлена на рис. 6.

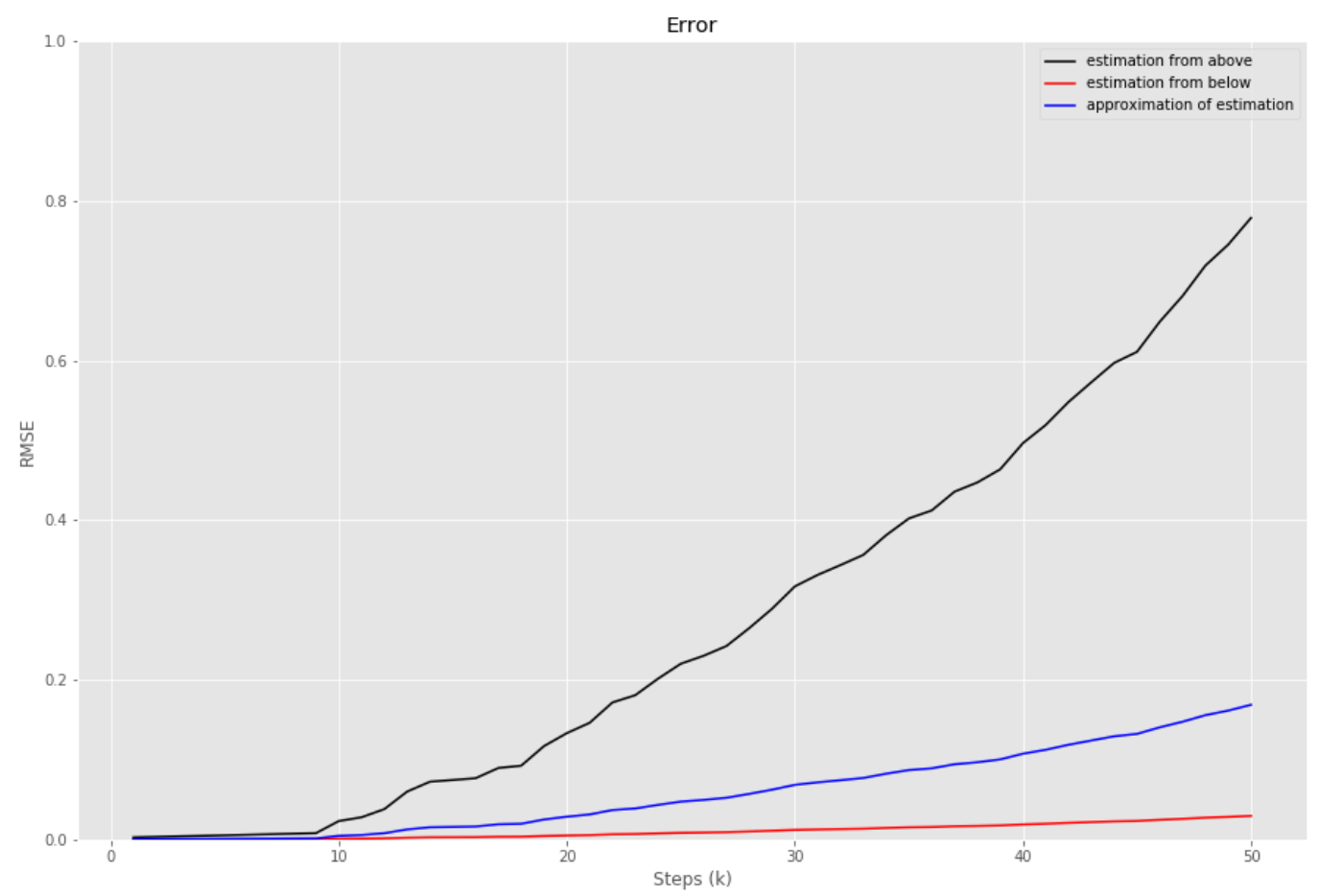

Рис.6. Аппроксимация оценки при $\alpha \in[0.9,1)$

Из полученных результатов видно, что при увеличении значения инвариантной меры, точка более пригодна к прогнозу, и многошаговое прогнозирование даёт лучшие результаты. Видим, что аппроксимация оценки ближе всего к оценке снизу при $\alpha>0.9$. 


\section{Выводы.}

1.Инвариантная мера показывает сильное влияние при прогнозировании на много шагов вперед.

2.Чтобы найти только те точки, на которые мы сможем опереться для получения более качественного прогноза, используя инвариантную меру, необходимо выбрать значение инвариантной меры между [0.9;1).

\section{Библиографические ссылки}

1. Aghabozorgi, S. Time-series clustering-A decade review [Text] / S. Aghabozorgi, A. S. Shirkhorshidi, T. Y. Wah // Information Systems. - 2015. - Vol. 53. - P. 16-38.

2. Benítez, I. Dynamic clustering of residential electricity consumption time series data based on Hausdorff distance Electric Power Systems Research [Text] / I. Benítez, J. L. Díezb, A. Quijanoa, I. Delgado // Online First. - 2016.

3. Goodfellow, I. Deep Learning [Text] / I. Goodfellow, Y. Bengio, A. Courville // MIT Press. 2015. - p. 643.

4. Малинецкий, Г.Г. Современные проблемы нелинейной динамики [Текст] / Г. Г. Малинецкий, А. Б. Потапов / Эдиториал УРСС. - 2000. - 336 с.

Надійшла до редколегії 26.09. 2019. 


\author{
В.А. Турчина, К.П. Гулько \\ Дніпровський національний університет імені Олеся Гончара
}

\title{
ЗАСТОСУВАННЯ АЛГОРИТМУ ФОРДА-ФАЛКЕРСОНА ДЛЯ ВИЯВЛЕННЯ НАДЛИШКОВОЇ ІНФОРМАЦЇ̈
}

Для відомої задачі про максимальний потік розглянуто питання побудови або всіх максимальних потоків, або заданої їх кількості. Отриманні результати використовуються для дослідження питання існування надлишкової інформації в мережі. На основі класичного методу Форда-Фалкерона запропонована його модифікація та алгоритм для знаходження надлишкової інформації.

Ключові слова: сіткові мережі, алгоритм Форда-Фалкерсона, максимальний потік в мережі.

Для известной задачи о максимальном потоке рассмотрен вопрос построения всех максимальних потоков или заданного их количества. Полученные результаты используются для исследования вопроса существования избыточной информации в сети. На основании классического метода Форда-Фалкерсона предложена его модификация и алгоритм нахождения избыточной информации.

Ключевые слова: сетевые сети, алгоритм Форда-Фалкерсона, максимальный поток в сети.

The object of the article is the network maximum flow algorithm, mainly the FordFulkerson algorithm. The algorithm began to be developed by two scientists: Ford and Fulkerson. This algorithm was proposed in order to find the maximum flow in the network. They began to be actively studied by scientists from the middle of the last century. The first report of "Maximum Network Flow" dates back to 1954. The authors of the report, Ford and Fulkerson had proved the theorem on the maximum flow and the minimum cross section for non-oriented graphs: the value of the maximum flow in the network is equal to the minimum throughput capacity of the section. The interest in the solution of these tasks was primarily due to practical needs, for that time construction of routes for the transportation of raw materials was not optimal and transported more raw materials than can transfer the connection between points. Such problems often arise when constructing connections that transport oil through pipes or transport coal through special excavators. The subject of the article is the problem of finding the maximum flow in the network. In graph theory, the transport network is an indicative graph in which each arc has no negative throughput and flow. Two peaks are distinguished: source and drain - such that any other vertex in the network lies on the way from source to drain.

The article consists of two sections. In the first section we consider the mathematical formulation of the problem and concrete examples of problems. The second section examines the classic Ford-Fulkerson algorithm, the modified Ford-Fulkerson algorithm to find excess information on the network, and the work of a modified algorithm on a specific example from the first section. The considered problems are relevant both from a theoretical and a practical point of view.

Keywords: Networks, Ford-Fulkerson algorithm, Maximum network flow.

(C) Турчина В.А., Гулько К.П., 2019 
Вступ. Серед задач дискретної оптимізації особливої уваги заслуговують оптимізаційні сіткові задачі, оскільки вони мають широке практичне застосування. В данній роботі розглядається одна із відомих сіткових задач, а саме задача про максимальний потік. Для іiї розв'язку відомий точний алгоритм поліноміальної складності для випадку цілочисельних спроможностей. В данній роботі вивчається задача аналізу сіткових мереж та потоків в них на предмет існування надлишкової інфориації, що дозволить суттєво економити ресурси.

Постановка задачі. Наведемо відому постановку задачі про максимальний потік.

Задано орієнтований зв'язний граф $G=\{V, U\}$, який складається з множин вузлів $V=\{1,2,3 \ldots n\}$ та множини дуг $U \subset V \times V$.

Кожній дузі (i, j) ставиться у відповідність невід'ємне число $b_{\mathrm{ij}}$, яке називається пропускною спроможністю дуги. В мережі виділені два спеціальних вузла. Один з них, в який немає вхідних дуг, називається джерелом та позначається як s, другий, що немає вихідних дуг, називають стоком та позначають $\mathrm{t}$. Таку мережу можно, наприклад, розглядати як водопровідну систему в якій труби відповідають дугам, джерело води відповідає джерелу s, стік води - t, a з'єднання - дуги в мережі. Пропускна спроможність дуги обмежує максимальний потік, який може проходити через дане сполучення. Потрібно визначити як саме пропустити максимальний потік 3 джерела в стік по цій мережі так, щоб мінімізувати втрати в цій мережі.

Сформулюємо цю задачу саме на математичній мові. Потоком 3 джерела s в стік t величини $v$ в мережі називають множину невід'ємних чисел $\mathrm{x}_{\mathrm{ij}}$ (кожне 3 яких визначається для дуги (i, j) в мережі), яка задовольняє наступним обмеженням:

$$
\sum_{i} x_{i j}-\sum_{j} x_{j k}=\left\{\begin{array}{c}
-v, \text { якщо } j=s \\
0, \text { якщо } j \neq s, t \\
v, \text { якщо } j=t \\
v \geq 0
\end{array}\right.
$$

при обмеженнях на $x_{i j}: 0 \leq x_{i j} \leq b_{i j}$ для усіх $(i, j)$.

Тут перша сума береться за дугами, які входять в вузол $\mathrm{j}$, а друга сума - по дугам, які виходять з вузла $\mathrm{j}$.

Обмеження (1) виражають, що в кожен вузол (окрім s та t) входить стільки потоку, скільки з нього виходить (закон збереження).

Нехай $X \subset U$, a $\bar{X}=U \backslash X$. Перерізом $(X, \bar{X})$ називається множина дуг (i, j) $\epsilon \mathrm{U}$, для яких або $i \in X, j \in \bar{X}$, або $j \in X, i \in \bar{X}$ та видалення яких перетворює мережу в незв'язну. Переріз $(X, \bar{X})$ називається перерізом, який розділяє вузли s та t, якщо $s \in X, t \in \bar{X}$. 
Пропускною спроможністю переріза $(X, \bar{X})$ називається величина $C(X, \bar{X})=\sum_{i, j} b_{i j}, i \in X, j \in \bar{X}$.

Існує відомий алгоритм для знаходження максимального потоку в мережі, а саме алгоритм Форда-Фалкерсона. Цей алгоритм має поліноміальну складність. Зрозуміло, що для тих дуг на яких потік дорівнює нулю, а також для дуг де він меньше пропускних спроможностей в деяких випадках можна економити ресурси. Виникає питання, а як визначити умови, при яких можна максимізувати цю економію. що максимальний потік може бути не єдиний.

В роботі запропоновано модифікацію алгоритму для знаходження усіх можливих потоків та процедуру знаходження надлишкової інформації в мережі.

Основна ідея алгоритму. Алгоритм базується на тому, що кроки при переході від однієї вершини до іншої запом'ятовуються. Модифікація полягає в тому, що пошук нового максимального потоку в s-t мережі враховує попередньо знайдені максимальні потоки. При кожному проході алгоритму ми порівнюємо теперішній шлях зі списком шляхів і якщо ми знайшли такий же, то перериваємо дію алгоритму та переходимо до розрахування надлишкової інформації в мережі та формулювання відповіді користувачу щодо зменшення пропускних спроможностей на деяких дугах.

Модифікація алгоритму. Розглянемо модифікований алгоритм ФордаФалкерсона, що полягає в записуванні шляхів до списку для того, щоб знаходити усі можливі потоки або задану кількість, а також алгоритм для знаходження надлишкової інформації в мережі. Алгоритм базується на відомому алгоритмі Форда-Фалкерсона.

\section{Крок 1 (процес розстановки поміток та запису їх).}

В процесі роботи алгоритму кожен вузол знаходиться в одному 3 трьох станів: «не помічений», «помічений та не переглянутий» або «помічений та переглянутий». Спочатку усі вузли в мережі «не помічені». Помітка довільного вузла ј завжди складається з двух частин. Перша частина - номер вузла i, котрий вказує, що можливо «надіслати» потік з і до j. Друга помітка - число, яке вказує максимальну величину потоку, котрий можливо «надіслати» 3 вузла і до вузлу j, не порушуючи обмежень на пропускну здатність дуг.

Також на першому кроці ми маємо пустий список дуг в котрий далі ми будемо заносити переглянуті дуги.

Джерело s завжди отримує фіктивну помітку $\left[s^{+}, \varepsilon(s)=\infty\right]$.

Оберемо будь-який помічений та не переглянутий вузол ј (на першому кроці це джерело s). Нехай він має помітку $\left[i^{+}, \varepsilon(j)\right] .3$ усіх вузлів, які суміжні з j, виділимо ті вузли $\mathrm{k}$, які не помічені та для яких $x_{i k}<b_{i k}$. Припишемо кожному з вузлів к помітку $\left[j^{+}, \varepsilon(k)\right]$, де $\varepsilon(k)=\min \left[\varepsilon(j), b_{j k}-x_{j k}\right]$ (такі вузли k тепер «помічені та не переглянуті»). Якщо вузол має помітку $\left[i^{-}, \varepsilon(j)\right]$, то 
після цього усім суміжним вузлам з $\mathrm{j}$ вузлам $\mathrm{k}$, які не помічені і для котрих $x_{i k}>0$, припишемо помітку $\left[j^{-}, \varepsilon(k)\right]$, де $\varepsilon(k)=\min \left[\varepsilon(j), x_{j k}\right]$ (такі вузли $\mathrm{k}$ тепер також «помічені та не переглянуті»). Тепер усі вузли, які є сусідами з $\mathrm{j}$, мають помітки. Тоді вузол ј вважається поміченим та переглянутим та його можливо більше не розглядати на цьому кроці. Може бути, що деякі сусідні вузли з ј помічені, а інші не можуть бути поміченими (або усі сусідні з ј вузли не можуть бути поміченими); в цих випадках вузол ј також вважається «поміченим та переглянутим» та додається до списку вузлів. Знаки «+» та «-» в першій частині поміток вказують як повинен змінитися потік на кроці 2.

Якщо список дуг пустий, то ми не робимо звірку з ним і йдемо далі за алгоритмом, а якщо він містить дуги, то ми виключаємо з розгляду при першому проході перші три дуги з одного маршруту від s до t. Потім ми не ігноруємо їх, щоб знайти максимальний потік. Якщо на одному з кроків не вдається знайти мережу, яка відміна від знайдених, то алгоритм закінчує свою роботу та не переходимо на процедуру знаходження надлишкової інформації.

Продовжимо приписувати помітки вузлам, які є сусідніми до помічених та не переглянутих вузлів, до тих пір, поки або вузол $\mathrm{t}$ виявиться поміченим, або не можливо буде більше помітити жоден з вузлів та стік виявиться не поміченим. Якщо t не може бути поміченим, тоді не існує шляху з $\mathrm{s}$ до $\mathrm{t}$, який збільшує потік, а отже побудований потік максимальний. Якщо $\mathrm{t}$ помічений, то на кроці 2 можливо знайти шлях, який збільшує потік.

\section{Крок 2 (зміна потоку).}

Припустимо, що стік $\mathrm{t}$ має помітку $\left[k^{+}, \varepsilon(t)\right]$. Тоді замінимо $x_{k t}$ на $x_{k t}+\varepsilon(t)$. Якщо вузол $\mathrm{k}$ має помітку $\left[r^{-}, \varepsilon(k)\right]$, то замінимо $x_{r k}$ на $x_{r k}-\varepsilon(k)$, а якщо $\left[r^{+}, \varepsilon(k)\right]$, то на $x_{r k}+\varepsilon(k)$. Записуємо дугу до початку списку з дугами. Продовжимо ці дії, поки не достигнемо джерела s. Після цього видалимо усі старі помітки вузлів і перейдемо до кроку 1.

Коли алгоритм закінчує роботу (на кроці 1 - не можемо помітити стік або ми отримуємо перші три дуги які вже існують в списку дуг, та які ми не розглядаємо), то отримуємо множину $\mathrm{X}$ помічених вузлів та множину дуг $(\mathrm{i}, \mathrm{j})$, де $i \in X, j \in \bar{X}$. Якщо список дуг не пустий, то ми заносимо його до списку маршрутів, які знайдені алгоритмом. Величина отриманого максимального потоку згідно $з$ теоремою Форда-Фалкерсона буде дорівнювати пропускній спроможності отриманого перерізу $(X, \bar{X})$.

Процедура знаходження надлишкової інформації в мережі. Нехай отримали множину максимальних потоків в s-t мережі. Для кожної $з$ цих мереж на тих дугах, де потік не нульовий і менший за пропускні спроможності, зменшуємо пропускні спроможності на максимальну можливу величину. Обераємо ту мережу де досягнуто максимальне зменшеннях пропускних спроможностей. 
Ілюстрація роботи на тестових прикладах. Проілюструємо роботу алгоритму на наступній мережі. Нехай кількість максимальних потоків дорівнює 3.

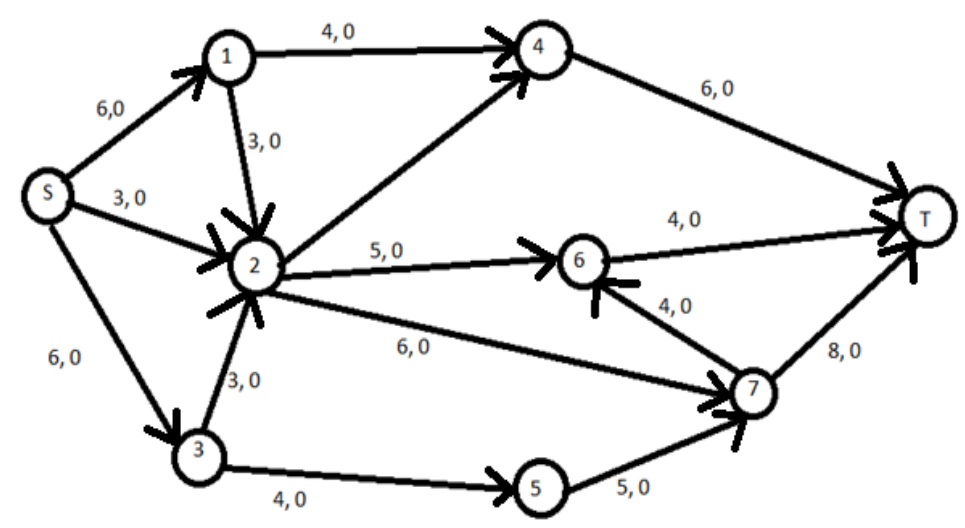

Рис. 1. Початкова мережа

Тепер будемо використовувати модифікований метод Форда-Фалкерсона для знаходження максимального потоку. Алгоритм повторюємо стільки разів стільки передбачено умовою задачі.

Перший прохід алгоритму:

1. S->2->6->T E(T) = 3. Збільшуємо на 3 одиниці.

2. $\mathrm{S}->1->4->\mathrm{T} \mathrm{E}(\mathrm{T})=4$. Збільшуємо на 4 одиниці.

3. S->1->2->4->T E $(\mathrm{T})=2$. Збільшуємо на 2 одиниці.

4. S->3->5->7-> T E $(\mathrm{T})=4$. Збільшуємо на 4 одиниці.

5. S->3->2->6-> Т E $(\mathrm{T})=1$. Збільшуємо на 1 одиницю.

6. $\mathrm{S}->3->2->7->\mathrm{T} \mathrm{E}(\mathrm{T})=1$. Збільшуємо на 1 одиницю.

$\mathrm{C}(\mathrm{X}, \bar{X})=15$.

Алгоритм закінчив свою роботу. Ми отримали наступну мережу:

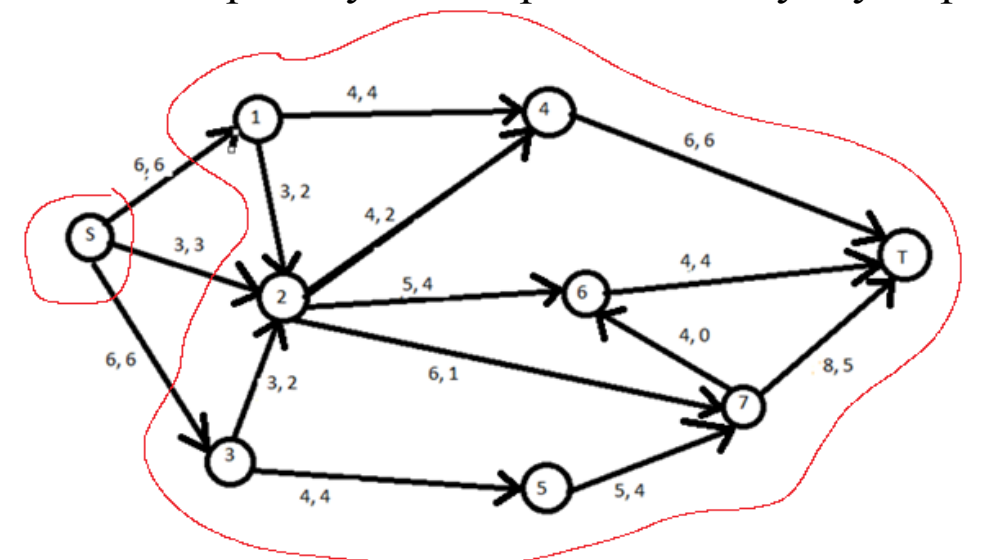

Рис. 2 Мережа після першої ітерації алгоритму

Другий прохід алгоритму:

1. S->2->7->6-> Т E (T) = 3. Збільшуємо на 3 одиниці.

2. S->3->2->7->6->Т E(T) $=1$. Збільшуємо на 1 одиницю.

3. S->3->5->7->T E $(\mathrm{T})=4$. Збільшуємо на 4 одиниці.

4. $\mathrm{S}->3->2->7->\mathrm{TE}(\mathrm{T})=1$. Збільшуємо на 1 одиницю.

5. S->1->4->T E(T) = 4. Збільшуємо на 4 одиниці.

6. $\mathrm{S}->1->2->7->\mathrm{T} \mathrm{E}(\mathrm{T})=1$. Збільшуємо на 1 одиницю.

7. $\mathrm{S}->1->2->6<-7->\mathrm{T} \mathrm{E}(\mathrm{T})=1$. Збільшуємо на 1 одиницю.

$\mathrm{C}(\mathrm{X}, \bar{X})=15$. 
Алгоритм закінчив свою роботу. Ми отримали таку мережу:

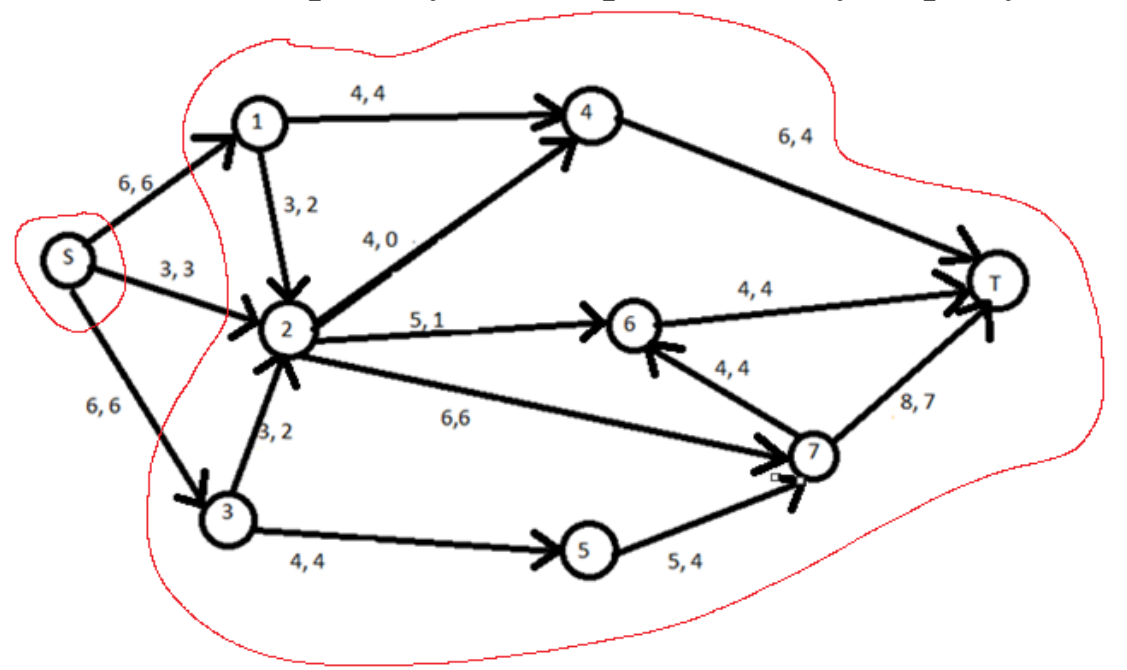

Рис. 3 Мережа після другої ітерації алгоритму

Третій прохід алгоритму:

1. $\mathrm{S}->2->7->\mathrm{T} \mathrm{E}(\mathrm{T})=3$. Збільшимо на 3 одиниці.

2. $\mathrm{S}->3->5->7->\mathrm{T} \mathrm{E}(\mathrm{T})=4$. Збільшимо на 4 одиниці.

3. $\mathrm{S}->3->2->7->\mathrm{T} \mathrm{E}(\mathrm{T})=1$. Збільшимо на 1 одиницю.

4. $\mathrm{S}->3->7->6->\mathrm{T} \mathrm{E}(\mathrm{T})=1$. Збільшимо на 1 одиницю.

5. S->1->4->T E (T) $=4$. Збільшимо на 4 одиниці.

6. S->1->2->7->6->T E(T) $=1$. Збільшимо на 1 одиницю.

7. $\mathrm{S}->1->2->6->\mathrm{T} \mathrm{E}(\mathrm{T})=1$. Збільшуємо на 1 одиницю.

$\mathrm{C}(\mathrm{X}, \bar{X})=15$.

Алгоритм закінчив свою роботу. Отримали таку мережу:

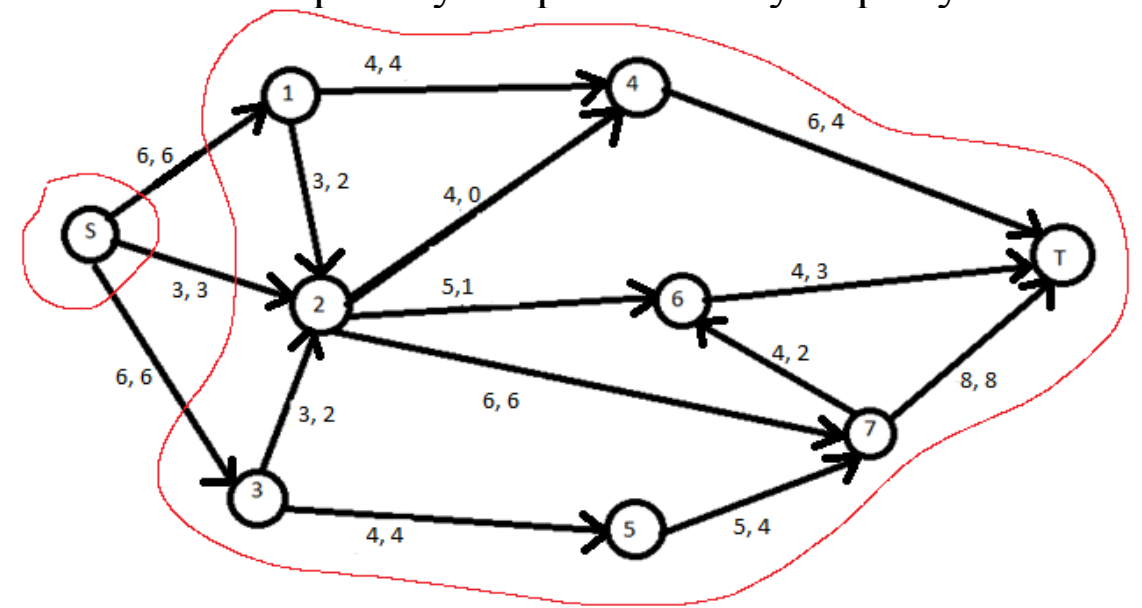

Рис. 4 Мережа після третьої ітерації алгоритму

Якщо ми подивимося на результат усіх проходів то ми можемо в деяких мережах зменшити пропускну спосібність.

3 першого ми можемо зменшити:

- $(1,2)-1$

- $(2,4)-2$

- $(2,6)-1$

- $(2,7)-5$

- $(3,2)-1$ 
- $(5,7)-1$

- $(7,6)-4$

- $(7, \mathrm{~T})-3$

В цьому випадку можемо заощаджити 18 одиниць (труби або іншого матеріалу).

3 другого:

- $(1,2)-1$

- $(2,4)-4$

- $(2,6)-4$

- $(3,2)-1$

- $(5,7)-1$

- $(4, \mathrm{~T})-2$

- $(5, \mathrm{~T})-1$

- $(7,6)-1$

- $(7, \mathrm{~T})-1$

В цьому випадку можемо заощадити 16 одиниць (труби або іншого матеріалу).

3 трєтього:

- $(1,2)-1$

- $(2,4)-4$

- $(2,6)-4$

- $(3,2)-1$

- $(5,7)-1$

- $(7,6)-2$

- $(4, \mathrm{~T})-1$

В цьому випадку можемо заощадити 14 одиниць (труби або іншого матеріалу).

Алгоритм закінчив свою роботу. Аналіз отриманих результатів показує, що оптимальний економії ресурсів відповідає перша мережа.

Висновки. В роботі модифіковано алгоритм для знаходження заданої кількості або усіх можливих максимальних потоків в мережі та на основі їх аналізу даються рекомендації, щодо можливої економії ресурсів за рахунок зменшення пропускних спроможностей дуг.

\section{Бібліографічні посилання}

1. Ермольев, Ю.М. Экстремальные задачи на графах. [Текст] / Ю.М. Ермольев, И.М. Мельник. - К.: "Наукова думка", 1968. - 176 с.

2. Bozhenyuk, A. The methods of maximum Flow and minimum cost flow finding in fuzzy network [Text] / A. Bozhenyuk, E. Gerasimenko, I Rozenberg // Proceedings of the Concept Discovery in Unstructured Data Workshop (CDUD 2012) co-located with the 10th International Conference on Formal Concept Analysis (ICFCA 2012) May 2012, Katholieke Universiteit Leuven, Leuven, Belgium 2012. - pp. 1-12.

3. Форд, Л. Потоки в сетях [Текст] / Л. Форд, Д. Фалкерсон.- М.: «МИР», 1966. - 276 с.

Надійшла до редколегіï 26.09. 2019. 
doi: $10.15421 / 321920$

\section{КАФЕДРІ ОБЧИСЛЮВАЛЬНОЇ МАТЕМАТИКИ ТА МАТЕМАТИЧНОЇ КІБЕРНЕТИКИ ДНУ 60 РОКІВ - DOCENDO DISCIMUS • 1959-2019}

Велич математики безмежна і неосяжна! Сьогодні цей факт важко збагнути до кінця фахівцям найвищого рівня у цій царині. Як досконала мова природничих наук, вона абстрактно і чітко моделює складні процеси та застосовує свої правила для отримання нових знань, тому, погортавши сторінки математичної класики, зустрінемо визначні імена велетів абстрактного мислення, які відкрили і розвинули фундаментальні істини, допомогли краще зрозуміти світ та його закони. Випускники кафедри обчислювальної математики та математичної кібернетики, які пройшли непростий шлях пізнання математичних істин, мають таку узагальнену думку щодо своєї професійної діяльності: «Реалізація різноманітних проектів у галузі комп'ютерних технологій, корисних для практичних потреб, можлива лише за однієї умови, - використання скарбниці розуму, який таїться у вічній та водночас молодій класичній математиці». ÏÏ розвиток неминуче призвів спочатку до появи окремих обчислювальних інструментів, а потім - перших комп'ютерів, можливості яких невпинно зростали. Маємо найголовніший математичний, технологічний і соціальний феномен другої половини двадцятого століття комп'ютеризація науки, освіти і суспільства взагалі.

Цілком природно, що глибинні витоки теорії обчислювальних процесів лежали в руслі розвитку фундаментальної математики. Дніпропетровському державному університету випала честь бути одним із чотирьох базових вузів країни, в якому відкрилась спеціальність «Обчислювальна математика» i проводилася підготовка майбутніх програмістів - представників загадкової професії того часу. Саме на фізико-математичному факультеті, за наказом міністра освіти від 17 червня 1959 року, було створено кафедру обчислювальної математики. В ті часи центром розвитку кібернетичної науки в СРСР став Київ, де в 1957 році в Інституті математики почала працювати перша обчислювальна лабораторія, а в 1962 році створений Інститут кібернетики. Порівняння дат свідчить, що засновники кафедри знаходились на передових позиціях свого часу, і заклали міцні підвалини для іiі майбутніх успіхів [1].

Першим завідувачем кафедри обчислювальної математики став Віктор Чернишенко, і це місце в іiі історії залишиться з ним назавжди. Народився в сільській сім’і, де панували любов до праці, відповідальність, серйозне ставлення та повага до освіти, народна естетика українського побуту та щиросердні відносини. В таких умовах зростав майбутній успішний студент, сталінський стипендіат спеціальності «Математика». Потім, в Московському дер- 
жавному університеті захистив кандидатську дисертацію, пройшов стажування у Паризькому університеті - Сорбонні. Фундаментальна математична освіта дозволила молодому завідувачу стати засновником напрямку «обчислювальна математика», а основною темою його наукових досліджень стала збіжність ітераційних процесів. Чернишенко В.М. підготував п’ять кандидатів фізико-математичних наук. Автору цих рядків довелось у далекому 1982 році бути на родинному святі у Чернишенків - інтелігентів-математиків того часу. У домашньому кабінеті я гортав безціні фоліанти рідкісної математичної літератури, а потім слухав мелодійні українські пісні у виконанні мами та дружини. Віктор Михайлович був одним з перших програмістів міста, i коли наприкінці п’ятдесятих з'явилися перші ЕОМ, то упроваджувалися вони в ДДУ виключно під його керівництвом. В цей час на механікоматематичному факультеті активно розвивається теоретична математика, представники якої входять до пантеону світової математичної слави, а їх наукові праці ставали визначальними для розвитку математики прикладної.

Один 3 них - Володимир Бурдюк, який очолив кафедру в 1975 році. Він, чи не найперший на факультеті, усвідомив, що розвиток обчислювальних технологій призводить до процесу поступового зміщення наукових та практичних інтересів від неперервної математики до дискретної. В.Я. Бурдюк започаткував процес докорінної зміни освітнього процесу, характеру та змісту дисциплін, що викладалися кафедрою. Зростала нова плеяда викладачів, формувалися власні наукові інтереси завідувача та тематика досліджень аспірантів. Під його керівництвом захищені чотири кандидатські дисертації. Свідченням високого рівня наукових результатів В.Я. Бурдюка та його учнів $\epsilon$ посилання на них науковців західного світу та пропозиція до співробітництва з боку наукових установ США. Звичайно, в часи комуністичного режиму та «залізної завіси», таке співробітництво було неможливим.

У 1983 році кафедру обчислювальної математики очолив професор Юрій Мельников, який у цей період активно і наполегливо створював факультет прикладної математики. За його ініціативою, відповідно до вимог часу та змістом дисциплін кафедра здобула нову назву «обчислювальної математики та математичної кібернетики». Якісно і динамічно проводились наукові дослідження, наповнювався новим змістом освітній процес. На кафедрі, де були відсутні доктори наук, в цей час захищено три докторських і чотири кандидатських дисертації. Такі події відбулись завдяки цінним настановам Ю. Мельникова, його організаційній та методичній допомозі, застосуванню ефективних форм дослідницької роботи, які сьогодні на кафедрі стали традиційними. Пам'ять про цей науковий прорив нетлінна. В той же час, профеcop Мельников був яскравим представником авторитетної на теренах СРСР дніпропетровської наукової школи механіків, започаткованої академіком Моссаковським. Тому цілком закономірно, що він був головою першої в Придніпровському регіоні спеціалізованої вченої ради для захисту докторських дисертацій відповідного профілю, на якій у 1991 році активний науко- 
вець кафедри Володимир Лобода успішно захистив докторську дисертацію, а після від’ізду Ю. Мельникова до США у 1992 році очолив кафедру.

Олена Кісельова, починаючи з перших днів роботи, була активним, високопрофесійним і відповідальним викладачем кафедри. Завжди у вирі освітньої роботи, вона готує нові актуальні та фундаментальні курси : «Основи теорії оптимального керування», «Чисельні методи оптимізації», «Дослідження операцій», «Чисельні методи лінійного програмування», «Теорія розпізнавання образів», «Методи мінімізації недиференційовних функцій», «Статистичний аналіз та прогнозування економічних процесів». У 1992 році відбувся захист іï докторської дисертації в Інституті кібернетики ім. В.М. Глушкова НАН України - установі найвищого наукового рівня і авторитету, а тому після переходу Володимира Лободи на механікоматематичний факультет, професор Кісельова очолить кафедру обчислювальної математики та математичної кібернетики та на довгі роки стане уособленням ії педагогічного та наукового авторитетів [3].

Згодом пані Олена буде обрана членом-кореспондентом Національної академії наук України, проте в усі часи вона була на сторожі вітчизняних наукових цінностей у галузі кібернетики і стала одним з потужних керманичів, завдяки роботі яких, було забезпечено неперервність та незнищенність струмка української освіти і науки у надскладний економічний період.

Спробуємо хоча б побіжно згадати зроблене. 31993 року професор Кісельова $€$ постійним керівником наукового семінару «Сучасні питання оптимізації та дискретної математики при Науковій раді НАН України з проблеми «Кібернетика», нею створена науково-дослідна лабораторія «Оптимізації складних систем», де протягом 25 років виконано 10 держбюджетних тем, захищено 19 дисертацій, у тому числі 3 докторських. Лабораторія здійснює плідне співробітництво з провідними науковими установами світу. Щорічно, починаючи з 2003 року на базі кафедри проводиться міжнародна науковопрактична конференція «Математичне та програмне забезпечення інтелектуальних систем» (співголови - ректор ДНУ М. Поляков та декан ФПМ О. Кісельова) 3 наступним друкуванням кращих доповідей у фаховому науковому збірнику «Питання прикладної математики і математичного моделювання».

Особисто професор Кісельова була керівником дев'ятнадцяти дисертацій i, таким чином, створила потужну наукову школу, яка плідно працює дотепер. Двадцять п'ять років під іiі керівництвом злагоджено та результативно працює спеціалізована вчена рада по захисту кандидатських, а останні чотири роки - докторських дисертацій за двома спеціальностями. Досягнення наукової школи та авторитет іiї керівника дозволили вперше, на регіональному рівні проводити захист кандидатських та докторських дисертацій за спеціальністю 01.05.01 - теоретичні основи інформатики та кібернетики. Наукові роботи дістали високий авторитет в академічних колах, їх захист відбувався безперервно, навіть, в період матеріальної скрути та руйнування духовних цінностей в суспільстві. В цей час професор Кісельова використовує позитивну 
можливість, яка з'явилась, і встановлює наукові зв'язки з зарубіжними установами: університетами штатів Принстона, Флориди, Тенесі, Техас (США); разом з учнями бере участь у міжнародних симпозіумах у США, Німеччині, Швейцарії, Молдові та Китаю.

Основні віхи життя і діяльності відображають участь Олени Кісельової в чисельних наукових спільнотах вітчизняного і світового рівнів: у 2000, 2006 pp. внесена Американським Біографічним Інститутом у довідник «Who's Whoof Professional\$Business Women” ; з 2003 - Член Американської Математичної Спілки; у 2012p. відзначена державною нагородою - орденом княгині Ольги III ступеня; з 2012 р. і дотепер - член секції Наукової ради МОНУ за фаховим напрямком «Математика»; у 2017 р. - Лауреат Державної премії України в галузі науки і техніки; нагороджена ювілейною медаллю «25 років Академії наук вищої школи України».

Неможливо оминути увагою наукову школу, яка була сформована професором Ободан Наталею Іллівною - науковим керівником науково-дослідної лабораторії надійності та живучості конструкцій. Під іiї науковим керівництвом захищено 2 докторських та 15 кандидатських дисертацій, а список наукових праць містить понад 300 найменувань та 5 авторських посвідчень. У 1998 р. внесена Американським Біографічним Інститутом у довідник «Who’s Whoof Professional\$Business Women”, а з 1991 р. була членом Президії Асоціації «Надійність» НАН України.

Для збереження і розвитку науково-педагогічного потенціалу кафедри іiі провідні фахівці використали весь свій авторитет, здобутий в академічних колах. Їх наукові та педагогічні досягнення, а також інтелектуальна велич дозволили зрушити з місця глибу нечуваної ваги : сьогодні професорськовикладацький склад кафедри, серед яких шість докторів наук мають високий методичний та науковий рівень, а їх кваліфікація забезпечує досконалий освітній процес. Про світовий рівень сучасних освітніх програм кафедри свідчить той факт, що сьогодні наші студенти з легкістю надають консультацію випускникам Лондонської фінансової школи та інших європейських вузів. Ми пишаємося, що випускники нашої кафедри різних років стали докторами наук, які успішно працюють у вітчизняних та закордонних наукових та освітніх установах: Васильєва Н.К., Гарт Л.Л., Громов В.О., Гук Н.А., Дейнеко В.Г., Шевельова А.С.

Слід зауважити, що потужна робота викладачів доповнюється плідною роботою навчально-допоміжного персоналу, який у своїй роботі вивчає i використовує весь арсенал засобів сучасного діловодства та можливостей комп'ютерної техніки для ведення документації.

Таку команду кафедральних фахівців вдалось сформувати не відразу. На їх ретельний добір з урахуванням професійних якостей, здібностей та особливостей характеру пішли роки та затрачені зусилля вартували того. Сьогодні у декана факультету прикладної математики професора Кісельової на кафедрі $\epsilon$ однодумці та сподвижники. За потреби вони підставлять плече і не підве- 
дуть. Прикладом успішного кадрового рішення було обрання завідувачкою кафедри у зв'язку з вимогою нового закону про заборону суміщення адміністративних посад. У 2016 році нею стала Валентина Турчина, усе життя якої пов'язане з Дніпровським національним університетом. Це понад п'ятдесят років освітньої наукової та професійної діяльності - відмінне навчання на факультеті, успішний захист дисертації та формування справжнього майстра педагогічного цеху в складній царині кібернетичних наук. Щодня голос доцента Турчиної лунає в аудиторіях та на кафедрі: вона просто, чітко, доступно пояснює найскладніші базові поняття спеціальності та зміст курсових та дипломних робіт. ІІЇ завзятість у виконанні посадових обов'язків органічно доповнюються колоритним характером української жінки, яка завжди турбується та вболіває за тих, хто їй підпорядкований. Вимогливість, контроль та прискіпливість завідувачки, які іноді здаються зайвими, насправді, є безцінними рисами в умовах побудови сучасної жорсткої стандартизованої системи управляння освітою.

Сьогодні кафедра обчислювальної математики та математичної кібернетики Дніпровського національного університету імені Олеся Гончара святкує свій шестидесятирічний ювілей. ЇЇ історичний розвиток відбувався у відповідності з моделлю класичного університету XXI століття в Україні [2]. Його аналіз свідчить, що це - глиба i, водночас, міцний фундамент, які дозволяють сьогодні впевнено дивитись у складне, мінливе та суперечливе ринкове майбутнє освітнього процесу. Кафедра з часу свого створення готувала фахівців з обчислювальної математики, втім завжди своєчасно відгукувалась на потреби ринку праці. Так, в 1998 р. була розпочата підготовка випускників 3 нової спеціальності «Інтелектуальні системи прийняття рішень», в 2008 р. за напрямком «Системний аналіз», в 2013 р. - бакалаврів і магістрів за спеціальністю «Системи і методи прийняття рішень», а в 2016 р.- за спеціальністю «Прикладна математика».

В дні свого ювілею кафедра займає достойне місце в структурі університету, бо забезпечує залучення значного об'єму коштів для підготовки спеціалістів. Варто ще раз зауважити, що ці досягнення стали можливими завдяки складній високопрофесійній і системній роботі професорсько-викладацького складу в різні періоди їі функціонування. Та сьогодні цього замало. При всій важливості традиційного підходу до освіти сучасні ринкові умови вимагають не тільки прищепити студенту любов до знань та передати їх, а й навчити його заробляти гроші. Слід врахувати також, що зараз відбувається стрімкий розвиток галузі інформаційних технологій, а тому без достатньої кількості таких фахівців українська економіка не зможе успішно конкурувати у світі. В цих умовах особливої уваги заслуговує робота доцента кафедри обчислювальної математики та математичної кібернетики Олександра Кузенкова - здібного, молодого менеджера освіти. Саме $з$ ним декан факультету та завідувачка кафедри наполегливо шукають іiі сучасні модальності і акценти, щоб відповідати майнстріму сьогодення. Для досяг- 
нення мети планується проведення лекцій та розробка актуальних і прикладних кейсів для лабораторних та практичних занять, вивчається та запроваджується нова технологія дуального навчання студентів. У січні 2018 року підписана Угода про співробітництво та організацію взаємовідносин з громадською організацією IT-Dnipro Community, яка об'єднує 27 найвідоміших компаній регіону, серед яких AMC Bridge, ISD, DataArt, SoftServe, Luxoft, WIX, Exigen Services та ін. Більшість цих установ очолюють наші випускники, які охоче залучилися до співпраці з кафедрою для удосконалення освітнього процесу. Слід зауважити також, що доцент Кузенков як заступник декана забезпечує ці заходи для всіх спеціальностей факультету.

Кафедра обчислювальної математики та математичної кібернетики $є$ випусковою для бакалаврів та магістрів за спеціальностями «Системний аналіз», «Прикладна математика» (освітня програма «Комп’ютерне моделювання та обчислювальні методи»). Щорічне зростання кількості абітурієнтів стало закономірним, бо в своїй роботі кафедра ні на мить не забуває про них. Проводяться профорієнтаційні заходи, дні відкритих дверей, безкоштовні пробні тестування $з$ математики. Це дуже важливо для школярів, які люблять математику, мають успіхи при ii вивченні та володіють основами комп’ютерної грамотності, адже вони думають про своє майбутнє професійне життя, бажають зробити його цікавим та наповненим інтелектуальним змістом.

Звертаючись до юних математиків та програмістів, хотілося б зауважити, що невід'ємною рисою успіху є достойна робота з високою заробітною платою. Це, в свою чергу, залежить від рівня знання математики, а якщо бути зовсім точними - системного аналізу та прикладної математики. Зрозуміло, що обраний таким чином життєвий шлях - непростий, але коли наважитись, зробити перші кроки і пройти його, то можна отримати ні з чим незрівняну насолоду від пізнання великих істин математики і водночас бути на «ти» із сучасним комп'ютером. Кафедра відчиняє двері у дивовижний світ побудови складних систем із застосуванням обчислювальних методів та комп'ютерних технологій, а це означає успіх у бізнесі, виробництві та науці.

Це переконує абітурієнтів, що не треба шукати щастя в інших світах, а просто любити свою країну, бути патріотом рідного Придніпров'я і поважати його освітні заклади та вступити на спеціальності «Системний аналіз» або «Прикладна математика»(освітня програма «Комп’ютерне моделювання та технології програмування») Дніпровського університету імені Олеся Гончаpa, а далі змушує бути старанним, сумлінним і відповідальним у навчанні. Майбутні студенти факультету розуміють, що невід'ємними складовими їх долі стануть творча наповненість життя, цікава робота, і достойна заробітна платня. Титанічні зусилля кафедри протягом тривалого часу спрямовані на те, щоб усі з радістю дізнаватись про ї чергові ювілеї, а у юних очах спалахували вогники завзяття і надії! 


\section{Бібліографічні посилання}

1. Кісельова, О.М. Факультет прикладної математики: 30 років [Текст] / О.М. Кісельова, Т.А. Зайцева, В.Д. Ламзюк, О.М. Притоманова, Н.С.Сегеда. - Д.: ДНУ, 2014. $-108 \mathrm{c}$.

2. Поляков, М.В. Класичний університет еволюція, сучасний стан, перспективи [Текст] / М.В. Поляков, В.С. Савчук. - К.: Генза, 2004. - 416 с.

3. Притоманова, О.М. Гармонійне поєднання суспільного інтересу та ролі особистості в становленні факультету прикладної математики [Текст] / О.М. Притоманова, В.Л. Волошко // Зб. ст. по мат. міжнародної науково-практичної конференції «Суспільна місія класичного університету в сучасному світі», приуроченої до 100-річчя ДНУ імені Олеся Гончара, Д.: ДНУ 11-12 жовтня 2018 р. - С. 488-492.

В.Л. Волошко 


\section{ДО ВІДОМА АВТОРІВ}

У статті подають представлені результати нових досліджень автора 3 повним їх обгрунтуванням. Посилання на неопубліковані праці недопустиме. Статті можуть бути написані українською, російською та англійською мовами. Оптимальний обсяг статті - до 12 сторінок.

Структура рукопису статті:

- анотація трьома мовами (українська, російська, англійська) - не більше 5 рядків. Якщо стаття написана українською мовою, обсяг англійської анотації повинен складати не менш 1800 знаків. Якщо мова статті - російська, обсяг англійської та української анотації повинен складати не менш 1800 знаків.

- Ключові слова - трьома мовами (українська, російська, англійська);

- постановка проблеми в загальному вигляді та її зв'язок із важливими науковими або практичними задачами, аналіз досягнень і публікацій за тематикою дослідження даної проблеми, наголошення на невирішених раніше питаннях загальної проблеми, розглядуваних у статті (Вступ);

- постановка розглядуваної задачі (Постановка задачі);

- викладення основного матеріалу з повним обгрунтуванням одержаних наукових результатів (Метод розв'язання та Аналіз одержаних результатів);

- висновки за проведеними дослідженнями і перспективи подальших досліджень (Висновки).

- На окремому аркуші додати назву статті, прізвища авторів та їх місце роботи трьома мовами (українська, російська, англійська).

\section{Вимоги до набору:}

- текст слід набирати виключно в MS Word 97-2003 (*.doc), шрифт - Times New Roman; 
- формат паперу - A4 (210x297), книжкова орієнтація;

- параметри сторінки (поля):

- верхне - 20 мм;

- нижне - 20 мм;

- ліве - 25 мм;

- праве - 20 мм.

- автоматичні переноси; сторінки не нумерують, відсутність «висячих» рядків; абзац (відступ першого рядка) - 5 мм;

- стиль і форматування для елементів статті (таблиця):

\begin{tabular}{|c|c|}
\hline УДК & $\begin{array}{l}\text { Шрифт: Times, } 14 \text { pt, прямий, усі літери великі; } \\
\text { вирівнювання: за лівим краєм; } \\
\text { міжрядковий інтервал: одинарний; } \\
\text { інтервал після: } 12 \mathrm{pt}\end{array}$ \\
\hline $\begin{array}{l}\text { Ініціали і прізвища } \\
\text { авторів (прізвище, } \\
\text { ім'я, по батькові) }\end{array}$ & $\begin{array}{l}\text { Шрифт: Times, } 14 \text { pt, напівжирний, прямий; } \\
\text { вирівнювання: за серединою; } \\
\text { міжрядковий інтервал: одинарний; }\end{array}$ \\
\hline Місце роботи & $\begin{array}{l}\text { Шрифт: Times, } 12 \text { pt, курсив; вирівнювання: за } \\
\text { серединою; міжрядковий інтервал: одинарний; } \\
\text { інтервал після: } 12 \mathrm{pt}\end{array}$ \\
\hline Назва статті & $\begin{array}{l}\text { Шрифт: Times, } 14 \text { pt, напівжирний, прямий, } \\
\text { усі літери великі; вирівнювання: за серединою; } \\
\text { міжрядковий інтервал: одинарний; } \\
\text { інтервал після: } 12 \text { pt }\end{array}$ \\
\hline Анотація & $\begin{array}{l}\text { Шрифт: Times, } 12 \mathrm{pt} \text {, напівжирний, прямий; } \\
\text { вирівнювання: за шириною; міжрядковий інтервал: } \\
\text { одинарний; інтервал після: } 12 \mathrm{pt}\end{array}$ \\
\hline $\begin{array}{l}\text { Основний текст } \\
\text { статті }\end{array}$ & $\begin{array}{l}\text { Шрифт: Times, } 14 \text { pt, прямий; вирівнювання: за } \\
\text { шириною; міжрядковий інтервал: одинарний }\end{array}$ \\
\hline $\begin{array}{l}\text { Заголовки } \\
\text { структурних } \\
\text { елементів статті } \\
\text { (вступ, постановка } \\
\text { задачі, висновки) }\end{array}$ & $\begin{array}{l}\text { Шрифт: Times, } 14 \text { pt, напівжирний, прямий; } \\
\text { вирівнювання: за шириною; } \\
\text { міжрядковий інтервал: одинарний }\end{array}$ \\
\hline
\end{tabular}




\begin{tabular}{|c|c|}
\hline $\begin{array}{l}\text { Заголовок } \\
\text { «Бібліографічні } \\
\text { посилання» }\end{array}$ & $\begin{array}{l}\text { Шрифт: Times, } 12 \mathrm{pt,} \text { напівжирний, прямий; } \\
\text { вирівнювання: за серединою; } \\
\text { міжрядковий інтервал: одинарний }\end{array}$ \\
\hline $\begin{array}{l}\text { Бібліографічні } \\
\text { посилання } \\
\text { алфавітному } \\
\text { порядку (зразок } \\
\text { наведено нижче) }\end{array}$ & $\begin{array}{l}\text { Шрифт: Times, } 12 \text { pt, (ПІБ - напівжирний, решта ні) } \\
\text { прямий, нумерований список; вирівнювання: за } \\
\text { шириною; відступ: номера - } 0 \text { мм, тексту: } 5 \text { мм; } \\
\text { міжрядковий інтервал: одинарний }\end{array}$ \\
\hline $\begin{array}{l}\text { Дата надходження } \\
\text { до редколегії }\end{array}$ & $\begin{array}{l}\text { Шрифт: Times, } 12 \text { pt, курсив; } \\
\text { вирівнювання: за лівим краєм; } \\
\text { міжсрядковий інтервал: одинарний }\end{array}$ \\
\hline $\begin{array}{l}\text { Підрисункові } \\
\text { підписи }\end{array}$ & $\begin{array}{l}\text { Шрифт: Times, } 12 \text { pt, напівжирний, прямий; } \\
\text { вирівнювання: за серединою }\end{array}$ \\
\hline $\begin{array}{l}\text { Назва таблиці } \\
\text { (перший } \quad \text { рядок: } \\
\text { слово } \quad \text { Таблищя; } \\
\text { другий: iї назва) }\end{array}$ & $\begin{array}{l}\text { Шрифт: Times, } 12 \text { pt, } \\
\text { перший рядок: курсив; вирівнювання: за правим краєм; } \\
\text { міжрядковий інтервал: одинарний; } \\
\text { другий рядок напівжирний, прямий; вирівнювання: за } \\
\text { серединою; міжрядковий інтервал: одинарний }\end{array}$ \\
\hline
\end{tabular}

\section{УВАГА!}

Лапки : « "
Дефic : -
Тире : -.

- УВАГА! Бібліографічні посилання оформлюють за зразком:

1. Слезкин, Н.А. Динамика вязкой несжимаемой жидкости [Текст] / Н.А. Слезкин. - М., 1955. - 493 с.

2. Белоносов, С.М. Краевые задачи для уравнений Навье-Стокса [Текст] / С.М. Белоносов, И.Л. Черноус. - М., 1985. - 312 с.

3. Евдокимов, Д.В. Построение матриц фундаментальных решений для системы уравнений Стокса [Текст] / Д.В. Евдокимов, Н.В. Поляков, А.Н. Фетищев // Вестн. Херсон. гос. техн. ун-та. - 2003. - № 3 (19). C. $127-130$. 
4. Справочник по специальным функциям с формулами, графиками и таблицами [Текст] / под ред. М. Абрамович, И. Стиган. - М., 1979.

5. Остапенко, Н.А. Необходимые и достаточные условия существования периодических решений в системах с переменной структурой [Текст] / Н.А. Остапенко // Вестн. Днепропетр. ун-та. Сер. «Математика» - 2002. Вып. 7. - С. 56-58.

6. Перехрест, В.I. Новий клас розв'язків гідродинамічних рівнянь Ейлера для осесиметричних вихорових течій [Текст] / В.І. Перехрест // Доп. НАНУ. - 2004. - № 3. - C. 35-42.

7. Перехрест, В.I. Кінематика взаємодії двох паралельних вихрових шнурів одного напрямку обертання та інтенсивності [Текст] : зб. наук. пр. / B.I. Перехрест, О.А. Мельник // Диференціальні рівняння та їх застосування. - Д., 2003. - С. 141-148.

8. Webometrics Ranking of World Universities: [Електронний ресурс]. - Режим доступу: http://www.webometrics.info

- рисунки виконують у будь-якому форматі, імпортованому графічними фільтрами MS Word. Рисунки вставляють у текст статті як окремий незалежний об’єкт (положення - у тексті), при цьому можна пересувати текст стосовно нього. Під рисунком обов'язково подають пояснювальний підпис із номером рисунка.

- формули набирають виключно у редакторі МathТуре (Шрифт: Times, 14 pt); якщо формула 3 номером, то вирівнюють за правим краєм, якщо ні - за серединою 3 стандартними установками. Латинські букви у формулах набирають курсивом, грецькі - прямим, математичні позначення ( $\mathrm{sin}, \mathrm{cos}$, tg, lim, ln, const, max, min, знак диференціала d) - прямим.

\section{До редакційної колегії потрібно подати:}

- у роздрукованому вигляді примірник статті, набраний згідно 3 вимогами щодо стилю й форматування для елементів статті, наведених вище;

- електронний варіант статті, набраний згідно з вимогами стосовно стилю й форматування для елементів статті, поданих вище;

- рецензію на статтю за підписом д-ра фіз.-мат. наук; 
ISSN 2074-5893 Питання прикладної математики і математичного моделювання. Випуск 19

- експертний висновок про можливість публікації статті;

- довідку про оригінальність твору.

Статті, виконані з порушенням правил, не будуть включені до збірника.

\section{Адреса редколегії:}

Дніпровський національний університет імені Олеся Гончара, факультет прикладної математики, кафедра обчислювальної математики та математичної кібернетики, просп. Яворницького, 35, корп. №3, м. Дніпро, Україна. 
Ya.S. Bondarenko, S.V. Kravchenko Bayesian approach to landing page testing

B.Є. Білозьоров, А.С. Івлев Нейромережевий підхід для моделювання цін на ринку дорогоцінних металів

Л.Т. Бойко, А.А. Конончук Алгоритм побудови прямого та оберненого оператора реального процесу

Н.В. Варех, Н.Л. Козакова, А.О. Лаврентьєва Дослідження асимптотичної поведінки розв'язків одного класу систем диференціальних рівнянь з відхиленням аргументу

В.Л. Волошко, М.П. Петулько Щодо розв'язування крайової задачі теорії пластин для областей складної форми

Л.Л. Гарт, М.О. Васенін, Н.В. Балейко Порівняльний аналіз алгоритмів розв'язання інтегрального рівняння Фредгольма другого роду у середовищі Matlab

Л.Л. Гарт, Н.А. Лобанцева Про обчислювальні аспекти реалізації різницевих схем розв'язання задачі Діріхле для еліптичного рівняння 3 мішаними похідними

В.Г. Городецкий Ідентифікація моделі гідроімпульсної системи 3 періодичною зовнішньою дією

Н.А. Гук, С.В. Диханов, С.Ф. Сірик Аналіз структури сайта за допомогою web-графа

С.М. Єфремов, Т.А. Зайцева Оптимізація розрахунку гістограми напрямлених градієнтів для розпізнавання зображення

О.М. Кісельова, О.М. Притоманова, С.В. Дзюба, В.Г. Падалко Розв'язання двоетапної неперервно-дискретної задачі оптимального розбиття-розподілу з нечіткими параметрами

О.М. Кісельова, О.М. Притоманова, С.В. Дзюба, В.Г. Падалко Побудова мультиплікативно зваженої діаграми Вороного з нечіткими параметрами 
Є.В. Косенко, А.С. Шевельова Про екстремальну задачу ідентифікації властивостей сегнетоелектриків

T. Nakonechnaya The cyclic inequality of N.P. Korneichuk and it's generalization

М.Є. Сердюк, С.Ф. Сірик, О.О. Сокол Автоматична колоризація цифрових напівтонових зображень з використанням нейронних мереж

I.C. Тонкошкур Моделювання процесів тепломасообміну в плівкових течіях нелінійно-в'язкої рідини

I.C. Тонкошкур, К.В. Калініченко Моделювання гравітаційних течій в'язкопластичної рідини по конічній поверхні

В.А. Турчина, В.В. Березин Использование прогнозных значений в промежуточных точках при прогнозировании хаотических временных рядов на много шагов вперед

В.А. Турчина, К.П. Гулько Застосування алгоритму ФордаФалкерсона для виявлення надлишкової інформації

В.Л. Волошко Кафедрі обчислювальної математики та математичної кібернетики ДНУ 60 років 


\title{
ПИТАННЯ ПРИКЛАДНОЇ МАТЕМАТИКИ І МАТЕМАТИЧНОГО МОДЕЛЮВАННЯ
}

\section{Збірник наукових праць}

\section{Випуск 19}

Українською, російською та англійською мовами

\author{
Свідоцтво про державну реєстрацію \\ державного засобу масової інформації \\ серія КВ № 23168-13008 ПР від 11.12.2017 р.
}

Редактор О.М. Гордієнко

Комп’ютерна верстка Н.С. Яцечко

Підписано до друку 14.11.19. Формат 60×84 1/16. Папір друкарський. Друк плоский. Гарнітура TimesNewRoman. Ум. друк. арк. 11,39. Тираж 100 пр. Зам. № 322.

Видавництво та друкарня ПП ”ЛІРА ЛТД"

49107, м. Дніпро, вул. Наукова, 5

Свідоцтво про внесення до Держреєстру

ДК № 6042 від 26.02.2018 